\title{
A Soft-Switching Inverter for High-Temperature Advanced Hybrid Electric Vehicle Traction Motor Drives
}

Final Report

March 31, 2012

Submitted to

Department of Energy

Contract No. DE-FC26-07NT43214

This report was prepared as an account of work sponsored by an agency of the United States Government. Neither the United States Government nor any agency thereof, nor any of their employees, makes any warranty, express or implied, or assumes any legal liability or responsibility for the accuracy, completeness, or usefulness of any information, apparatus, product, or process disclosed, or represents that its use would not infringe privately owned rights. Reference herein to any specific commercial product, process, or service by trade name, trademark, manufacturer, or otherwise does not necessarily constitute or imply its endorsement, recommendation, or favoring by the United States Government or any agency thereof. The views and opinions of authors expressed herein do not necessarily state or reflect those of the United States Government or any agency thereof. 


\title{
A Soft-Switching Inverter for High-Temperature Advanced Hybrid Electric Vehicle Traction Motor Drives
}

\author{
Jason Lai, Wensong Yu, and Pengwei Sun \\ Virginia Polytechnic Institute and State University \\ Scott Leslie and Duane Prusia \\ Powerex, Inc.
}

Beat Arnet, Chris Smith, and Art Cogan

Azure Dynamics

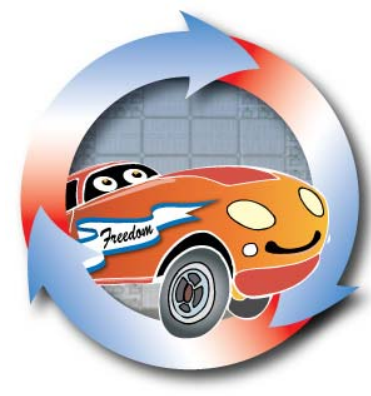

Virginia Polytechnic Institute and State University Future Energy Electronics Center 106 Plantation Road (0356) Blacksburg, Virginia 24061 540-231-4741

www.feec.ece.vt.edu
Final Report March 2012

Contract No. DE-FC26-07NT43214 


\section{Table of Contents}

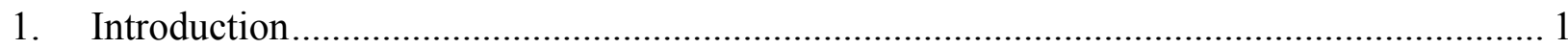

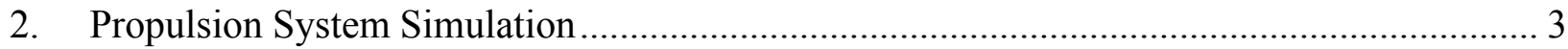

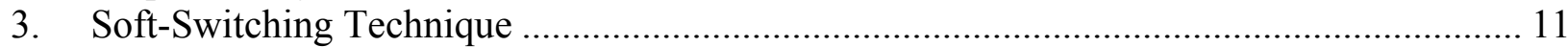

3.1. Variable Timing Soft-Switching Technique............................................................. 11

3.2. Circuit Level Simulation for Device Selection....................................................... 14

3.3. Select and Characterize Power Devices for High Temperature Operation ................. 17

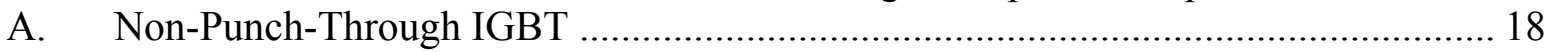

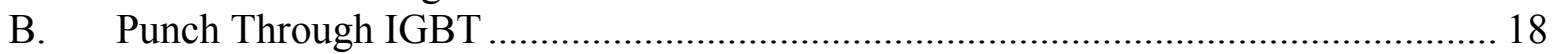

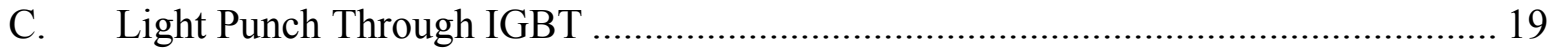

3.4. Conduction loss Measurement Results................................................................ 20

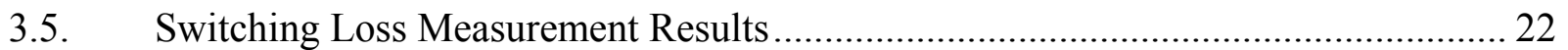

4. Soft-Switching Power Module Development ………....................................................... 30

4.1. Soft-Switching Module Configuration ................................................................... 30

4.2. Gen-1 Module Development ........................................................................ 32

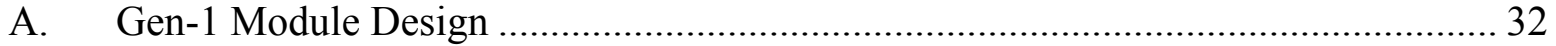

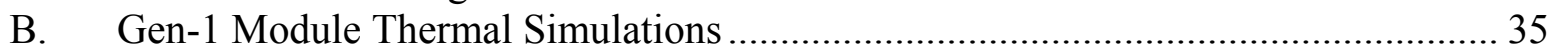

C. Gen-1 Module Conduction Characteristics Test Results........................................... 36

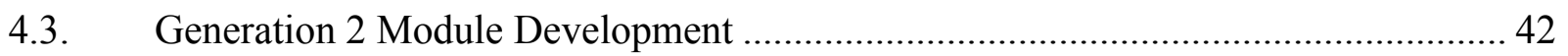

A. Gen-2 Module Design .................................................................................. 42

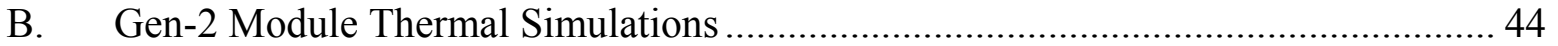

C. Gen-2 Module Conduction Characteristics Test Results.......................................... 46

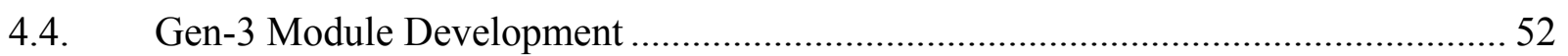

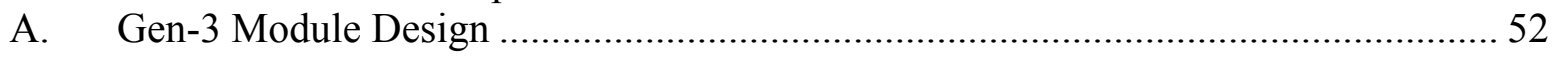

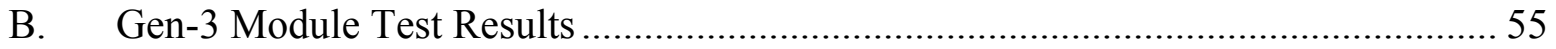

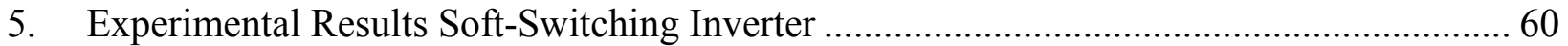

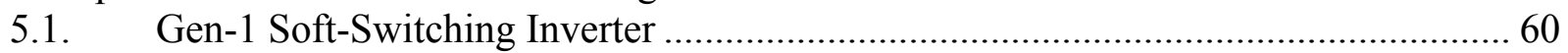

A. Soft-Switching Module Conduction Loss Measurement Results................................ 60

B. Soft-Switching Module Switching Loss Measurement Results ...................................... 61

C. Inverter Power Loss Measurement and Efficiency Prediction Results ........................63 63

D. Inverter Efficiency Test under Motor Load Condition................................................ 64

E. Inverter Efficiency Test with Calibrated Calorimeter .................................................6 66

F. Improve Design with Failure Mode Effect Analysis...................................................... 67

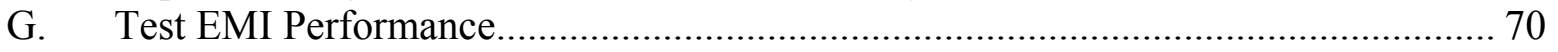

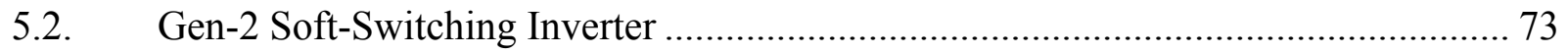

A. Conduction Loss Measurement Results …………........................................................ 73

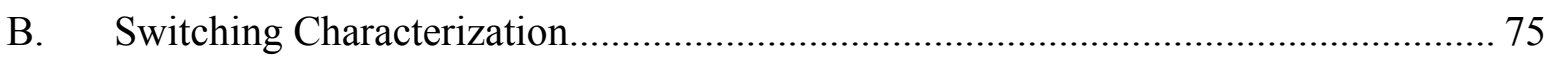

C. Power Loss Measurement Results ......................................................................... 78

C. Projected Efficiency Using the Loss Measurement Results ........................................ 80

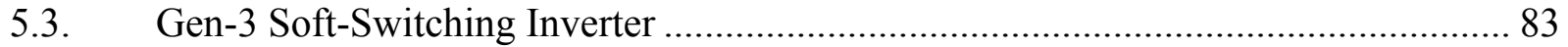

A. Conduction Loss Measurement Results ...................................................................... 83

B. Comparison of Voltage Drop Between Gen-1, Gen-2, and Gen-3 Modules.............. 87

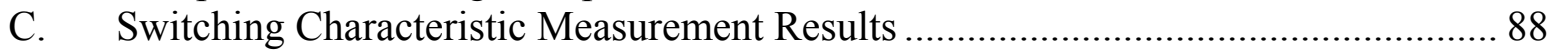

C. Gen-3 Assembly and Preliminary Efficiency Measurement Results .......................... 91 


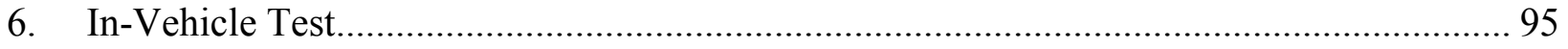

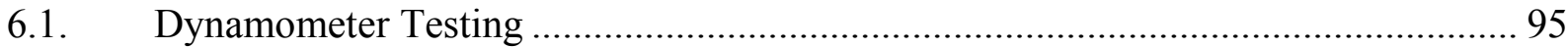

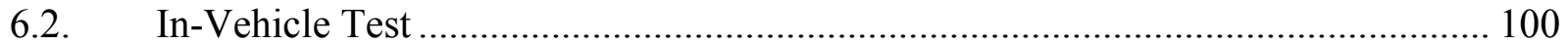

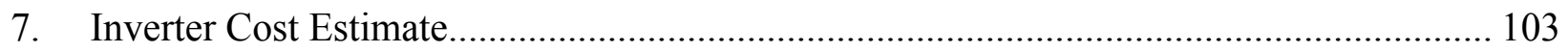

7.1. Soft-Switching Module Cost Estimate .................................................................... 103

7.2. Soft-Switching Inverter Cost Estimate ………..................................................... 103

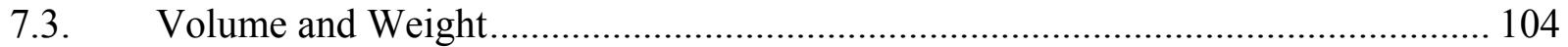

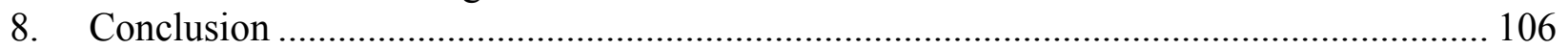

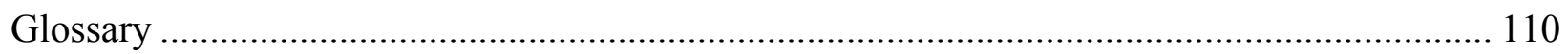

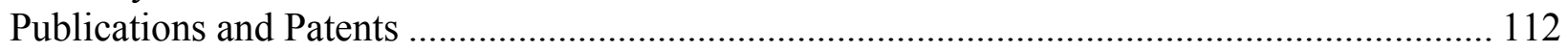

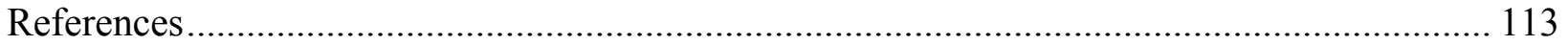




\section{List of Figures}

Figure 2.1. The overall propulsion system simulation........................................................... 4

Figure 2.2. Vehicle Speed over US06 drive cycle. Speed is on the Y-axis in MPH. The X-axis is seconds.

\section{5}

Figure 2.3. The motor torque commanded by the speed regulator and the actual torque produced are shown above. Torque (y-axis) is shown in Newton-meters and time is shown in

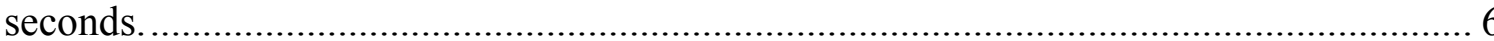

Figure 2.4. The inverter power (y-axis) is shown in watts above. The $\mathrm{x}$-axis is time in seconds. 7 Figure 2.5. The inverter output voltage (line-neutral) amplitude is shown above. The $\mathrm{x}$-axis is

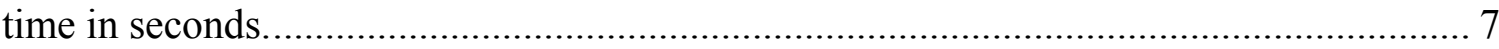

Figure 2.6. The amplitude of the phase current commanded by the motor control block is shown

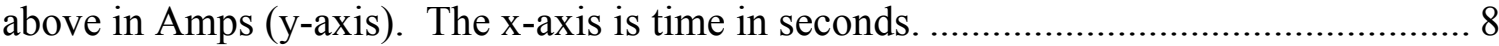

Figure 2.7. The motor power factor average is 0.68 over the entire cycle. ............................. 8

Figure 2.8. The ESR of the battery causes the output voltage to dip or rise when large amounts

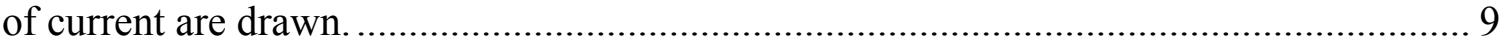

Figure 3.1. Soft-switching converter circuit with variable timing control for zero-voltage switching: (a) conceptual circuit diagram, and (b) switching timing and key voltage and current waveforms.

Figure 3.2. Variable timing controlled soft switching simulation for positive current cycle at high current $(300 \mathrm{~A})$, medium current $(150 \mathrm{~A})$, and zero current conditions........................ 12

Figure 3.3. Variable timing controlled soft switching simulation for negative current cycle at

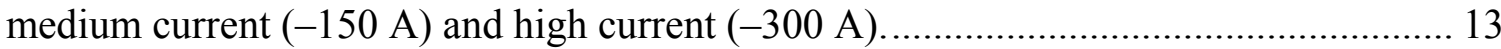

Figure 3.4. Verification of variable timing with simulation and experimental results: (a) simulation of soft switching under different current conditions, and (b) experimental verification of soft switching under different current conditions.

Figure 3.5. Closed speed loop simulation results with fully utilization of DC bus voltage at the rated speed and torque condition.

Figure 3.6. Simulated voltage and current waveforms for the entire SVM controlled inverter-

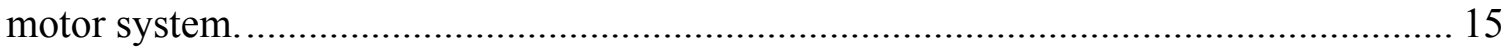

Figure 3.7. Efficiency comparison between soft switching and hard switching: (a) using 400-A

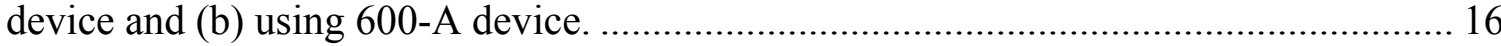

Figure 3.8. Efficiency comparison between different devices under hard and soft switching conditions: (a) hard switching and (b) soft switching.............................................. 17

Figure 3.9. Internal structure comparison of different IGBTs. .......................................... 18

Figure 3.10. Normalized $E_{\text {off }}$ comparison among three different IGBTs.............................. 20

Figure 3.11. Normalized $V_{c e}$ comparison among three different IGBTs............................... 20

Figure 3.12. Measured LPT-IGBT and diode conduction characteristics in comparison with

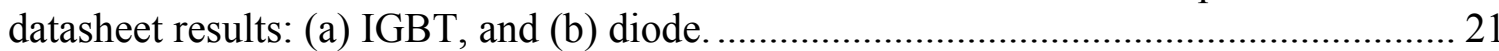

Figure 3.13. Measured IGBT and diode voltage drop as a function of temperature: (a) IGBT and

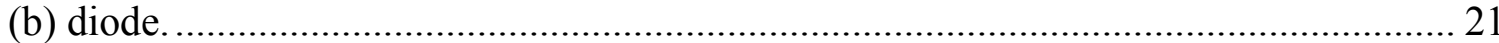

Figure 3.14. NPT IGBT and SiC Schottky diode conduction voltage drop under different

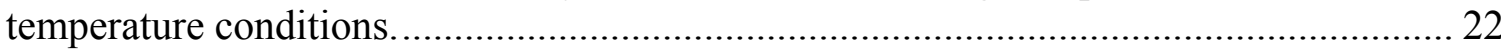

Figure 3.15 . Hard switching voltage and current switching measurement results at $300-\mathrm{A}, 25^{\circ} \mathrm{C}$ condition. 
Figure 3.16. Hard switching voltage and current switching measurement results at $400-\mathrm{A}, 25^{\circ} \mathrm{C}$

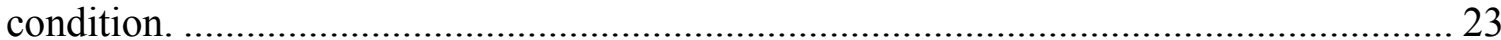

Figure 3.17. Switching voltage and current waveforms under $300-\mathrm{V}, 300-\mathrm{A}$ at $100^{\circ} \mathrm{C} \ldots \ldots \ldots \ldots . . . . .23$

Figure 3.18. Switching voltage and current waveforms under $300-\mathrm{V}, 400-\mathrm{A}$ at $100^{\circ} \mathrm{C} \ldots \ldots \ldots \ldots . . .24$

Figure 3.19. IGBT turn-on voltage and current waveforms comparison between $25^{\circ} \mathrm{C}$ and $100^{\circ} \mathrm{C}$

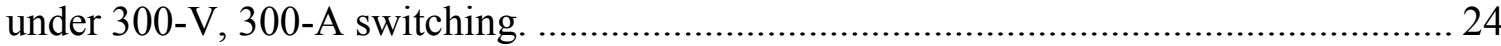

Figure 3.20. IGBT turn-on voltage and current waveforms comparison between $25^{\circ} \mathrm{C}$ and $100^{\circ} \mathrm{C}$

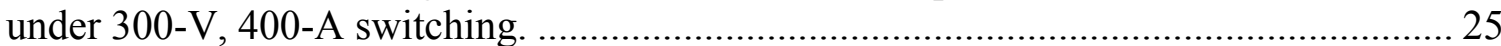

Figure 3.21. Soft-switching voltage and current waveforms under $300-\mathrm{V}, 150-\mathrm{A}, 25^{\circ} \mathrm{C}$ test

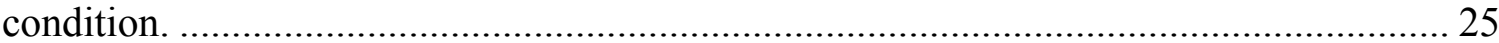

Figure 3.22. Soft-switching voltage and current waveforms under $300-\mathrm{V}, 230-\mathrm{A}, 25^{\circ} \mathrm{C}$ test

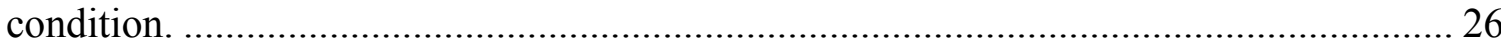

Figure 3.23. Soft-switching voltage and current waveforms under $300-\mathrm{V}, 100-\mathrm{A}, 100^{\circ} \mathrm{C}$ test

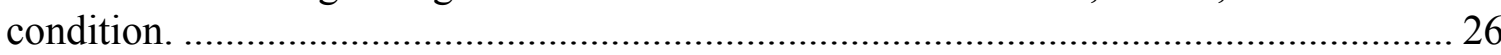

Figure 3.24. Soft-switching voltage and current waveforms under $300-\mathrm{V}, 200-\mathrm{A}, 100^{\circ} \mathrm{C}$ test

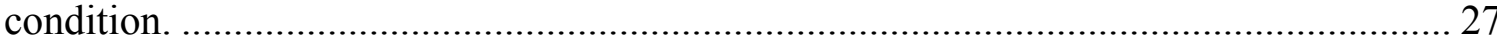

Figure 3.25. Soft-switching voltage and current waveforms under $300-\mathrm{V}, 300-\mathrm{A}, 100^{\circ} \mathrm{C}$ test condition.

Figure 3.26. Soft-switching voltage and current waveforms at $25^{\circ} \mathrm{C}$ and at different current

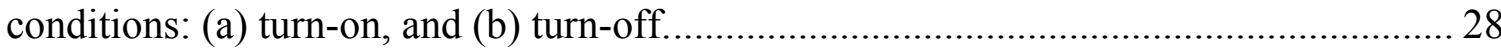

Figure 3.27. Soft-switching voltage and current waveforms at $100^{\circ} \mathrm{C}$ and at different current

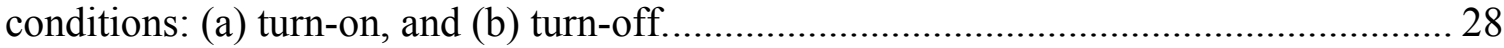

Figure 3.28. Measured switching energy under hard- and soft-switching and at different

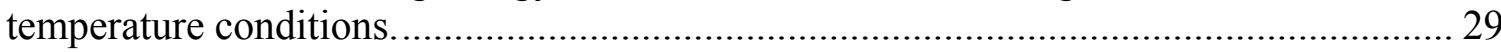

Figure 3.29. Efficiency projection based on the measured device loss calculation.................... 29

Figure 4.1. Basic circuit configuration for a single phase, soft switched IGBT module............. 30

Figure 4.2. Photos showing the evolution of the three generations of power modules along with

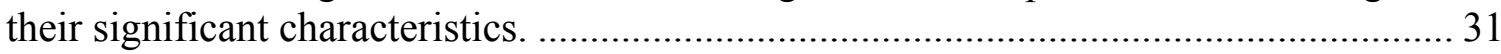

Figure 4.3. Overall view of the Phase 1, single phase, IGBT module................................... 34

Figure 4.4. Internal chip and wirebond layout for Gen 1 module........................................ 34

Figure 4.5. Cross section of Gen 1 module showing heat flow path and layers........................ 35

Figure 4.6. Bottom view of module baseplate showing pin-fins for liquid cooling.................. 35

Figure 4.7. Results of FEA simulations of temperature drop from junctions to pin-fins. .......... 36

Figure 4.8. Average $V_{c e-s a t}$ of the IGBT stages at 25C for Gen-1 modules SN101 \& SN102. The effect of the parallel MOSFET at low current levels is evident in the Output Stage $V_{c e-s a t}$

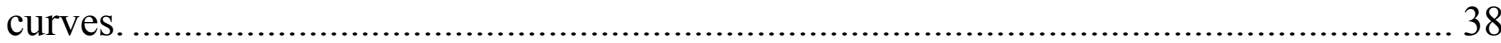

Figure 4.9. Average $V_{f}$ of the diodes at $25^{\circ} \mathrm{C}$ for Gen-1 modules SN101 \& SN102................ 38

Figure 4.10. Gen 1 module coolant flow. .......................................................................... 39

Figure 4.11. Results of Gen-1 module junction-to-coolant temperature drop at full average

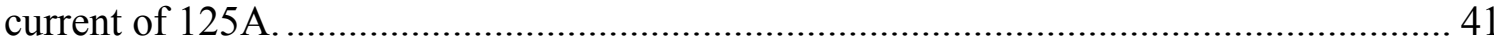

Figure 4.12. Results of Gen-1 module liquid-cooled thermal resistance at full average current of $125 \mathrm{~A}$ showing the dependence of junction-to-liquid thermal resistance as a function of

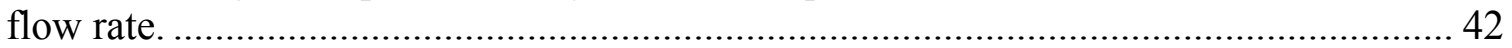

Figure 4.13. Gen-2 low profile package design.............................................................. 43

Figure 4.14. Gen-2 low profile package design showing power and control terminal/pin locations. 
Figure 4.15. Gen-2 low profile package design showing chip locations

Figure 4.16. Photographs of Gen-2 soft-switching module layout: (a) before wirebond, (b) after wirebond.

Figure 4.17. 3D FEA simulation results of the temperature rise from junction to baseplate for the various chips in the Gen 2 design at the dissipation levels at full power operation. The comparison between the full FEA 3-D and Quasi-3D analytical results are listed in the table inset. For the results shown in the graphic, the bottom of the baseplate was held at $25 \mathrm{C}$.

Figure 4.18. Comparison of junction-ambient temperature drops for the three cooling options possible for the Gen 2 module.................................................................................... 46

Figure 4.19. Voltage drops for the power stage IGBT, MOSFET, MOSFET/IGBT combination and main free-wheel diode $\left(D_{1}\right)$ at $T_{j}=25^{\circ} \mathrm{C}$ for Gen-2 module SN201, $Q_{1} \ldots \ldots \ldots \ldots \ldots \ldots \ldots . . . . .48$

Figure 4.20. Voltage drops for the power stage IGBT, MOSFET, MOSFET/IGBT combination and main free-wheel diode $\left(D_{1}\right)$ at $T_{j}=125^{\circ} \mathrm{C}$ for Gen-2 module SN201, $Q_{1} \ldots \ldots \ldots \ldots \ldots \ldots . . . .48$

Figure 4.21. Voltage drops for the auxiliary IGBT $\left(Q_{x 1}\right)$, free-wheel diode $\left(D_{x 1}\right)$ and resonant

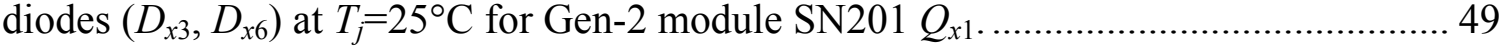

Figure 4.22. Voltage drops for the auxiliary IGBT $\left(Q_{x 1}\right)$, free-wheel diode $\left(D_{x 1}\right)$ and resonant diodes $\left(D_{x 3}, D_{x 6}\right)$ at $T_{j}=125^{\circ} \mathrm{C}$ for Gen-2 module SN201 $Q_{x 1}$.

Figure 4.23. Voltage drops for the power stage IGBT, MOSFET, MOSFET/IGBT combination and main free-wheel diode $\left(D_{2}\right)$ at $T_{j}=25^{\circ} \mathrm{C}$ for Gen-2 module SN201, $\mathrm{Q}_{2} \ldots \ldots \ldots \ldots \ldots \ldots \ldots . .50$

Figure 4.24. Voltage drops for the power stage IGBT, Mosfet, Mosfet/IGBT combination and main free-wheel diode $\left(\mathrm{D}_{2}\right)$ at $\mathrm{T}_{\mathrm{j}}=125^{\circ} \mathrm{C}$ for Gen-2 module SN201, $\mathrm{Q}_{2} \ldots \ldots \ldots \ldots \ldots \ldots \ldots \ldots \ldots . . .50$

Figure 4.25. Voltage drops for the auxiliary IGBT $\left(Q_{x 2}\right)$, free-wheel diode $\left(D_{x 2}\right)$ and resonant

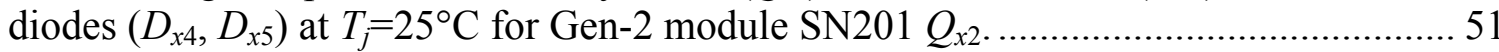

Figure 4.26. Voltage drops for the auxiliary IGBT $\left(Q_{x 2}\right)$, free-wheel diode $\left(D_{x 2}\right)$ and resonant

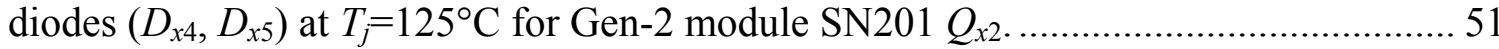

Figure 4.27. Voltage drop comparison of the Gen 1 and 2 modules. ........................................5 52

Figure 4.28. Comparison of Gen 2 and Gen 3 modules........................................................... 53

Figure 4.29. Pin locations (top) and chip layout (bottom) for the Gen-3 auxiliary and power

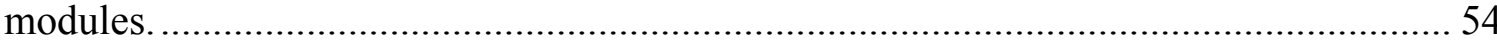

Figure 4.30. Voltage drop of the upper and lower Gen-3 switches at (a) $T_{j}=25^{\circ} \mathrm{C}$ and (b) $125^{\circ} \mathrm{C}$ as a function of current. Also plotted are the reverse conduction losses of the MOSFET

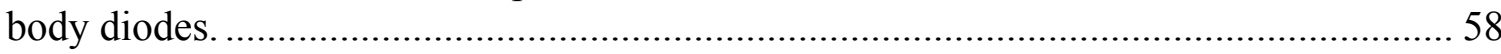

Figure 4.31. Voltage drop of the (a) upper and (b) lower power switches comparing results at $T_{j}$ $=25$ and $125^{\circ} \mathrm{C}$. Also compared are the reverse conduction losses of the MOSFET body

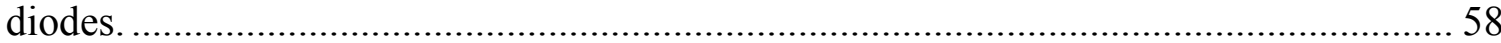

Figure 4.32. Effects of MOSFET channel conduction on the reverse conduction voltage drop comparison between body diode and inclusion of MOSFET channel conduction............58

Figure 4.33. Comparison of the forward voltage drops of the three generations of modules. ..... 59

Figure 5.1. Conduction I-V curve comparison between designed module and commercial module

Figure 5.2. Switching-on waveforms with $0.1-\mu \mathrm{F}$ resonant capacitance at: (a) $25^{\circ} \mathrm{C}$ and (b) $90^{\circ} \mathrm{C}$. 61

Figure 5.3. Switching-off waveforms with $0.1-\mu \mathrm{F}$ resonant capacitance at different temperature conditions: (a) $25^{\circ} \mathrm{C}$ and (b) $90^{\circ} \mathrm{C}$.

Figure 5.4. Switching energy with $0.1 \mu \mathrm{F}$ resonant capacitance at different temperatures........... 62 
Figure 5.5. Power loss as a function of the output $\mathrm{kVA}$ under different line frequencies and

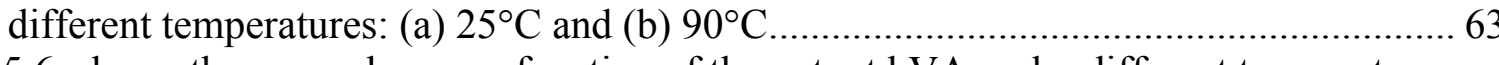

Figure 5.6. shows the power loss as a function of the output $\mathrm{kVA}$ under different temperatures

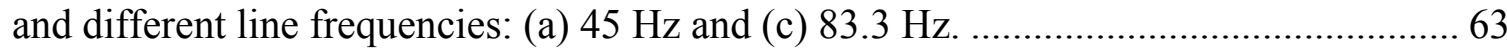

Figure 5.7. Efficiency measurement at $83.3-\mathrm{Hz}$ line frequency and different temperatures........ 64

Figure 5.8. Efficiency comparison at $90^{\circ} \mathrm{C}$ and different line frequency conditions................. 64

Figure 5.9. Efficiency profile of the soft-switching inverter under motor-dynamometer test...... 65

Figure 5.10. Photographs showing (a) differential-chamber based calorimeter with flow meter box in foreground and inverter chamber partially open in back; (b) main chamber cover removed for the view of coolant inlet and outlet.

Figure 5.11. Calorimeter measurement at 27kW: (a) coolant temperatures, (b) inverter efficiency.

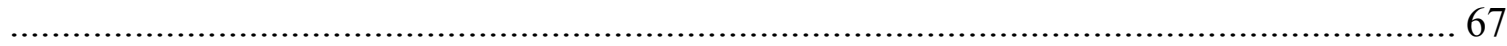

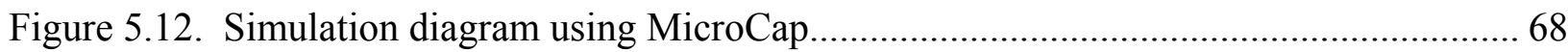

Figure 5.13. Resonant inductor voltage and current under normal operation. ........................... 69

Figure 5.14. Simulated resonant inductor voltages and currents under communication failure... 69

Figure 5.15. Simulation result with loss of communication that interrupts the auxiliary and main gate signals. 70

Figure 5.16. Schematic Diagram of EMI Measurement Setup............................................... 71

Figure 5.17. Measured High Frequency Range DM Noise at DC Side.................................... 71

Figure 5.18. Measured High Frequency Range CM Noise at DC Side................................... 72

Figure 5.19. Measured High Frequency Range CM Noise at AC Side................................... 72

Figure 5.20. Voltage drop comparison between Gen-1 and Gen-2 modules: (a) upper device and

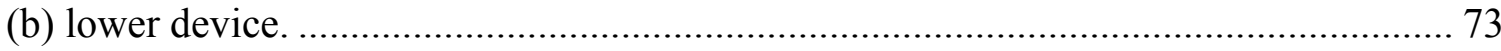

Figure 5.21. Comparison of Gen-2 module prototypes. .................................................... 74

Figure 5.22. Device voltage drop comparison between Gen-1 and Gen-2 modules. .................. 74

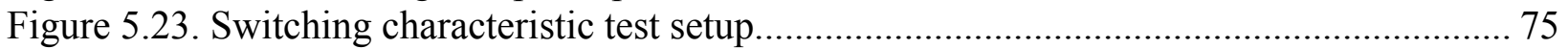

Figure 5.24. Zero load current switching characterization waveforms (left side-Gen 1 module,

right side-Gen 2 module).............................................................................. 76

Figure 5.25. 100A load current switching characterization waveforms (left side-Gen 1 module, right side-Gen 2 module).................................................................................... 76

Figure 5.26. 200A load current switching characterization waveforms (left side-Gen 1 module,

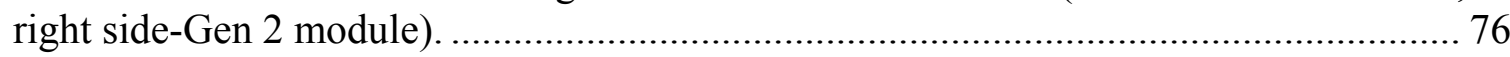

Figure 5.27. 300A load current switching characterization waveforms (Gen 2 module)........... 77

Figure 5.28. 400A load current switching characterization waveforms (Gen 2 module)............ 77

Figure 5.29. Parasitic inductance measurement at 300-A load current case. ........................... 78

Figure 5.30. Power loss as a function of the output $\mathrm{kVA}$ under different line frequencies and

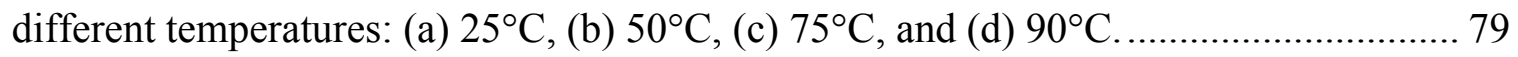

Figure 5.31. Power loss as a function of the output kVA under different temperatures and

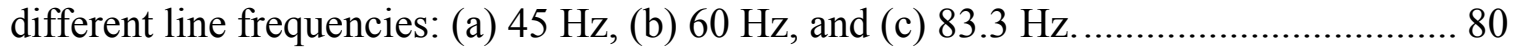

Figure 5.32. Efficiency measurement at $83.3-\mathrm{Hz}$ line frequency and different temperatures..... 81

Figure 5.33. Efficiency measurement at $60-\mathrm{Hz}$ line frequency and different temperatures........ 81

Figure 5.34. Efficiency measurement at $45-\mathrm{Hz}$ line frequency and different temperatures........ 81

Figure 5.35. Efficiency comparison at $25^{\circ} \mathrm{C}$ and different line frequency conditions. .............. 82

Figure 5.36. Efficiency comparison at $50^{\circ} \mathrm{C}$ and different line frequency conditions. .............. 82

Figure 5.37. Efficiency comparison at $75^{\circ} \mathrm{C}$ and different line frequency conditions. ............... 83

Figure 5.38. Efficiency comparison at $90^{\circ} \mathrm{C}$ and different line frequency conditions. ............... 83 
Figure 5.39. (a) voltage drop $V_{c e}$ of individual devices and their combination of Gen-3 module including upper device $\left(Q_{1} / M_{1}\right)$ and lower device $\left(Q_{2} / M_{2}\right)$; (b) $V_{c e}$ of individual diode and MOSFET and their combination of Gen-3 module including upper device $\left(D_{1} / M_{1}\right)$ and lower device $\left(D_{2} / M_{2}\right)$. 85

Figure 5.40. Model verification using Gen-1 module to predict performance of possible Gen-3 module designs

Figure 5.41. Voltage drop comparison between Gen-1, Gen-2, and Gen-3 modules: (a) upper device and (b) lower device.

Figure 5.42. Switching characteristics measurement setup: (a) Gen-3 module power board assembly and (b) complete setup with gate driver board and resonant circuit connection.

Figure 5.43. Switching characteristic comparison between Gen-1 and Gen-2 modules: (a) Gen-1

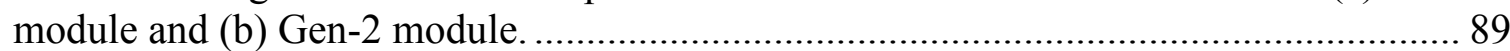

Figure 5.44. Switching characteristic comparison between Gen-2 and Gen-3 modules: (a) Gen-2

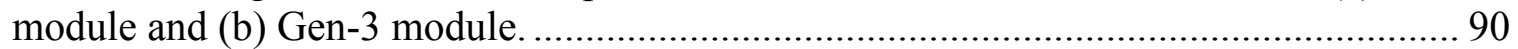

Figure 5.45. Comparison of projected efficiency between Gen-1, Gen-2, and Gen-3 inverters. . 90 Figure 5.46. Gen-3 soft-switching inverter assembly: (a) front view and (b) side view............ 91 Figure 5.47. Photograph of Gen-1 inverter assembly....................................................... 91

Figure 5.48. Photograph of Gen-2 inverter assembly.................................................... 92

Figure 5.49. Photograph of Gen-3 inverter assembly..................................................... 92

Figure 5.50. Comparison of measured efficiency between Gen-1, Gen-2, and Gen-3 inverters at

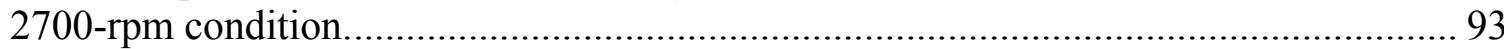

Figure 5.51. Comparison of measured efficiency between Gen-1, Gen-2, and Gen-3 inverters at 3600-rpm condition..................................................................................... 93

Figure 5.52. Comparison of measured efficiency between Gen-1, Gen-2, and Gen-3 inverters at

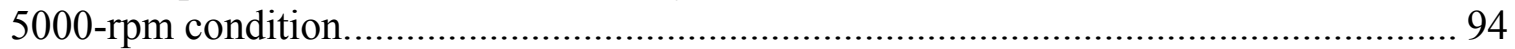

Figure 6.1. Three-phase soft-switching inverter using hybrid switches, and (b) Photograph of a $325-\mathrm{V}, 30-\mathrm{kW}$ prototype............................................................................... 95

Figure 6.2. Photograph of the Gen-3 soft-switching inverter prototype: (a) front view and (b)

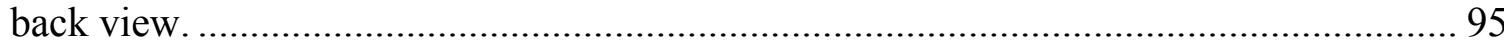

Figure 6.3. Photograph showing the Gen-3 inverter mounted on the test rack for the dyno testing.

Figure 6.4. Experimental inverter output current waveforms at (a) 40-kW, 3029rpm, $115 \mathrm{Nm}$, and (b) 27-kW, $1030 \mathrm{rpm}, 225 \mathrm{Nm}$................................................................... 97

Figure 6.5. Experimental inverter output current waveforms at (a) $275 \mathrm{~V}, 39 \mathrm{~kW}$ and (b) $375 \mathrm{~V}$,

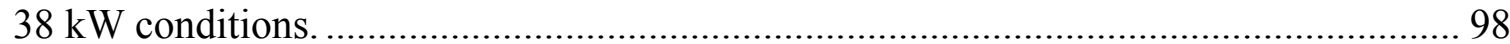

Figure 6.6. (a) Measured efficiency as a function of output power at 3000-rpm operation, and (b) Measured module case temperature over a 12-minute interval at $38-\mathrm{kW}$ output condition.

Figure 6.7. Photograph of all-electric Citivan for in-vehicle testing. .................................... 100

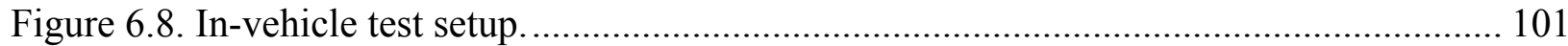

Figure 6.9. Recorded in-vehicle tested motor speed and phase current during a 4-minute city

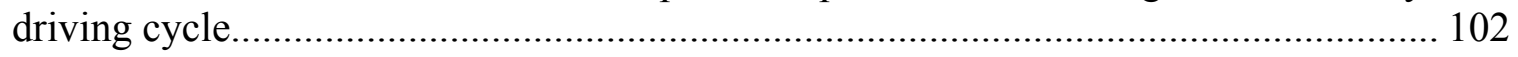




\section{List of Tables}

Table 2.1. Parameters used during system simulation........................................................ 3

Table 2.2. Siemens 1PV5135 motor parameters................................................................ 3

Table 2.3. The circuit conditions present at the worst case $55-\mathrm{kW}$ operating point....................9

Table 3.1. Loss comparison at full load condition between hard and soft switching inverters.... 16

Table 4.1. Single Phase, Soft-Switched Gen-1 IGBT Module Requirements ........................... 32

Table 4.2. Estimated Power Dissipation \& Maximum Chip Temperatures .............................. 33

Table 4.3. Test Results for a sample of the Gen 1 Modules .................................................... 37

Table 4.4. Gen-1 module fully powered $Q_{1} M_{1}$ chip set thermal resistance results for pure water $\&$

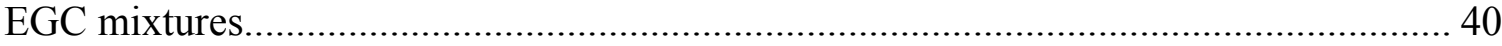

Table 4.5. Gen-1 fully powered $Q_{1} M_{1}$ and $Q_{x 1}$ thermal resistance results for pure water \& EGC

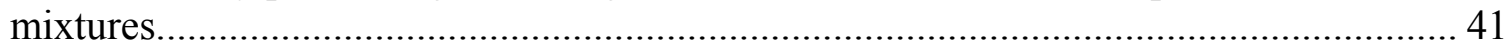

Table 4.6. Test Results for a sample of the Gen-2 Modules................................................. 47

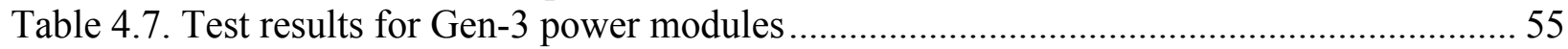

Table 4.8. Test results for Gen-3 auxiliary modules......................................................... 57

Table 5.1. Conduction loss measurement of $Q_{1}-M_{1}$ at different temperature conditions ............ 60

Table 5.2. Efficiency measurement with motor test at different temperatures.......................... 65

Table 5.3. Efficiency comparison between inductive load and motor test at different

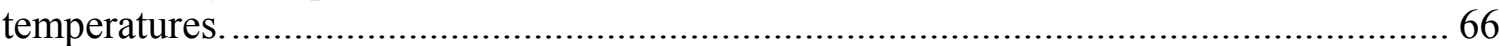

Table 5.4. Readings from power meter at $1600 \mathrm{rpm}, 27 \mathrm{~kW}$ condition ..................................6. 66

Table 5.5. Gen-2 module parasitic inductance measurement. ............................................. 78

Table 5.6. Measured main power module voltage drop for SN 301P at different temperatures .. 84

Table 5.7. Measured main power module voltage drop for SN 302P at different temperatures .. 84

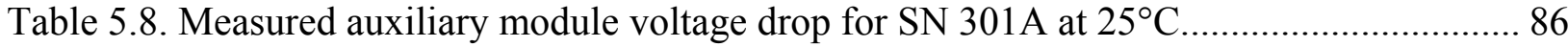

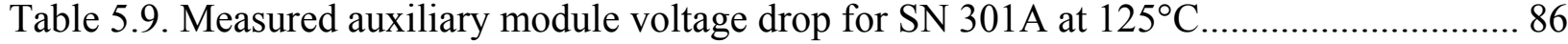

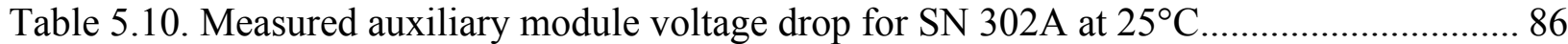

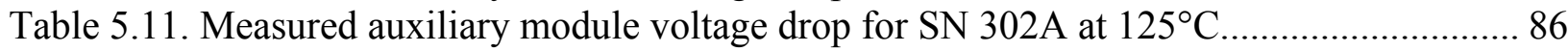

Table 6.1. Test conditions that are run more than 10 minutes for each data set....................... 97

Table 6.2. Loss separation under three input voltage and two load conditions .......................... 99

Table 7.1. Cost comparison between Gen-1 and Gen-2 modules. ....................................... 103

Table 7.2. Cost estimate for the soft-switching inverter at 100,000 quantity production.......... 104

Table 7.3. Comparison of the VT prototype and DOE target .............................................. 105 


\section{INTRODUCTION}

The state-of-the-art hybrid electric vehicles (HEVs) require the inverter cooling system to have a separate loop to avoid power semiconductor junction over temperatures because the engine coolant temperature of $105^{\circ} \mathrm{C}$ does not allow for much temperature rise in silicon devices. The proposed work is to develop an advanced soft-switching inverter that will eliminate the device switching loss and cut down the power loss so that the inverter can operate at high-temperature conditions while operating at high switching frequencies with small current ripple in low inductance based permanent magnet motors. The proposed tasks also include high-temperature packaging and thermal modeling and simulation to ensure the packaged module can operate at the desired temperature. The developed module will be integrated with the motor and vehicle controller for dynamometer and in-vehicle testing to prove its superiority.

The main objectives are

1. Develop a soft-switching module to minimize the parasitic components and associated losses.

2. Develop an advanced controlled method for the soft-switching inverter to achieve efficiency higher than $98 \%$ over a wide speed and torque range.

3. Optimize the resonant circuit design to reduce the auxiliary circuit losses.

4. Develop an advanced package to allow the soft-switching module to operate with a coolant temperature of $105^{\circ} \mathrm{C}$.

5. Test soft-switching inverter under dynamometer and in-vehicle conditions to verify the desired performance.

6. Reduce the inverter cost for electric and hybrid electric vehicle applications.

The approaches to achieving the project goals include the following:

1. Obtain inverter component V-I stresses through vehicle level and motor drive simulations.

2. Develop a variable timing controlled circuit for switching loss reduction for a wide speed and torque range.

3. Develop a hybrid soft switch module by combining IGBT and MOSFET for conduction loss reduction.

4. Develop a low thermal impedance module with integrated heat sink for high temperature operation.

5. Develop a highly integrated soft-switch module for low-cost and low parasitic packaging.

6. Predict device junction temperature and optimize module design through modeling and simulation.

7. Develop high-accuracy ratio metric calorimeter for ultrahigh efficiency inverter/dyno testing

8. Test the soft-switching inverter with existing EV platform and dynamometer for EMI and efficiency performance verification.

9. Test electromagnetic interference (EMI) performance 
10. Test and validate module level thermal performance

This report will describe the detailed technical design of the soft-switching inverters and their test results. The experiments were conducted both in module level for the module conduction and switching characteristics and in inverter level for its efficiency under inductive and dynamometer load conditions. The performance will be compared with the DOE original specification. 


\section{Propulsion System Simulation}

The purpose of the propulsion system level simulation is to determine the voltage and current stresses the inverter will be subjected to in a typical vehicle application. Also, the simulation will confirm that the inverter specification is adequate in all operating conditions for standard vehicle use. The purpose of the simulation is not to find inverter efficiency or motor efficiency. An assumed efficiency is used to provide more accurate inverter voltages and currents, but no great effort is made to accurately model the inverter. Once typical use data is known, typical operating points can be chosen for later efficiency study and reliability study. Table 2.1 shows key parameters used in the vehicle level simulation. Table 2.2 shows circuit parameters of the Siemens 1PV5135 induction motor.

Table 2.1. Parameters used during system simulation.

\begin{tabular}{|l|c|l|}
\hline \multicolumn{1}{|c|}{ Parameter } & Value & \multicolumn{1}{c|}{ Comment } \\
\hline DC bus voltage: $V_{d c}$ & $312 \mathrm{~V}$ & Nominal voltage in vehicle application \\
\hline Battery internal resistance: $R_{\text {bat }}$ & $0.3 \Omega$ & Medium stiffness battery pack \\
\hline Inverter efficiency: $\eta_{\text {inv }}$ & 0.95 & $\begin{array}{l}\text { Assumed inverter efficiency for DC bus } \\
\text { current calculation }\end{array}$ \\
\hline Inverter output peak current: $I_{\max }$ & $400 \mathrm{~A}$ & Peak phase current out of inverter \\
\hline Vehicle mass: $\mathrm{m}$ & $1600 \mathrm{~kg}$ & Vehicle Mass \\
\hline Tire radius: $r$ & $0.292 \mathrm{~m}$ & Tire radius \\
\hline Gear ratio: $g$ & 11 & Gear ratio \\
\hline Density of air: $\rho$ & $1.2 \mathrm{~kg} / \mathrm{m}^{3}$ & Density of air \\
\hline Vehicle drag coefficient: $c_{d}$ & 0.32 & Vehicle drag coefficient \\
\hline Vehicle frontal area: $A_{f}$ & $2.5 \mathrm{~m}^{2}$ & Vehicle frontal area \\
\hline
\end{tabular}

Table 2.2. Siemens 1PV5135 motor parameters.

\begin{tabular}{|l|c|l|}
\hline \multicolumn{1}{|c|}{ Parameter } & Value & \multicolumn{1}{c|}{ Comment } \\
\hline Stator resistor: $R_{s}$ & $0.012 \Omega$ & Stator resistance \\
\hline Leakage inductance: $L_{l k}$ & $140 \mu \mathrm{H}$ & Assume same for both stator and rotor \\
\hline Rotor resistance: $R_{r}$ & $0.0065 \Omega$ & Rotor resistance \\
\hline Pole pairs: $P_{p}$ & 2 & Pole pairs \\
\hline Magnetizing inductance: $L_{m}$ & $1500 \mu \mathrm{H}$ & Magnetizing Inductance \\
\hline
\end{tabular}

The propulsion system simulation is shown below in Figure 2.1. The simulation was conducted using Matlab Simulink and PLECS. PLECS is an electrical circuit simulator that runs within Simulink. The inverter electronics were modeled by a controlled three-phase voltage source, which was then connected to the PLECS AC induction motor model. The motor model was adjusted so that saturation was present at high magnetizing currents. The inverter and motor are represented by the yellow block in Figure 2.1. The inputs to the inverter are the previously mentioned AC voltage command and the motor speed as set by the vehicle speed. The inverter and motor outputs are the phase current, electrical angle of the rotor, torque produced, and several other internal values for troubleshooting purposes. 
The vehicle portion of the simulation is represented by the orange block below. The torque acts on the vehicle mass through the gear box and tire diameter to provide traction to the road. Air resistance and a fixed rolling resistance are also modeled. The vehicle block outputs are vehicle speed and motor shaft speed. The inside of the vehicle block is shown in Figure 2.1. For the purposes of this simulation no gear box loss is used.

The motor shaft speed is fed back to the motor control block shown on the center of Figure 2.1 in blue. This block takes in commanded torque, available DC bus voltage, measured current, shaft speed, and flux position. With that information the motor utilization portion of the control decides how to best control the current and voltage to achieve the desired torque. The desired D and Q axis current are fed into a controller, which then looks at the actual DQ current and adjusts the DQ voltage to achieve the desired current. Finally, the DQ voltages are converted to the stationary reference frame and fed to the inverter block. The slip is also brought out so that it can be used to determine the flux position. The inside of this block contains proprietary algorithms and is not shown at this time.

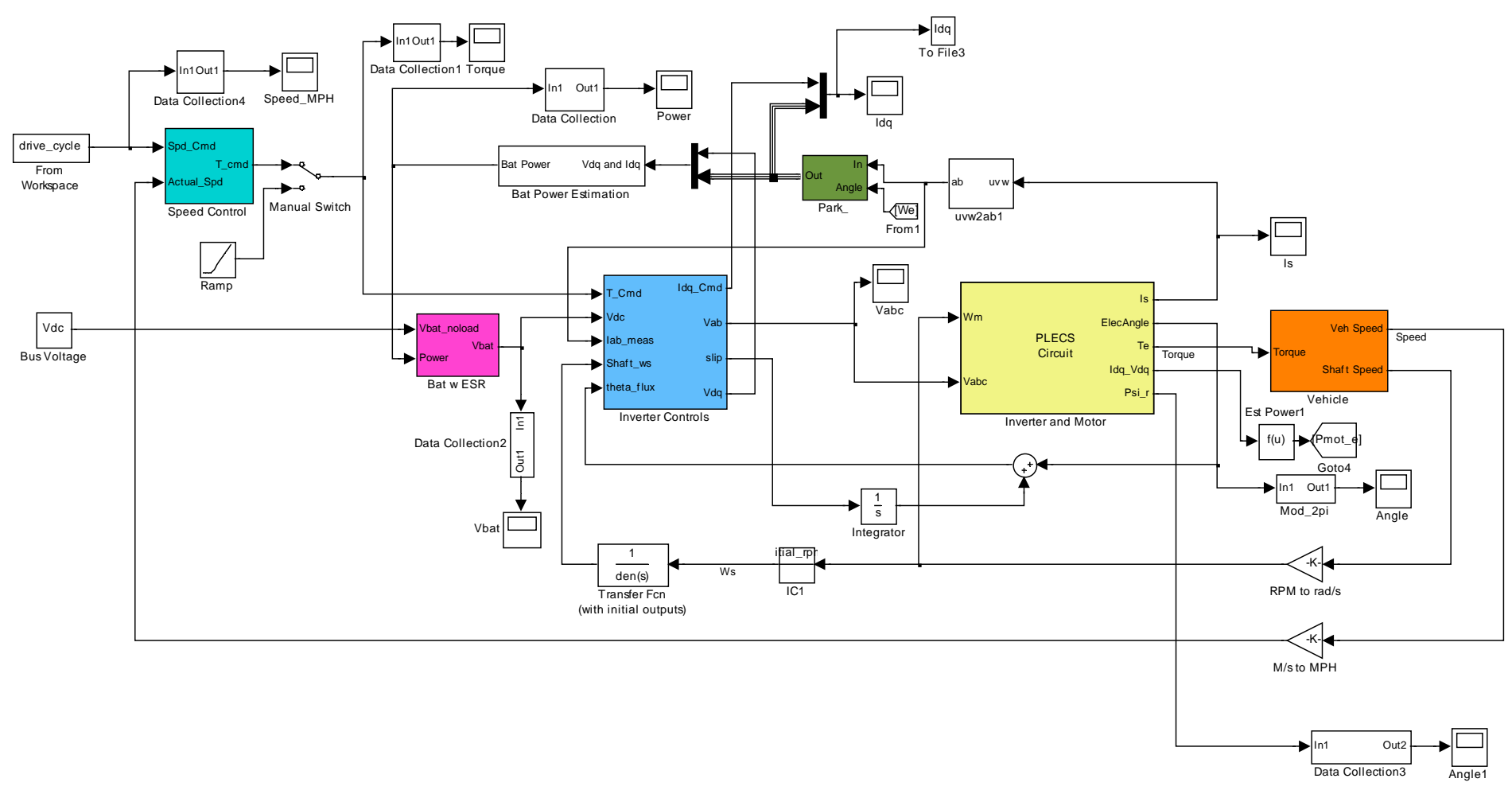

Figure 2.1. The overall propulsion system simulation.

The battery is modeled by the pink block in Figure 2.1. This block takes the open circuit voltage of the battery pack and battery power consumed. With this information it calculates the actual output voltage of the pack using the series resistance parameter. In the white block above the battery block the inverter output power is calculated using the output voltage and current. From there it is assumed that the inverter is $95 \%$ efficient and the required input power is calculated. 
The speed regulator is shown in teal on the left hand side of Figure 2.1. Its job is to act like the driver of the vehicle. Its inputs are the drive cycle speed and the actual vehicle speed. The actual controller is a PI regulator but it is tuned conservatively so that it does not react too quickly. Its output is the commanded torque which is the same as the accelerator pedal output. The regulator also has a limit for positive and negative torque $210 \mathrm{Nm}$ and $-100 \mathrm{Nm}$ respectively. The positive limit is above the actual motor limit and the negative limit is in place to prevent huge power spikes during braking. In an actual vehicle the friction brakes would take over when the regenerative braking had reached its limit.

The US06 drive cycle was chosen because it is one of the more practical drive cycles available. It includes a good mix of both low speed (city) driving and high speed (highway) driving. The drive cycle speed and the actual speed from the simulation are shown in Figure 2.2. It should be noted that the vehicle does not follow the trace exactly for several reasons. First on some of the harder accelerations at high speed ( $300 \mathrm{~s}$ and $580 \mathrm{~s}$ ) the motor doesn't have quite enough torque available. This is not a huge concern because the purpose of the simulation is only to stress the inverter as it might be used in a vehicle. The trace also misses on some of the steep deceleration areas but as mentioned previously the additional breaking would be provided by friction brakes.

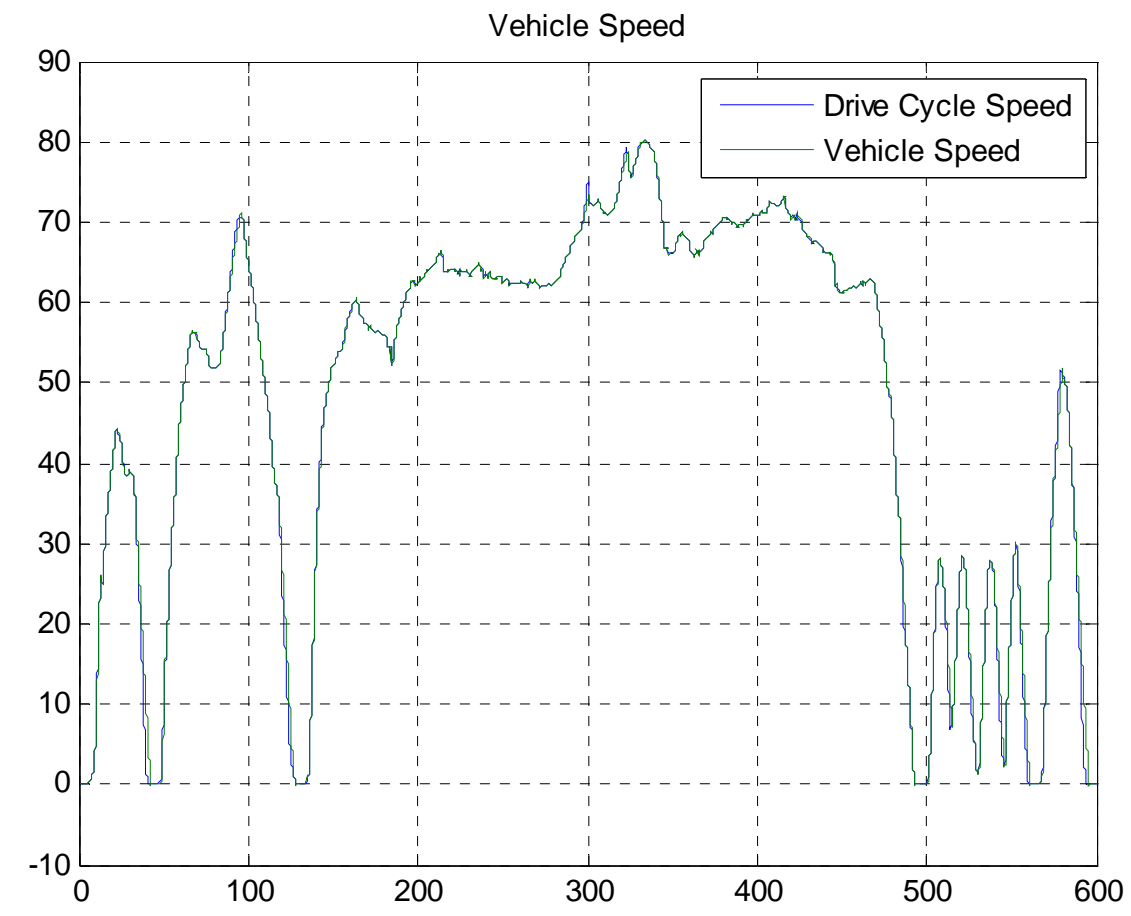

Figure 2.2. Vehicle Speed over US06 drive cycle. Speed is on the Y-axis in MPH. The $x$-axis is seconds.

The commanded motor torque and actual torque are shown in Figure 2.3. At higher speed the available motor torque is significantly reduced. When the speed regulator starts to stop tracking it saturates the motor torque to its peak output command of $210 \mathrm{Nm}$. Once the speed is tracking well the commanded torque comes back down to the actual required level. 


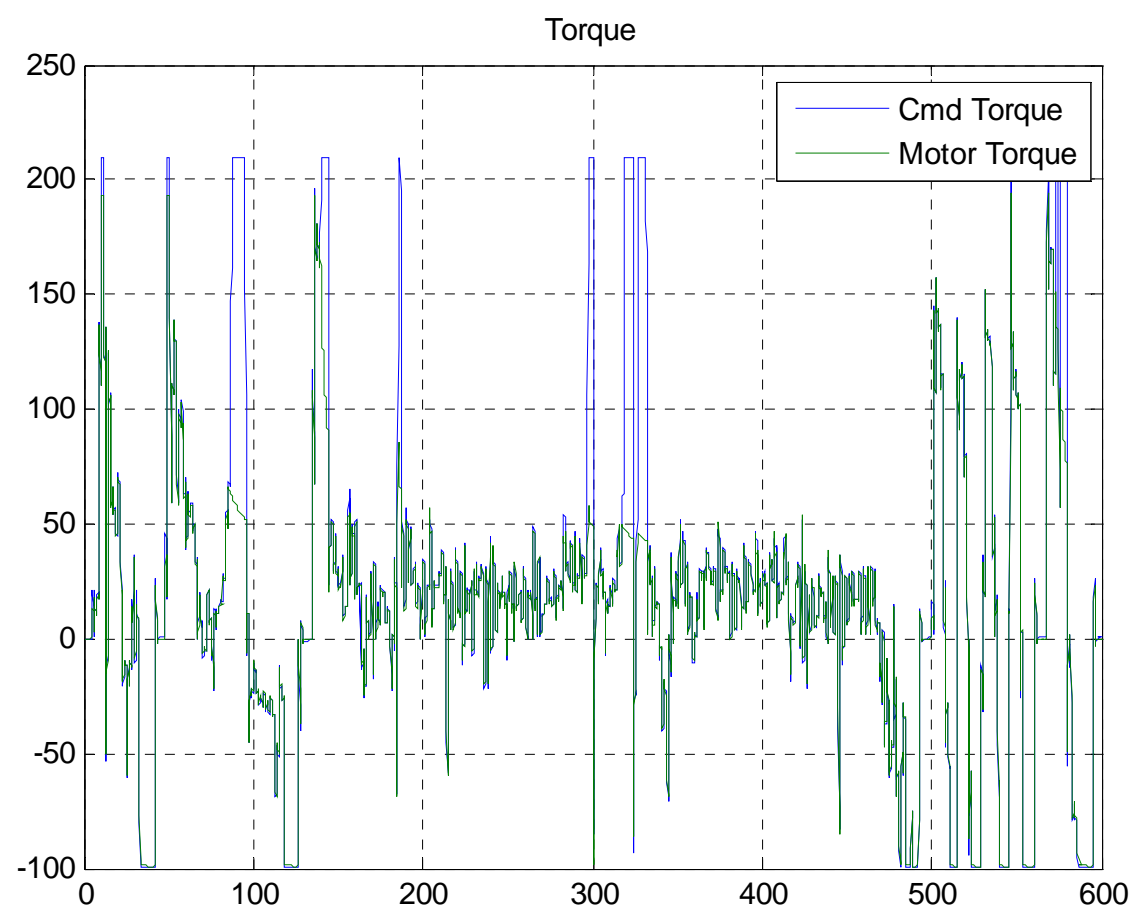

Figure 2.3. The motor torque commanded by the speed regulator and the actual torque produced are shown above. Torque (y-axis) is shown in Newton-meters and time is shown in seconds.

The power required at various places in the simulation is shown below in Figure 2.4. The inverter output is the same as motor input, shown in red. The inverter output peaks at just below $60 \mathrm{~kW}$. The motor shaft output power is also shown in green. The motor output is less than the input for efficiency reasons. It should be noted that this is not a comprehensive motor loss simulation so that data should only be used for comparison purposes. 


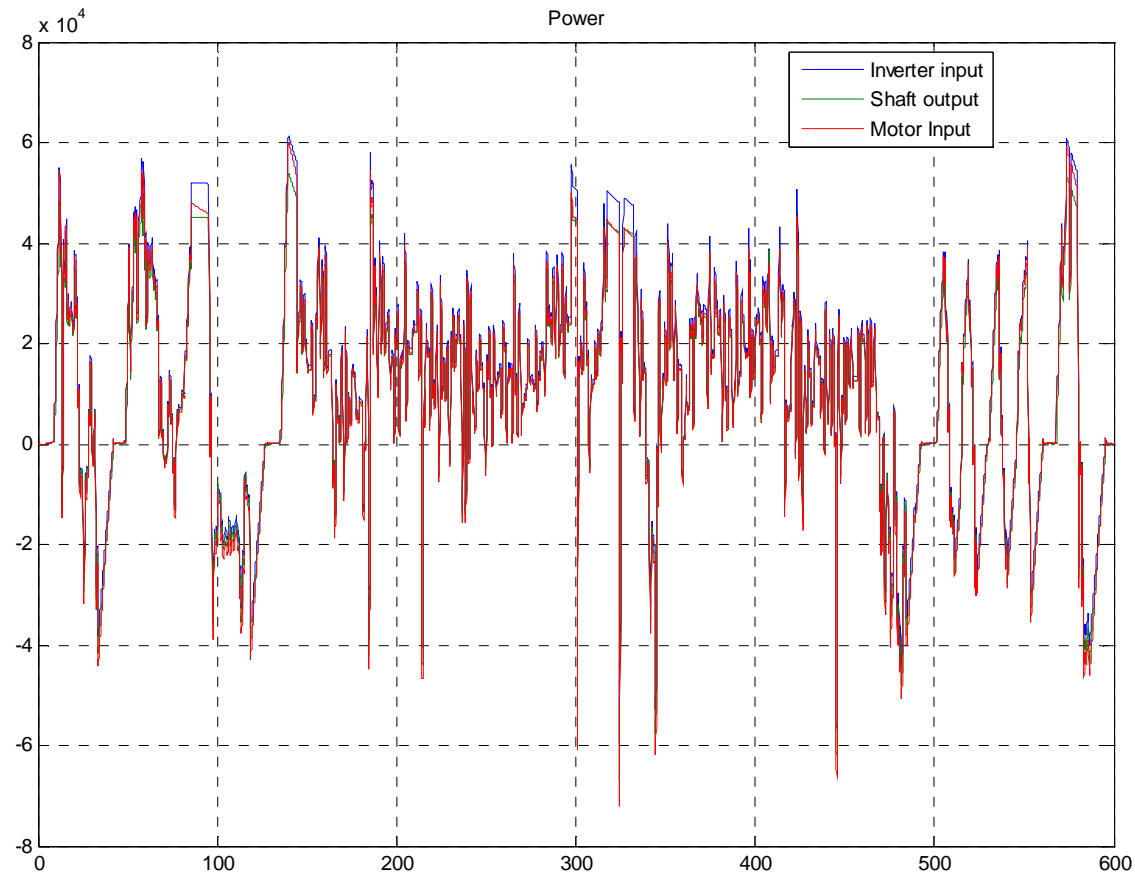

Figure 2.4. The inverter power (y-axis) is shown in watts above. The $x$-axis is time in seconds.

The inverter output line-to-neutral voltage peak amplitude is shown in Figure 2.5. The commanded current amplitude (again the crest of the sine wave) is shown below in Figure 2.6. It does not include any additional peak due to switching ripple. The peak current exceeds $400 \mathrm{~A}$ under heavy load conditions.

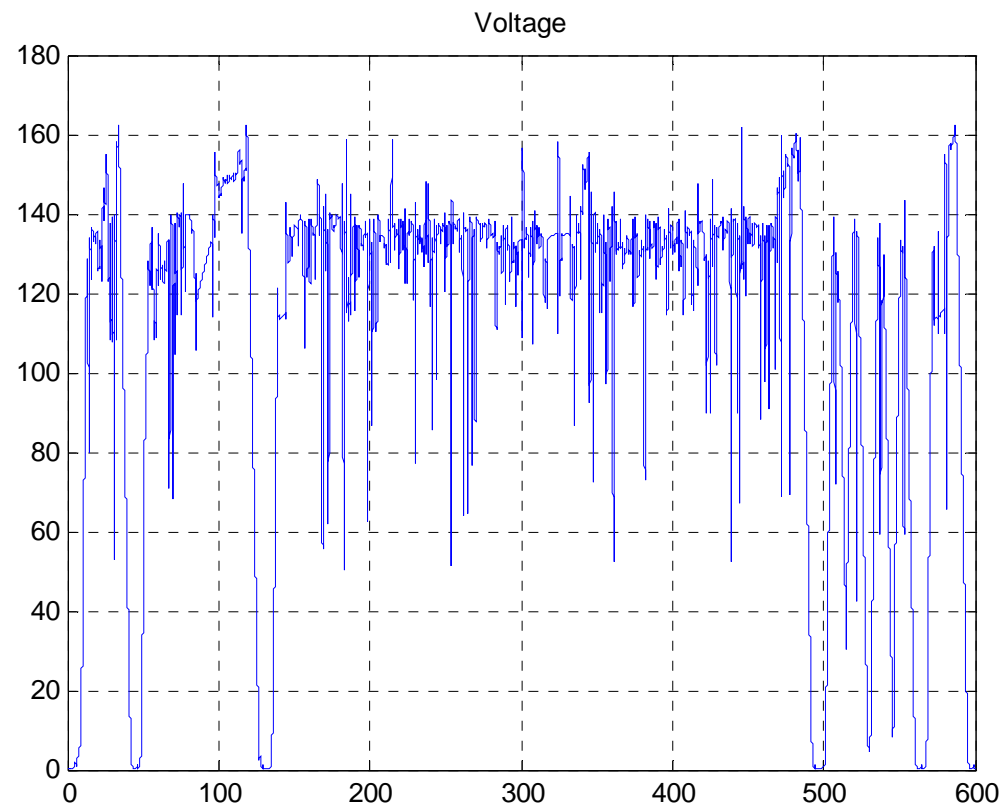

Figure 2.5. The inverter output voltage (line-neutral) amplitude is shown above. The $x$-axis is time in seconds. 


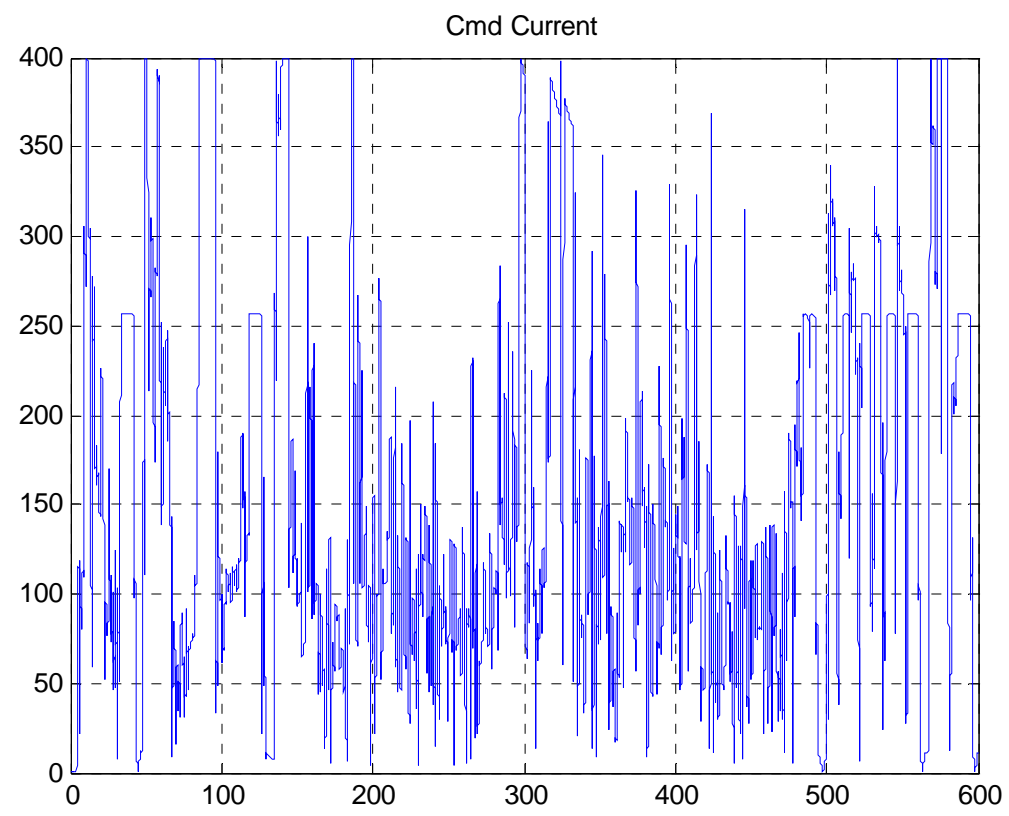

Figure 2.6. The amplitude of the phase current commanded by the motor control block is shown above in Amps ( $y$-axis). The $x$-axis is time in seconds.

The motor power factor is shown below in Figure 2.7. The power factor varies quite a bit. It can reach all the way up to unity power factor (1) and down to almost all reactive power (0). Negative power factor is present when the current leads the voltage and typically only occurs during transients. The DC bus voltage for the battery under load is shown in Figure 2.8. Under heavy load condition, the DC bus voltage drops below $240 \mathrm{~V}$.

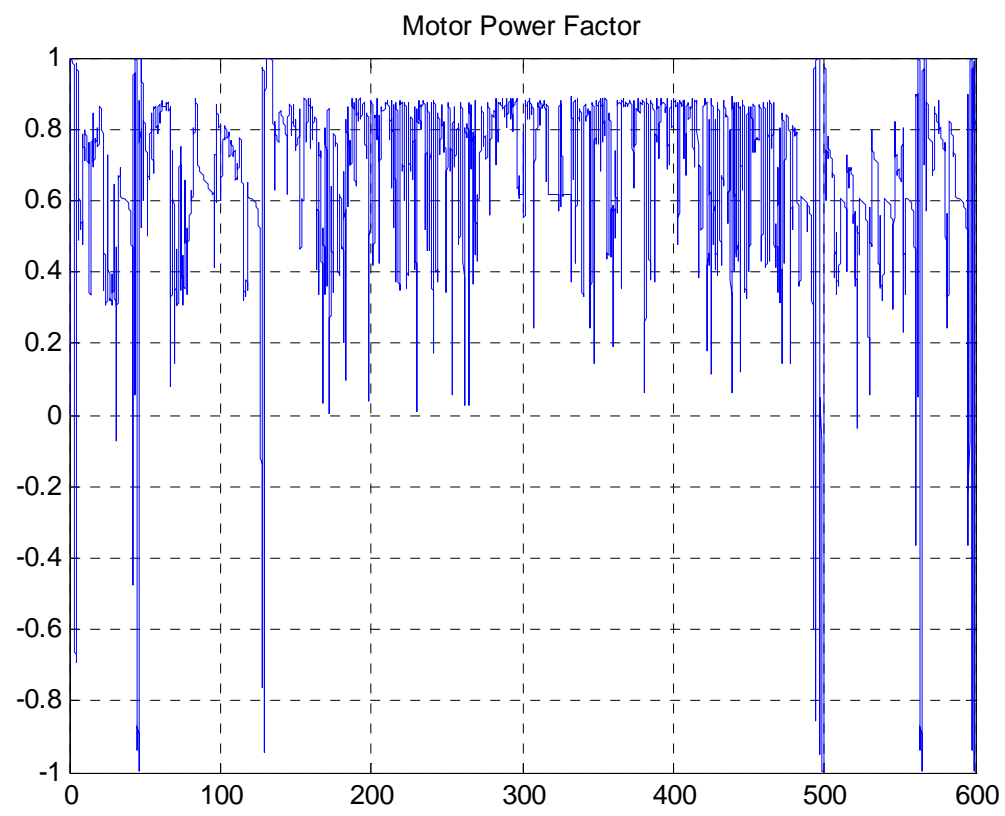

Figure 2.7. The motor power factor average is 0.68 over the entire cycle. 


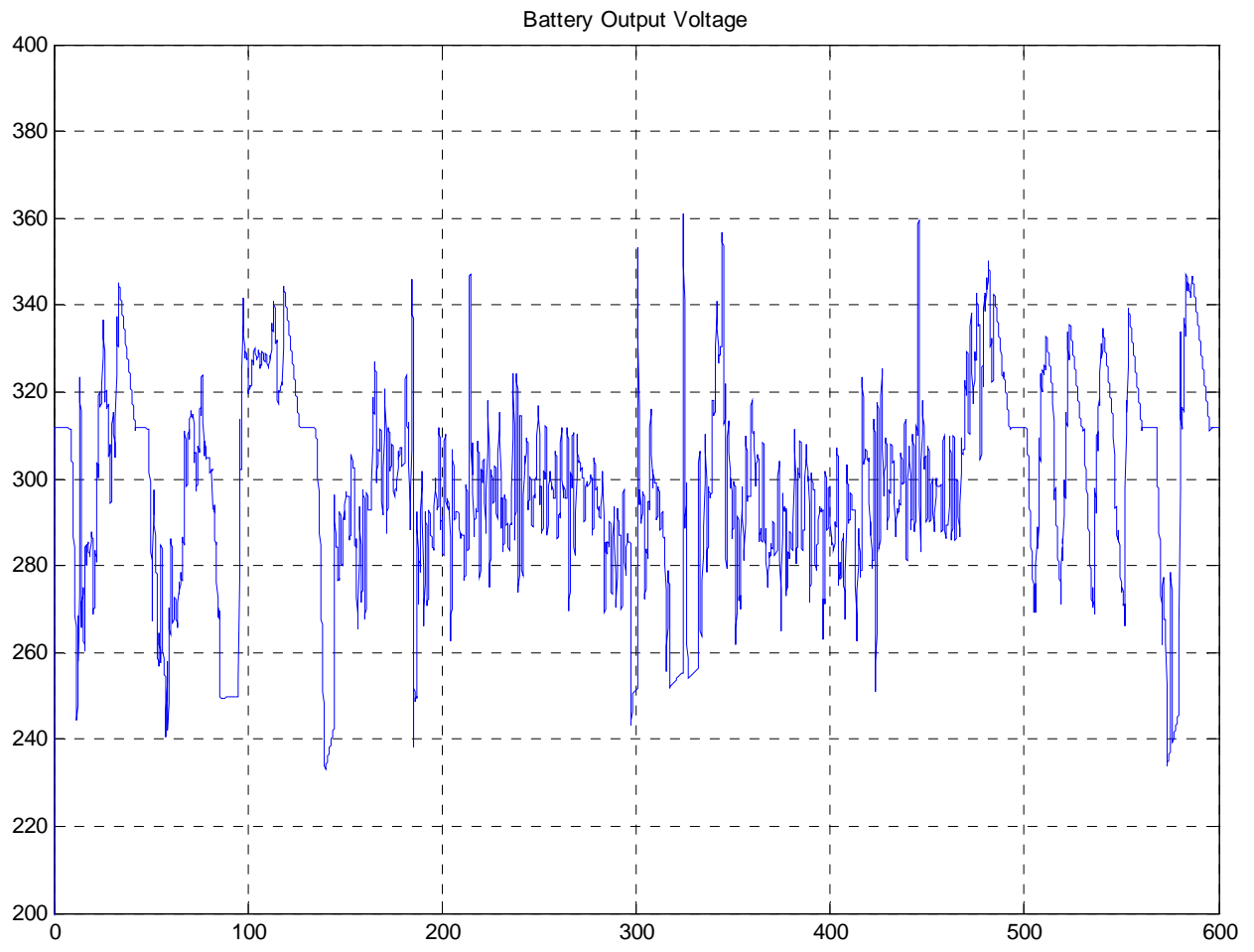

Figure 2.8. The ESR of the battery causes the output voltage to dip or rise when large amounts of current are drawn.

The peak power called out in the DOE proposal was $55 \mathrm{~kW}$ for 18 seconds. The worst case for this peak is at lower speed. At zero speed it is not possible to achieve this power level due to low output voltage. From the previous sets of figures one could choose the point at about 3 seconds as the lowest speed possible to achieve $55 \mathrm{~kW}$. The inverter conditions at that point are summarized below in Table 2.3.

Table 2.3. The circuit conditions present at the worst case $55-\mathrm{kW}$ operating point

\begin{tabular}{|c|c|}
\hline Measurement & Quantity \\
\hline$V_{d c}$ & $244 \mathrm{~V}$ \\
\hline$I_{a c-p k}$ & $400 \mathrm{~A}$ \\
\hline$V_{a c-p s}$ & $112 \mathrm{~V}$ \\
\hline Power Factor & 0.78 \\
\hline
\end{tabular}

The proposed current limit of 400-A peak is adequate for a $55-\mathrm{kW}$ motor or $60-\mathrm{kW}$ inverter for vehicle use. The Siemens motor was chosen because of its ease of integration into a vehicle and its high speed capability. Other motors such as permanent magnet may seem attractive but have their own problems at high speed when the back EMF voltage is dangerously high unless properly controlled. Higher voltage electronics must be used and this contributes to increased cost and lower efficiency. It appears that a permanent magnet design is overall less robust and 
more costly in automotive applications. The Siemens motor power factor is quite good (0.85) at certain operating points.

The data shown in the previous figures is available as an accompanying Excel spreadsheet for further analysis such as reliability predictions and thermal modeling. The output current, voltage, and power factor could also be used as an input into a circuit level model of our softswitching inverter. The data shown is not a comprehensive list of all worst case scenarios. Other operating points such as DC current out of the inverter for an indefinite amount of time should also be considered. The numbers above should be used as an average use profile for the inverter design. 


\section{SOFT-SWITCHING TECHNIQUE}

\subsection{Variable Timing Soft-Switching Technique}

Figure 3.1 shows a possible implementation for variable timing controlled soft-switching converter circuit, where $S$ and $D$ are the main switch and freewheeling diode, $S_{x}$ is the auxiliary switch, and $C_{r}$ is the resonant capacitor. A typical switching sequence is to turn on the auxiliary switch according to the pulse-width modulation (PWM) signal. After the auxiliary current $I_{a u x}$ exceeds the load current $I_{\text {load }}$, the excess current will discharge the resonant capacitor $C_{r}$ and thus resulting in a resonance, which reduces the device voltage $V_{s}$ down to zero. During the zero voltage period, switch $S$ can be turned on without incurring loss. The conventional approach to turn the main switch on is to use a fixed timing delay or controlling the delay turn-on based on the current magnitude. The proposed variable timing technique is to sense the device voltage and wait until it reaches almost zero, then turn on the main switch at the exact zero-voltage condition. The conceptual implementation circuit in Figure 3.1(a) is to use a comparator that compares reference voltage $V_{\text {ref }}$ and the sensed voltage $V_{s}$. When $V_{s}$ drops below $V_{r e f}$, the comparator output becomes high. When both comparator output and PWM signals are high, then the main switch is turned on. The reference voltage can be zero for a low voltage system. For the dc bus voltage $V_{d c}$ higher than a few hundred volts, the reference voltage can be set at a few volts to allow time for the comparator and logic control circuit to react. The output of the comparator goes through a hysteresis to tolerate the noise once the zero-voltage switching is achieved.

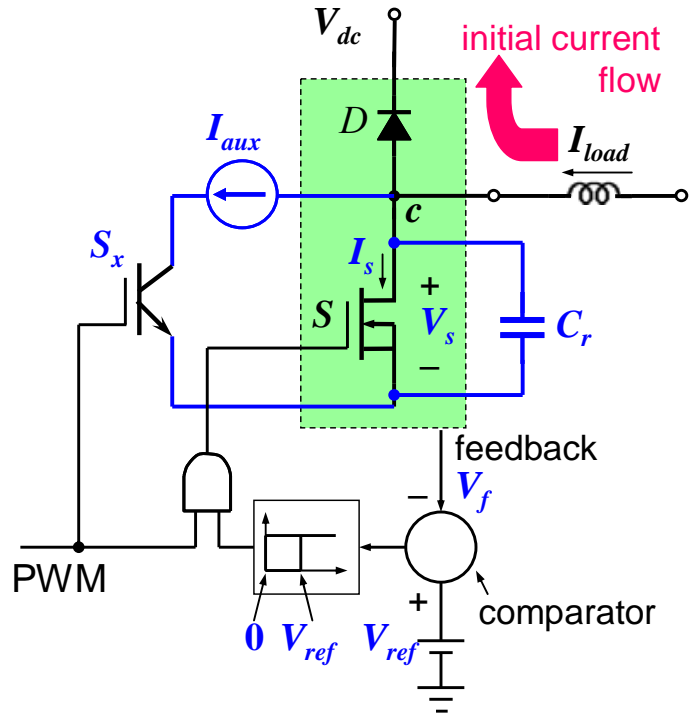

(a)

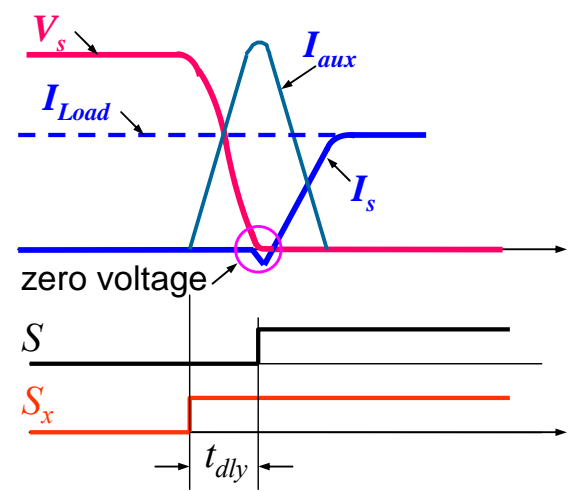

- $S_{x}$ turns on following the PWM signal

- $S$ waits the zero-voltage crossing to turn on after receiving PWM signal

- Fixed timing control: $t_{d l y}=$ constant

- Variable timing control: $t_{d l y}=$ variable and is a function of load current

(b)

Figure 3.1. Soft-switching converter circuit with variable timing control for zero-voltage switching: (a) conceptual circuit diagram, and (b) switching timing and key voltage and current waveforms.

Figure 3.1(b) shows the switching timing and key voltage and current waveforms of the variable timing controlled soft switching converter. Here $S_{x}$ follows the PWM command to turn on. The auxiliary current $I_{\text {aux }}$ increases linearly until it reaches the load current $I_{\text {load }}$. When $I_{\text {aux }}$ is higher than $I_{\text {load }}$, the excess current will discharge the resonant capacitor $C_{r}$, which and results in a resonance. During resonance, the device voltage $V_{s}$ swings down to zero, and the main switch $S$ 
can be turned on at zero volts. The switch current $I_{s}$ starts increasing until it reaches the load current $I_{\text {load }}$ and then stabilizes. With the proposed approach, the turn-on time of the main switch $S$ is always at zero voltage, which implies the switching delay $t_{d l y}$ needs to be variable. Because the time for the auxiliary current to reach the load current varies with the load condition, the fixed delay timing control cannot guarantee the switch turn-on at zero-voltage condition. The variable timing is thus preferred to the fixed timing approach.

Figure 3.2 shows variable timing controlled soft switching simulation results for positive current cycle at high current $(300 \mathrm{~A})$, medium current $(150 \mathrm{~A})$, and zero current conditions. Under different current conditions, the device current rises after voltage $V_{c e}$ drops to zero with the same timing delay.
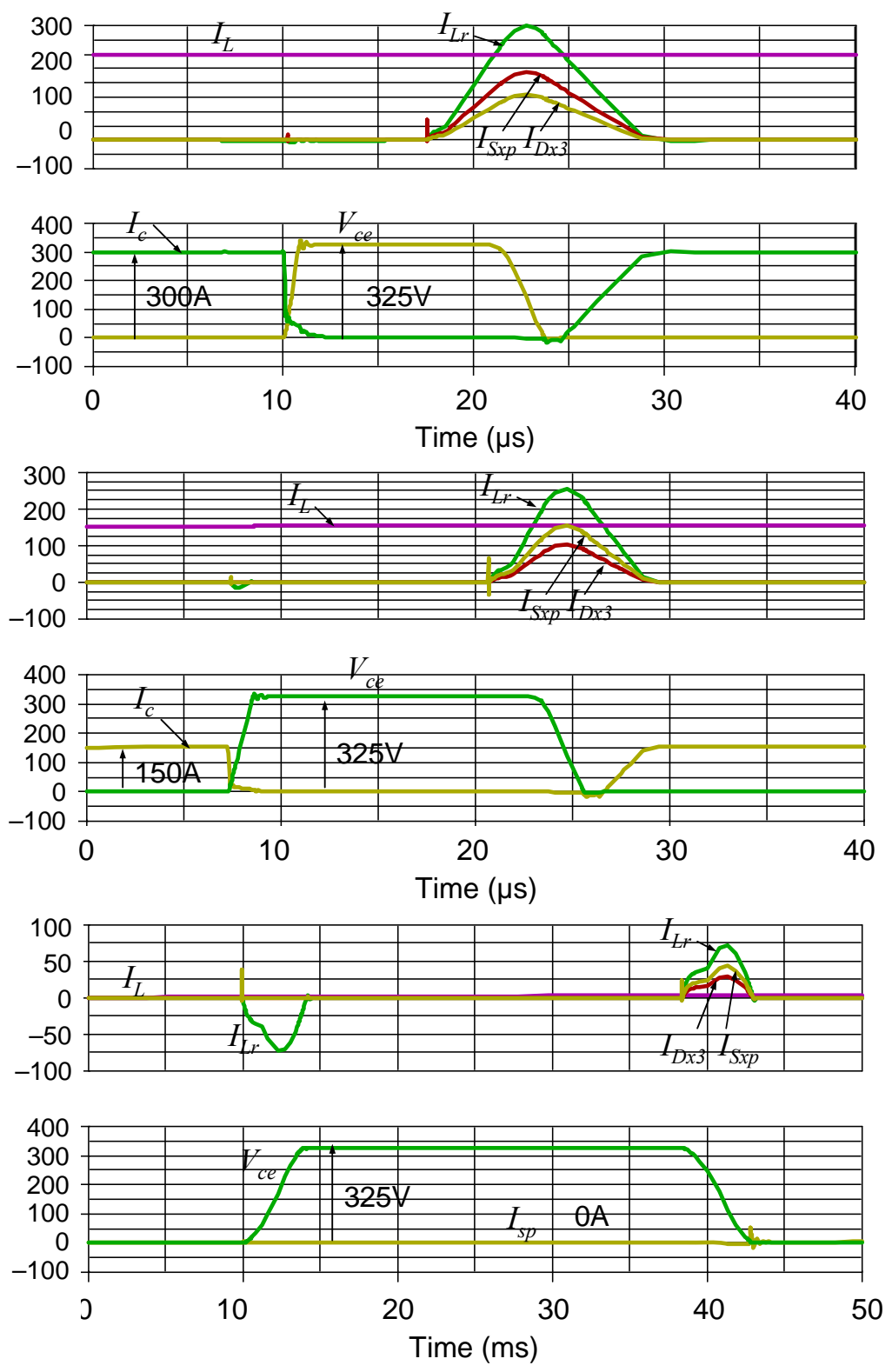

Figure 3.2. Variable timing controlled soft switching simulation for positive current cycle at high current (300 A), medium current (150 A), and zero current conditions. 
Figure 3.3 shows variable timing controlled soft switching simulation for negative current cycle at medium current $(-150 \mathrm{~A})$, high current $(150 \mathrm{~A})$, and zero current conditions. Under different current conditions, the device current rises after voltage $V_{c e}$ drops to zero with the same timing delay.
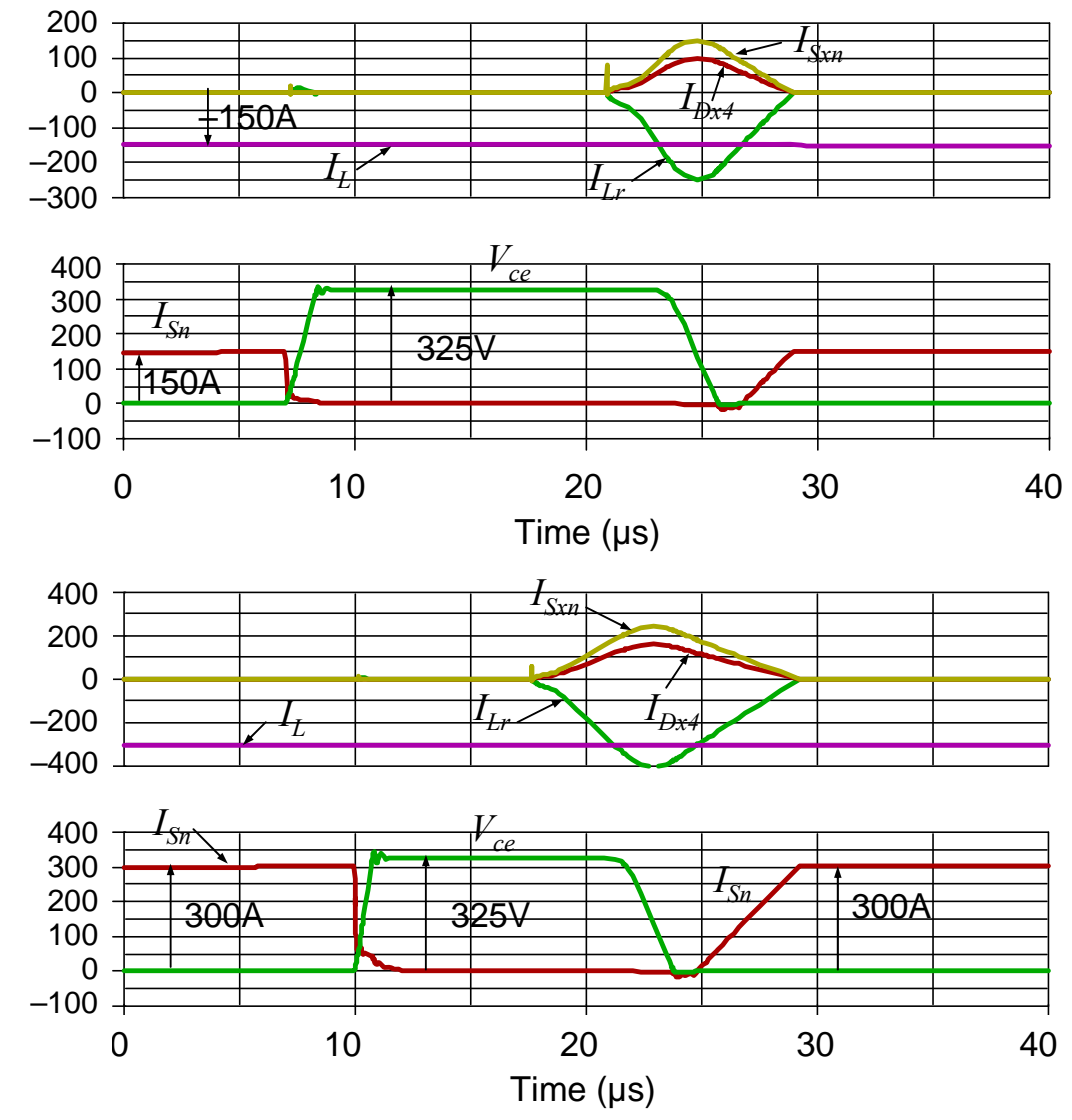

Figure 3.3. Variable timing controlled soft switching simulation for negative current cycle at medium current (-150 A) and high current (-300 A).

Figures 3.4(a) and 3.4(b) show verification of variable timing control with simulation and experimental results. Under different load conditions, the delay time $t_{d l y}$ varies. However, the gate turn-on delay after device voltage $V_{C E 2}$ drops to zero, $t_{z}$, is fixed. Both simulation and experimental results agree with each other very well at three different current conditions. 


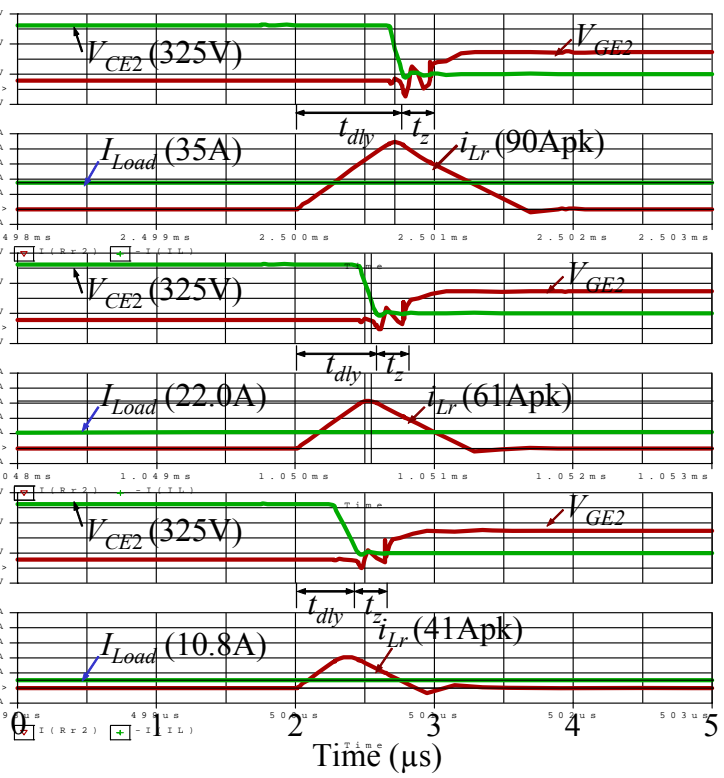

(a)

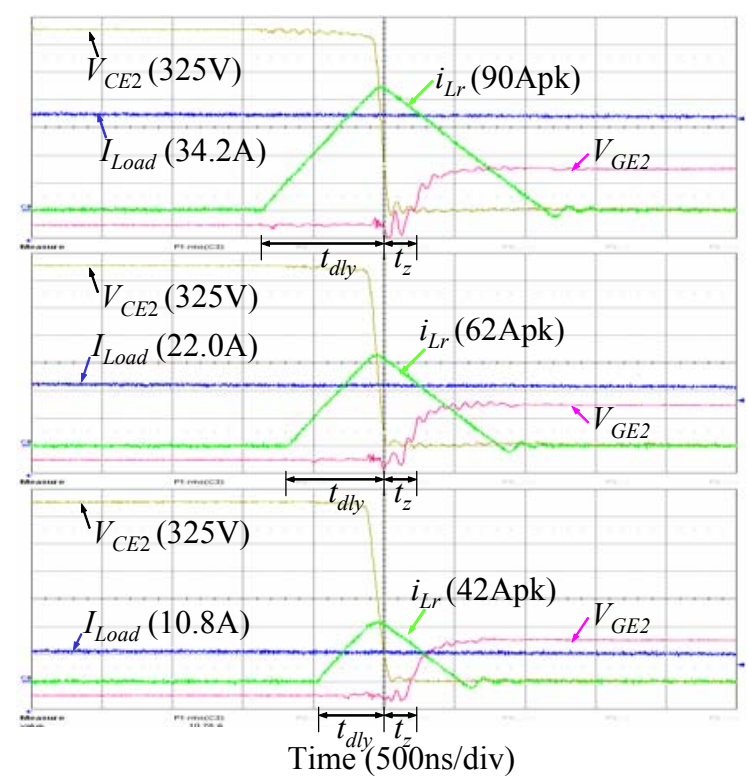

(b)

Figure 3.4. Verification of variable timing with simulation and experimental results: (a) simulation of soft switching under different current conditions, and (b) experimental verification of soft switching under different current conditions.

\subsection{Circuit Level Simulation for Device Selection}

With the base frequency $83.3 \mathrm{~Hz}$, which should produce $2500 \mathrm{rpm}$ for the 2 pole-pair machine, the load torque is $210 \mathrm{Nm}$. All other circuit parameters are the same as those used in vehicle level simulation. Figure 3.5 shows the simulated closed speed loop control results using the above available voltage at the rated speed and torque. The stator voltage and current are $158.4 \mathrm{~V}$ and $340 \mathrm{~A}$, respectively. 

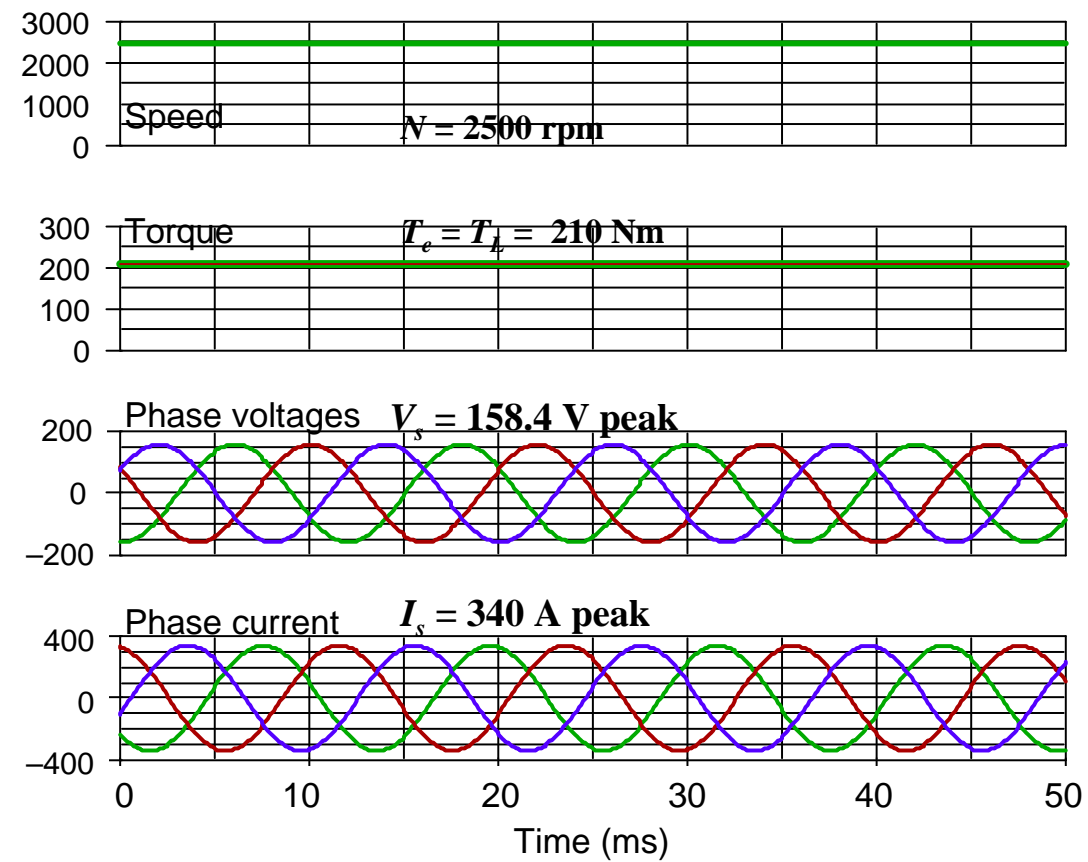

Figure 3.5. Closed speed loop simulation results with fully utilization of DC bus voltage at the rated speed and torque condition.

By connecting the above motor to the standard 6-bridge inverter, the simulated voltage and current waveforms can be shown in Figure 3.6. In this simulation, the inverter output voltage is maximized with space vector modulation (SVM). The DC bus voltage is $280 \mathrm{~V}$, and the output peak current is $330 \mathrm{~A}$. With PWM phase voltage, the motor input draws sinusoidal current with a power factor of 0.87 .

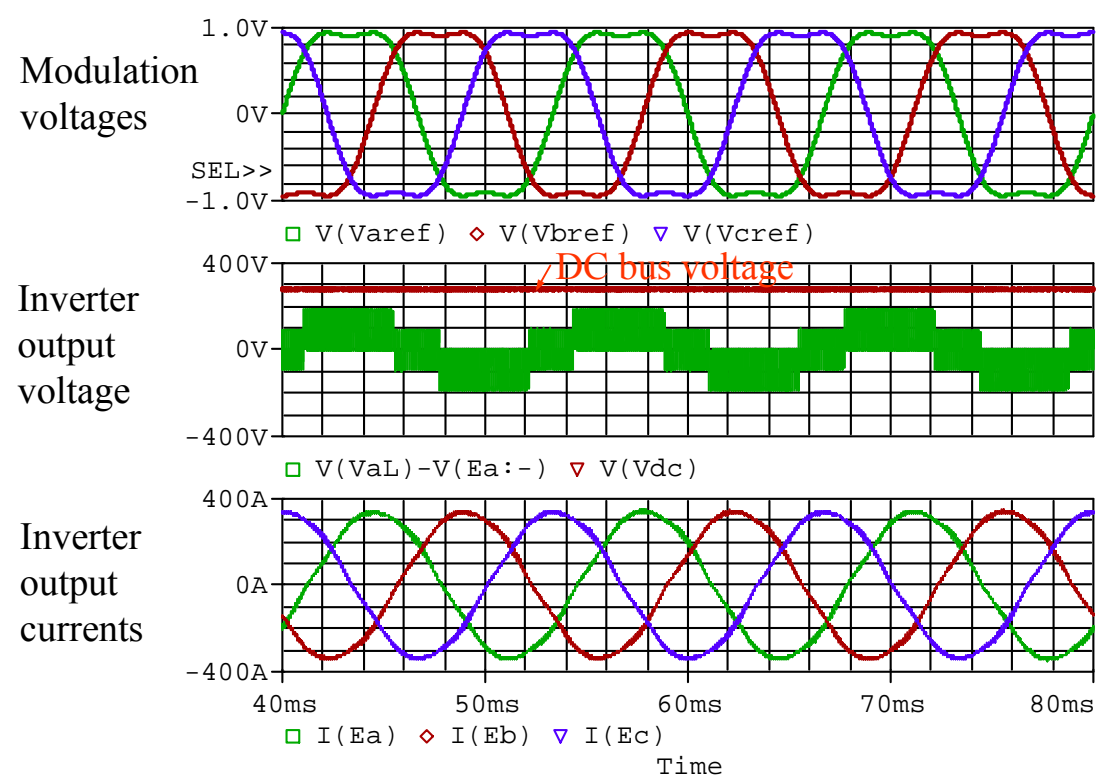

Figure 3.6. Simulated voltage and current waveforms for the entire SVM controlled inverter-motor system. 
The complete motor drive has been simulated under hard and soft switching conditions using 300-A, 400-A, and 600-A devices. The purpose of the simulation is to ensure sufficient efficiency and acceptable junction temperature under $105^{\circ} \mathrm{C}$ operation. Figure 3.7 shows efficiency comparisons between soft switching and hard switching: (a) using 400-A device and (b) using 600-A device. The variable timing achieves higher efficiency at light loads for both 400 and 600-A devices. The 600-A device has a slightly higher efficiency at heavy load conditions for both hard and soft switching inverters; however, its efficiency improvement is insignificant to be noticeable. The junction temperature should be lower with a larger die size, and the use of 600-A device is almost necessary under hard switching condition. However, for soft switching inverter, the efficiency with 400-A is significantly higher than that with 600-A under hard switching condition, and therefore, the soft-switching with 400-A device is favored through the comprehensive comparison here.

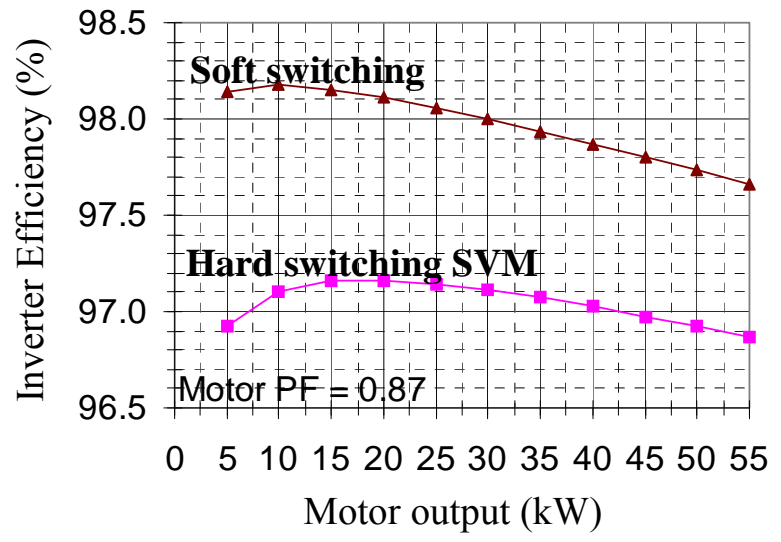

(a)

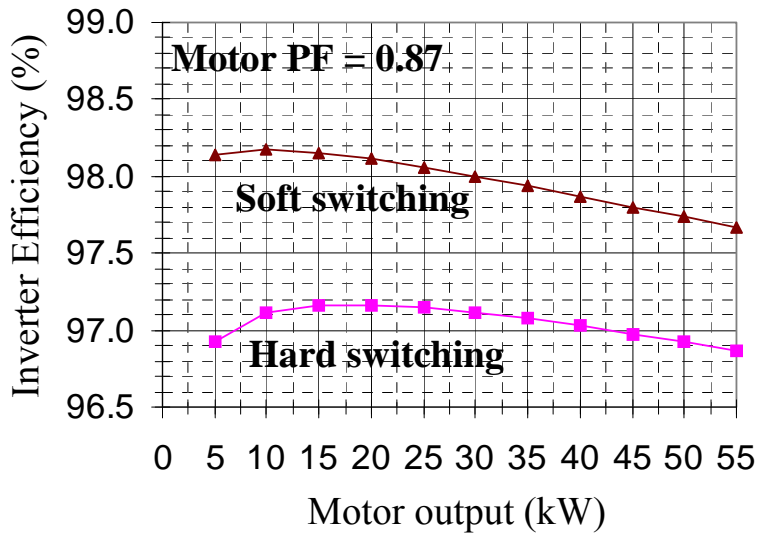

(b)

Figure 3.7. Efficiency comparison between soft switching and hard switching: (a) using 400-A device and (b) using 600-A device.

Table 3.1 compares conduction and switching losses at full load condition between hard and soft switching inverter. Under hard switching condition, the switching loss is the same level as the conduction loss. With either device, the soft switching inverter reduces switching loss about $60 \%$ or total loss about $30 \%$.

Table 3.1. Loss comparison at full load condition between hard and soft switching inverters.

\begin{tabular}{|l|l|l|l|l|}
\hline \multirow{2}{*}{$\begin{array}{l}\text { Device loss at } \\
\text { 55-kW output }\end{array}$} & Use of 400-A IGBT & Use of 600-A IGBT \\
\cline { 2 - 5 } Conduction (W) & 882 & 882 & 752 & 752 \\
\hline Switching (W) & 824 & 360 & 895 & 392 \\
\hline Total (W) & 1706 & 1242 & 1647 & 1144 \\
\hline
\end{tabular}

Figure 3.8 compares efficiency profiles using different current rating IGBTs for hard and soft switching inverter. Figure 3.8(a) compares the losses using (a) 300-A device, (b) 400-A device, 
and (c) 600-A device under hard switching condition. The 300-A device drops the efficiency very quickly under heavy load condition. Although the light load efficiency favors 300-A device, the junction temperature at heavy load is a major concern. Figure 3.8(b) compares the losses using (a) 300-A device, (b) 400-A device, and (c) 600-A device under soft switching condition. The efficiency with 300-A device is the lowest among them, but it is still significantly higher than any of hard switching cases. For cost consideration, 300-A IGBT has a chance to be successfully used in this case even at $105^{\circ} \mathrm{C}$ coolant condition. However, to be conservative, our first prototype will go with 400-A.

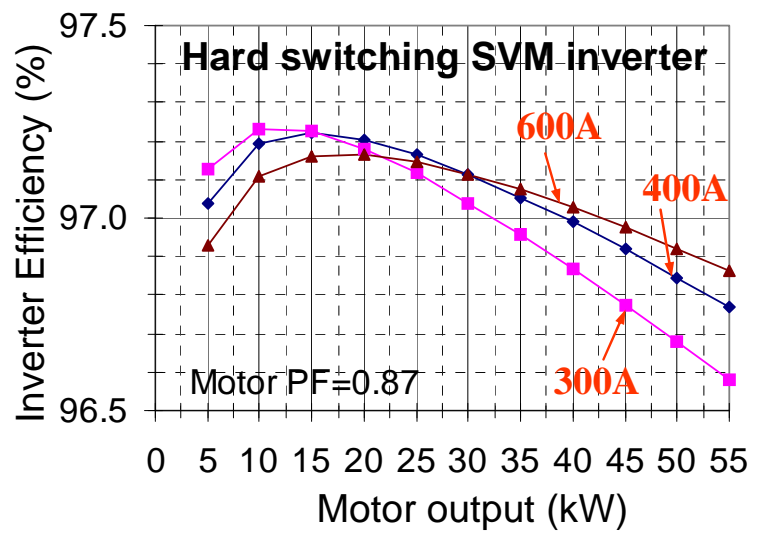

(a)

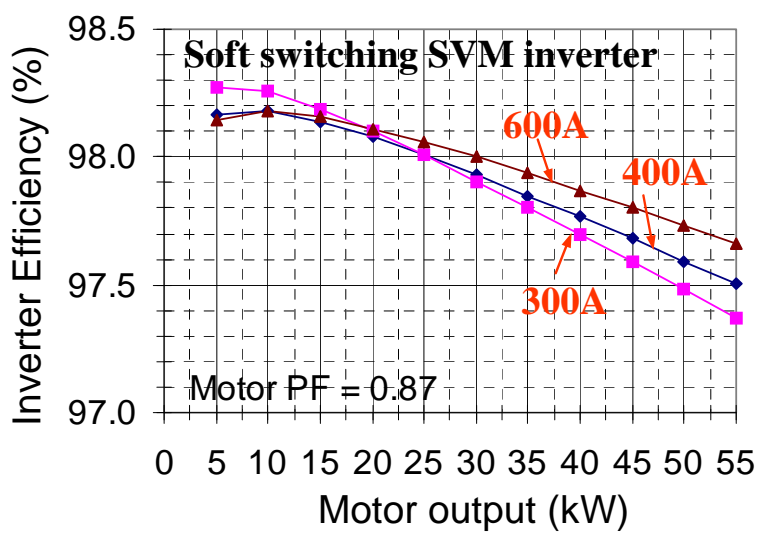

(b)

Figure 3.8. Efficiency comparison between different devices under hard and soft switching conditions: (a) hard switching and (b) soft switching.

\subsection{Select and Characterize Power Devices for High Temperature Operation}

The device conduction and switching performances at high temperature conditions differ among different IGBTs. At high temperatures, some devices have lower conduction voltage drop, and some devices present higher switching loss devices. It is well known that Schottky diodes and power MOSFETs have positive temperature characteristics, and thus it can be easily justified that these two devices are not suitable for high temperatures. Instead, the conventional junction diodes and IGBTs are more suitable for high temperature. However, some IGBTs that are suitable for high temperatures may not be suitable for soft switching operation. The following section compares the three common IGBT configurations: non punch through (NPT), punch through (PT), and light punch through (LPT). Cross sectional views of each device are shown in Figure 3.9. These sections examine how their fabrication affects the current they produce during zero voltage switching. 


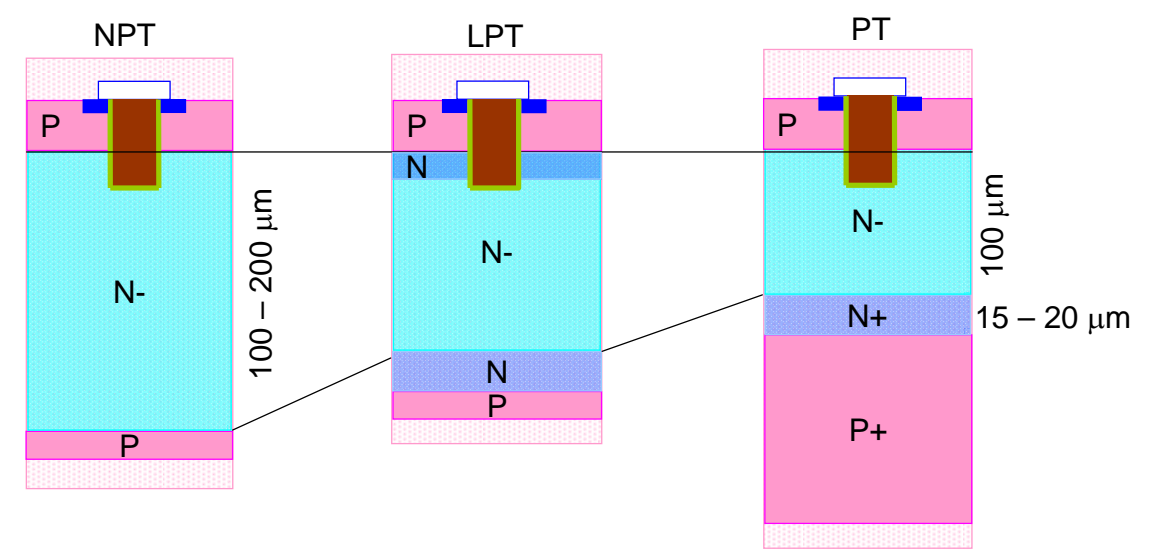

Figure 3.9. Internal structure comparison of different IGBTs.

\section{A. Non-Punch-Through IGBT}

Non-punch-through (NPT) devices employ the relative low-cost float-zone wafer and are characterized by having a wide, lightly doped base. High power NPT IGBT's have $\mathrm{N}^{-}$layer base widths within the range of $100-200 \mu \mathrm{m}$. With a high value of base width, the gain of the PNP transistor within the IGBT becomes very low. Even when the rated values of forward voltage are dropped across the device and the depletion region is at a maximum, the remaining undepleted base is wide enough to keep the value of $\beta_{P N P}$ low. The wide base also means charge carriers are distributed over a wider region, driving down the value of $\delta_{p}$. These characteristics maintain low magnitude current tail during zero voltage switching. However, carrier lifetime is relatively long (1-15 $\mu \mathrm{s})$ in the base of this device, causing the tail to propagate for long periods.

The conduction voltage drop $V_{c e}$ is proportional to the thickness of the $\mathrm{N}^{-}$layer. To reduce the $V_{c e}$ drop, thinner $\mathrm{N}^{-}$layer is necessary. However, it will reduce the blocking voltage capability because it lacks a P-type buffer layer that is present in the punch-through (PT) type IGBT.

\section{B. Punch Through IGBT}

The significant difference between PT and NPT IGBTs is within the base region. The PT devices employ relatively expensive epitaxial structure and has a heavily doped n-type buffer $\left(\mathrm{N}^{+}\right)$layer at the emitter-base junction, usually around $15-20 \mu \mathrm{m}$ in width. The buffer layout allows higher blocking voltage capability as compared to that of NPT devices, thus it allows a lightly doped $\mathrm{N}^{-}$base region, which is significantly thinner than the base region in a comparable NPT device. A thinner $\mathrm{N}^{-}$base region results in improved forward conduction characteristics, but this thinner base can cause problems with higher values of $\beta_{\text {PNP }}$ during switching and increased carrier concentration close to the collector-base junction. This can potentially cause current tails with significant magnitude. To counter this problem, the carrier lifetime of the base region is significantly reduced using carrier lifetime killing techniques. Typical values of carrier lifetime in the base of a PT device range from $0.5-0.01 \mu \mathrm{s}$. 
Shortening the carrier lifetime causes fast recombination of carriers in the base and significantly reduces current tail. However, when the carrier lifetime is reduced enough, the RC time constant of the IGBT becomes dominant and will affect the response of the device.

\section{Light Punch Through IGBT}

Light punch through (LPT) devices are relatively new and have a characteristic in between PT and NPT devices by having a moderately doped buried layer between the collector and the base $\mathrm{N}^{-}$region of the device, often termed the carrier stored layer. This carrier-stored layer helps maintain a suitable number of carriers near the collector-base junction. There is still an N+ buffer layer between the emitter and the base region, but this is not as heavily doped as buffer layers in PT devices. The width of the LPT base region is greater than a PT but less than a NPT base width. Carrier lifetime killing techniques are not used during the fabrication of LPT IGBTs. The additional buffer layer between the collector and the base of the device is significant in impeding the rapid expansion of the depletion region into the base at the onset of increasing voltage. The concentration of holes and free electrons swept by the depletion region is much smaller and $\beta$ of the internal PNP transistor remains small because the change in depletion width is greatly impeded, causing the tail current to be negligible through most or all of the switch off transition.

With the compromise in buffer layer and the thickness of N- region, the LPT device present conduction and switching characteristics in between those of PT and NPT. Figures 3.10 and 3.11 compare the normalized turn-off loss $E_{\text {off }}$ and conduction voltage drop $V_{c e}$ among them. Assuming $E_{\text {off }}=1$ at $25^{\circ}$ condition, the PT device shows much higher turn-off loss at high temperatures due to a larger current tail magnitude. The NPT device, on the other hand, has a near constant turn-off loss due to small tail current. For the conduction voltage drop $V_{c e}$, NPT has a positive temperature coefficient, and PT has a negative temperature coefficient. The LPT device characteristic can be anywhere in between.

The problem with NPT is clearly on the positive temperature coefficient that will increase the conduction loss. For a relatively low voltage system, it is not desirable. The problem with PT is also clearly on the turn-off energy penalty at high temperature. However, if the soft switching can reduce or eliminate the turn-off loss, then PT is preferred. 


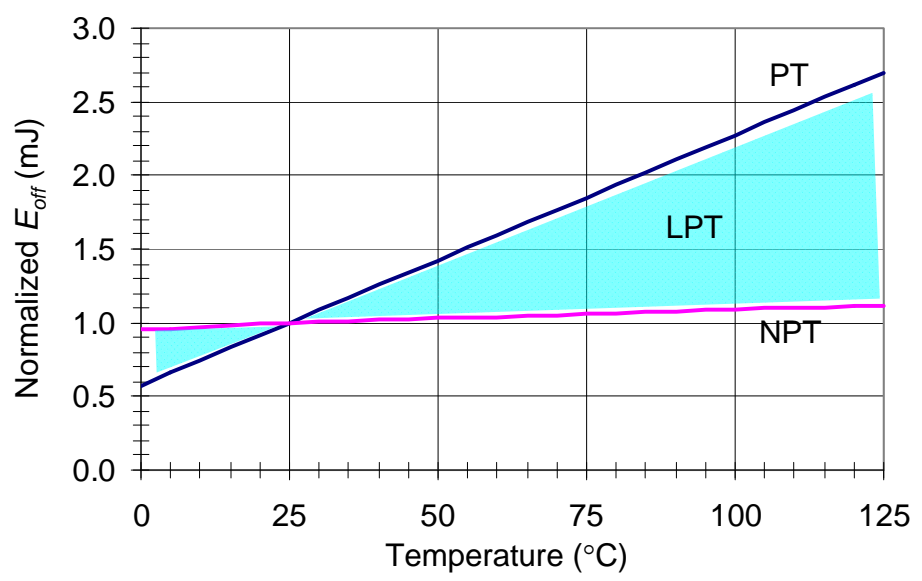

Figure 3.10. Normalized $E_{\text {off }}$ comparison among three different IGBTs.

Since the proposed zero-voltage soft switching is to eliminate the turn-on loss and to reduce the turn-off loss by a lossless snubber capacitor. In this case, it depends on how much loss reduction can be gained. If the PT device loss reduction is only $50 \%$, then the overall gain may not be justified. Therefore, our search goes to LPT type, which has near negative temperature coefficient and less sensitive temperature coefficient than that of PT devices. LPT device employs the float-zone wafer material and is potentially lower cost than that of the epitaxialbased PT devices. Through device conduction voltage drop and switching loss evaluation, the commercially available CM400DY-12NF, rated 600V, 400A and 600A LPT type IGBTs are considered the candidate for the high-temperature soft-switching applications.

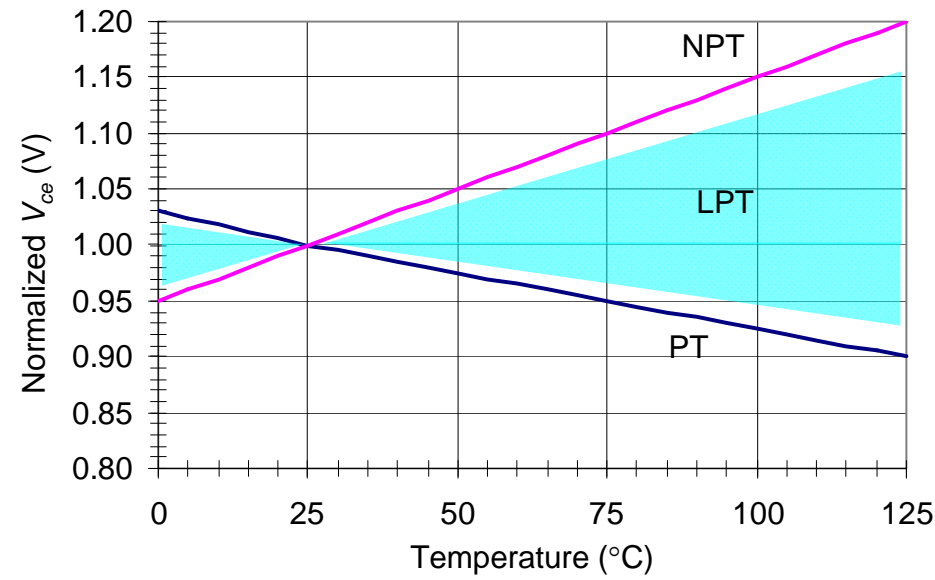

Figure 3.11. Normalized $V_{c e}$ comparison among three different IGBTs.

\subsection{Conduction loss Measurement Results}

In order to prove that the selected device conduction voltage drop has a negative temperature coefficient, the device conduction voltage drop was measured first against datasheet value and second at different temperatures. Figure 3.12 shows the measured LPT-IGBT and diode voltage 
drops against the datasheet. The LPT-IGBT voltage drop tends to be higher than that of the datasheet value possibly due to parasitics, while the diode voltage drop tends to have a lower voltage drop possibly due to self-heating effect.

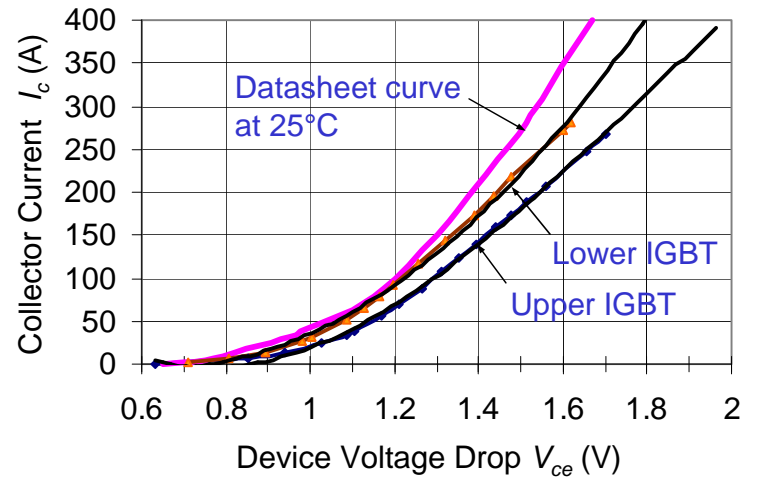

(a)

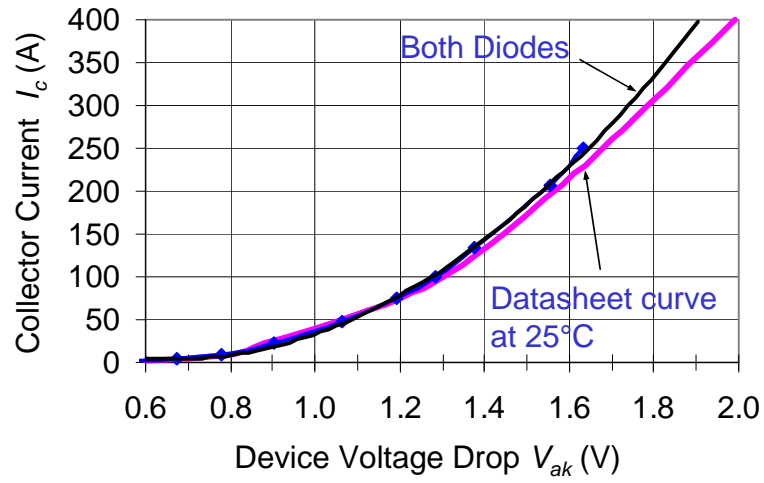

(b)

Figure 3.12. Measured LPT-IGBT and diode conduction characteristics in comparison with datasheet results: (a) IGBT, and (b) diode.

Figure 3.13 shows measured LPT-IGBT and diode voltage drops at different temperatures. In this test, the temperature is well regulated with a chiller. Both IGBT and diode show negative temperature coefficient. The diode voltage drop is significantly lower at a higher temperature. The IGBT shows a significant lower voltage drop at lower current region, but the difference is diminishing at higher current condition. However, both IGBT and diode present the desired negative temperature coefficient.

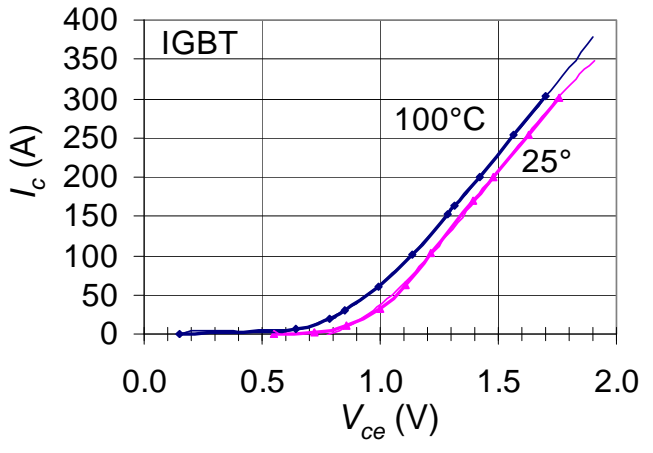

(a)

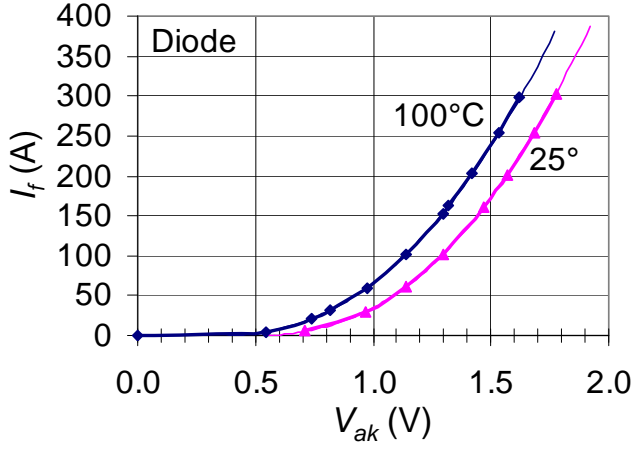

(b)

Figure 3.13. Measured IGBT and diode voltage drop as a function of temperature: (a) IGBT and (b) diode.

For comparison purposes, NPT IGBT and SiC Schottky diodes were measured to see their conduction voltage drop performance under different temperature conditions. Figures 3.14(a) and 3.14(b) show conduction voltage drop of NPT IGBT and SiC Schottky diode at $25^{\circ} \mathrm{C}$ and $100^{\circ} \mathrm{C}$ conditions. The NPT IGBT is rated $1200 \mathrm{~V}, 400 \mathrm{~A}$, and the SiC Schottky diode is rated $1200 \mathrm{~V}, 200 \mathrm{~A}$. The voltage drop of both NPT IGBT and SiC Schottky diode under high temperature condition is higher than that under low temperature condition, thus both are considered positive temperature coefficient and are not suitable for high temperature operation. 
The VI curves of $\mathrm{SiC}$ diode under both temperature conditions do not match with basic diode characteristic due to self-heating effect.

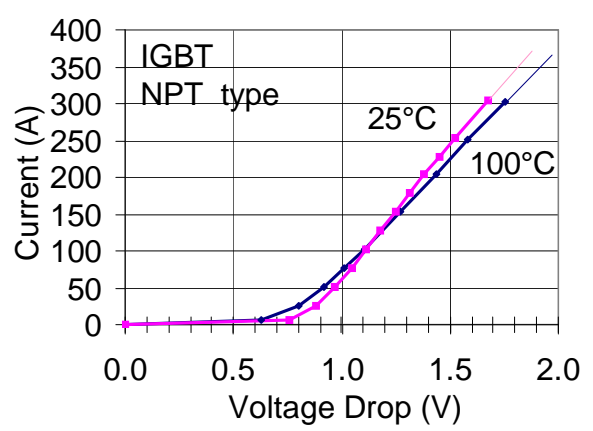

(a)

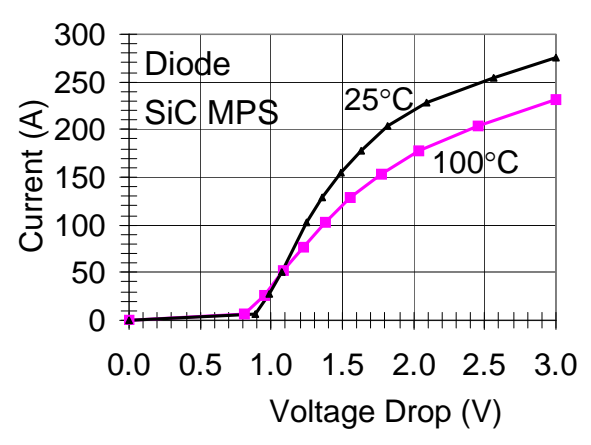

(b)

Figure 3.14. NPT IGBT and SiC Schottky diode conduction voltage drop under different temperature conditions.

\subsection{Switching Loss Measurement Results}

Figure 3.15 shows measured voltage and current waveforms at $300-\mathrm{V}, 300-\mathrm{A}$ condition. The switching energy is obtained from the integration of the product of voltage and current. In this case, the turn-on energy is $6.39 \mathrm{~mJ}$, and turn-off energy is $11.93 \mathrm{~mJ}$. The diode reverse recovery energy can be obtained from integration of the product of diode voltage and current. In this case it is $1.24 \mathrm{~mJ}$. Based on the $V_{c e}$ drop during the current rise period, the parasitic inductance that includes the dc bus capacitor, bus bar, bushing, and internal device wire bonds altogether is estimated about $60 \mu \mathrm{H}$. Figure 3.16 shows measured voltage and current waveforms at $300-\mathrm{V}$, 400 -A condition. The turn-on energy is increased to $8.31 \mathrm{~mJ}$, and the turn-off energy is increased to $15.77 \mathrm{~mJ}$.

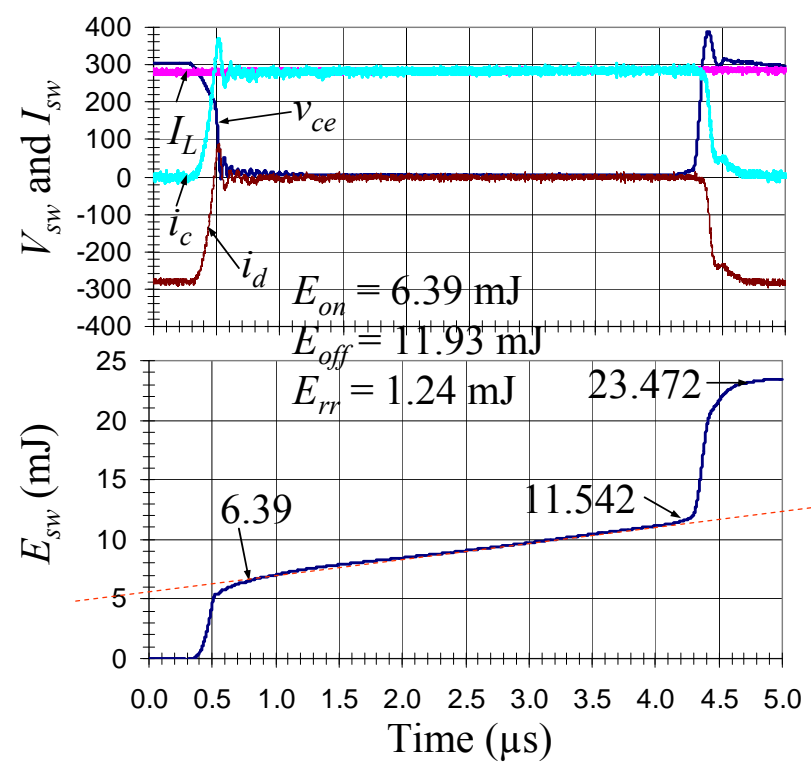

Figure 3.15. Hard switching voltage and current switching measurement results at $300-\mathrm{A}, 25^{\circ} \mathrm{C}$ condition. 


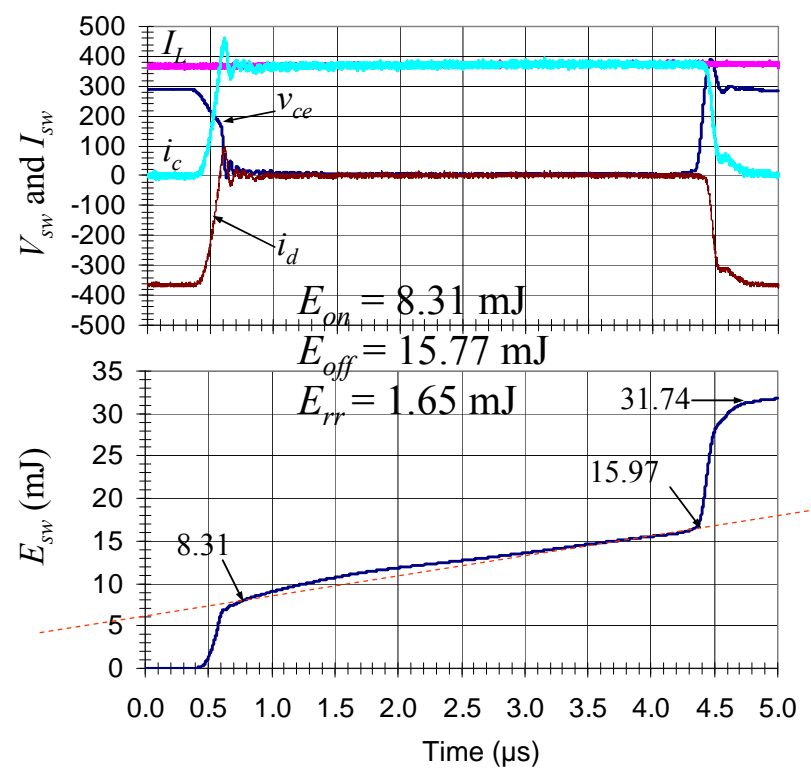

Figure 3.16. Hard switching voltage and current switching measurement results at $400-\mathrm{A}, 25^{\circ} \mathrm{C}$ condition.

Figures 3.17 and 3.18 repeat the measured voltage and current waveforms at $300-\mathrm{V}, 300-\mathrm{A}$ and 400-A conditions with $100^{\circ} \mathrm{C}$ coolant. The switching energy is obtained from the integration of the product of voltage and current. In this case, the turn-on energy is $9.89 \mathrm{~mJ}$ under $300-\mathrm{A}$ condition and $15.33 \mathrm{~mJ}$ under 400 A condition. The turn-off energy is $18.1 \mathrm{~mJ}$ under $300-\mathrm{A}$ condition and $25.6 \mathrm{~mJ}$ under $400-\mathrm{A}$ condition.

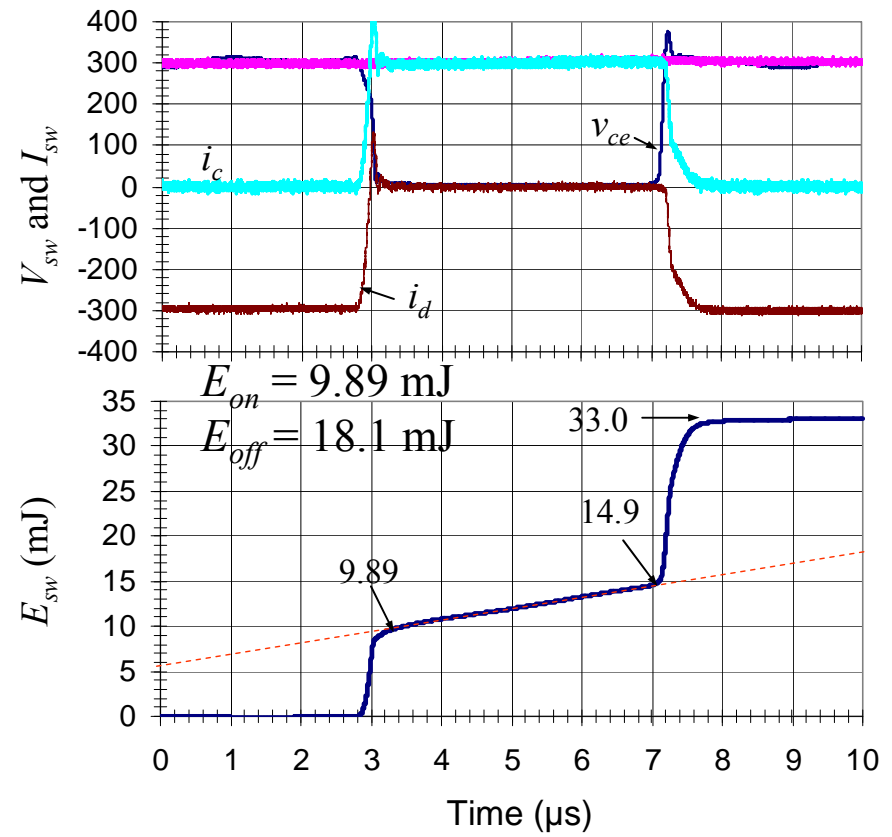

Figure 3.17. Switching voltage and current waveforms under $300-\mathrm{V}, 300-\mathrm{A}$ at $100^{\circ} \mathrm{C}$ 


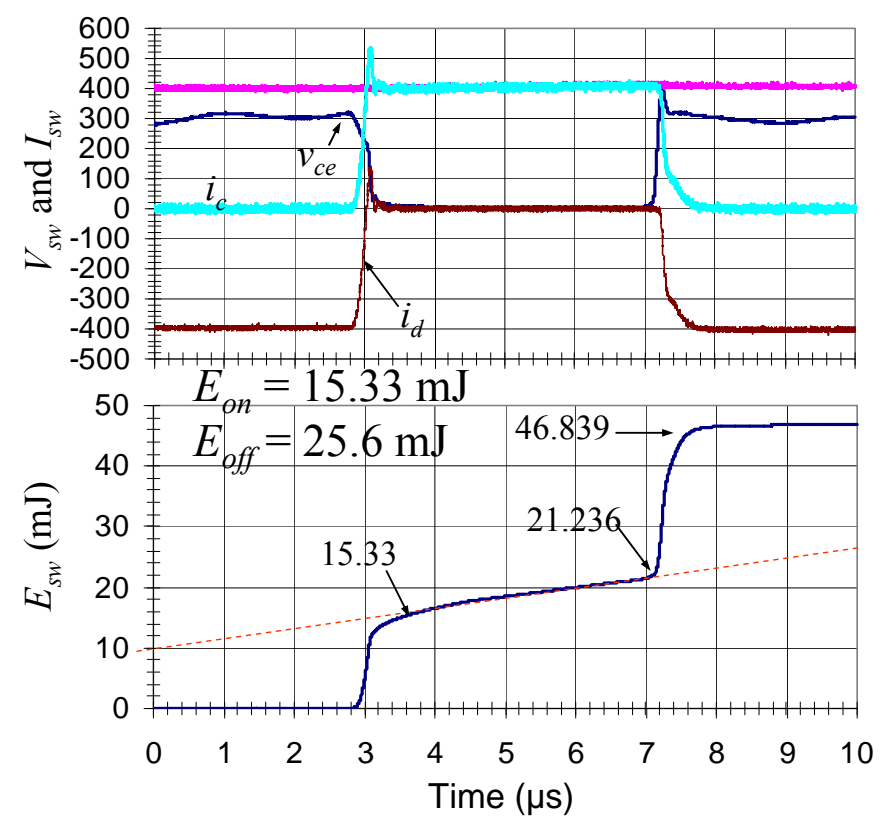

Figure 3.18. Switching voltage and current waveforms under $300-\mathrm{V}, 400-\mathrm{A}$ at $100^{\circ} \mathrm{C}$.

Figures 3.19 and 3.20 show detailed voltage and current switching waveforms during turn-on and turn-off at 300-A and 400-A respectively. The waveforms also compare voltage, current, and switching energy between $100^{\circ} \mathrm{C}$ and $25^{\circ} \mathrm{C}$ conditions. The turn-on and -off speeds are slower at high temperature conditions, and thus their high-temperature switching energies are increased significantly on both $300-\mathrm{A}$ and 400 -A cases. Approximately, the switching loss is increased by $40 \%$ from $25^{\circ} \mathrm{C}$ to $100^{\circ} \mathrm{C}$.
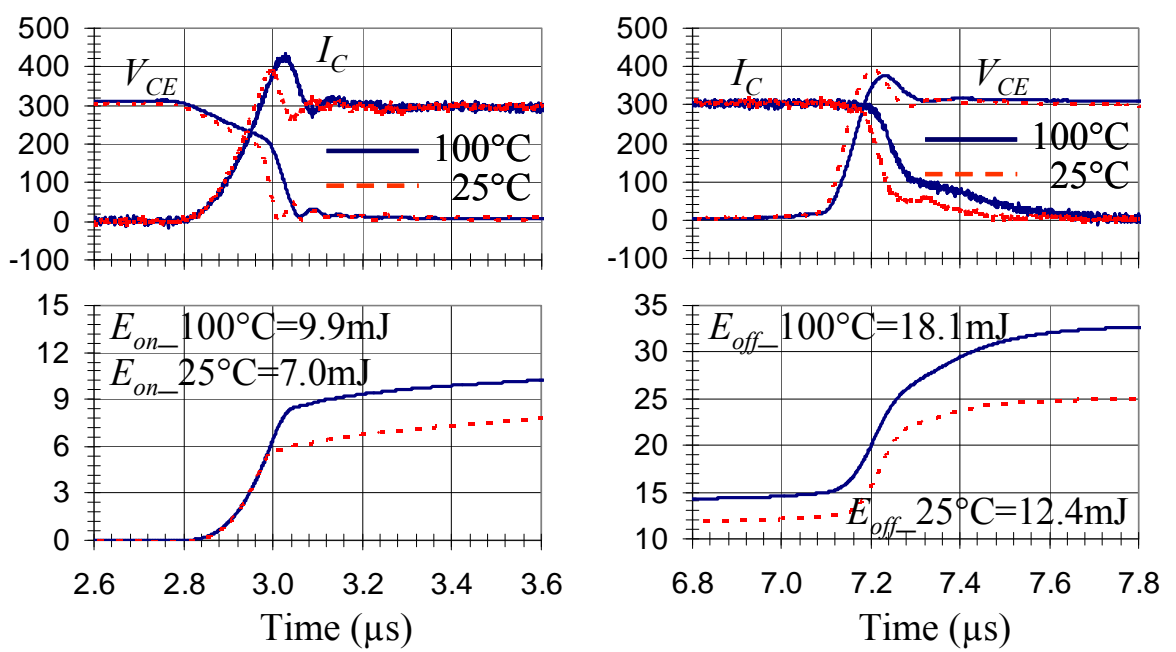

Figure 3.19. IGBT turn-on voltage and current waveforms comparison between $25^{\circ} \mathrm{C}$ and $100^{\circ} \mathrm{C}$ under 300-V, 300-A switching. 

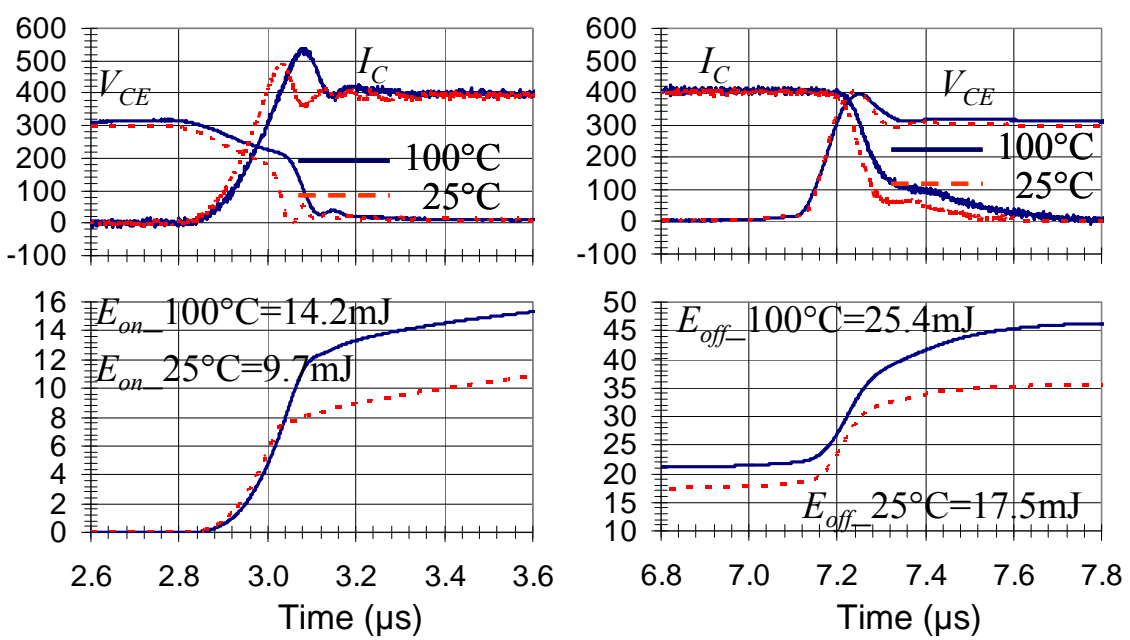

Figure 3.20. IGBT turn-on voltage and current waveforms comparison between $25^{\circ} \mathrm{C}$ and $100^{\circ} \mathrm{C}$ under 300-V, 400-A switching.

Figures 3.21 and 3.22 show soft-switching operation under $25^{\circ} \mathrm{C}, 300-\mathrm{V}, 150-\mathrm{A}$ and $230-\mathrm{A}$ conditions, respectively. Unlike hard-switching condition, the device voltage $V_{C E}$ drops to zero before the gate signal $V_{G E}$ is turned on, or device current $I_{C}$ is conducting. The device current tends to oscillate after turn-on because of the parasitic ringing. During turn-off, the device voltage oscillates due to added current sensing elements. The turn-off overlapping period between device current and voltage is significantly reduced, thus the turn-off loss should also be reduced.

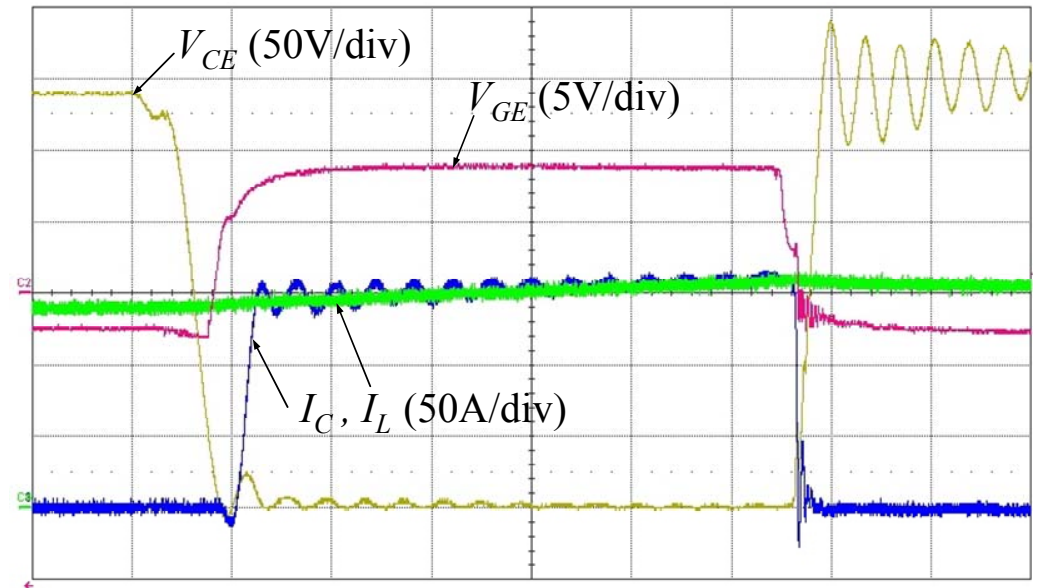

Time $(2 \mu \mathrm{s} / \mathrm{div})$

Figure 3.21. Soft-switching voltage and current waveforms under $300-\mathrm{V}, 150-\mathrm{A}, 25^{\circ} \mathrm{C}$ test condition. 


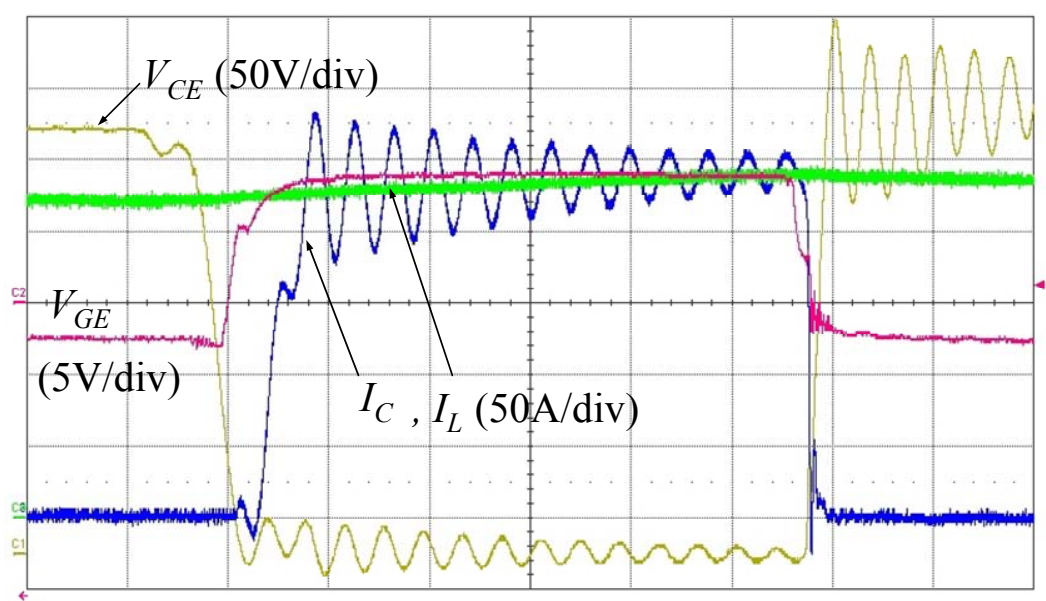

Time $(2 \mu \mathrm{s} / \mathrm{div})$

Figure 3.22. Soft-switching voltage and current waveforms under $300-\mathrm{V}, 230-\mathrm{A}, 25^{\circ} \mathrm{C}$ test condition.

Figures $3.23,3.24$, and 3.25 show soft-switching operation at $100^{\circ} \mathrm{C}, 300-\mathrm{V}, 100-\mathrm{A}, 200-\mathrm{A}$, and 300-A conditions, respectively. The ringing of device voltage and current seems to be reduced, possibly due to a reduction in parasitic path. In this test, a new smaller Rogowski coil is used, which allow cutting down the parasitic inductance in the measurement loop. The resonant current $I_{L r}$ is not much larger than the device current because of the use of variable timing control, with which the resonant current adapts to load current, so the auxiliary circuit can minimize the resonant peak current requirement. This variable timing should allow efficiency improvement in light loads.

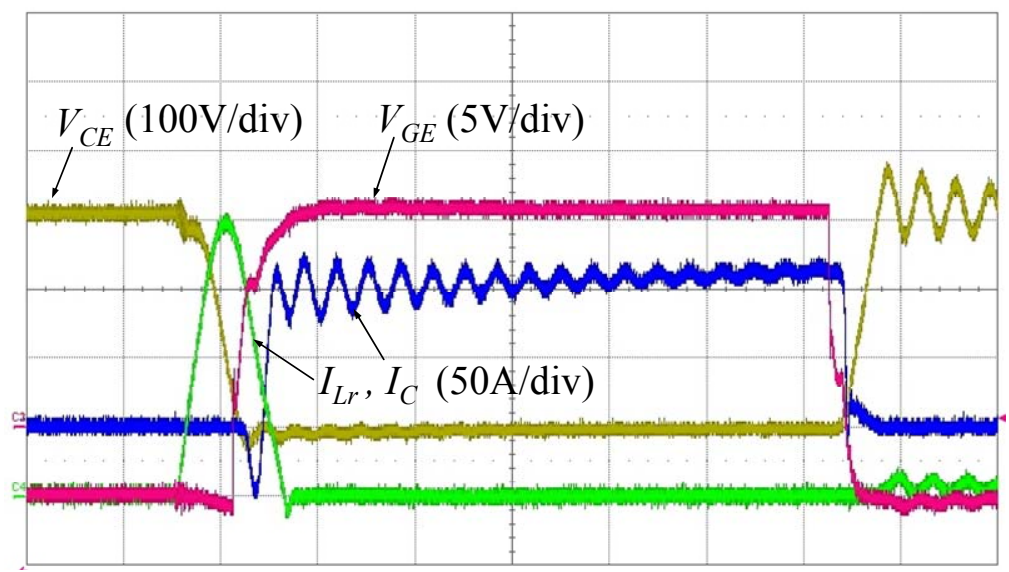

Time $(\mu \mathrm{s})$

Figure 3.23. Soft-switching voltage and current waveforms under $300-\mathrm{V}, 100-\mathrm{A}, 100^{\circ} \mathrm{C}$ test condition. 


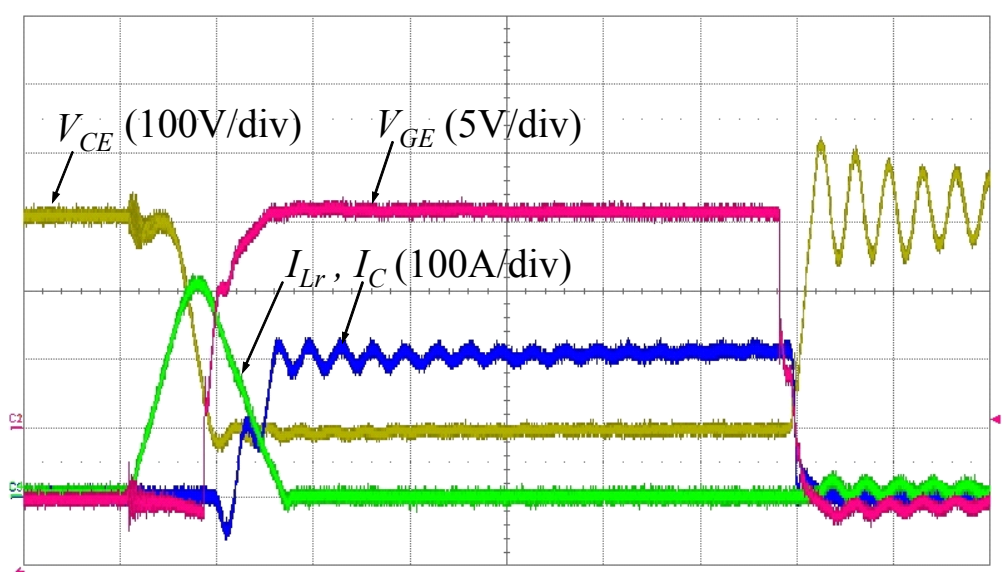

Time $(\mu \mathrm{s})$

Figure 3.24. Soft-switching voltage and current waveforms under $300-\mathrm{V}, 200-\mathrm{A}, 100^{\circ} \mathrm{C}$ test condition.

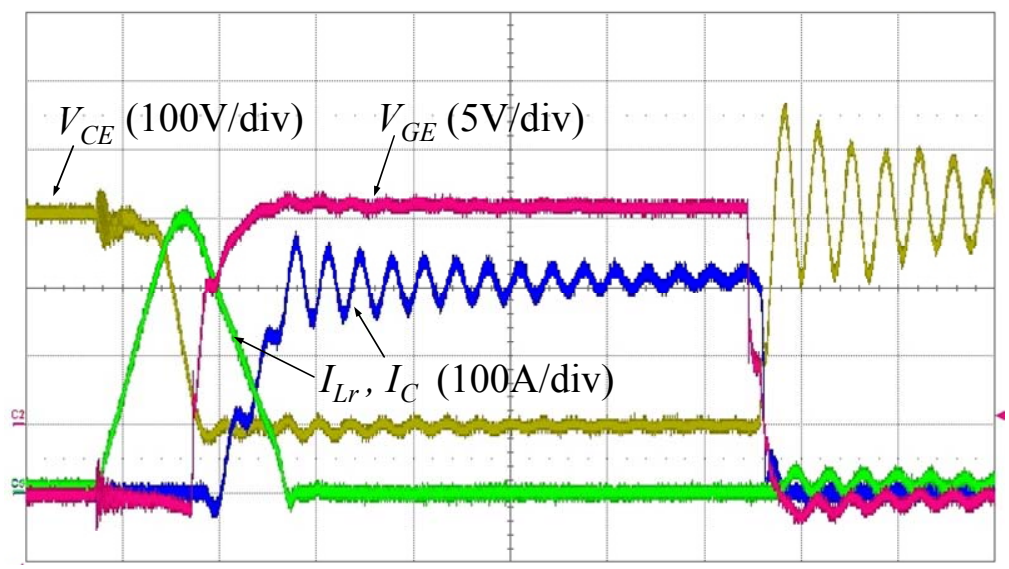

Time $(\mu \mathrm{s})$

Figure 3.25. Soft-switching voltage and current waveforms under $300-\mathrm{V}, 300-\mathrm{A}, 100^{\circ} \mathrm{C}$ test condition.

Figures 3.26 and 3.27 show detailed voltage and current waveforms at $25^{\circ} \mathrm{C}$ and $100^{\circ} \mathrm{C}$ and at different current conditions. The stored waveforms are used for switching energy calculation. It was found that the turn-on energy is practically zero, but the turn-off energy remains visible due to increased tail bump, even though the overlap between device voltage and current is much reduced. 

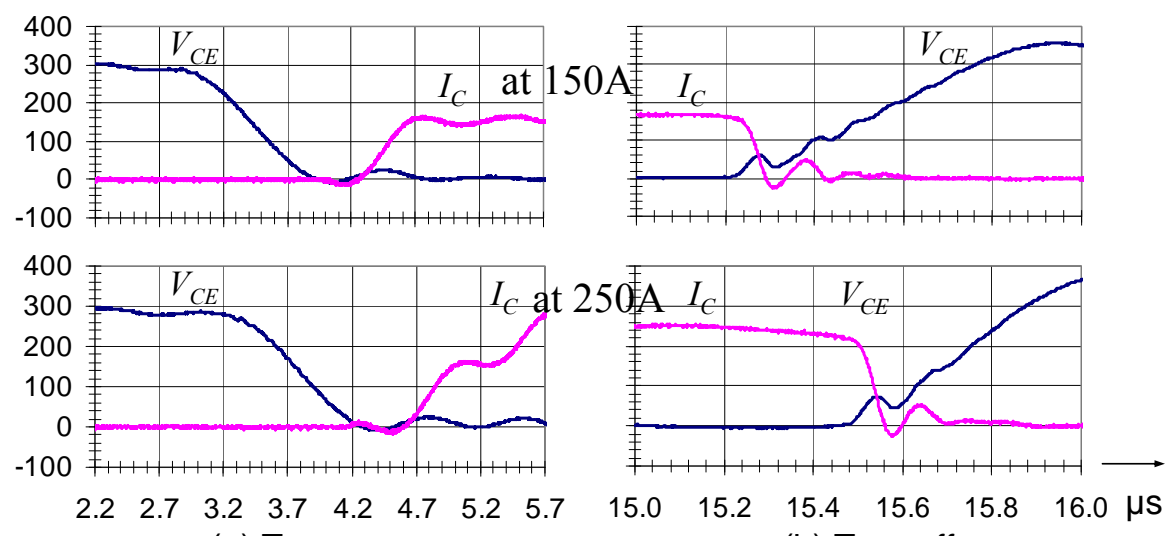

(a) Turn-on

(b) Turn-off

Figure 3.26. Soft-switching voltage and current waveforms at $25^{\circ} \mathrm{C}$ and at different current conditions: (a) turn-on, and (b) turn-off.

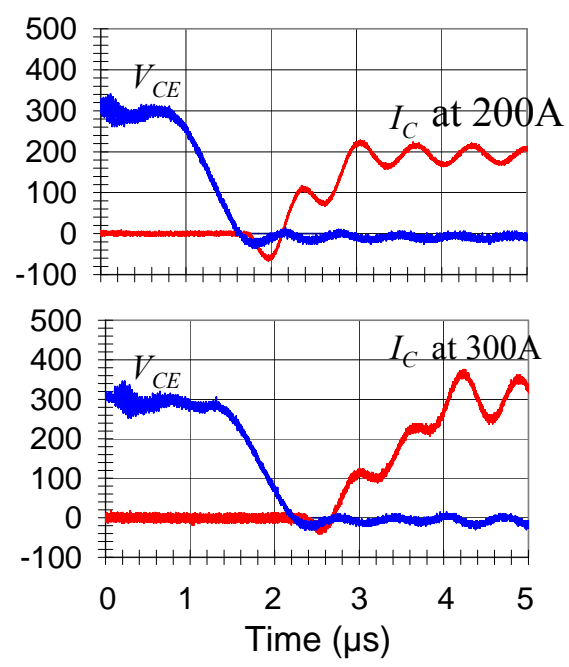

(a) Turn-on

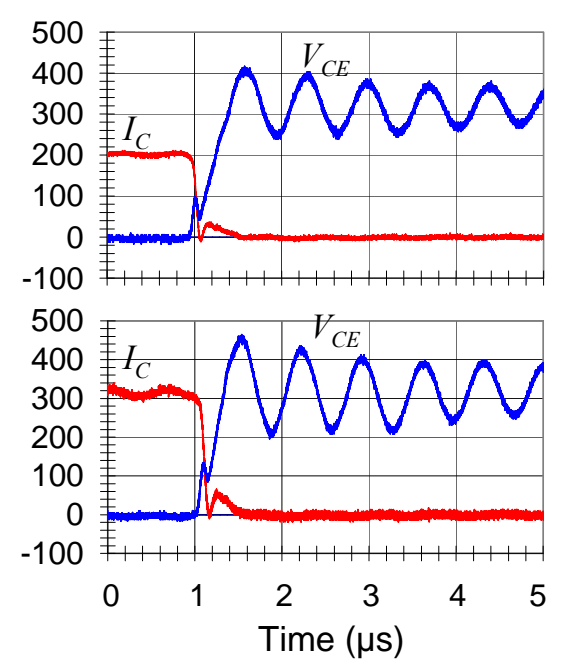

(b) Turn-off

Figure 3.27. Soft-switching voltage and current waveforms at $100^{\circ} \mathrm{C}$ and at different current conditions: (a) turn-on, and (b) turn-off.

The parasitic ringing is expected to be eliminated with fully integrated module as the evidence of improvement by a smaller current sensor. The tail current induced turn-off loss, as compared to the hard-switching counterpart, is much reduced. Figure 3.28 compares the switching energy under hard- and soft-switching and different temperature conditions. The turn-on loss under soft switching can be considered zero. A small number shown in the plot is due to measurement error or parasitic loss. Under high-temperature hard-switching condition, the device switching losses increases substantially. As a rule of thumb, 40 to 50 percent switching loss increase is observed for the temperature increased from $25^{\circ} \mathrm{C}$ to $100^{\circ} \mathrm{C}$. Under soft-switching condition, however, the turn-on loss remains zero at $100^{\circ} \mathrm{C}$. The turn-off loss, as compared to hard-switching case, is reduced by $72 \%$. In NPT devices, this high-temperature turn-off loss reduction is normally within $30 \%$, but the LPT devices apparently demonstrate another advantage that was not obvious from device internal characteristics. The main reason is the resonant capacitor tends to modulate 
the turn-off behavior, and thus the NPT device cannot take advantage of relatively low turn-off loss under high-temperature hard-switching condition.

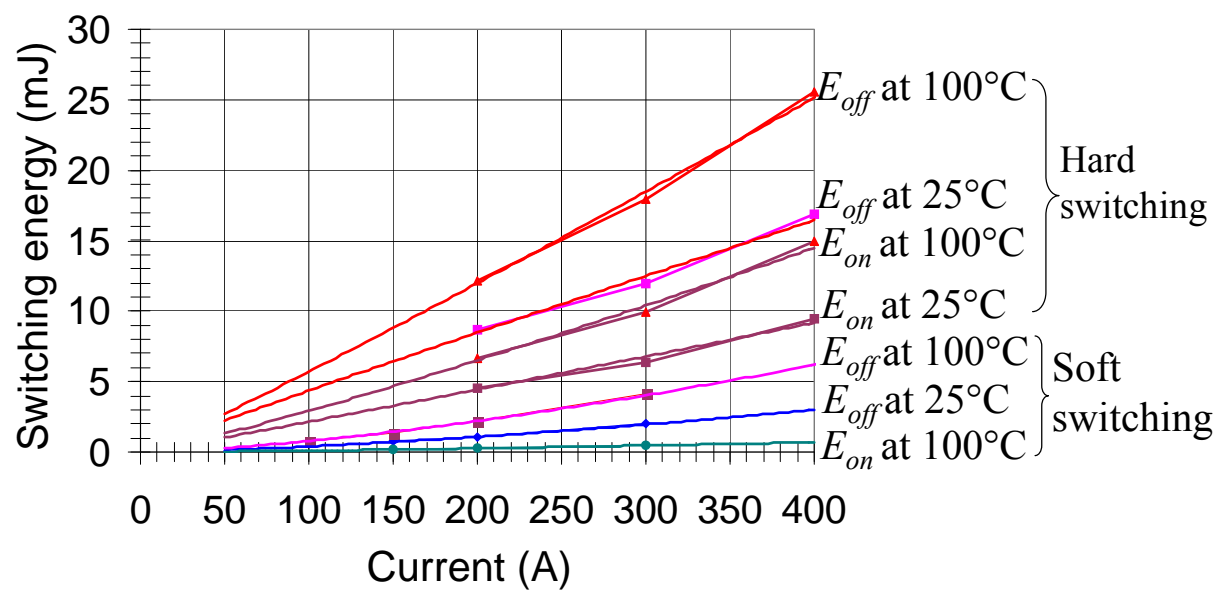

Figure 3.28. Measured switching energy under hard- and soft-switching and at different temperature conditions.

Using the above conduction and switching loss information, the entire inverter loss can be calculated, and the efficiency can be projected, as shown in Figure 3.29. The soft switching inverter maintains above $98.5 \%$ up to $30 \%$ power and higher than $97.5 \%$ at full load. The hardswitching inverter efficiency is slightly higher than $97 \%$ for the most power level and drops below $97 \%$ at the full load.

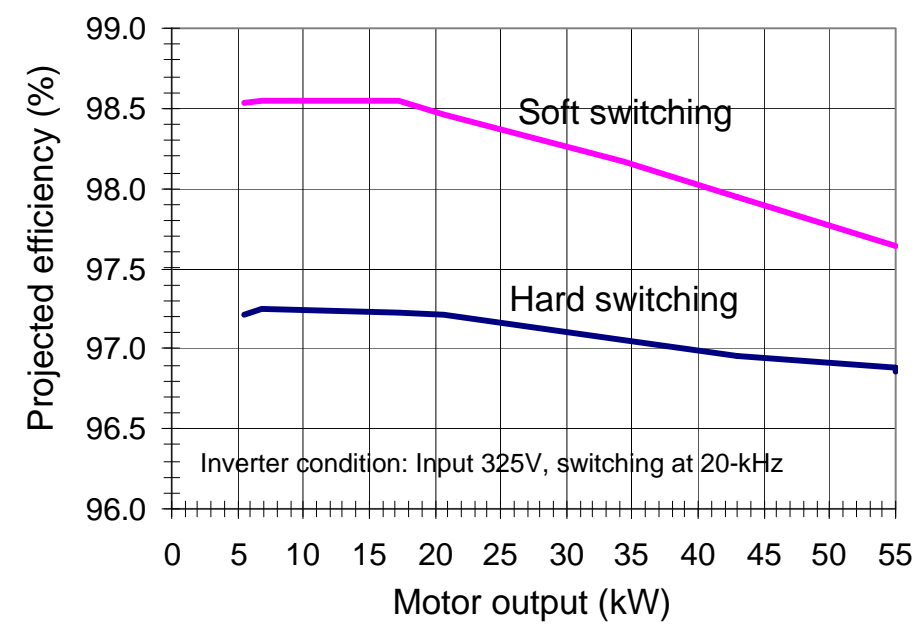

Figure 3.29. Efficiency projection based on the measured device loss calculation. 


\section{Soft-Switching Power Module Development}

\subsection{Soft-Switching Module Configuration}

The purpose of the soft-switching power module development performed by Powerex was to develop a high performance, low-loss, thermally efficient, reliable and cost-effective, softswitching IGBT module for the $55 \mathrm{~kW}$ vehicle inverter. The module design and semiconductor device selection along with the soft-switching architecture were all critical to achieving the low losses required to ensure inverter efficiencies $>98 \%$ over wide operating ranges. Another critical goal of the program was to develop a module that could be either air-cooled or liquid- cooled with the primary vehicle coolant loop while keeping the maximum power semiconductor junction temperatures below $125^{\circ} \mathrm{C}$ with inlet coolant temperatures rising as high as $105^{\circ} \mathrm{C}$.

The strategy to achieve the inverter efficiency and primary coolant loop compatibility goals was to utilize resonant soft-switching of the power switches to minimize losses incurred during the switching, primarily the turn-on, transients. A complementary novel strategy utilizing a parallel combination of IGBTs and MOSFETs in the power switch also served to reduce losses at lower current output levels compared to using IGBTs only. The schematic of the power module is shown in Figure 4.1. The IGBT $\left(Q_{1}\right)$, MOSET $\left(M_{1}\right)$ and antiparallel diode $\left(D_{1}\right)$ constitute the upper power switch, while $Q_{2}, M_{2}$ and $D_{2}$ form the lower switch of the half H-bridge circuit used in the inverter. Three modules make up the 3-Phase inverter power circuit. The resonant switching is effected by the auxiliary circuit comprised of $Q_{x 1}, D_{x 1}, D_{x 3}, D_{x 6}, Q_{x 2}, D_{x 2}, D_{x 4}$ and $D_{x 5}$. The capacitors and inductors required for the resonant soft-switching are located external to the module. The resonant switching method and results are discussed elsewhere in this report.

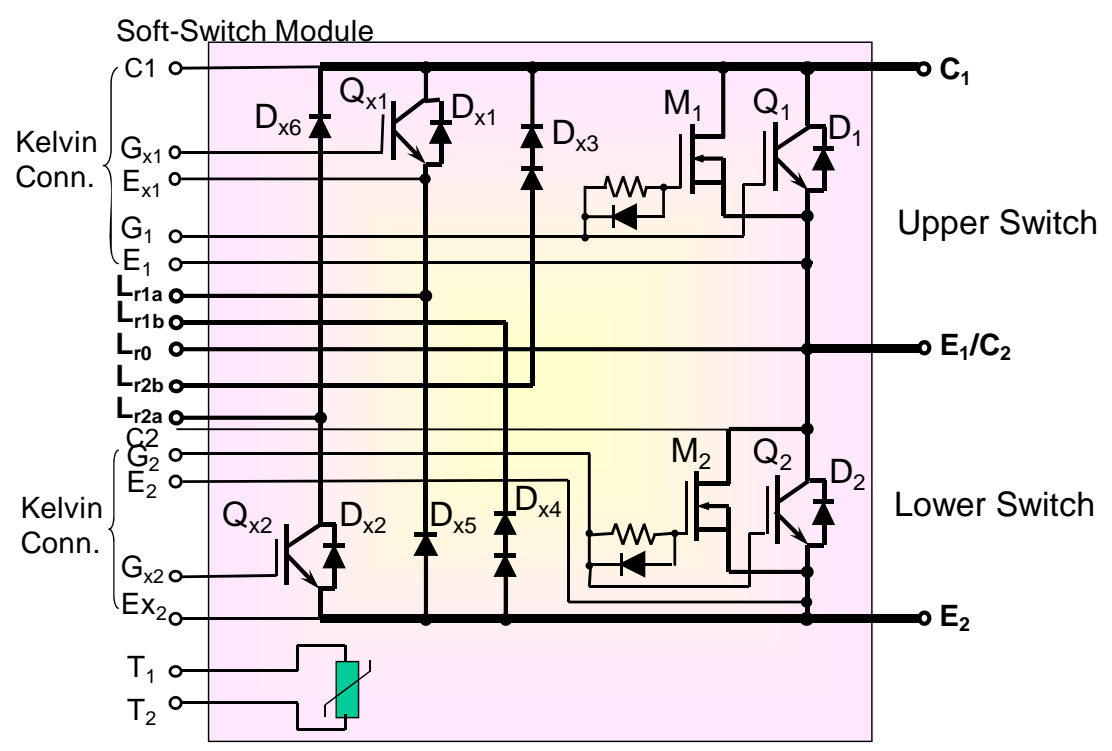

Figure 4.1. Basic circuit configuration for a single phase, soft switched IGBT module.

The parallel combination of the IGBTs and MOSFETs effectively reduces the conduction losses at low current levels, since the unipolar MOSFET acts as a resistor with a voltage drop below 
that of the built-in junction drop of the bipolar IGBT. At higher current levels where the resistance of the MOSFET exhibits higher voltage drops, the majority of the current flow is transferred to the IGBT, which has a lower effective on-resistance. Also included in the module is a resistive temperature detector (RTD) to monitor the operating junction temperature of the IGBTs and MOSFETs.

The three generations of power modules are shown in Figure 4.2. The first generation (Gen-1) was designed to be directly liquid-cooled by means of a built-in chill plate. At the onset of the program, we were uncertain of the power dissipation levels that would occur in the module and thus designed the module to have as low a thermal resistance from junction to liquid as possible. Subsequent power dissipation and efficiency measurements in the Gen-1 inverter tests confirmed that the power semiconductor losses were low enough that the module could be either air-cooled or liquid-cooled without the need for a built-in chill plate. The design details and performance of the Gen-1 module will be discussed in subsequent sections. Drawbacks of the Gen-1 design were a high internal inductance, difficulty of assembly and a high profile which made integrating it with the other power components in the inverter and the control boards difficult.

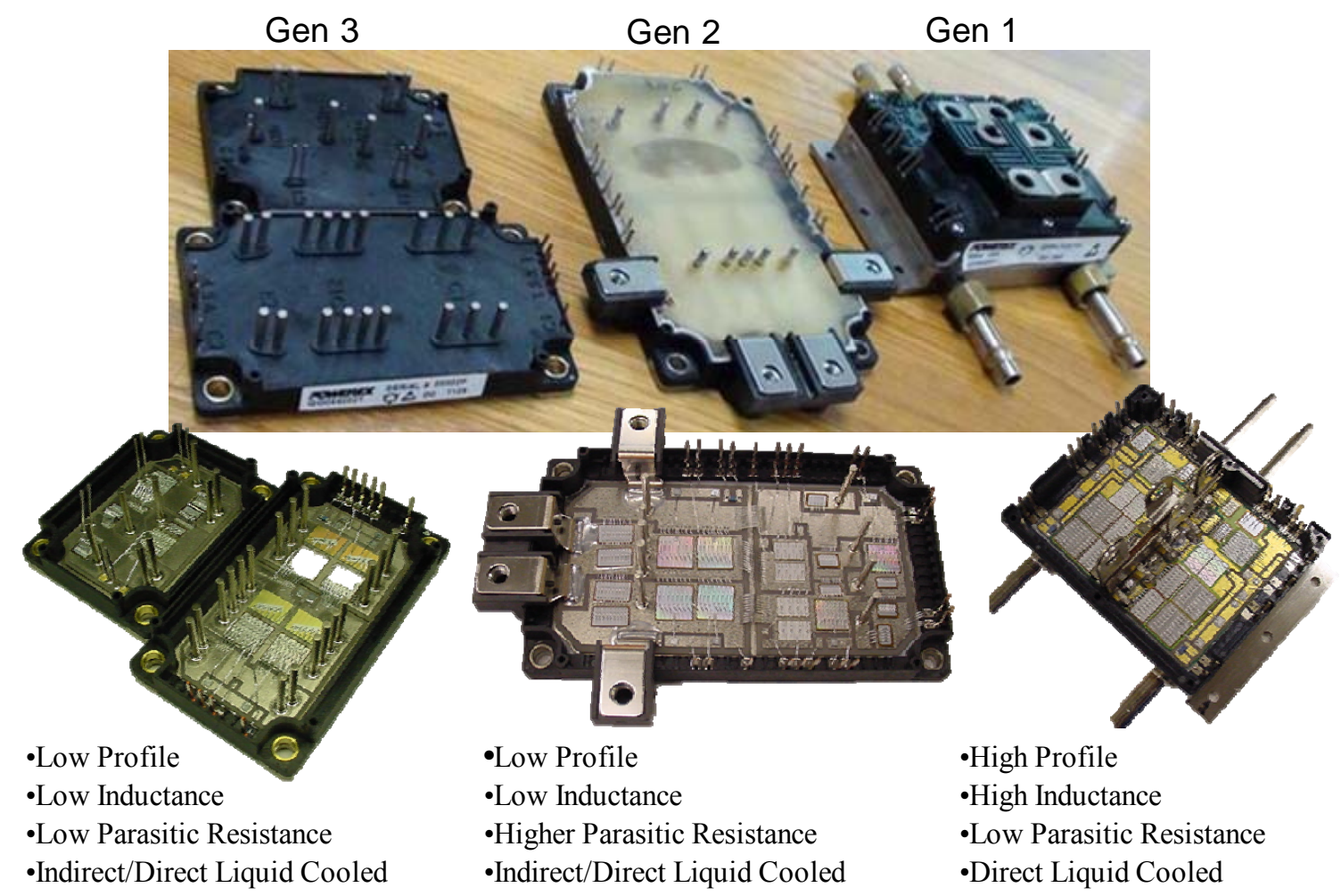

Figure 4.2. Photos showing the evolution of the three generations of power modules along with their significant characteristics.

The second generation module, as shown in Figure 4.2, was designed to have a low profile to dramatically reduce the internal and external inductances while facilitating mating to the power and control printed circuit boards (PCBs) mounted directly on top of it. Even though the modules that were supplied utilized a flat baseplate for mounting on a conventional liquid-cooled chill plate or air-cooled heatsink, they could also have been assembled with a built-in liquid chill plate similar to the Gen-1 design. The Gen-2 module did dramatically reduce the parasitic 
inductance in the Gen-2 inverter. However, one disadvantage of the low-profile layout was an increase in the internal parasitic resistance of the module. This was due to the longer distances the current had to travel laterally in the thin layer (0.012" thick) of copper bonded to the top of the aluminum-nitride (AIN) insulator to flow from one power terminal through the IGBT/ MOSFET chips and out to the other power terminal. This parasitic resistance effectively increased the conduction losses of the module and resulted in a drop in overall efficiency of the Gen-2 inverter compared to that of Gen-1.

The Gen-3 design was focused on reducing the internal parasitic resistance and inductance, as well as replacing both the existing MOSFET and antiparallel diode with a new, lower on-drop resistance $\left(R_{d s-o n}\right)$ Mosfet with an improved internal body diode capable of handling the freewheeling currents. The large, single module was also split into two separate modules to decrease the size of the AlN substrates, which will improve thermal cycling reliability. One module consists of the power stage (half H-bridge) and the other the auxiliary resonant-switching section. As discussed later, the Gen-3 module exhibited lower conduction losses and inductance than both Gen-1 and Gen-2 designs. The Gen-3 module utilizes a flat baseplate like Gen-2, but is capable of being assembled on a built-in liquid chill plate similar to Gen-1. The Gen-3 inverter exhibited such low losses/high efficiency that air cooling was utilized.

\subsection{Gen-1 Module Development}

\section{A. Gen-1 Module Design}

The design for the Gen-1, single phase-leg, soft-switched IGBT module will be discussed in this section. The basic circuit configuration for the module is shown in Figure 4.1. Circuit simulations performed by Virginia Tech provided the average and peak currents for each device in the module and also the power terminals. The modeling also provided the power dissipation for each device, facilitating the selection of the individual semiconductors and determination of the number of paralleled chips. The module requirements based on the results of the circuit simulations are tabulated in Table 4.1.

Table 4.1. Single Phase, Soft-Switched Gen-1 IGBT Module Requirements

\begin{tabular}{|c|c|c|c|c|c|c|c|c|}
\hline $\begin{array}{l}\text { Module } \\
\text { Section }\end{array}$ & $\begin{array}{l}\text { Device } \\
\text { Number }\end{array}$ & $\begin{array}{l}\text { Peak Current/ } \\
\text { Switch } \\
\text { (A) }\end{array}$ & $\begin{array}{c}\text { RMS } \\
\text { Current/ } \\
\text { Switch } \\
\text { (A) } \\
\end{array}$ & $\begin{array}{c}\text { Total } \\
\text { Avg Power } \\
\text { Loss/Switch } \\
\text { (W) } \\
\end{array}$ & $\begin{array}{l}\text { Number of } \\
\text { Chips I } \\
\text { Switch }\end{array}$ & $\begin{array}{c}\text { Total } \\
\text { Avg Power } \\
\text { Loss/Chip } \\
\text { (W) } \\
\end{array}$ & $\begin{array}{l}\text { Peak Current/ } \\
\text { Chip } \\
\text { (A) }\end{array}$ & $\begin{array}{c}\text { RMS } \\
\text { Current/ } \\
\text { Chip } \\
\text { (A) }\end{array}$ \\
\hline \multirow{3}{*}{ Main Switch } & Q1, Q2 & 340 & 108 & 232 & 2 & 116 & 170 & 54 \\
\hline & $\mathrm{D} 1, \mathrm{D} 2$ & 290 & 55 & 116 & 2 & 58 & 145 & 28 \\
\hline & M1, M2 & 50 & 34 & 72 & 2 & 36 & 25 & 17 \\
\hline Auxilary & $\mathrm{Q} \times 1, \mathrm{Q} \times 2$ & 240 & 21 & 18 & 1 & 18 & 240 & 21 \\
\hline Switch & $D \times 1, D \times 2$ & 10 & 1 & 0.5 & 1 & 0.5 & 10 & 1 \\
\hline $\begin{array}{l}\text { Re-Setting } \\
\text { Diode }\end{array}$ & $D \times 3, D \times 4$ & 160 & 14 & 6.5 & 1 & 6.5 & 160 & 14 \\
\hline \multirow{2}{*}{$\begin{array}{l}\text { Main Switch } \\
\text { Terminals }\end{array}$} & $\mathrm{C} 1 \& \mathrm{E} 2$ & 400 & 280 & & & & & \\
\hline & E1/C2 (Common) & 400 & 280 & & & & & \\
\hline \multirow{3}{*}{ Auxilary Terminals } & Lr1 & 240 & 21 & & & & & \\
\hline & LrO & 400 & 35 & & & & & \\
\hline & Lr2 & 240 & 21 & & & & & \\
\hline
\end{tabular}


The power dissipation and peak current requirements drive the IGBT and diode chip selection and quantities of chips to parallel. The peak currents drive the size of the terminals and number of wirebonds per chip. The RMS currents drive the terminal size and internal conductor pad sizes. Table 4.2 lists the chip selections and estimated maximum chip temperatures above the incoming coolant temperature. The IGBT and diode chips selected for the module are the latest generation Mitsubishi/Powerex Carrier Storage Trench-Gate Bipolar Transistor (CSTBT) IGBT's and accompanying fast, soft-recovery diodes. The parallel MOSFETs are Infineon IPW60R045CP Cool MOS chips.

Table 4.2. Estimated Power Dissipation \& Maximum Chip Temperatures

\begin{tabular}{|c|c|c|c|c|c|c|c|c|c|}
\hline $\begin{array}{l}\text { Module } \\
\text { Section }\end{array}$ & $\begin{array}{l}\text { Device } \\
\text { Number }\end{array}$ & Chip Rating & $\begin{array}{l}\text { Chip Size } \\
(\mathrm{L} \times \mathrm{W}) \\
(\mathrm{mm})\end{array}$ & $\begin{array}{l}\text { Chip Area } \\
\text { (cm2) }\end{array}$ & $\begin{array}{l}\text { Number of } \\
\text { Chips Used }\end{array}$ & $\begin{array}{c}\text { Total } \\
\text { Avg Power } \\
\text { Loss/Chip } \\
\text { (W) }\end{array}$ & $\begin{array}{l}\text { Total Avg } \\
\text { Power } \\
\text { Density/Chip } \\
\text { (W/cm2) }\end{array}$ & $\begin{array}{l}\text { Estimated } \\
\text { Module } \\
\text { Thermal } \\
\text { Resistivity } \\
\text { Junc - Liq } \\
\text { (C-cm2/W) }\end{array}$ & $\begin{array}{c}\text { Delta Temp } \\
\text { Junc - Liq } \\
\text { ( C ) }\end{array}$ \\
\hline \multirow{3}{*}{ Main Switch } & Q1, Q2 & $\begin{array}{c}\text { IGBT } \\
200 \mathrm{~A}, 600 \mathrm{~V} \\
\end{array}$ & $12.0 \times 12.0$ & 1.44 & 2 & 116 & 40.3 & 0.40 & 16.1 \\
\hline & D1, D2 & $\begin{array}{c}\text { FWD } \\
600 \mathrm{~V}, 200 \mathrm{~A} \\
\end{array}$ & $7.1 \times 12.0$ & 0.85 & 2 & 58 & 34.0 & 0.40 & 13.6 \\
\hline & M1, M2 & $\begin{array}{c}\text { MOSFET } \\
650 \mathrm{~V}, 60 \mathrm{~A} \\
\end{array}$ & $6.0 \times 9.5$ & 0.57 & 2 & 36 & 31.6 & 0.40 & 12.6 \\
\hline Auxilary & $\mathrm{Q} \times 1, \mathrm{Q} \times 2$ & $\begin{array}{c}\text { IGBT } \\
150 \mathrm{~A}, 600 \mathrm{~V}\end{array}$ & $10.5 \times 11.0$ & 1.16 & 1 & 18 & 15.6 & 0.40 & 6.2 \\
\hline Switch & $\mathrm{D} \times 1, \mathrm{D} \times 2$ & $\begin{array}{c}\text { FWD } \\
600 \mathrm{~V}, 75 \mathrm{~A}\end{array}$ & $4.1 \times 7.8$ & 0.32 & 1 & 0.5 & 1.6 & 0.40 & 0.6 \\
\hline $\begin{array}{l}\text { Re-Setting } \\
\text { Diode }\end{array}$ & $D \times 3, D \times 4$ & $\begin{array}{c}\text { FWD } \\
1200 \mathrm{~V}, 100 \mathrm{~A}\end{array}$ & $6.8 \times 12.0$ & 0.82 & 1 & 6.5 & 7.9 & 0.40 & 3.2 \\
\hline
\end{tabular}

Each IGBT has its own dedicated internal series gate resistor (not shown in Figure 4.1) to ensure sharing of the gate pulse amongst paralleled devices. The IGBTs also have dedicated emitter potential return leads for low internal inductance gate loops and also to prevent gate voltage shifts caused by the emitter currents as the IGBT switches on and off. Also shown in the schematic in Figure 4.1 is an internal temperature sensor mounted as close to possible to both $Q_{1}$ and $Q_{2}$ for over-temperature sensing $\&$ shut down protection. Adequate dielectric insulation is an important consideration for components in electrical systems, particularly HEV automotive inverters. Dielectric insulation internal to the module is provided by silicone rubber gels and potting compounds. These materials, which are used extensively in the power module industry, are effective and stable insulators, even in the presence of ambient laden with moisture. Design rules established by Powerex for internal and external conductor spacing in $600 \mathrm{~V}$ modules were followed.

The single phase-leg module design is shown in Figure 4.3. The height of the main power terminals (+/- DC Link \& AC Output) are at the same height as the main DC Link capacitors, permitting the use of a flat, low-inductance, laminated bus to connect the three modules to the capacitors. The module has a pin-fin baseplate that is mounted to a liquid cooled manifold for thermal management of the semiconductor chips. 


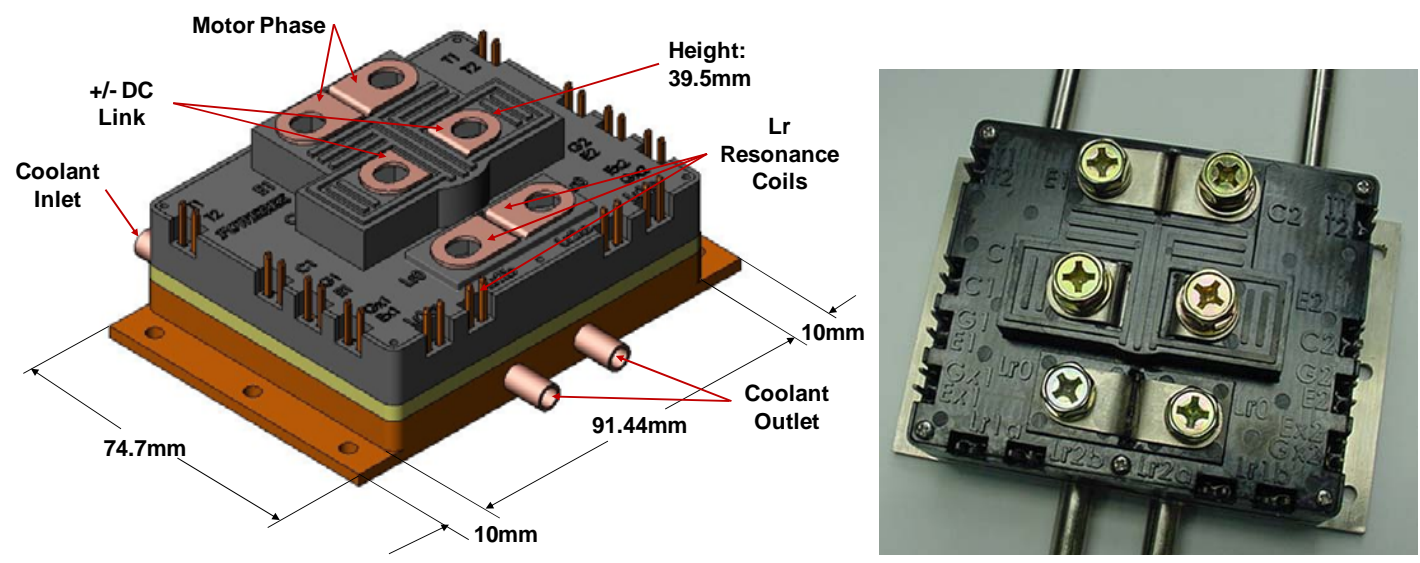

Figure 4.3. Overall view of the Phase 1, single phase, IGBT module.

The internal chip, wirebond and terminal layout is shown in Figure 4.4. The chips are soldered to a 0.025 inch thick aluminum nitride (AIN) ceramic substrate that is clad with direct bond copper $(\mathrm{DBCu})$ layers 0.012 inch thick. Most power modules use DBC AlN as the insulating ceramic due to its relatively high thermal conductivity $(170 \mathrm{~W} / \mathrm{mK})$. This is important since the AlN is in the heat flow path from the chip to the coolant, as shown in Figure 4.5. The DBC AIN substrate is then soldered to the baseplate, which is flat on the top surface and has pin fins protruding from the bottom surface for efficient liquid cooling, as shown in Figure 4.6. The upper $\left(Q_{1} \& Q_{x 1}\right)$ and lower $\left(Q_{2} \& Q_{x 2}\right)$ switches are on two separate AlN substrates to minimize stress during temperature cycling due to mismatches in the expansion and contraction rates of the ceramic and baseplate materials. Copper was used for the pin-fin baseplate due to its high thermal conductivity.

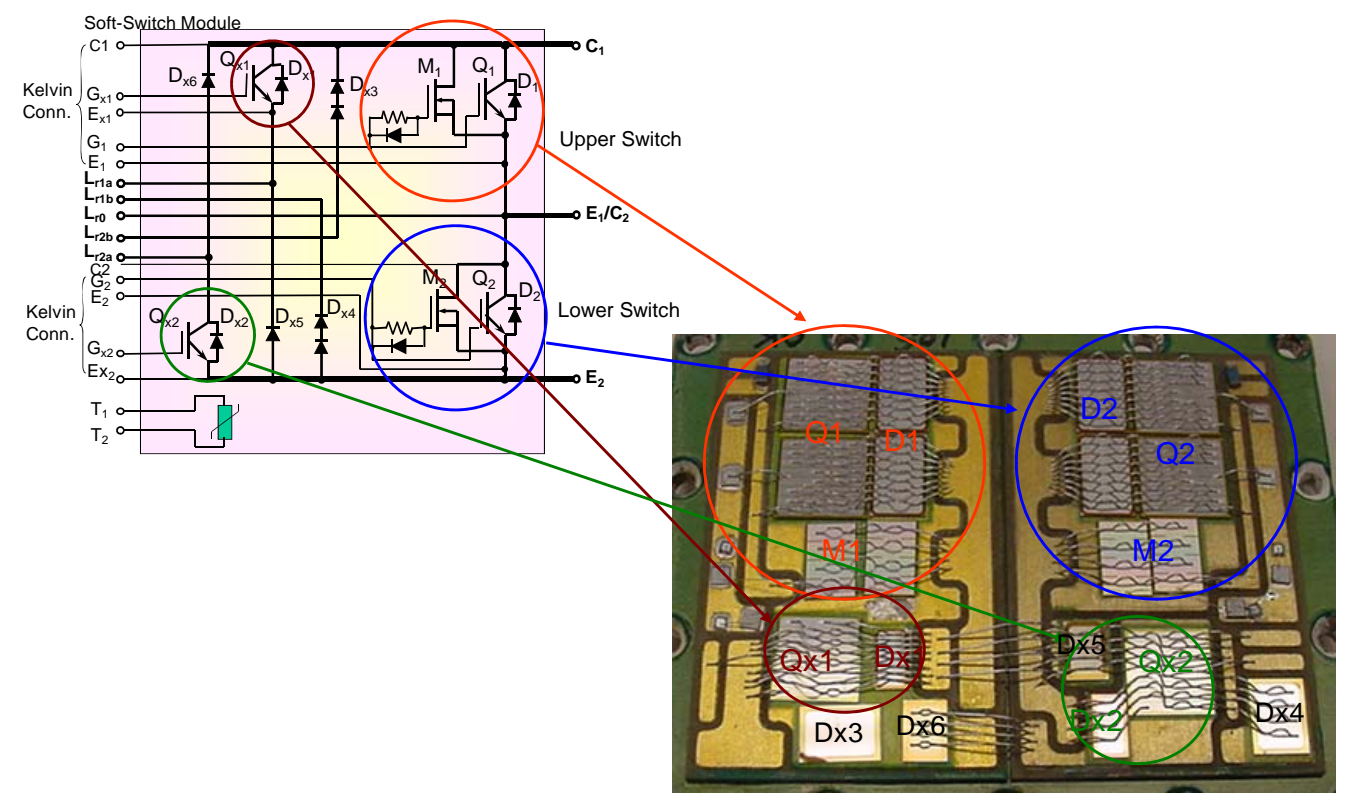

Figure 4.4. Internal chip and wirebond layout for Gen 1 module. 


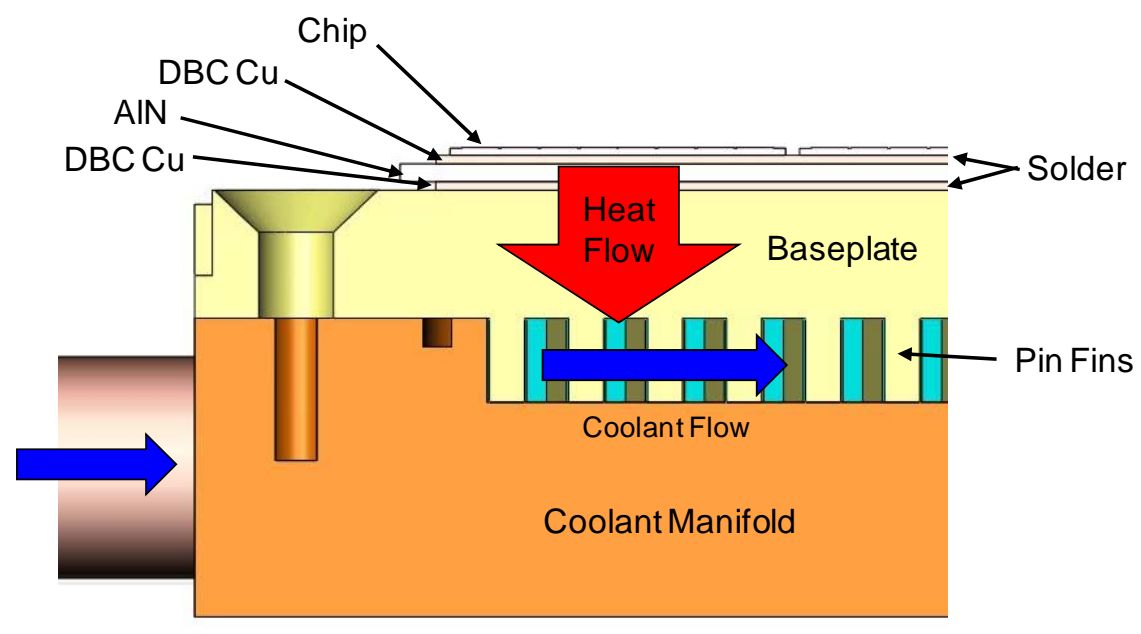

Figure 4.5. Cross section of Gen 1 module showing heat flow path and layers.

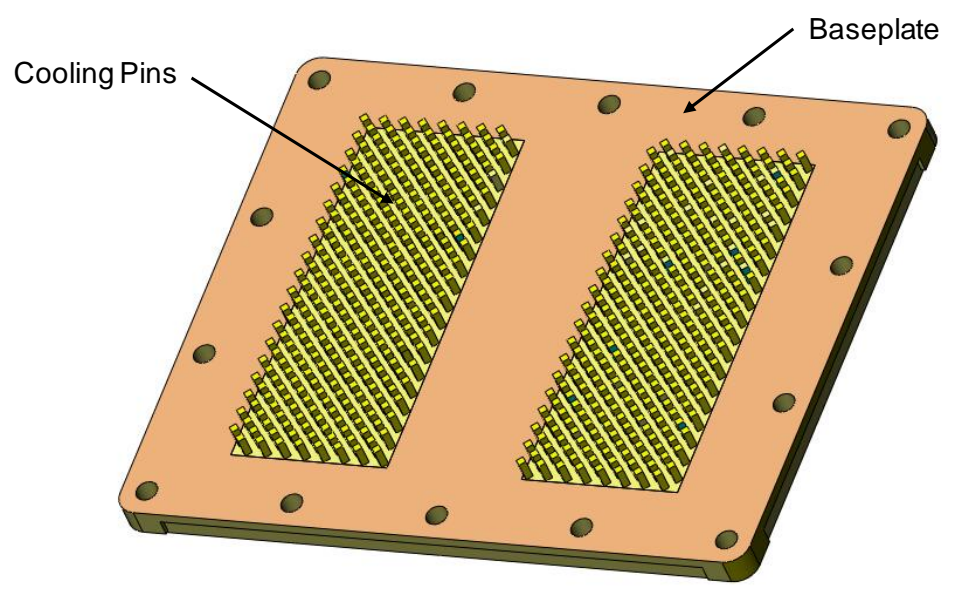

Figure 4.6. Bottom view of module baseplate showing pin-fins for liquid cooling.

\section{B. Gen-1 Module Thermal Simulations}

The hybrid vehicle thermal management requirements present a significant challenge for the power module designer. The peak coolant inlet temperature of $105^{\circ} \mathrm{C}$, coupled with the desire to keep the maximum junction temperatures below $125^{\circ} \mathrm{C}$ for good device reliability, dictates a maximum temperature drop from junction to coolant of only $20^{\circ} \mathrm{C}$. This low $\Delta \mathrm{T}$, along with relatively low coolant flow rates of 5 GPM total for all three modules in the 3-Phase system $(1.67 \mathrm{GPM} /$ module or $0.8 \mathrm{GPM} / \mathrm{sw}$ itch), require a low thermal resistance path from the chip to the liquid. In addition, the chips must be sized to minimize power dissipation. Fortunately, the resonant-switching circuit topology used in the inverter for this program minimizes overall power dissipation by virtually eliminating IGBT switching losses.

The temperature gradient from junction to the liquid was modeled using a two-step technique. A 3-dimensional finite element (FEA) model was used to model the temperature gradient from 
the junctions of the semiconductor devices to the pin fin cooling surfaces on the bottom of the baseplate. In this simulation, the average power dissipation for each chip listed in Table 4.2 was used. In the second step, the temperature drop from the pin fins to the coolant was scaled from measurements made on similar, but smaller, pin-fin test baseplates fabricated for thermal resistance measurements. The estimated $\Delta \mathrm{T}$ from pin-fins to coolant was then added to the theoretical drop from junction to pin-fin. The results of the FEA model from junction to pin-fin are shown in Figure 4.7. The total estimated $\Delta \mathrm{T}$ from junction to coolant is listed in Table 4.2 for each chip. As is evident from Table 4.2, the estimated $\Delta \mathrm{T}$ is lower than the $20^{\circ} \mathrm{C}$ objective.

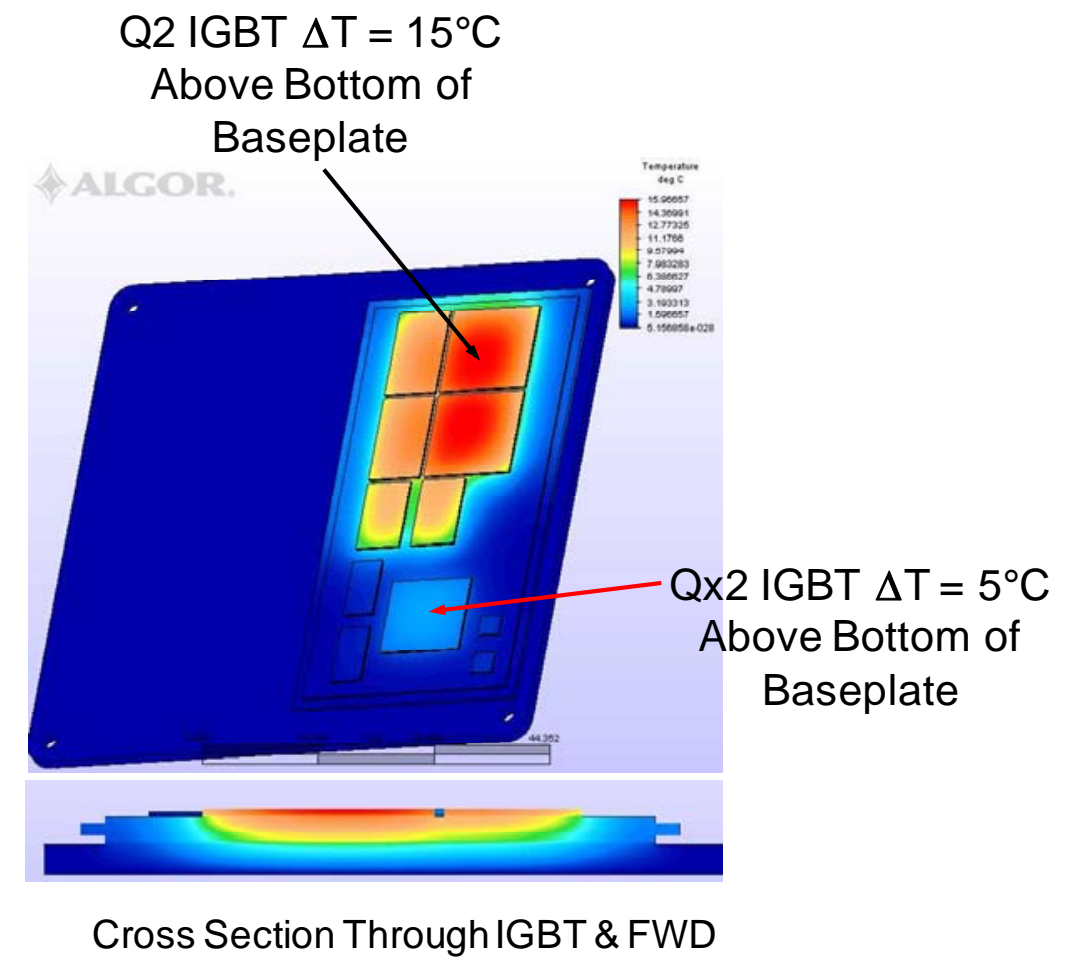

Figure 4.7. Results of FEA simulations of temperature drop from junctions to pin-fins.

\section{Gen-1 Module Conduction Characteristics Test Results}

Test data from a sample of the Gen-1 modules delivered to Virginia Tech are listed in Table 4.3. Parametric electrical measurements were performed at 25 and $125^{\circ} \mathrm{C}$. Average device voltage drop ( $V_{\text {cesat }}$ ) values for $Q_{1} / M_{1}, Q_{2} / M_{2}, Q_{x 1}$ and $Q_{x 2}$ for Gen 1 modules SN 101 and 102 are plotted versus current in Figure 4.8. The resistive slope of the MOSFET carrying most of the current at levels below 50A is apparent in Figure 4.8, revealing the savings in conduction losses compared to using IGBTs only. The average voltage drops of the diodes $\left(V_{f}^{\prime}\right.$ 's) in SN 101 and SN 102 are plotted versus current in Figure 4.9. 
Table 4.3. Test Results for a sample of the Gen 1 Modules
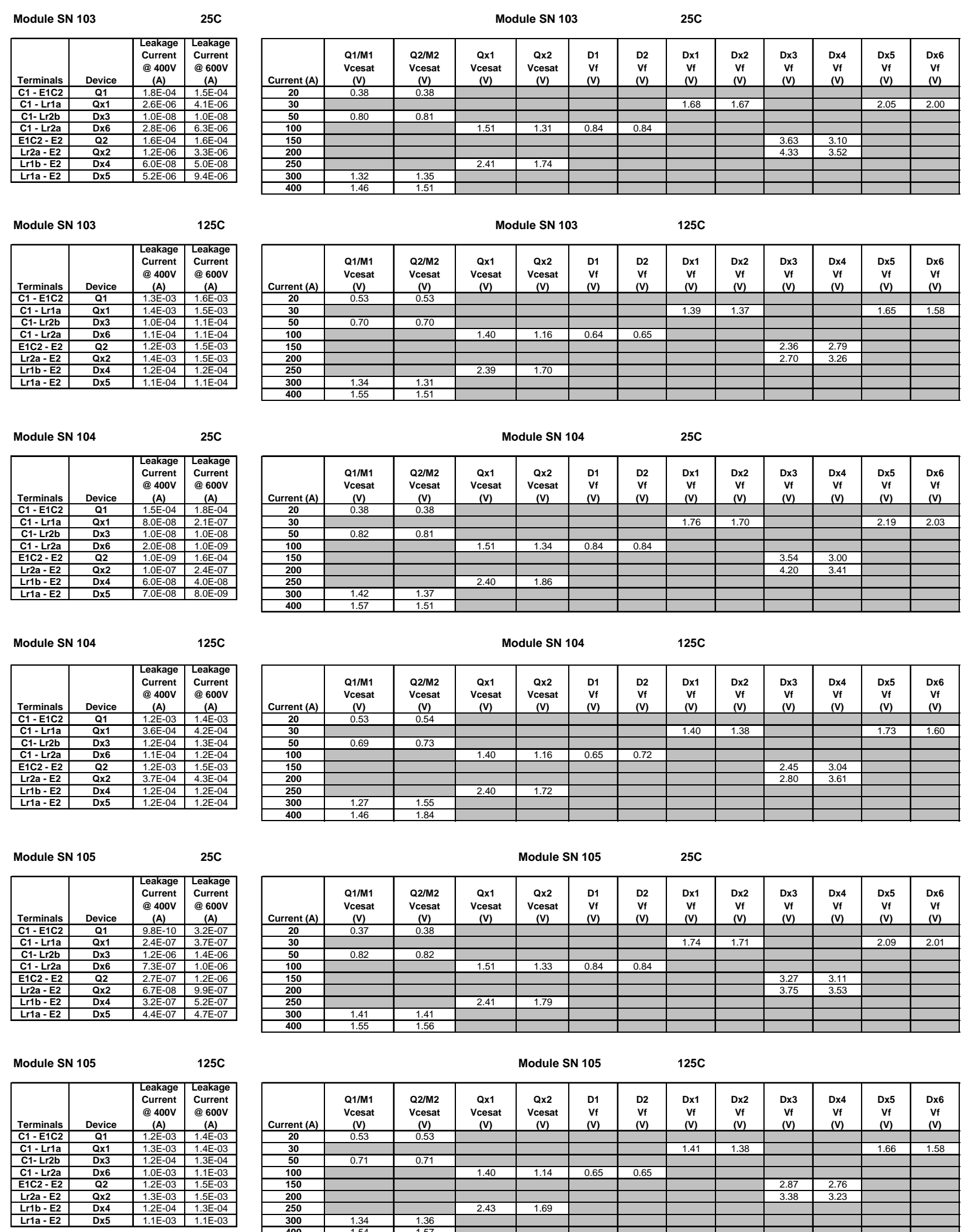

\begin{tabular}{|c|c|c|c|c|c|c|c|c|c|c|c|c|}
\hline & & & & Module & 105 & & $125 \mathrm{C}$ & & & & & \\
\hline Current (A) & $\begin{array}{l}\text { Q1/M1 } \\
\text { Vcesat } \\
\text { (V) }\end{array}$ & $\begin{array}{c}\text { Q2/M2 } \\
\text { Vcesat } \\
\text { (V) }\end{array}$ & $\begin{array}{l}\text { Qx1 } \\
\text { Vcesat } \\
\text { (V) }\end{array}$ & $\begin{array}{c}\text { Qx2 } \\
\text { Vcesat } \\
\text { (V) }\end{array}$ & $\begin{array}{l}\mathrm{D} 1 \\
\mathrm{Vf} \\
\text { (V) }\end{array}$ & $\begin{array}{l}\mathrm{D} 2 \\
\mathrm{Vf} \\
\text { (V) }\end{array}$ & $\begin{array}{l}\text { Dx1 } \\
\text { Vf } \\
\text { (V) }\end{array}$ & $\begin{array}{l}\text { Dx2 } \\
\text { Vf } \\
\text { (V) }\end{array}$ & $\begin{array}{l}\text { Dx3 } \\
\text { Vf } \\
\text { (V) }\end{array}$ & $\begin{array}{l}\text { Dx4 } \\
\text { Vf } \\
\text { (V) }\end{array}$ & $\begin{array}{c}\text { Dx5 } \\
\text { Vf } \\
\text { (V) }\end{array}$ & $\begin{array}{c}\text { Dx6 } \\
\text { Vf } \\
\text { (V) }\end{array}$ \\
\hline 20 & 0.53 & 0.53 & & & & & & & & & & \\
\hline 30 & & & & & & & 1.41 & 1.38 & & & 1.66 & 1.58 \\
\hline 50 & 0.71 & 0.71 & & & & & & & & & & \\
\hline 100 & & & 1.40 & 1.14 & 0.65 & 0.65 & & & & & & \\
\hline 150 & & & & & & & & & 2.87 & 2.76 & & \\
\hline 200 & & & & & & & & & 3.38 & 3.23 & & \\
\hline 250 & & & 2.43 & 1.69 & & & & & & & & \\
\hline 300 & 1.34 & 1.36 & & & & & & & & & & \\
\hline 400 & 1.54 & 1.57 & & & & & & & & & & \\
\hline
\end{tabular}




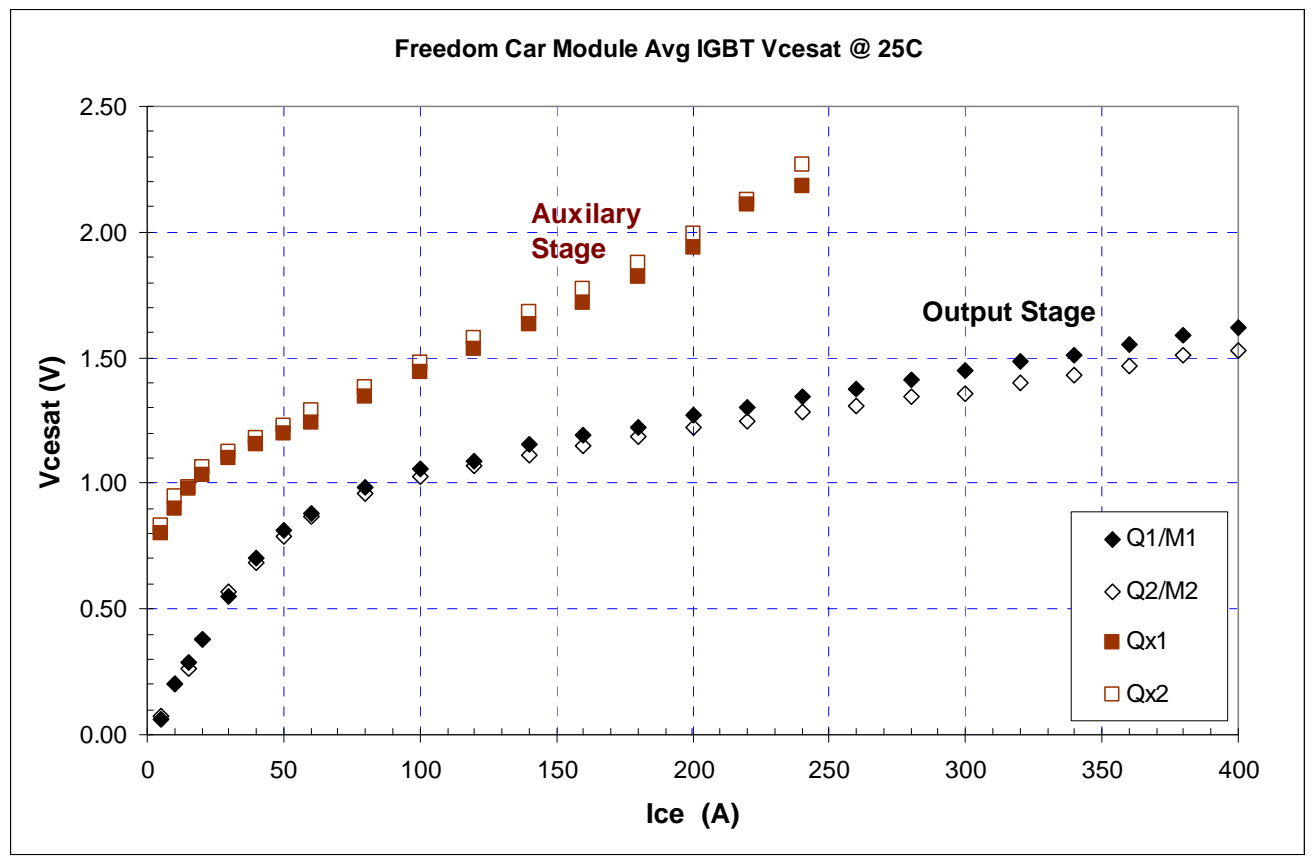

Figure 4.8. Average $V_{c e-s a t}$ of the IGBT stages at 25C for Gen-1 modules SN101 \& SN102. The effect of the parallel MOSFET at low current levels is evident in the Output Stage $V_{\text {ce-sat }}$ curves.

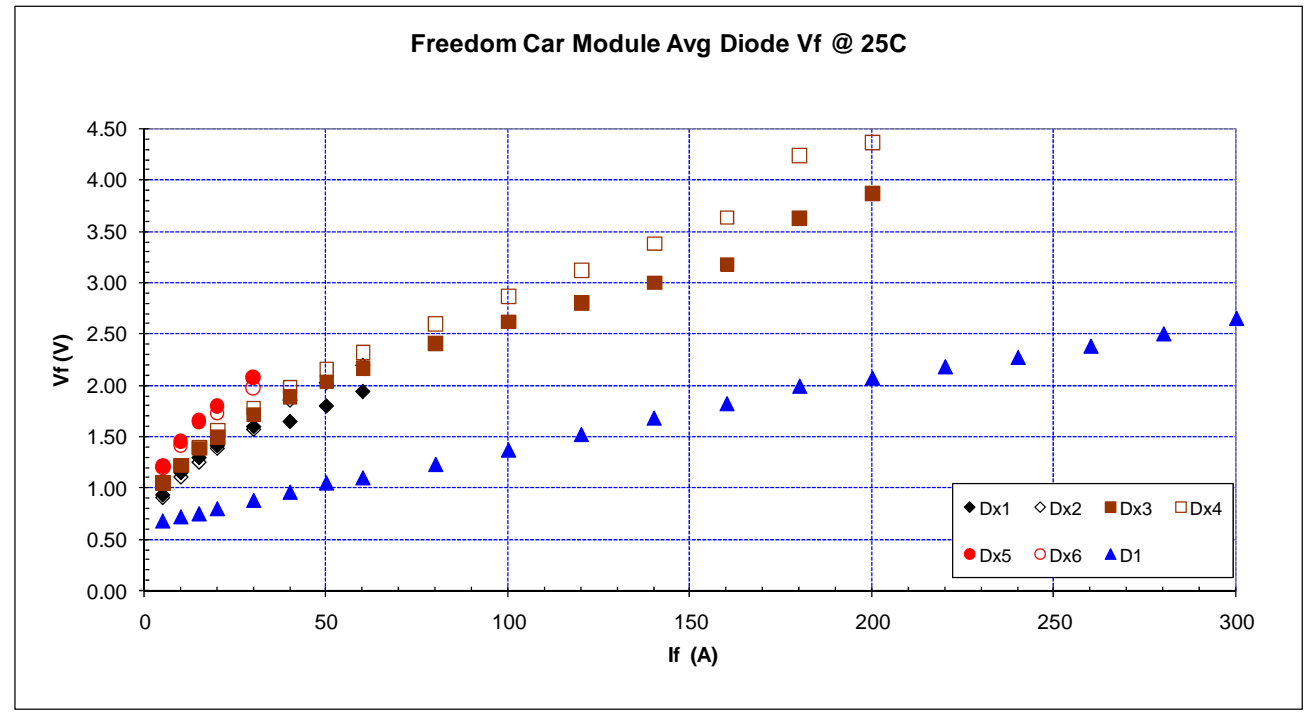

Figure 4.9. Average $V_{f}$ of the diodes at $25^{\circ} \mathrm{C}$ for Gen-1 modules SN101 \& SN102.

The thermal resistance of the first generation module was measured to determine the performance of the integrated liquid-cooled chill plate. The results discussed in this report are for pure water and a 50/50 water/ethylene-glycol (EGC) mix. The technique used for measuring the thermal resistance was as follows:

1. The $V_{\text {cesat }}$ 's of the IGBTs and $V_{f}$ 's of the diodes were measured at several different pulsed current levels (low duty cycle) at temperatures of $25,75,100 \& 125^{\circ} \mathrm{C}$. 
2. Junction temperature vs $V_{\text {cesat }} / V_{f}$ curves at a given current were generated from the parametric data taken in step 1.

3. The module was then connected to a liquid to air heat exchanger system and the coolant was flowed through one switch of the module. Liquid flow rate, inlet/outlet liquid temperature and inlet/outlet liquid pressure were measured. The flow rates were varied from 0.3 to 1.0 liters/minute.

4. Each chip set $\left(Q_{1} M_{1}, D_{1}, Q_{x 1}, D_{x 1}, D_{x 3}\right.$, and $\left.D_{x 6}\right)$ was powered individually at DC currents matching one or more of the current levels measured in step 1. The $V_{\text {cesat }}$ or $V_{f}$ of each powered chip set was measured.

5. The junction temperature of each chip set was determined using the $V_{\text {cesat }}$ or $V_{f}$ value and the calibration curve for the current used.

6. Chip sets $Q_{1} M_{1}, Q_{x 1}$ and $D_{x 3}$ were then powered simultaneously with 125,20 and 20A DC, respectively, to simulate operation under average current conditions. The DC current levels were selected based on the RMS current values from the Virginia Tech inverter simulations.

Individual chip sets were powered to determine the thermal resistance of each chip set without the influence of heating by other chip sets, in order to validate a simple 2-D thermal model. Of course, this is not the way the module actually operates in the inverter, so as many chip sets as possible were subsequently powered simultaneously at their respective average/RMS current levels to determine the true thermal resistance. In these measurements, $Q_{1} M_{1}$ (main switch), $Q_{x 1}$ (auxiliary switch) and $D_{x 3}$ (re-setting diode) were powered. Since the average current through $D_{x 6}$ is normally very low (according to the simulations), it was not powered during these measurements. The coolant flow path of the integrated chill plate is shown in Figure 4.10.

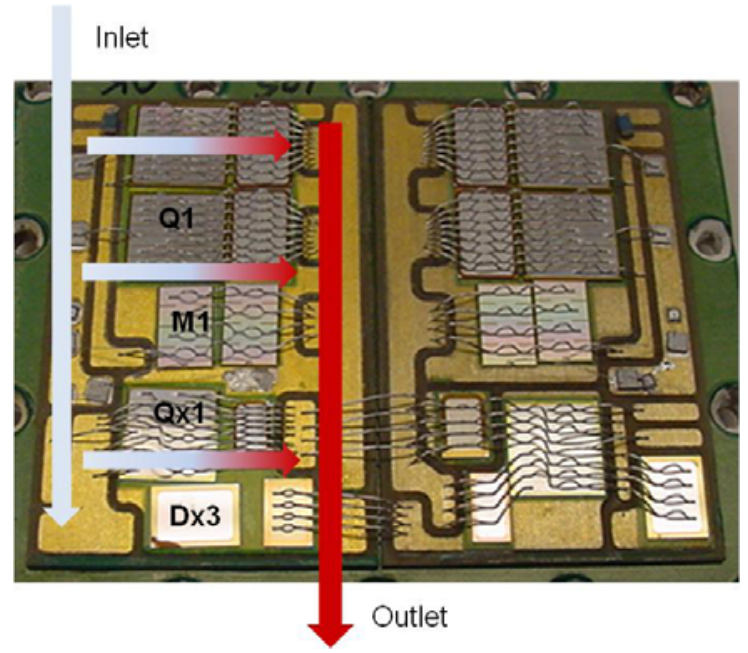

Figure 4.10. Gen 1 module coolant flow.

The experimental results for the $Q_{1} M_{1}$ chip set measurements are listed in Table 4.4 at 125 and $200 \mathrm{~A}$ for both coolant types. For the $Q_{1} M_{1}$ chip set, the thermal resistance decreases with increasing liquid flow rate, as expected. The working flow rate for each switch in the 3-phase inverter will be 0.4 gallons/min, i.e. $2.5 \mathrm{gpm}$ divided by 6 switches. The maximum flow rate 
used in these measurements was $0.26 \mathrm{gpm}$, which is well below the $0.4 \mathrm{gpm}$ available. Also, the measured thermal resistance of the EGC mixture is higher than pure water, which is also expected.

Table 4.4. Gen-1 module fully powered $Q_{1} M_{1}$ chip set thermal resistance results for pure water \& EGC mixtures

Junction - Inlet Liquid Thermal Results For Q1M1 With H2O Coolant

\begin{tabular}{|c|c|c|c|c|c|c|c|c|}
\hline \multirow[b]{2}{*}{$\begin{array}{l}\text { Flow Rate } \\
\text { (Gal/min) }\end{array}$} & \multirow[b]{2}{*}{$\begin{array}{c}\text { Flow Rate } \\
\text { (L/min) }\end{array}$} & \multirow[b]{2}{*}{$\begin{array}{l}\text { Pressure } \\
\text { Drop (psi) }\end{array}$} & \multicolumn{3}{|c|}{$\mathrm{Q} 1 \mathrm{M} 1(\mathrm{Ic}=125 \mathrm{~A})$} & \multicolumn{3}{|c|}{ Q1M1 $(I C=200 A)$} \\
\hline & & & $\begin{array}{l}\text { Power } \\
\text { Dissipation } \\
\text { (W) }\end{array}$ & $\begin{array}{c}\text { Delta } \\
\text { Temperature } \\
\text { Junc - Inlet } \\
\left({ }^{\circ} \mathrm{C}\right)\end{array}$ & $\begin{array}{c}\text { Rth } \\
\text { junc-inlet } \\
\text { (C/W) }\end{array}$ & $\begin{array}{l}\text { Power } \\
\text { Dissipation } \\
\text { (W) }\end{array}$ & $\begin{array}{c}\text { Delta } \\
\text { Temperature } \\
\text { Junc - Inlet } \\
\left({ }^{\circ} \mathrm{C}\right)\end{array}$ & $\begin{array}{c}\text { Rth } \\
\text { junc-inlet } \\
\text { (C/W) }\end{array}$ \\
\hline 0.08 & 0.3 & 0.2 & 129.0 & 8.6 & 0.067 & 231.5 & 26.1 & 0.113 \\
\hline 0.10 & 0.4 & 0.3 & 129.3 & 7.3 & 0.056 & 232.0 & 20.2 & 0.087 \\
\hline 0.13 & 0.5 & 0.5 & 129.5 & 5.8 & 0.045 & 232.4 & 14.6 & 0.063 \\
\hline 0.16 & 0.6 & 0.7 & 129.6 & 5.8 & 0.045 & 232.6 & 12.0 & 0.052 \\
\hline 0.21 & 0.8 & 0.8 & 129.6 & 5.5 & 0.042 & 233.0 & 6.4 & 0.027 \\
\hline 0.26 & 1.0 & 1.1 & 129.9 & 4.4 & 0.034 & 233.2 & 3.8 & 0.016 \\
\hline
\end{tabular}

Junction - Inlet Liquid Thermal Results For Q1M1 With 50 EGC / 50 H2O Coolant

\begin{tabular}{|c|c|c|c|c|c|c|c|c|}
\hline \multirow[b]{2}{*}{$\begin{array}{l}\text { Flow Rate } \\
\text { (Gal/min) }\end{array}$} & \multirow[b]{2}{*}{$\begin{array}{c}\text { Flow Rate } \\
\text { (L/min) }\end{array}$} & \multirow[b]{2}{*}{$\begin{array}{l}\text { Pressure } \\
\text { Drop (psi) }\end{array}$} & \multicolumn{3}{|c|}{$\mathrm{Q} 1 \mathrm{M} 1(\mathrm{Ic}=125 \mathrm{~A})$} & \multicolumn{3}{|c|}{ Q1M1 $(I C=200 A)$} \\
\hline & & & $\begin{array}{l}\text { Power } \\
\text { Dissipation } \\
\text { (W) }\end{array}$ & $\begin{array}{c}\text { Delta } \\
\text { Temperature } \\
\text { Junc - Inlet } \\
\left({ }^{\circ} \mathrm{C}\right)\end{array}$ & $\begin{array}{c}\text { Rth } \\
\text { junc-inlet } \\
\text { (C/W) }\end{array}$ & $\begin{array}{l}\text { Power } \\
\text { Dissipation } \\
\text { (W) }\end{array}$ & $\begin{array}{c}\text { Delta } \\
\text { Temperature } \\
\text { Junc - Inlet } \\
\left({ }^{\circ} \mathrm{C}\right)\end{array}$ & $\begin{array}{c}\text { Rth } \\
\text { junc-inlet } \\
(\mathrm{C} / \mathrm{W})\end{array}$ \\
\hline 0.08 & 0.3 & 0.3 & 127.6 & 19.7 & 0.154 & 227.3 & 56.7 & 0.249 \\
\hline 0.10 & 0.4 & 0.4 & 127.9 & 17.8 & 0.139 & 228.0 & 54.0 & 0.237 \\
\hline 0.13 & 0.5 & 0.5 & 128.0 & 16.8 & 0.131 & 228.4 & 52.8 & 0.231 \\
\hline 0.16 & 0.6 & 0.6 & 128.1 & 16.1 & 0.126 & 228.8 & 51.7 & 0.223 \\
\hline 0.21 & 0.8 & 0.8 & 128.4 & 14.8 & 0.115 & 229.4 & 50.5 & 0.220 \\
\hline 0.26 & 1.0 & 1.1 & 128.5 & 14.1 & 0.110 & 229.6 & 50.3 & 0.219 \\
\hline
\end{tabular}

The results listed in Table 4.4 for the higher flow rates of the pure water coolant indicate lower thermal resistances for currents of $200 \mathrm{~A}$ compared to $125 \mathrm{~A}$. The reason for this is unclear at this time. One of the issues with the $V_{\text {cesat }}$ vs junction temperature method used in these measurements is that the $V_{\text {cesat }}$ of an IGBT does not vary linearly with temperature. In this case, the rate at which the $V_{\text {cesat }}$ decreases is very slow at temperatures from 25 to $60^{\circ} \mathrm{C}$. The $V_{\text {cesat }}$ decreases more rapidly with temperature above $60^{\circ} \mathrm{C}$. As a result, at the lower junction temperatures obtained with higher coolant flows, there is more error in determining the actual junction temperature using the $V_{\text {cesat }}$ method, which introduces error in the junction - coolant temperature drop and ultimately the calculated thermal resistances. However, the junction coolant temperature drops are still less than $20 \mathrm{C}$, even at the low flow rates with the greater accuracy. This will permit the semiconductors in the module to operate below $125 \mathrm{C}$ with coolant temperatures up to $105^{\circ} \mathrm{C}$.

The results of the fully powered thermal tests are listed in Table 4.5. As expected, the thermal resistance is slightly higher than the case in Table 4.4 where only $Q_{1} M_{1}$ is powered, due to the effects of the simultaneous heat generation of the other chip sets. The temperature drop from 
junction to inlet coolant is well below $20^{\circ} \mathrm{C}$ at $0.26 \mathrm{gpm}$ for both the pure water and EGC mix. The temperature rise from junction to liquid and thermal resistance as functions of coolant flow rates at full average current loading are plotted in Figures 4.11 and 4.12.

Table 4.5. Gen-1 fully powered $Q_{1} M_{1}$ and $Q_{x 1}$ thermal resistance results for pure water \& EGC mixtures

Junction - Inlet Liquid Thermal Results With H2O Coolant -- Q1N1, Qx1 \& Dx3 Powered

\begin{tabular}{|c|c|c|c|c|c|c|c|c|}
\hline \multirow[b]{2}{*}{$\begin{array}{l}\text { Flow Rate } \\
\text { (Gal/min) }\end{array}$} & \multirow[b]{2}{*}{$\begin{array}{l}\text { Flow Rate } \\
\text { (L/min) }\end{array}$} & \multirow[b]{2}{*}{$\begin{array}{l}\text { Pressure Drop } \\
\quad(p s i)\end{array}$} & \multicolumn{3}{|c|}{ Q1M1 $(I c=125 A)$} & \multicolumn{3}{|c|}{$Q \times 1(I C=20 A)$} \\
\hline & & & $\begin{array}{c}\text { Power } \\
\text { Dissipation } \\
\text { (W) }\end{array}$ & $\begin{array}{c}\text { Delta } \\
\text { Temperature } \\
\text { Junc - Inlet } \\
\left({ }^{\circ} \mathrm{C}\right)\end{array}$ & $\begin{array}{c}\text { Rth } \\
\text { junc-inlet } \\
(\mathrm{C} / \mathrm{W})\end{array}$ & $\begin{array}{c}\text { Power } \\
\text { Dissipation } \\
\text { (W) }\end{array}$ & $\begin{array}{c}\text { Delta } \\
\text { Temperature } \\
\text { Junc - Inlet } \\
\left({ }^{\circ} \mathrm{C}\right)\end{array}$ & $\begin{array}{c}\text { Rth } \\
\text { junc-inlet } \\
\text { (C/W) }\end{array}$ \\
\hline 0.08 & 0.3 & 0.2 & 127.9 & 16.0 & 0.125 & 20.0 & 15.0 & 0.752 \\
\hline 0.10 & 0.4 & 0.5 & 128.2 & 14.0 & 0.129 & 20.1 & 13.5 & 0.672 \\
\hline 0.13 & 0.5 & 0.5 & 128.4 & 13.2 & 0.103 & 20.2 & 13.2 & 0.654 \\
\hline 0.16 & 0.6 & 0.6 & 128.6 & 12.6 & 0.098 & 20.2 & 12.1 & 0.598 \\
\hline 0.21 & 0.8 & 0.7 & 128.8 & 11.8 & 0.092 & 20.3 & 11.2 & 0.552 \\
\hline 0.26 & 1.0 & 1.1 & 128.9 & 10.9 & 0.085 & 20.3 & 10.1 & 0.497 \\
\hline
\end{tabular}

Junction - Inlet Liquid Thermal Results With 50 EGC / 50 H2O -- Q1M1, QX1 \& Dx3 Powered

\begin{tabular}{|c|c|c|c|c|c|c|c|c|}
\hline \multirow[b]{2}{*}{$\begin{array}{l}\text { Flow Rate } \\
\text { (Gal/min) }\end{array}$} & \multirow[b]{2}{*}{$\begin{array}{c}\text { Flow Rate } \\
\text { (L/min) }\end{array}$} & \multirow[b]{2}{*}{$\begin{array}{l}\text { Pressure Drop } \\
\quad(p s i)\end{array}$} & \multicolumn{3}{|c|}{ Q1M1 $(I C=125 A)$} & \multicolumn{3}{|c|}{ Qx1 $(I C=20 A)$} \\
\hline & & & $\begin{array}{c}\text { Power } \\
\text { Dissipation } \\
\text { (W) }\end{array}$ & $\begin{array}{c}\text { Delta } \\
\text { Temperature } \\
\text { Junc - Inlet } \\
\left({ }^{\circ} \mathrm{C}\right)\end{array}$ & $\begin{array}{c}\text { Rth } \\
\text { junc-inlet } \\
(\mathrm{C} / \mathrm{W})\end{array}$ & $\begin{array}{c}\text { Power } \\
\text { Dissipation } \\
\text { (W) }\end{array}$ & $\begin{array}{c}\text { Delta } \\
\text { Temperature } \\
\text { Junc - Inlet } \\
\left({ }^{\circ} \mathrm{C}\right)\end{array}$ & $\begin{array}{c}\text { Rth } \\
\text { junc-inlet } \\
(\mathrm{C} / \mathrm{W})\end{array}$ \\
\hline 0.08 & 0.3 & 0.2 & 127.4 & 19.1 & 0.150 & 19.7 & 18.3 & 0.927 \\
\hline 0.10 & 0.4 & 0.5 & 127.8 & 16.5 & 0.129 & 19.9 & 16.1 & 0.810 \\
\hline 0.13 & 0.5 & 0.6 & 128.0 & 15.0 & 0.117 & 20.0 & 14.8 & 0.741 \\
\hline 0.16 & 0.6 & 0.6 & 128.2 & 14.2 & 0.111 & 20.0 & 14.1 & 0.704 \\
\hline 0.21 & 0.8 & 0.9 & 128.4 & 12.8 & 0.100 & 20.1 & 12.9 & 0.642 \\
\hline 0.26 & 1.0 & 1.0 & 128.5 & 11.9 & 0.093 & 20.2 & 11.9 & 0.590 \\
\hline
\end{tabular}

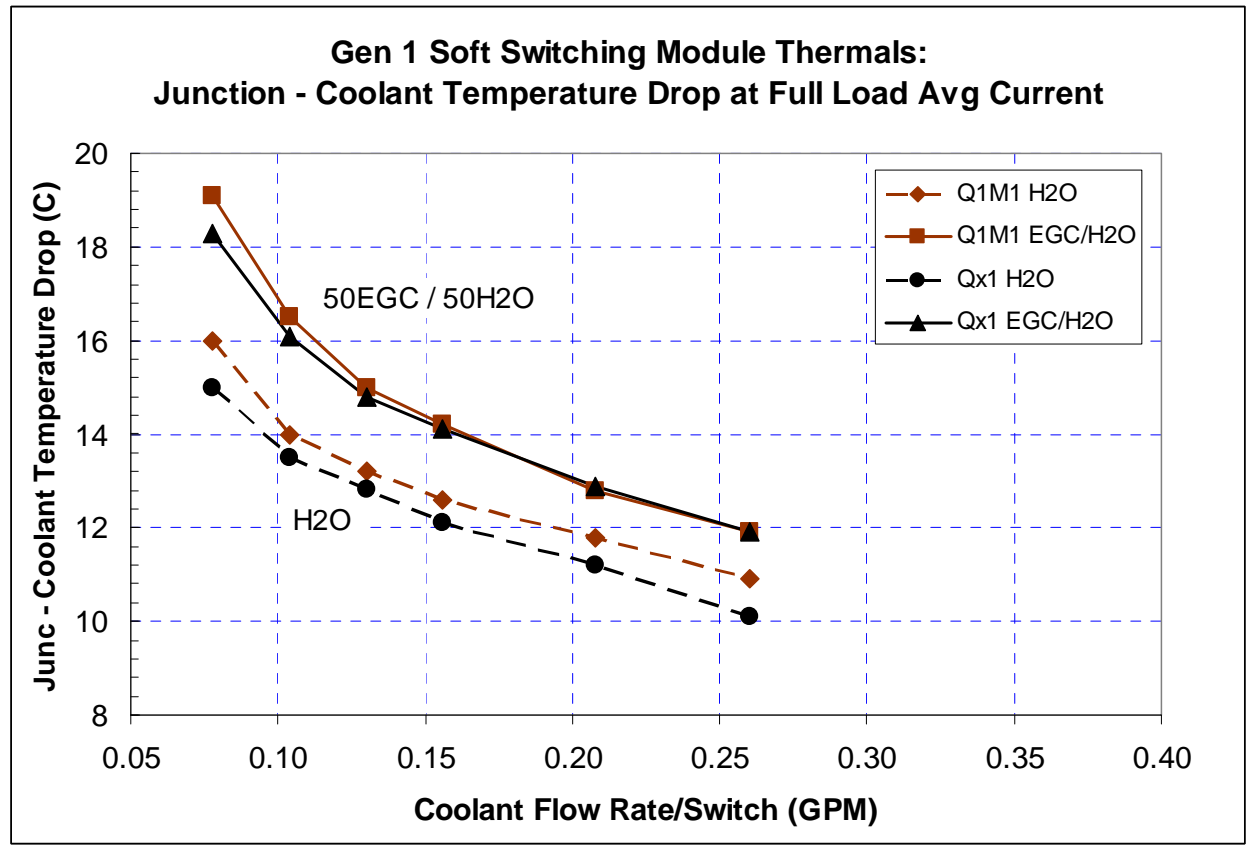

Figure 4.11. Results of Gen-1 module junction-to-coolant temperature drop at full average current of 125A. 


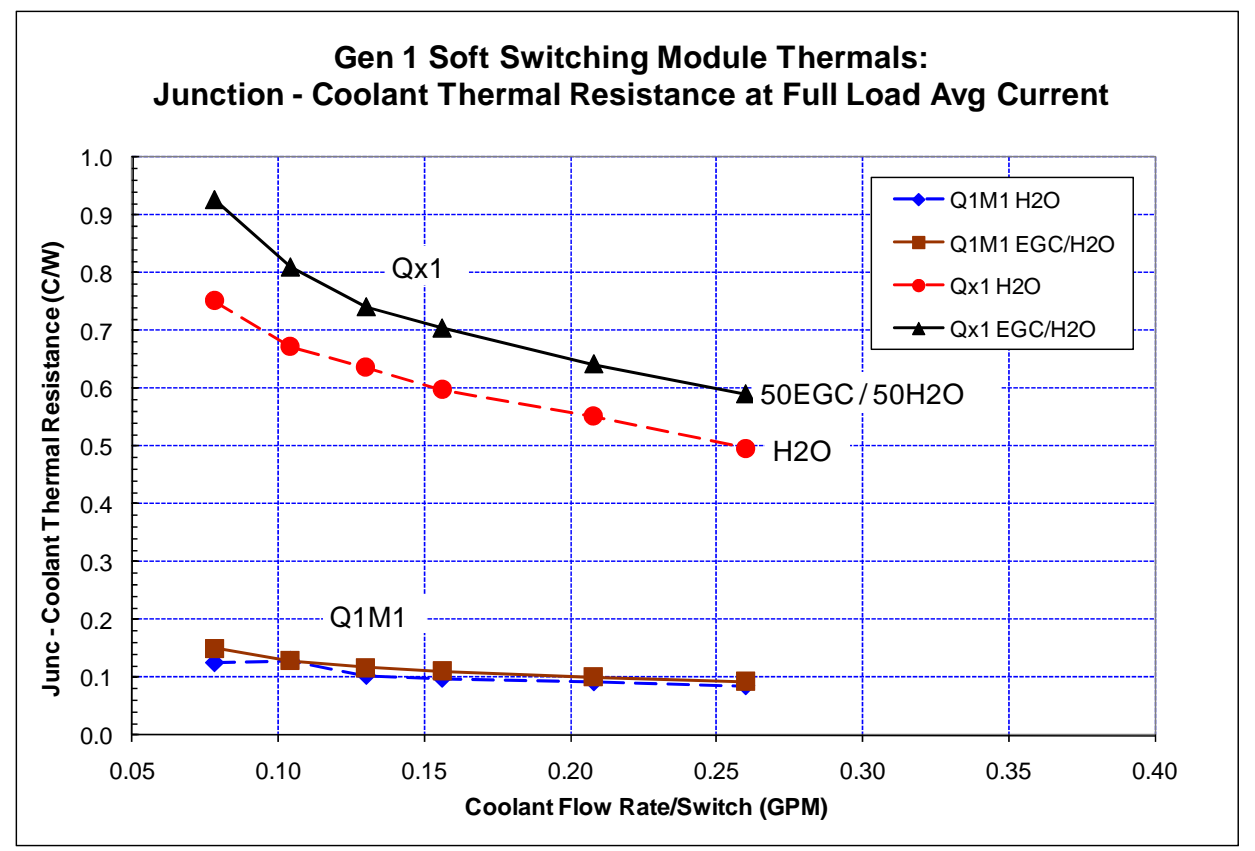

Figure 4.12. Results of Gen-1 module liquid-cooled thermal resistance at full average current of 125A showing the dependence of junction-to-liquid thermal resistance as a function of flow rate.

\subsection{Generation 2 Module Development}

\section{A. Gen-2 Module Design}

The design for the second generation, single phase, soft-switched IGBT module utilizes the same basic circuit configuration as that for the previous generation. The only difference is that the gate connections for $Q_{1,2}$ and $M_{1,2}$ in the power section are brought out separately to permit independent gate control for each type of device. The semiconductor chips, anticipated losses, peak currents and RMS currents per device are also the same for this generation and are summarized in Tables 4.1 and 4.2.

The primary changes in the Gen-2 module are the layout and package designs to reduce internal inductance and cost. The layout has reduced internal path lengths for terminal connections, especially those between the resonant capacitors and chips. Separate power post terminals are brought out directly from the substrate for the resonant capacitor connections. The substrate and housing package adopts the low profile, industry-standard Powerex "NX" series package design. The Gen 2 design has the same height, but will be slightly longer and wider than the standard NX package. Figures 4.13 and 4.14 show the terminal and control pin locations of the module. All gate drive \& control pins are located on both sides of the package. Two AC power terminals and DC bus terminals are screw mounted. All of the auxiliary resonant capacitor and inductor connections are through center posts that solder to a heavy copper layer on the power printed circuit board of the inverter. Figure 4.15 shows the chip layout in the module. Photos of the module before and after wirebonding are shown in Figure 4.16. This design can be assembled on 
a conventional flat baseplate or a built-in liquid-cooled chill plate used for the Gen-1 module. A conventional flat baseplate was utilized for this generation. The modules were bolted to a liquid cooled chill plate in the inverter.

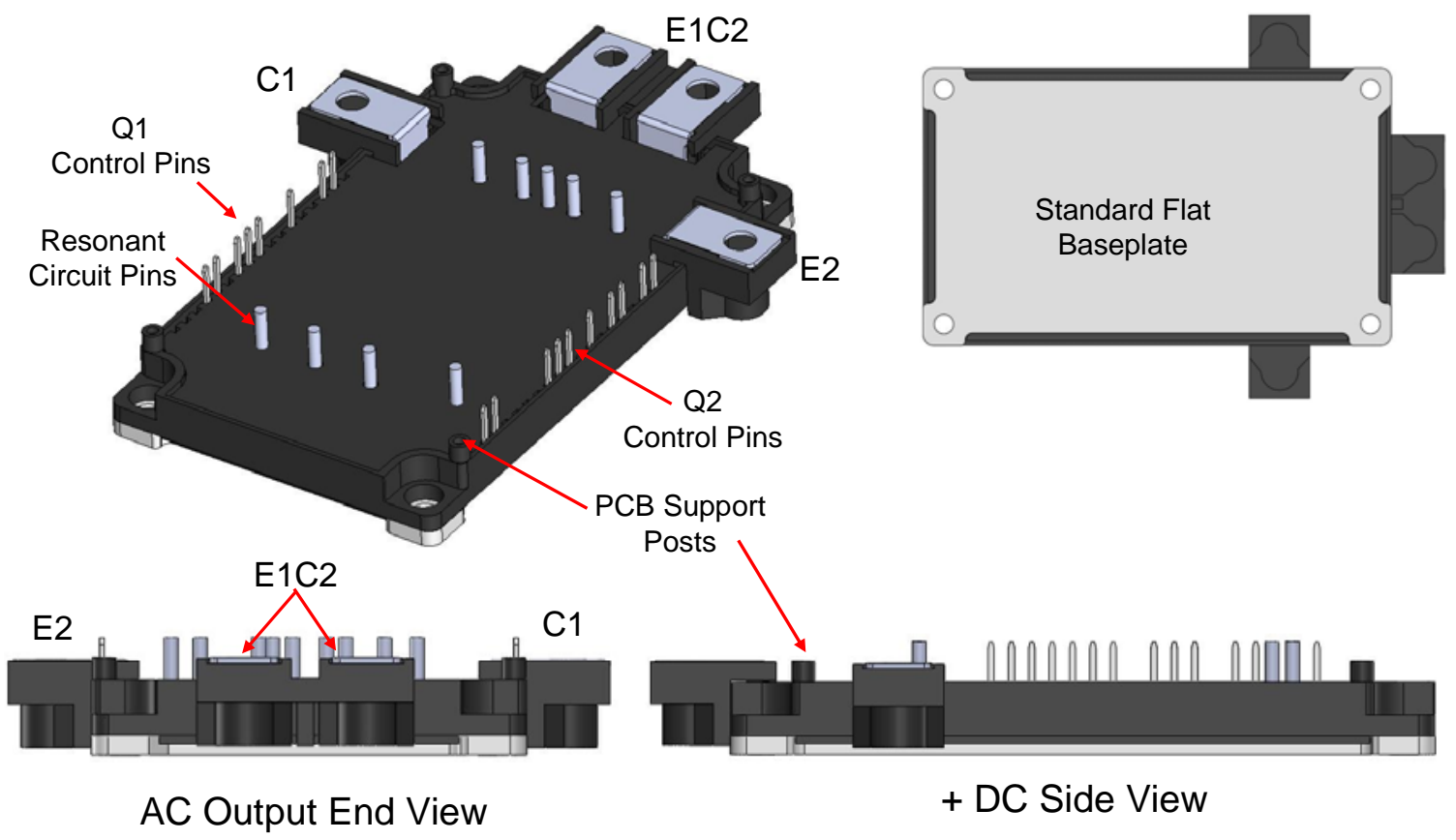

Figure 4.13. Gen-2 low profile package design.

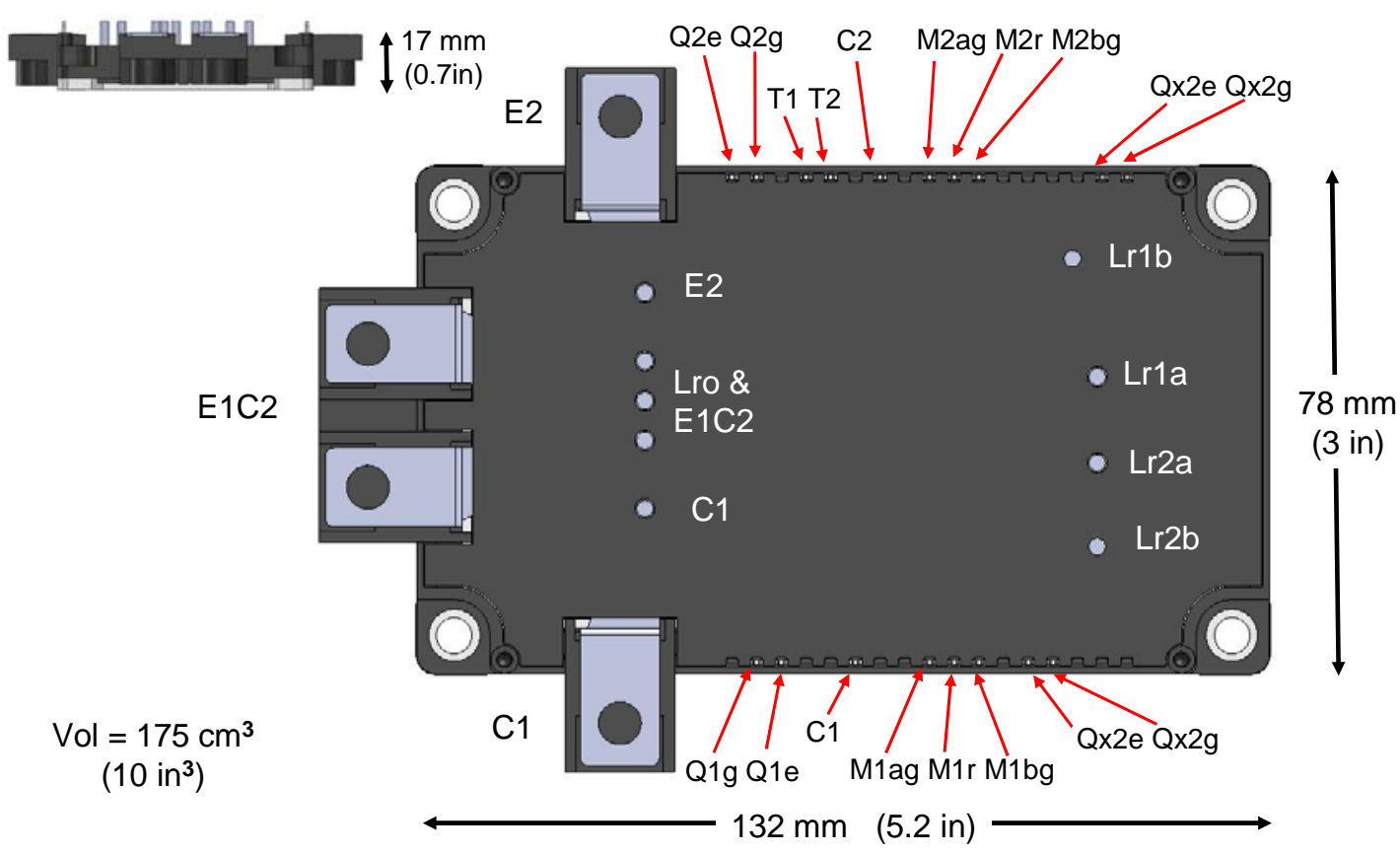

Figure 4.14. Gen-2 low profile package design showing power and control terminal/pin locations. 


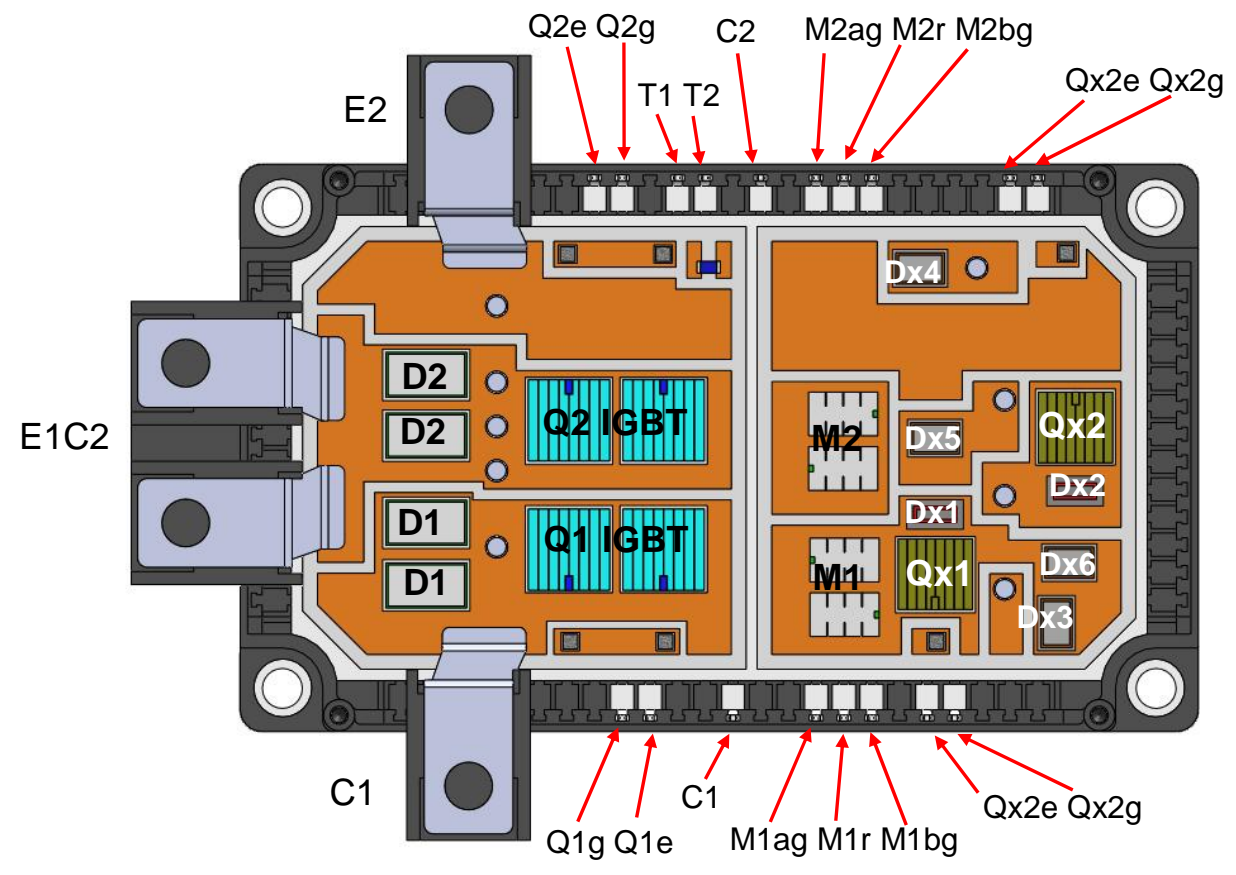

Figure 4.15. Gen-2 low profile package design showing chip locations.

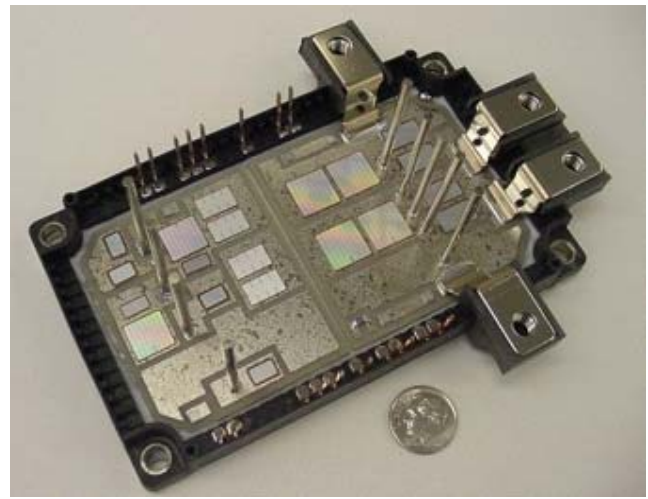

(a) Before wirebond

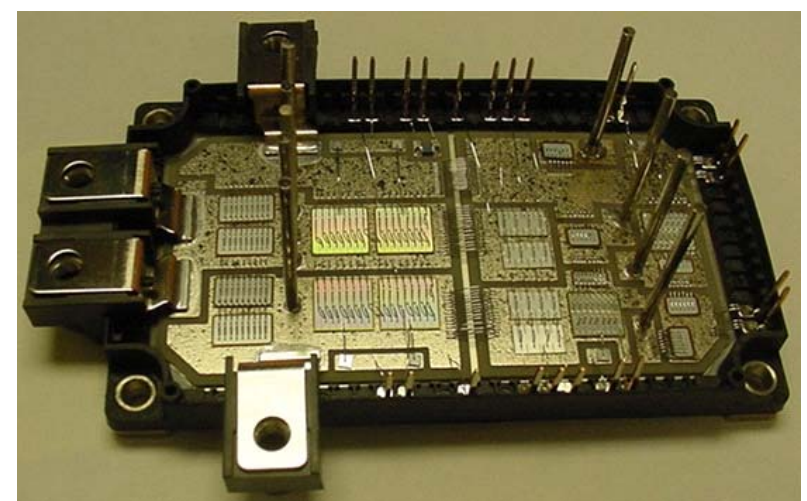

(b) After wirebond

Figure 4.16. Photographs of Gen-2 soft-switching module layout: (a) before wirebond, (b) after wirebond.

\section{B. Gen-2 Module Thermal Simulations}

As discussed earlier, the Gen-2 module design is compatible with 3 different cooling options:

1) Standard air-cooled (flat baseplate mounted to air cooled heatsink)

2) Standard liquid-cooled (flat baseplate mounted to conventional liquid-cooled chill plate)

3) Direct liquid-cooled (built-in liquid-cooled chill plate).

Modeling was performed to assess the thermal performance of the three cooling options. The thermal resistances of the three options were estimated using the three methods below:

1) Computer 3D Finite Element Analysis (FEA) was used to determine the thermal resistance from junction to baseplate using Algor FEA software. Quasi-3D analytical 
calculations were also performed as a "sanity check" to validate the FEA simulations. This was followed by an FEA analysis of the thermal resistance from baseplate to ambient of a bonded-fin, air-cooled heat sink using an on-line simulator provided by a commercial heat-sink supplier. The heat sink simulated was similar to that used by Azure Dynamics in their air-cooled electric vehicle drive systems.

2) The datasheet junction-baseplate thermal resistance values of the Powerex CM400DX12A IGBT module were used, since it uses the same IGBT chips and has a nearly identical thermal-path design as the Gen-2 module. The thermal resistance from baseplate to ambient for the CM400DX-12A was modeled using the same on-line simulator as used in Method 1. Simulations were performed for the same air-cooled heat sink in Method 1 as well as a standard commercial liquid-cooled chill plate.

3) The results of the direct liquid-cooled thermal measurements performed on the Gen-1 modules were used to estimate the Gen-2 direct liquid-cooled thermal resistance.

The results of the FEA and Quasi-3D calculations of the junction-baseplate thermal drops at full chip power dissipation levels are shown in Figure 4.17. There is good agreement between the full 3D FEA computer simulations and Quasi-3D analytical calculations. The chip temperatures in the graphic are for the case where the bottom of the baseplate held fixed at $25^{\circ} \mathrm{C}$. The values in the table are the chip temperatures in the graphic menu $25^{\circ} \mathrm{C}$. This indicates a temperature rise form junction to baseplate of $7^{\circ} \mathrm{C}$ for the power IGBTs $\left(\mathrm{Q}_{1,2}\right)$ and a $4^{\circ} \mathrm{C}$ rise for the power MOSFETs $\left(\mathrm{M}_{1,2}\right)$. Of course, this temperature rise must be added to that of the heat sink or chill plate.

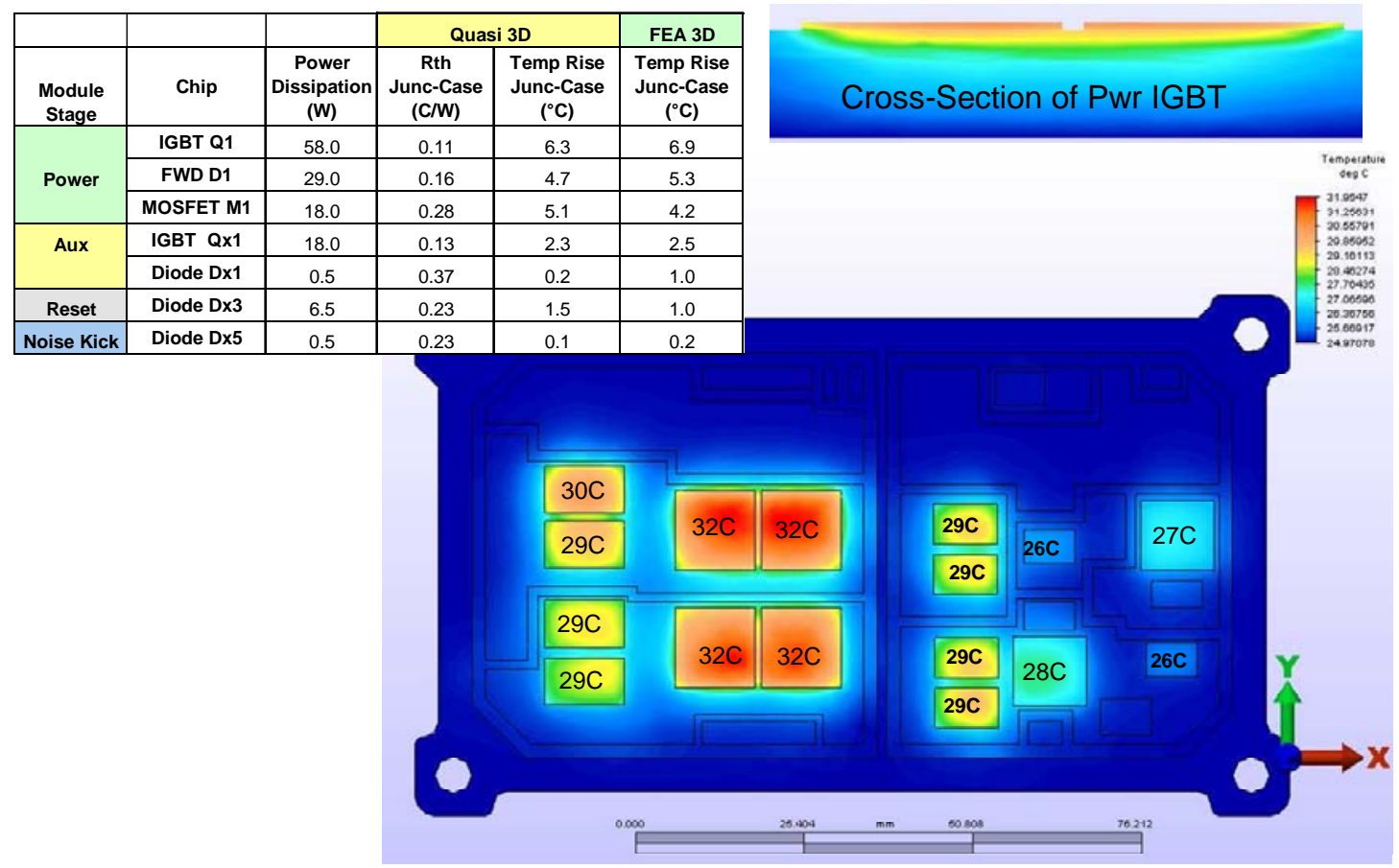

Figure 4.17. 3D FEA simulation results of the temperature rise from junction to baseplate for the various chips in the Gen 2 design at the dissipation levels at full power operation. The comparison between the full FEA 3-D and Quasi-3D analytical results are listed in the table inset. For the results shown in the graphic, the bottom of the baseplate was held at $25 \mathrm{C}$. 
The full temperature drops from junction to ambient coolant are shown in Figure 4.18 for the three methods just discussed. As expected, air-cooling results in the highest temperature drops from junction to ambient of $35-37^{\circ} \mathrm{C}$, indicating that maximum inlet air temperatures must be kept under $88^{\circ} \mathrm{C}$ for the IGBT junctions to operate below $125^{\circ} \mathrm{C}$. The conventional liquidcooling design exhibits a $28^{\circ} \mathrm{C}$ rise from junction to liquid at full power operation, which would result in junction temperatures of $133^{\circ} \mathrm{C}$ if the inlet coolant was at its peak temperature of $105^{\circ} \mathrm{C}$ and the inverter was operating at full output power simultaneously. The directly liquid-cooled design maintains junction temperatures well below $125^{\circ} \mathrm{C}$, even with maximum inlet temperatures of $105^{\circ} \mathrm{C}$.

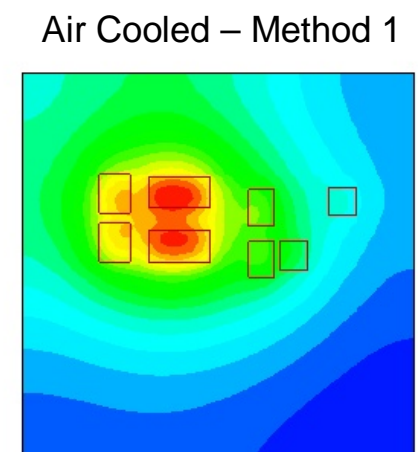

Air Cooled - Method 2

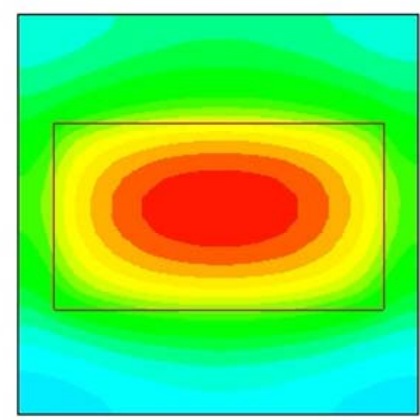

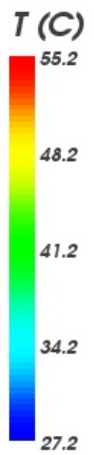

$T(C)$

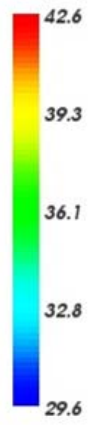

\begin{tabular}{|c|c|c|c|c|}
\hline \multicolumn{2}{|c|}{ Standard Air-Cooled } & $\begin{array}{c}\text { Standard } \mathrm{H}_{2} \mathrm{O} \\
\text { Cooled }\end{array}$ & $\begin{array}{c}\text { Direct } \\
\mathrm{H}_{2} \mathrm{O} \\
\text { Cooled }\end{array}$ & $\begin{array}{c}\text { Direct } \\
\text { EGC/ } \mathrm{H}_{2} \mathrm{O} \\
\text { Cooled }\end{array}$ \\
\hline Method 1 & Method 2 & Method 2 & Method 3 & Method 3 \\
\hline $\begin{array}{c}\text { Pwr IGBT } \\
\Delta \text { Tj-air } \\
\left({ }^{\circ} \mathrm{C}\right) \\
\end{array}$ & $\begin{array}{c}\text { Pwr IGBT } \\
\Delta \text { Tj-air } \\
\left({ }^{\circ} \mathrm{C}\right) \\
\end{array}$ & $\begin{array}{c}\text { Pwr IGBT } \\
\Delta \text { Tj-liq } \\
\left({ }^{\circ} \mathrm{C}\right)\end{array}$ & $\begin{array}{c}\text { Pwr IGBT } \\
\Delta \text { Tj-liq } \\
\left({ }^{\circ} \mathrm{C}\right) \\
\end{array}$ & $\begin{array}{c}\text { Pwr IGBT } \\
\Delta \text { Tj-liq } \\
\left({ }^{\circ} \mathrm{C}\right) \\
\end{array}$ \\
\hline 37 & 35 & 28 & 11 & 12 \\
\hline
\end{tabular}

$\mathrm{H}_{2} \mathrm{O}$ Cooled - Method 2

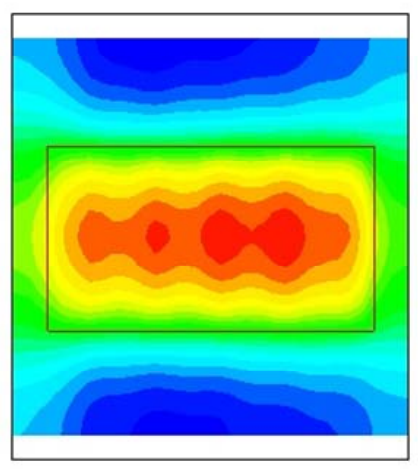

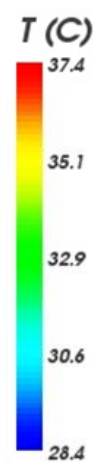

Figure 4.18. Comparison of junction-ambient temperature drops for the three cooling options possible for the Gen 2 module.

\section{Gen-2 Module Conduction Characteristics Test Results}

Test results from a sample of three of the Gen-2 modules delivered to Virginia Tech are listed in Table 4.6. A complete set of parametric measurements were conducted on three modules (serial numbers 201, 202 and 210). The results for SN 201 are plotted in the following curves in Figures 4.19-4.26 for both switches. The $V_{\text {cesat }}$ and $V_{d s-o n}$ of the power stage IGBT and MOSFET chips were measured separately by gating one set on while simultaneously biasing the other set off by shorting the gate pin to the emitter/source return pin. The $V_{\text {cesat }}$ of the parallel combination was measured by gating both sets of chips on at the same time. The plots in Figures 4.19, 4.20, 4.23, and 4.24 show the low voltage drops at currents $<50 \mathrm{~A}$ due to the low resistive drop of the 
MOSFETs in parallel with the IGBTs. Most of the current above 50 to $75 \mathrm{~A}$ is carried by the IGBTs. At elevated temperatures, the $R_{d s-o n}$ of the MOSFETs increases, resulting in higher conduction losses for $\mathrm{I}<50 \mathrm{~A}$ compared to lower temperatures. This is somewhat offset by the slight reduction in $V_{\text {cesat }}$ of the IGBTs at higher temperatures, as shown in Figures 4.20 and 4.24.

Table 4.6. Test Results for a sample of the Gen-2 Modules
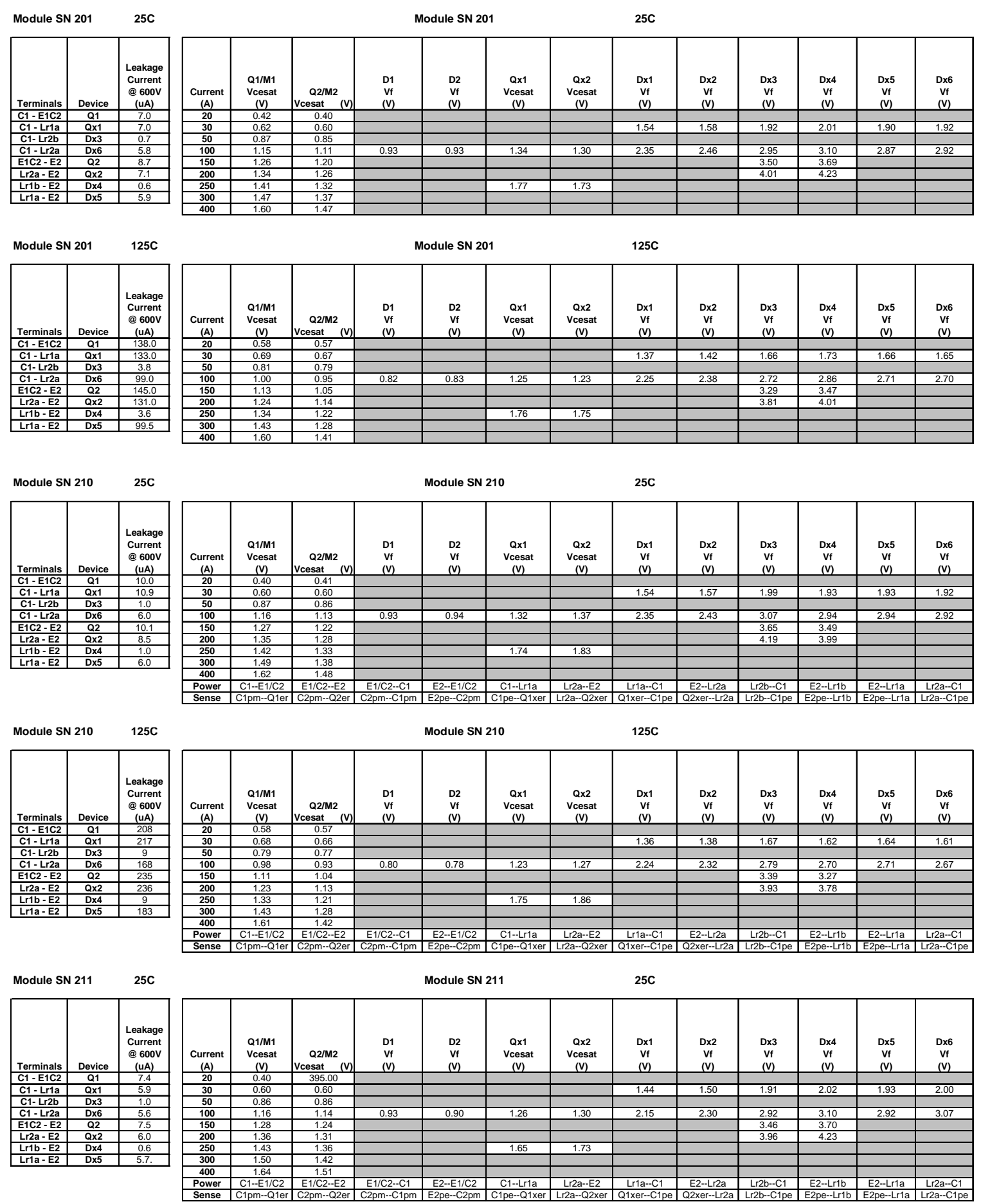
The conduction losses of the auxiliary stage IGBT and resonant diodes are shown in Figures $4.21,4.22,4.25$, and 4.26 for junction temperatures of 25 and $125^{\circ} \mathrm{C}$. Since the same $1200 \mathrm{~V}$, 50 A chip is used for $D_{x 3}, D_{x 6}, D_{x 4}$ and $D_{x 5}$, the $V_{f}$ values are essentially the same. The slight difference in the $V_{f}$ values for $D_{x 4}$ and $D_{x 5}$ in $Q_{x 2}$ is due to the placement of the Kelvin probes during the voltage measurement.

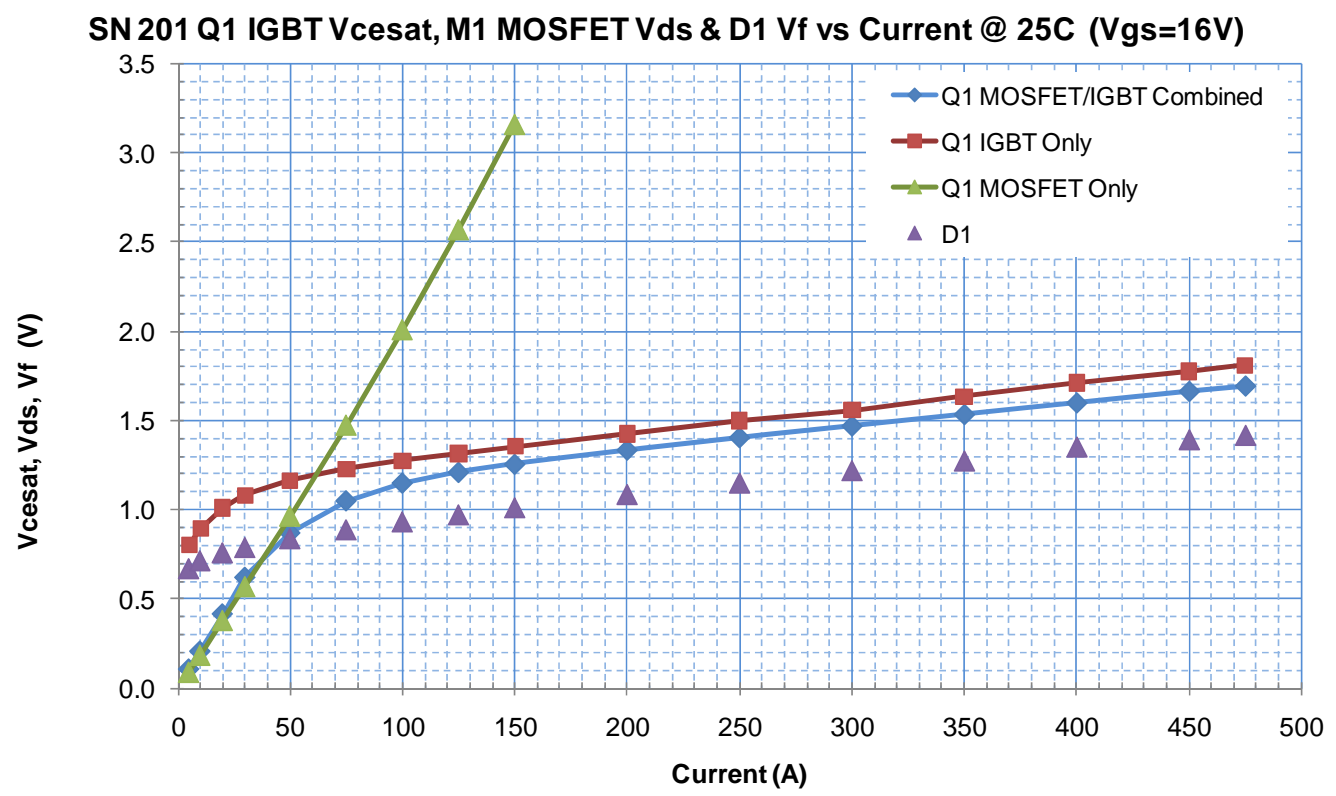

Figure 4.19. Voltage drops for the power stage IGBT, MOSFET, MOSFET/IGBT combination and main free-wheel diode $\left(D_{1}\right)$ at $T_{j}=25^{\circ} \mathrm{C}$ for Gen-2 module SN201, $Q_{1}$.

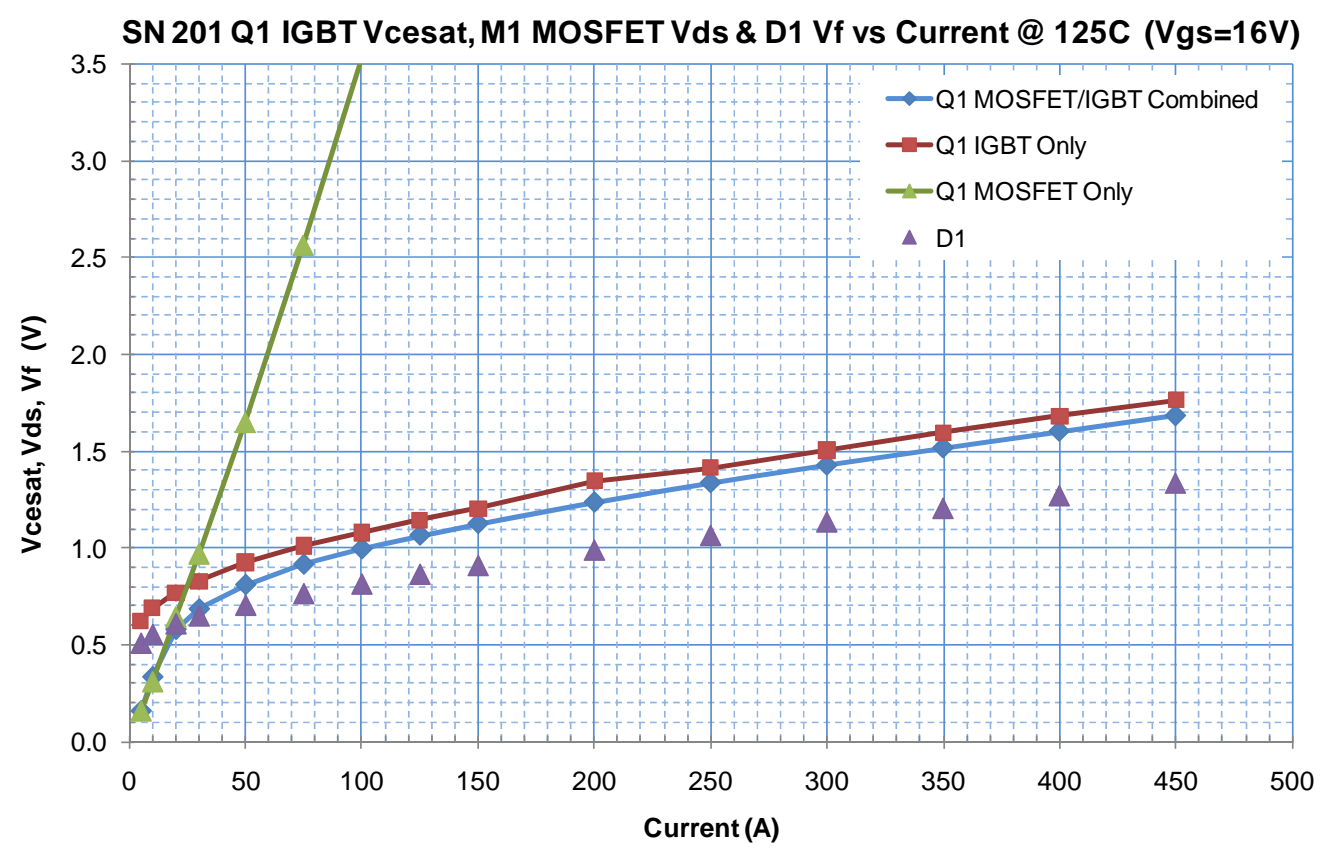

Figure 4.20. Voltage drops for the power stage IGBT, MOSFET, MOSFET/IGBT combination and main free-wheel diode $\left(D_{1}\right)$ at $T_{j}=125^{\circ} \mathrm{C}$ for Gen-2 module SN201, $Q_{1}$. 


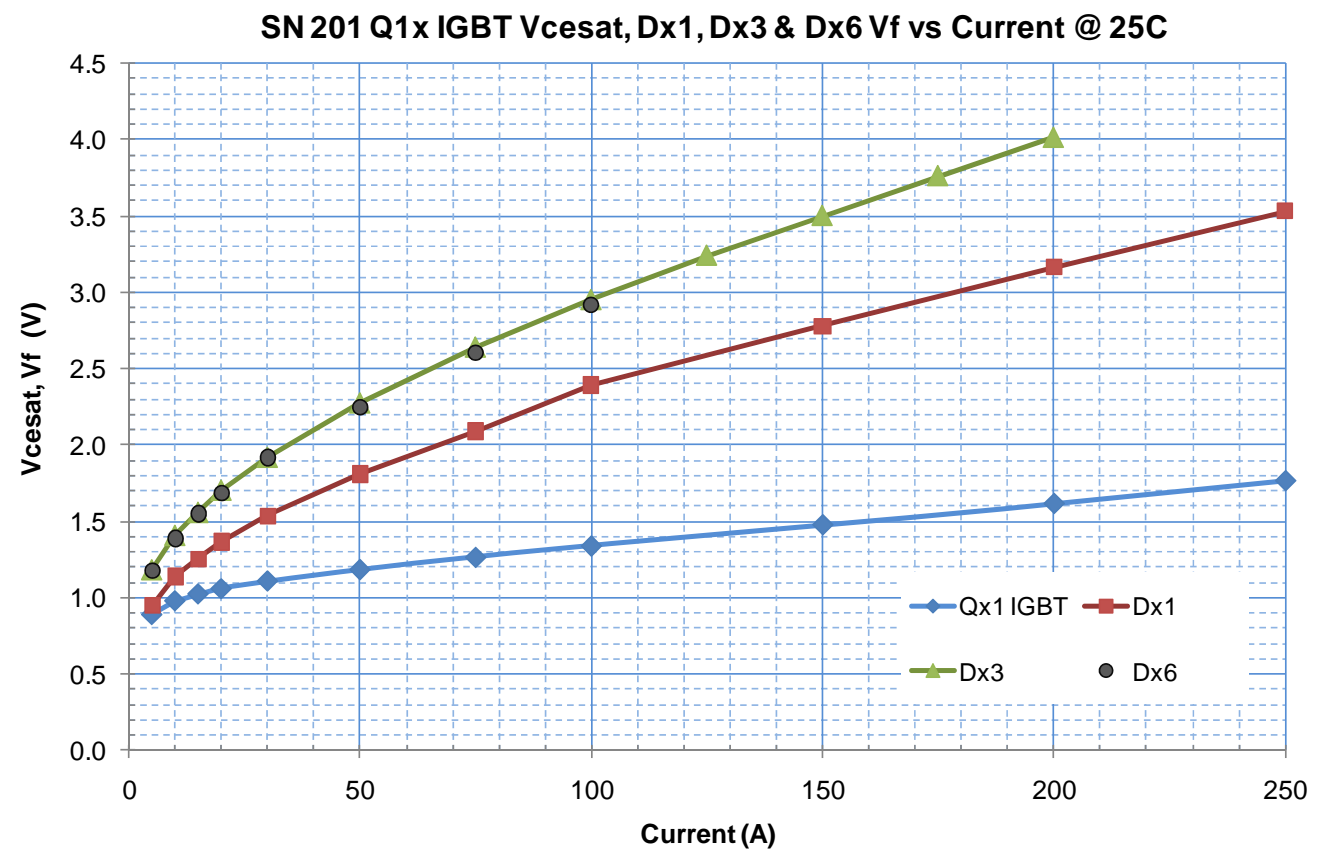

Figure 4.21. Voltage drops for the auxiliary IGBT $\left(Q_{x 1}\right)$, free-wheel diode $\left(D_{x 1}\right)$ and resonant diodes $\left(D_{x 3}, D_{x 6}\right)$ at $T_{j}=25^{\circ} \mathrm{C}$ for Gen-2 module SN201 $Q_{x 1}$.

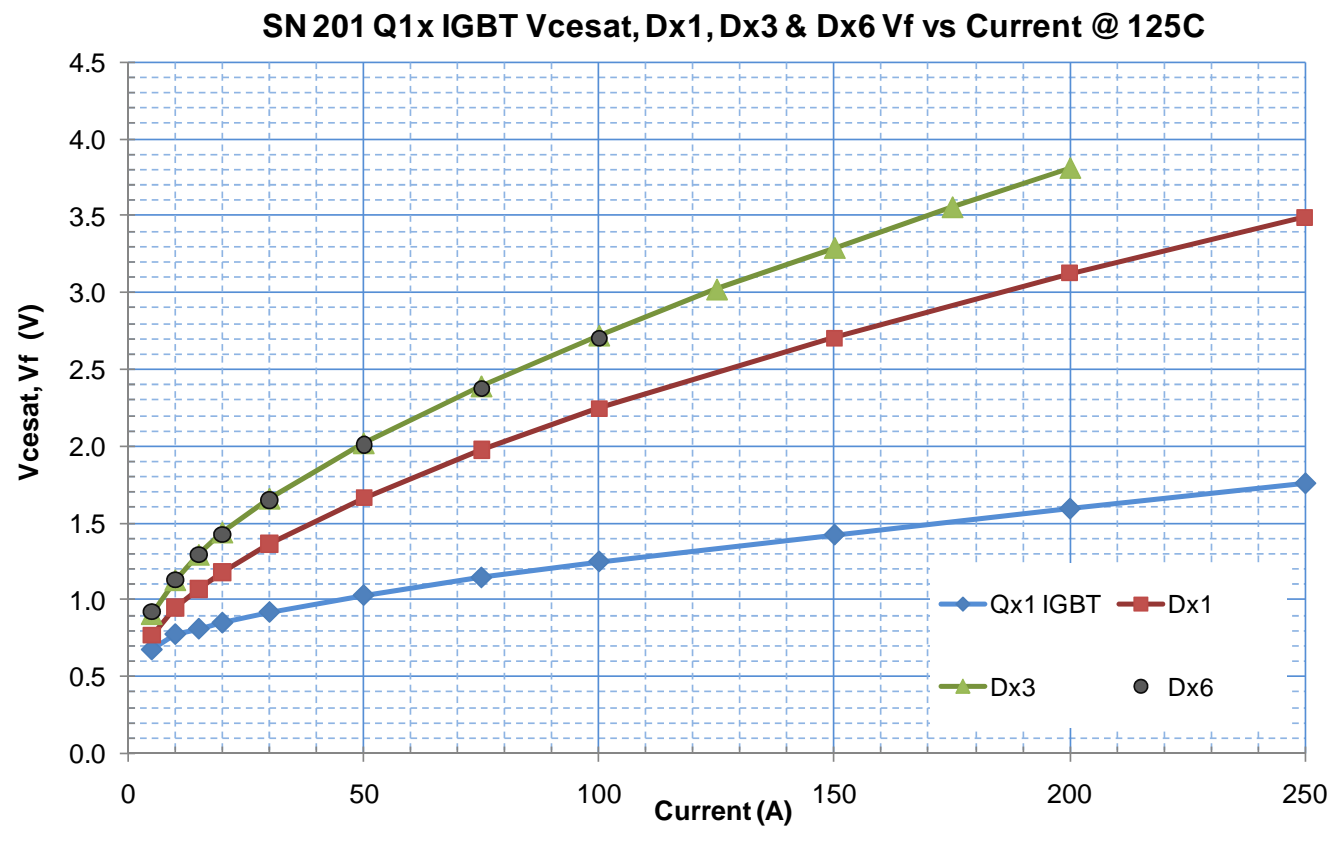

Figure 4.22. Voltage drops for the auxiliary IGBT $\left(Q_{x 1}\right)$, free-wheel diode $\left(D_{x 1}\right)$ and resonant diodes $\left(D_{x 3}, D_{x 6}\right)$ at $T_{j}=125^{\circ} \mathrm{C}$ for Gen-2 module SN201 $Q_{x 1}$. 


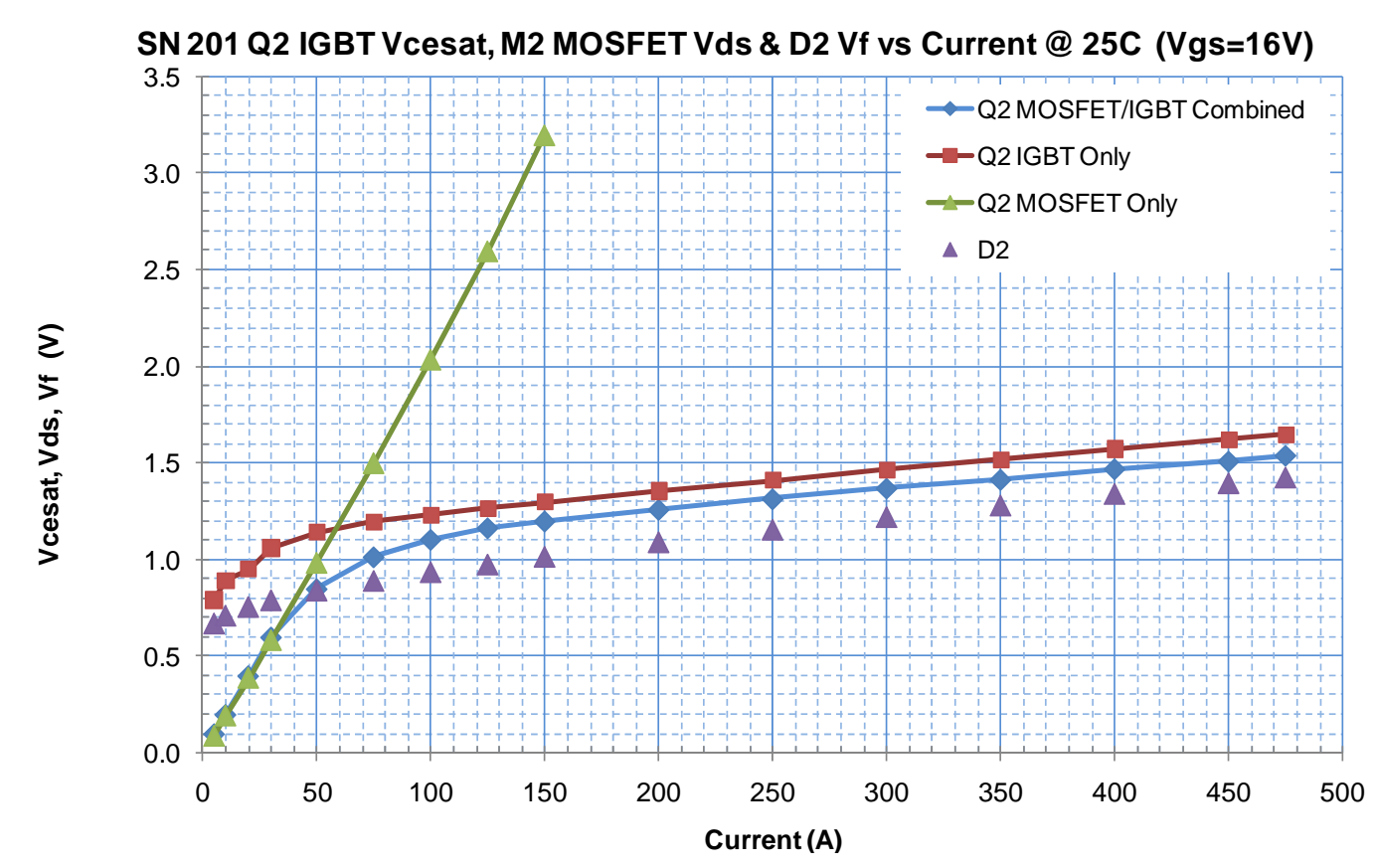

Figure 4.23. Voltage drops for the power stage IGBT, MOSFET, MOSFET/IGBT combination and main free-wheel diode $\left(D_{2}\right)$ at $T_{j}=25^{\circ} \mathrm{C}$ for Gen-2 module SN201, $Q_{2}$.

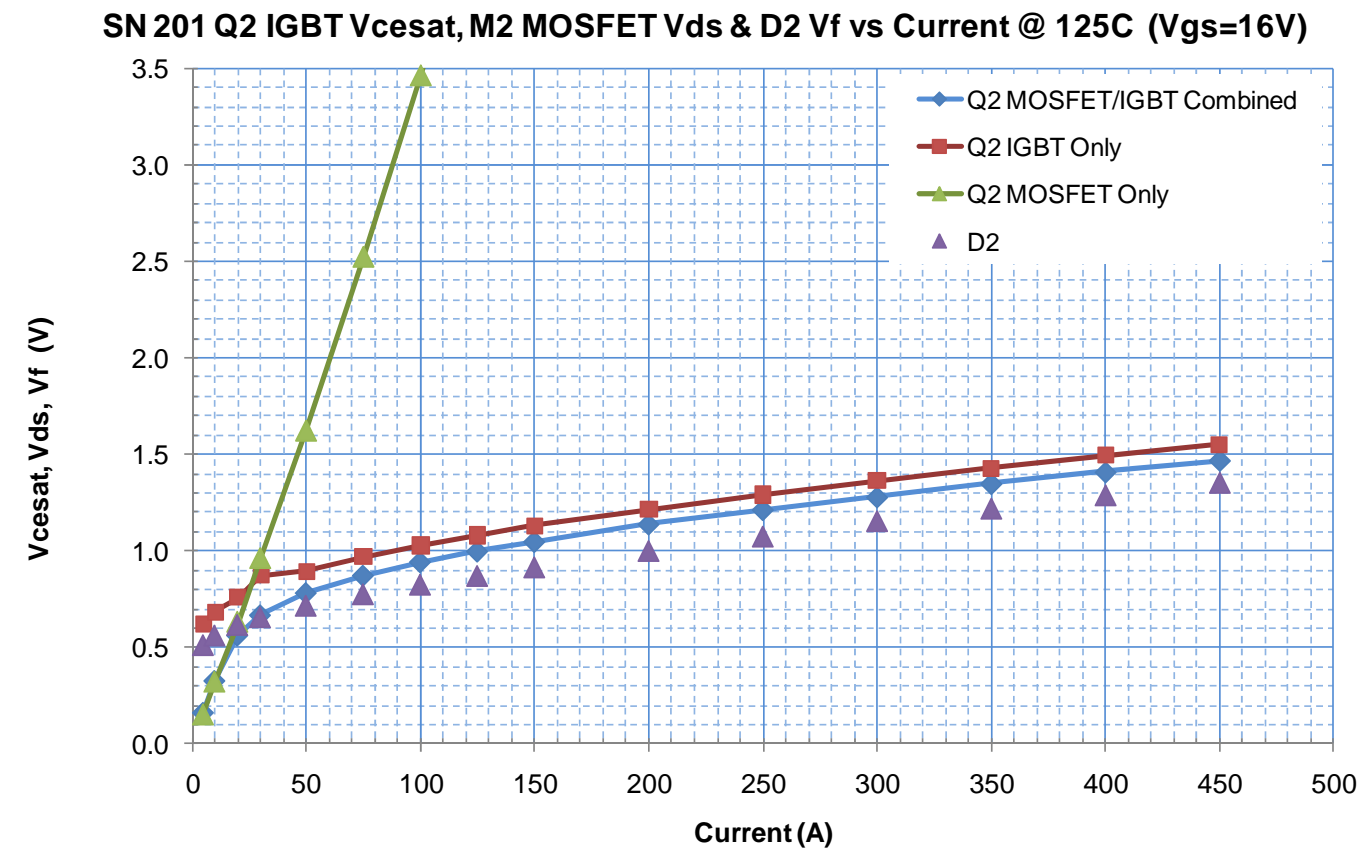

Figure 4.24. Voltage drops for the power stage IGBT, Mosfet, Mosfet/IGBT combination and main free-wheel diode $\left(D_{2}\right)$ at $T_{j}=125^{\circ} \mathrm{C}$ for Gen-2 module SN201, $Q_{2}$. 


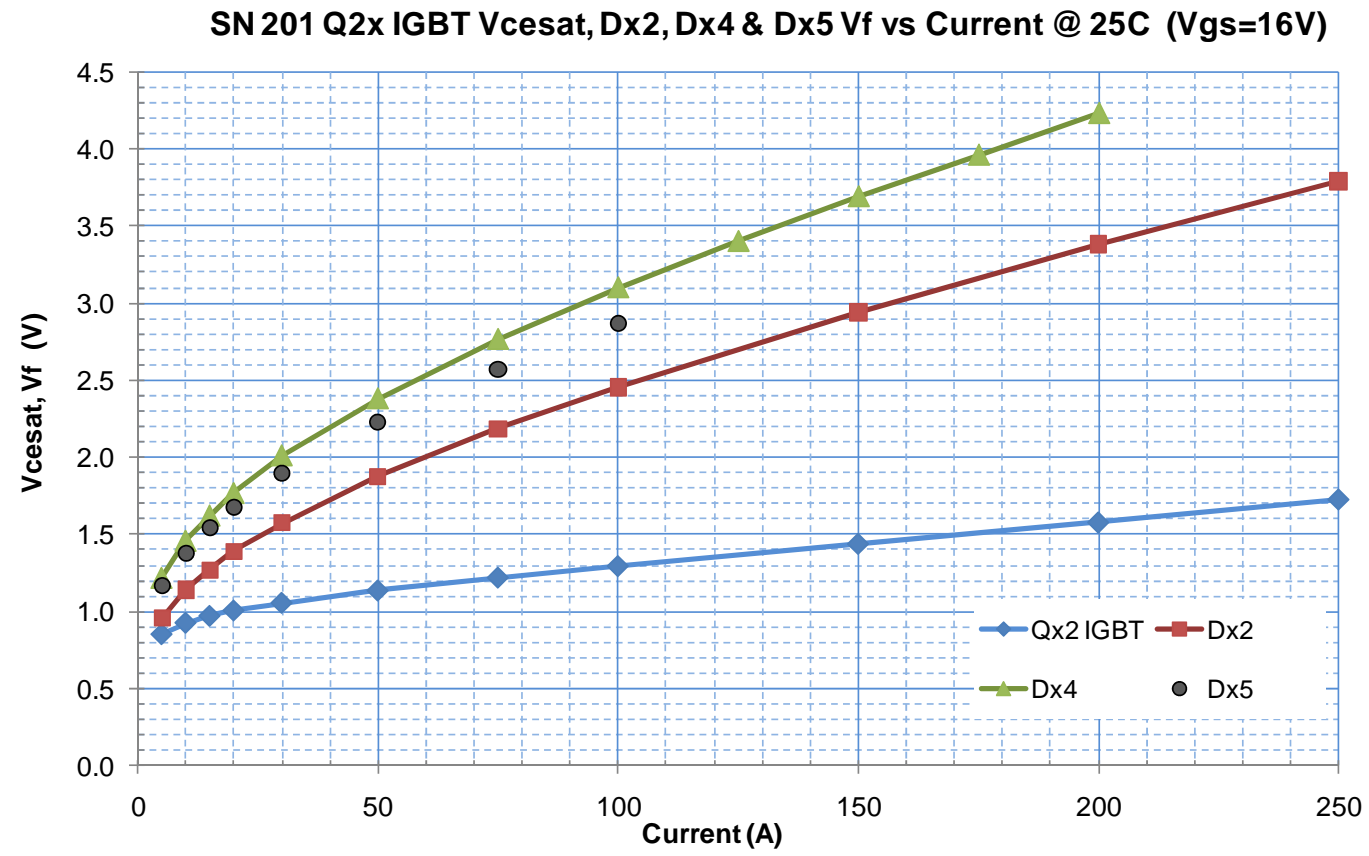

Figure 4.25. Voltage drops for the auxiliary IGBT $\left(Q_{x 2}\right)$, free-wheel diode $\left(D_{x 2}\right)$ and resonant diodes $\left(D_{x 4}, D_{x 5}\right)$ at $T_{j}=25^{\circ} \mathrm{C}$ for Gen-2 module SN201 $Q_{x 2}$.

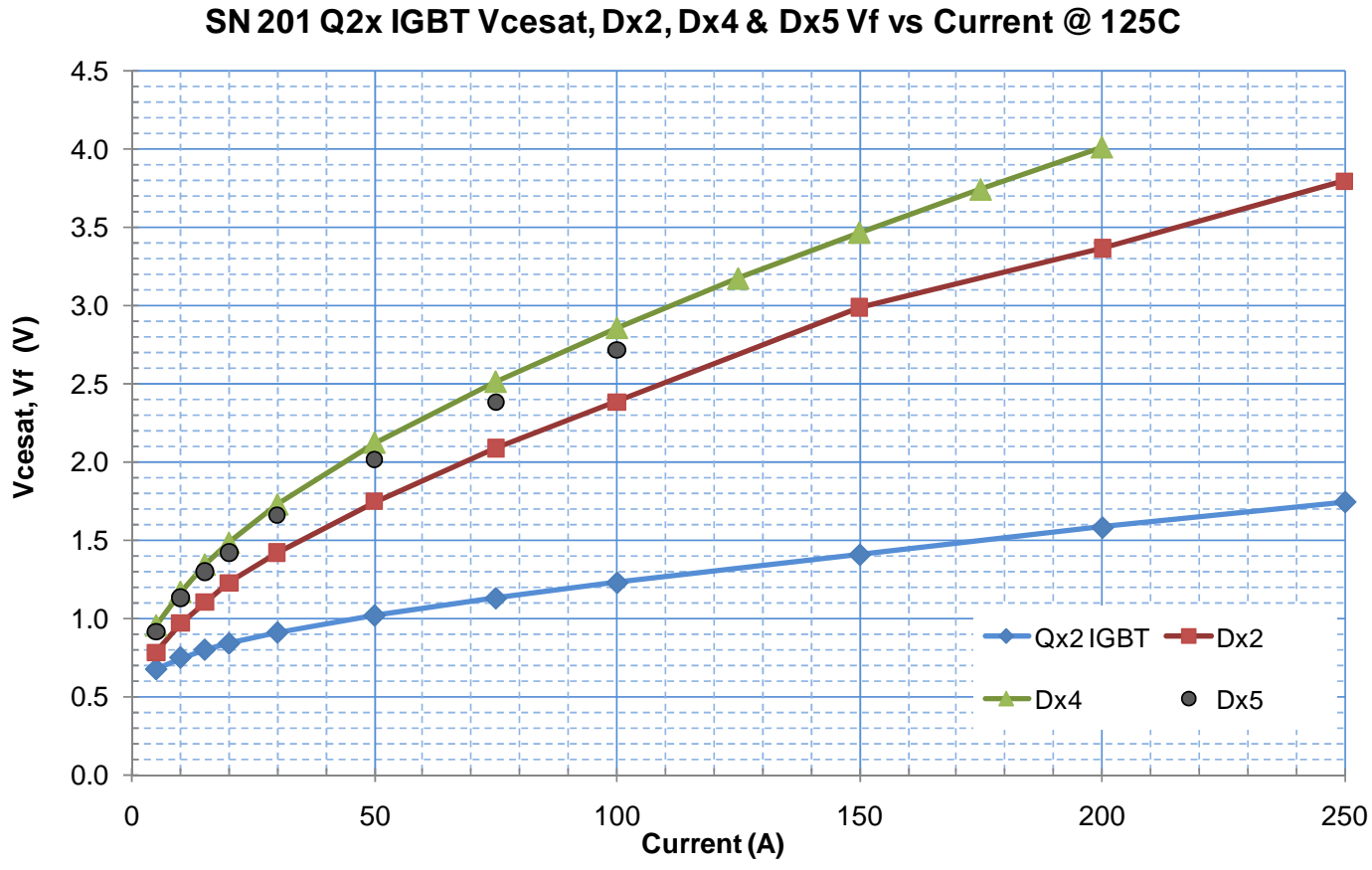

Figure 4.26. Voltage drops for the auxiliary IGBT $\left(Q_{x 2}\right)$, free-wheel diode $\left(D_{x 2}\right)$ and resonant diodes $\left(D_{x 4}, D_{x 5}\right)$ at $T_{j}=125^{\circ} \mathrm{C}$ for Gen-2 module SN201 $Q_{x 2}$. 
Even though the Gen-2 design exhibited a $79 \%$ reduction in internal inductance as compared with Gen 1, one disadvantage is the higher internal resistance in the power section due to the longer lateral current-flow paths in the 0.012 inch thick copper pads on the AlN substrate. A comparison of the conduction voltage drops (terminal - terminal) of the Gen-1 and Gen-2 modules is shown in Figure 4.27. The Gen 2 modules have a $200 \mathrm{mV}$ higher voltage drop at $400 \mathrm{~A}$ than the Gen 1 modules, which resulted in at least a $0.3 \%$ point reduction in efficiency of the inverter.

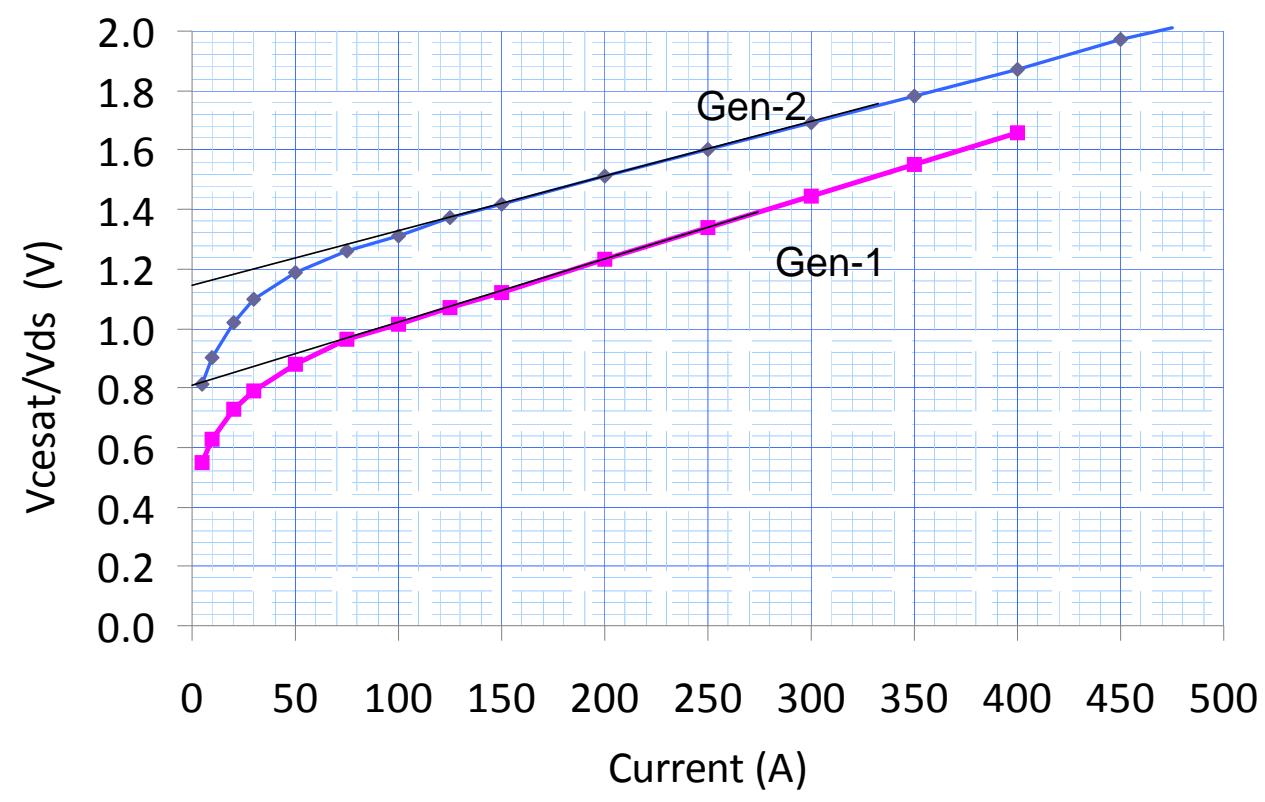

Figure 4.27. Voltage drop comparison of the Gen 1 and 2 modules.

\subsection{Gen-3 Module Development}

\section{A. Gen-3 Module Design}

The Gen-3 design was focused on reducing the internal parasitic resistance and inductance, as well as replacing both the existing MOSFET and antiparallel diode with a new, lower $R_{d s-o n}$ MOSFET with an improved internal body diode capable of handling the free-wheeling currents. The large, single module was also split into two separate modules to decrease the size of the AlN substrates to improve thermal cycling reliability. One module consists of the power stage (half H-bridge) and the other the auxiliary resonant-switching section. The Gen 3 module utilizes a flat baseplate like Gen-2, but is capable of being assembled on a built-in liquid chill-plate similar to Gen-1. The Gen-3 inverter exhibited such low losses and high efficiencies that air cooling was utilized. The Gen-2 and Gen-3 designs are compared in Figure 4.28.

The Infineon Cool-MOS MOSFET used in the two previous generations was replaced by a ST Microelectronics STY112N65M5, which has a lower $R_{d s-o n}$ than the Infineon device. In addition, testing of the reverse recovery characteristics of the body diode by Virginia Tech indicated comparable performance compared to the Infineon device. The total chip area of ST devices is sufficient to handle the freewheeling current, thus allowing elimination of the extra antiparallel 
diodes in the power section. Based on extensive circuit modeling performed by Virginia Tech, it was decided to use two of the new STY112N65M5 MOSFETs (each rated at 93A average) and two of the existing Powerex 200A rated IGBTs per switch for the Gen-3 modules.

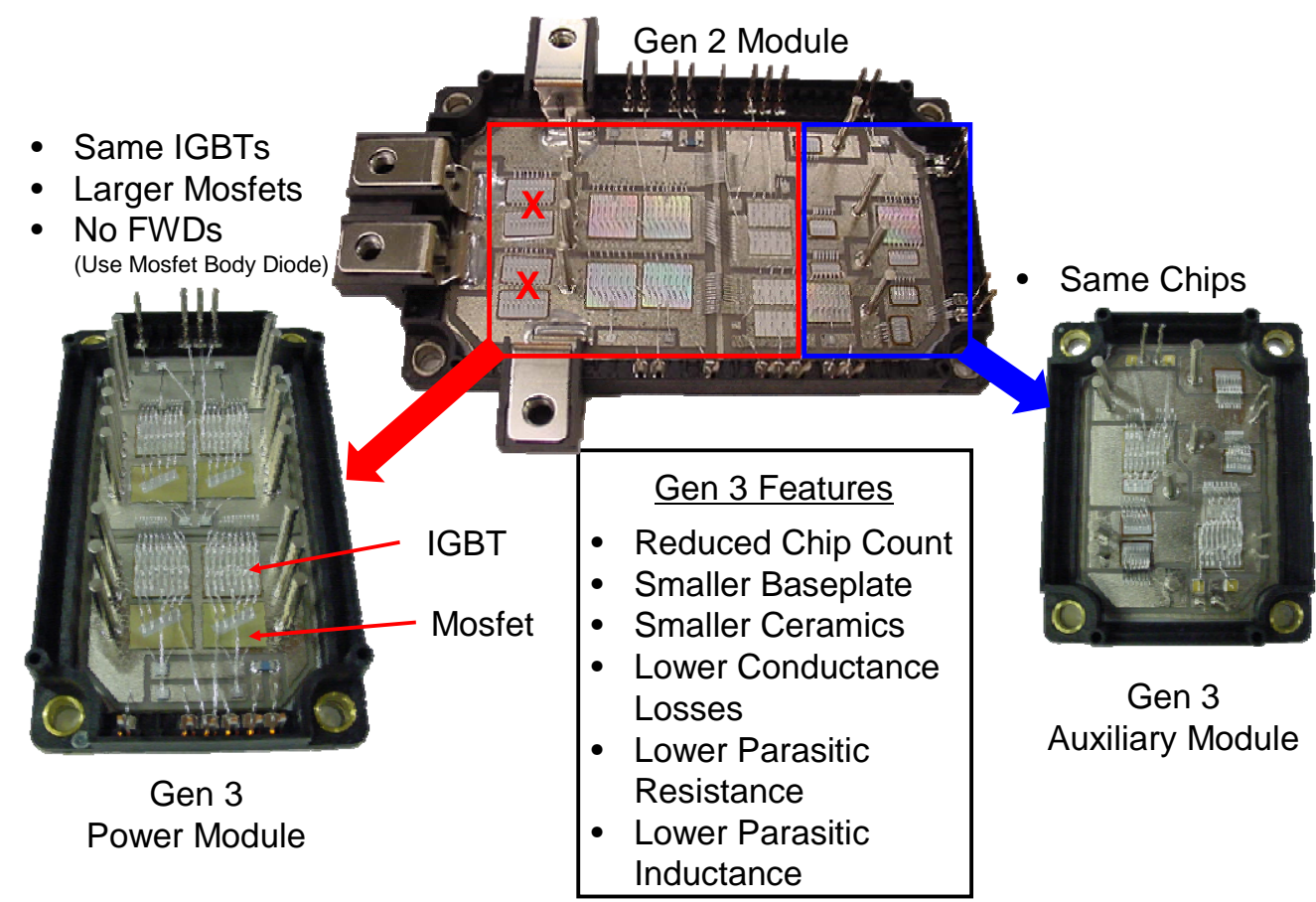

Figure 4.28. Comparison of Gen 2 and Gen 3 modules.

The screw power terminals of the previous generations were replaced by heavy-duty copper posts located adjacent to the IGBT and MOSFET chips as shown in Figure 4.29. The posts are soldered to the power bus PC board located directly above the module. This minimizes both the internal inductance and parasitic resistance of the power stage. The high current connections are made to the auxiliary module in the same manner. The resonant currents during the softswitching periods circulate between the power and auxiliary modules via the power bus PCB.

Even though the Gen-3 MOSFETs are slightly larger in area than the Gen-2 devices, the two designs are sufficiently similar that it was deemed not necessary to perform thermal resistance simulations for this design. 

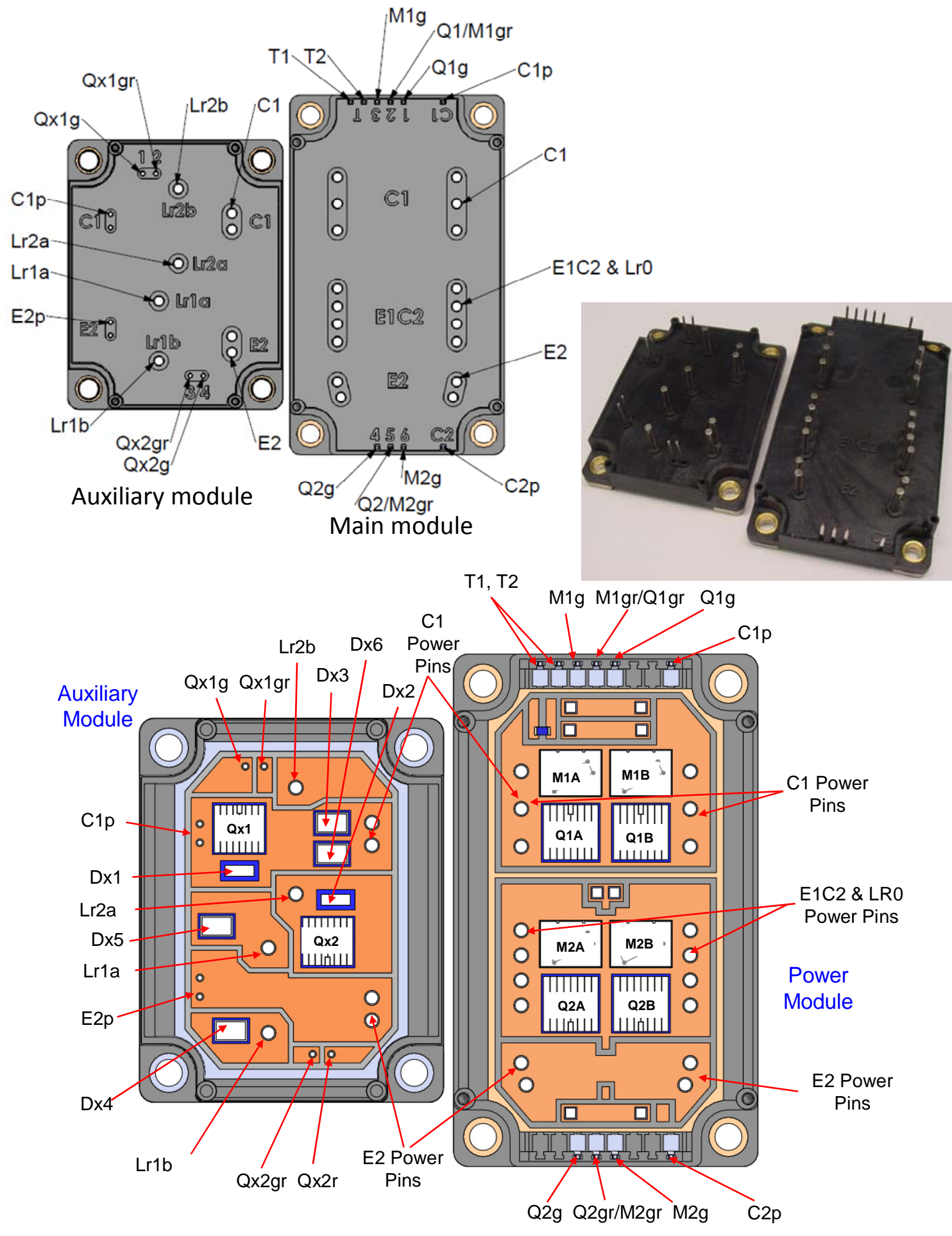

Figure 4.29. Pin locations (top) and chip layout (bottom) for the Gen-3 auxiliary and power modules. 


\section{B. Gen-3 Module Test Results}

The test results for a sample of the power modules shipped to Virginia Tech are listed in Table 4.7. The test results for the auxiliary modules are listed in Table 4.8. The typical voltage drop curves for forward and reverse conduction are plotted as a function of current in Figures 4.30 and 4.31 for the upper and lower power switches, respectively. Independent control of the MOSFET gates permits the MOSFET to be gated on during the reverse recovery transient, thus reducing the losses during that period as shown in Figure 4.32. Finally, the forward voltage drops of the three generations of modules are compared in Figure 4.33. The reduction of the internal parasitic resistance and the use of higher current MOSFETs in the Gen-3 design resulted in significant decreases in the losses at low and high current levels.

Table 4.7. Test results for Gen-3 power modules

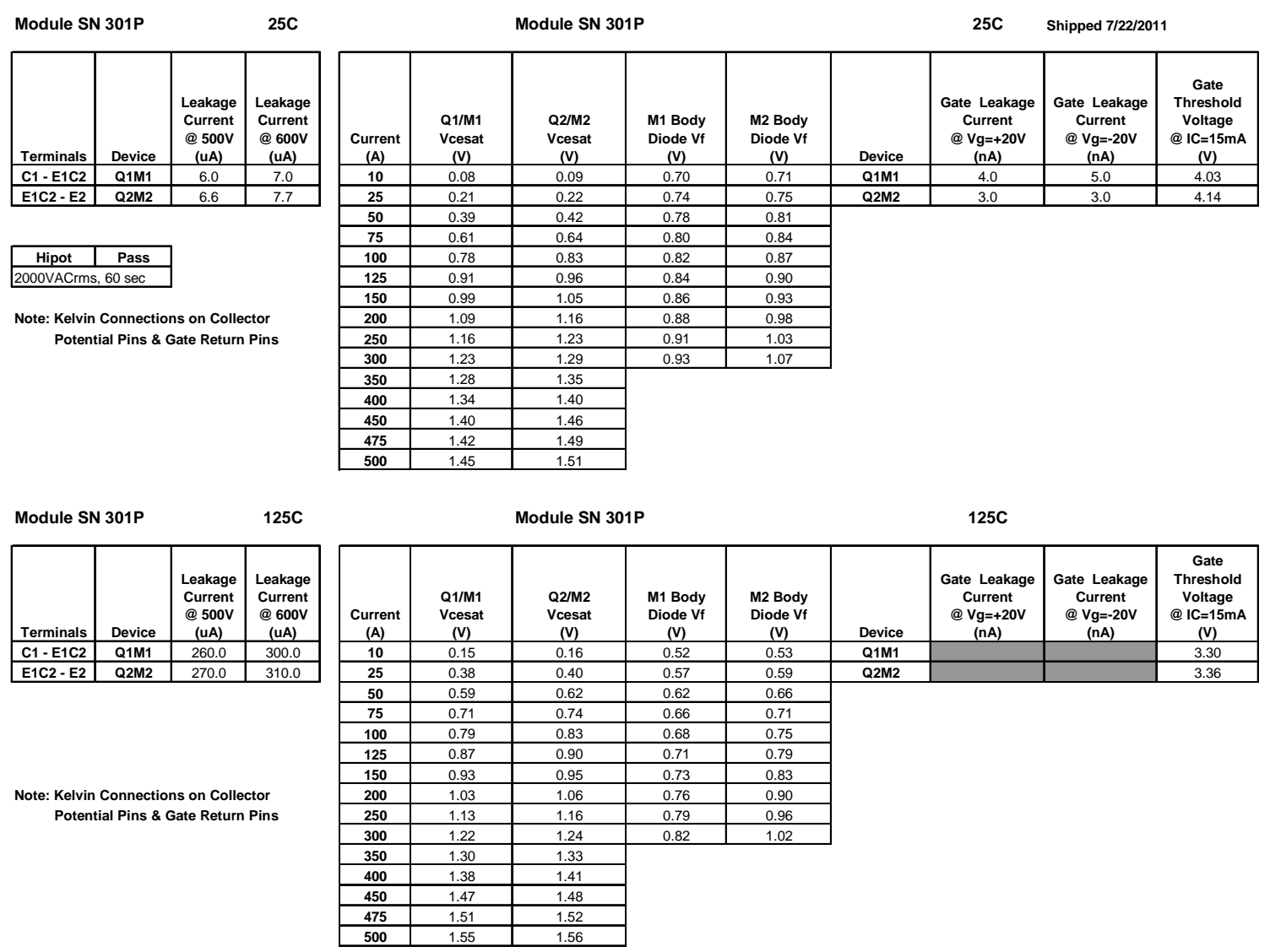




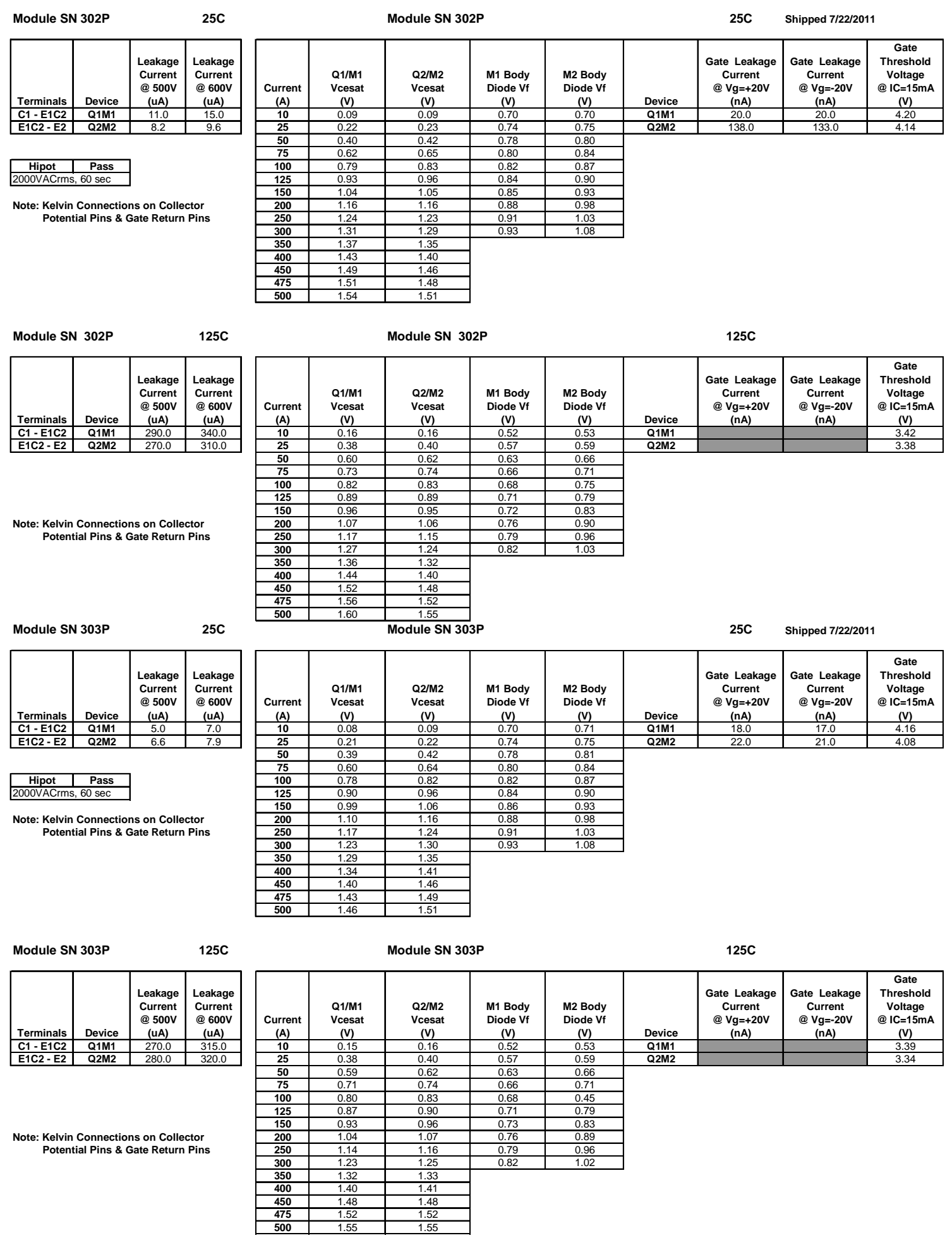


Table 4.8. Test results for Gen-3 auxiliary modules
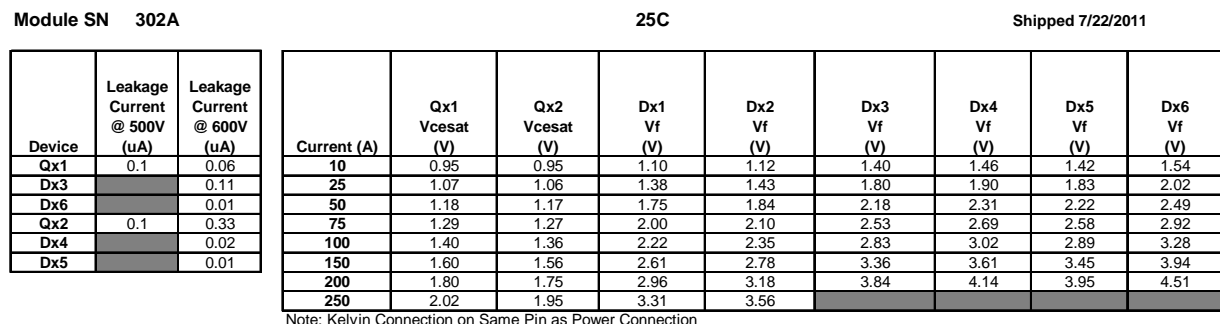

Module SN 302A

$125 \mathrm{C}$
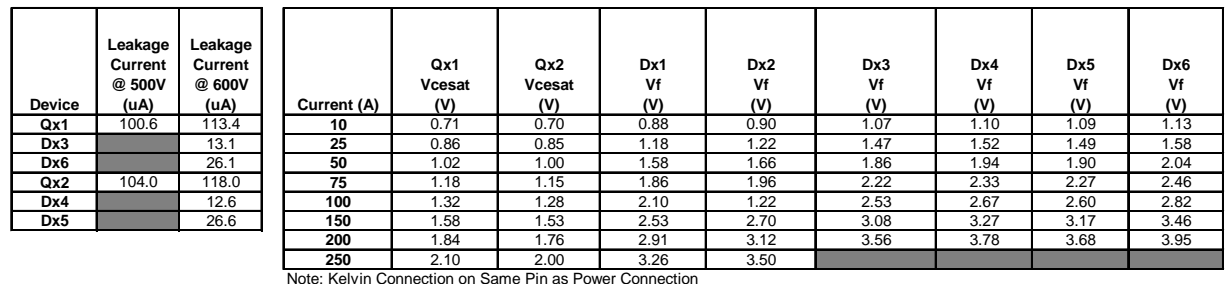

Module SN 303A

Shipped 7/22/2011
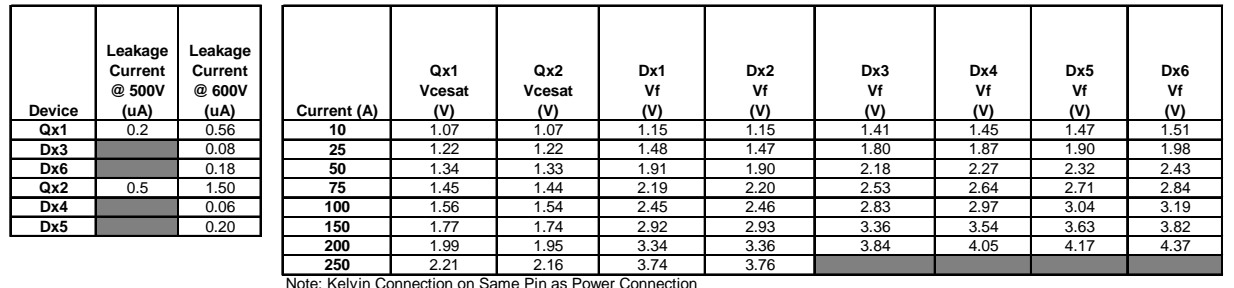

Module SN 303A

$125 \mathrm{C}$
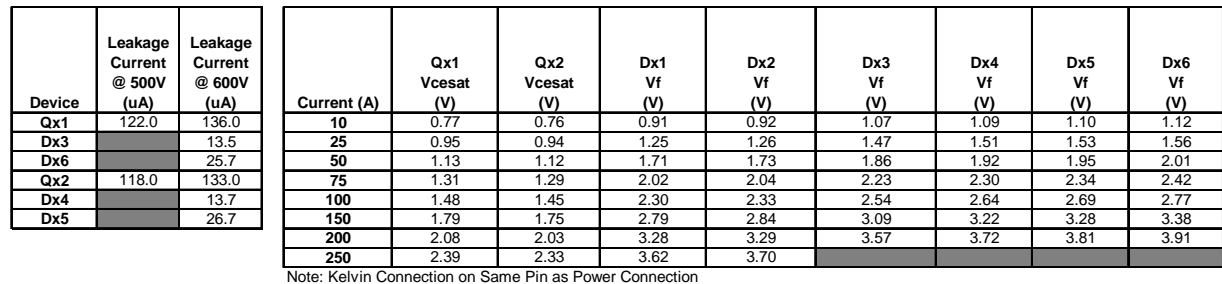

Module SN 305A

$25 \mathrm{C}$

Shipped 7/22/2011
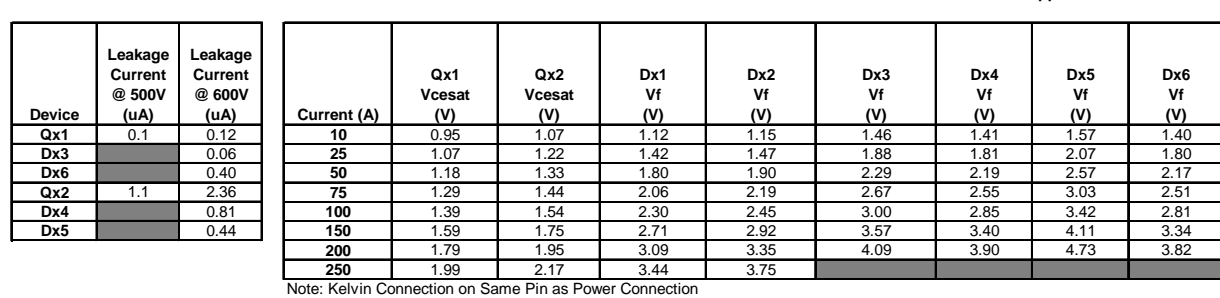

Module SN 305A
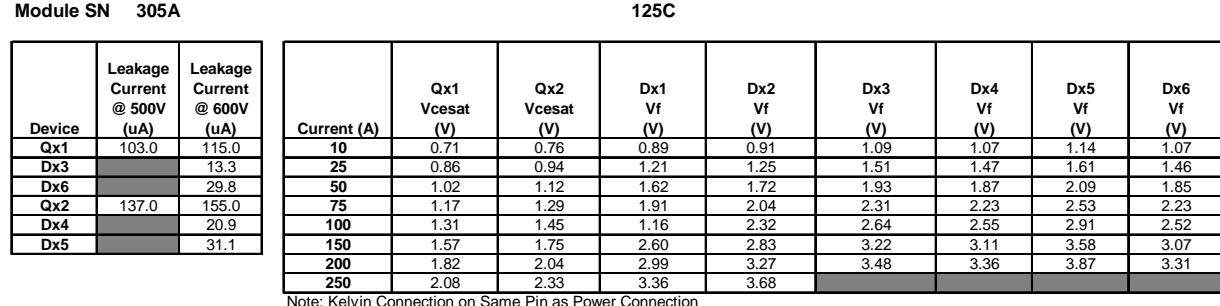


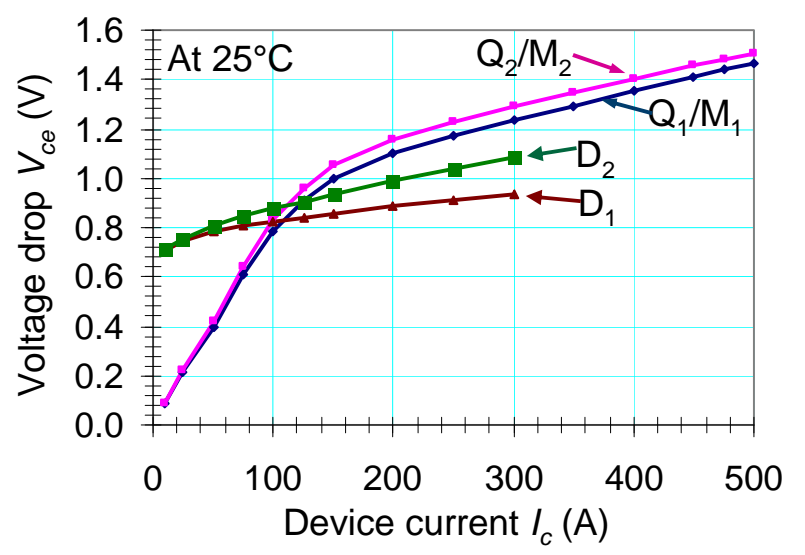

(a)

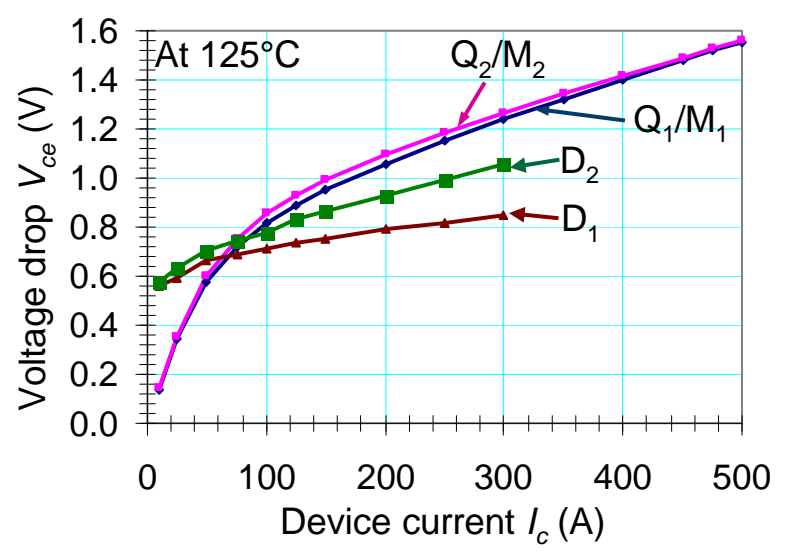

(b)

Figure 4.30. Voltage drop of the upper and lower Gen-3 switches at (a) $T_{j}=25^{\circ} \mathrm{C}$ and (b) $125^{\circ} \mathrm{C}$ as a function of current. Also plotted are the reverse conduction losses of the MOSFET body diodes.

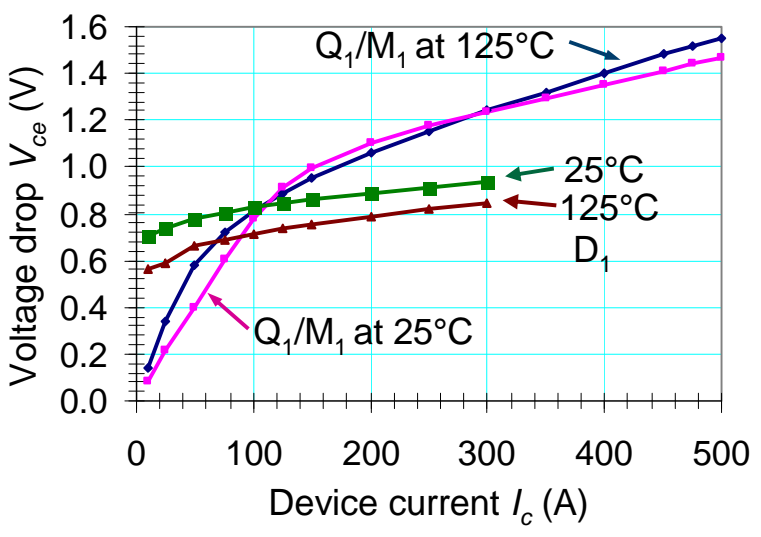

(a)

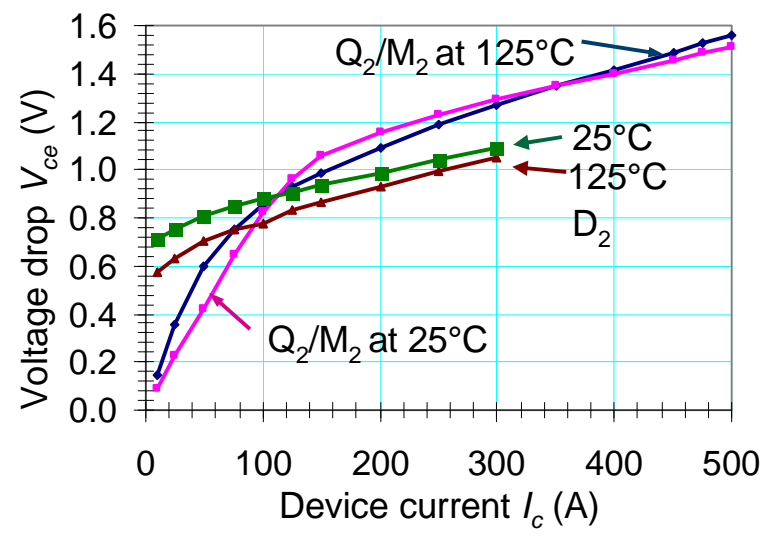

(b)

Figure 4.31. Voltage drop of the (a) upper and (b) lower power switches comparing results at $T_{j}=$ 25 and $125^{\circ} \mathrm{C}$. Also compared are the reverse conduction losses of the MOSFET body diodes.

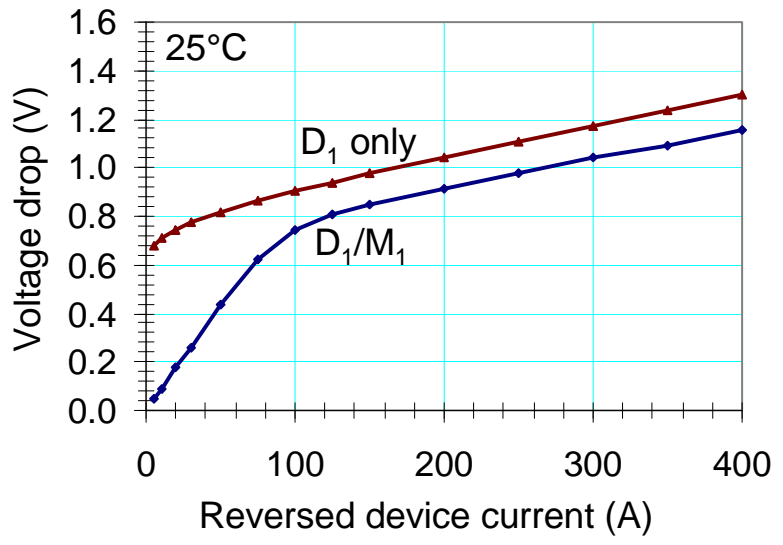

Figure 4.32. Effects of MOSFET channel conduction on the reverse conduction voltage drop comparison between body diode and inclusion of MOSFET channel conduction. 


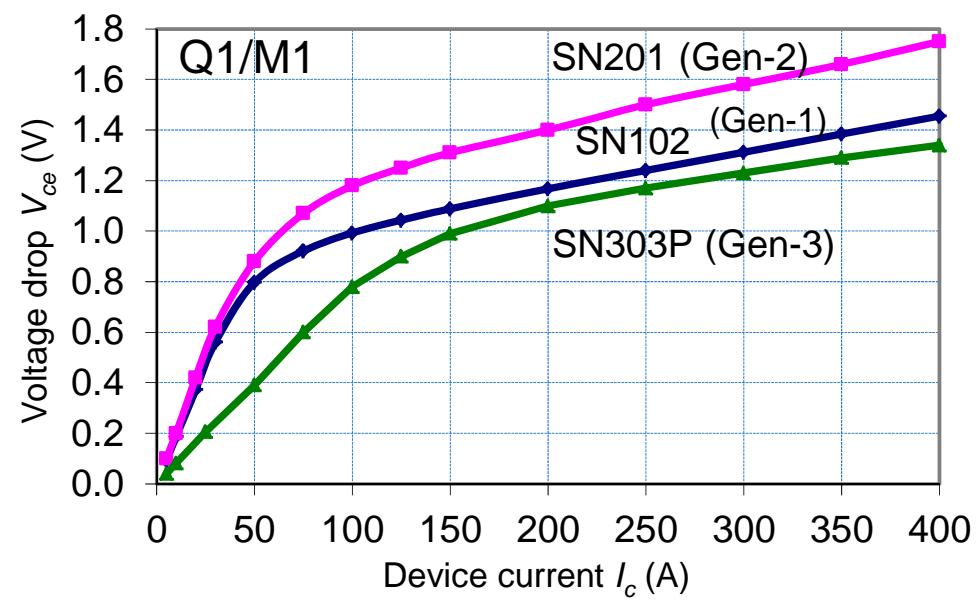

Figure 4.33. Comparison of the forward voltage drops of the three generations of modules. 


\section{EXPERIMENTAL RESULTS SOFT-SWITCHING INVERTER}

\subsection{Gen-1 Soft-Switching Inverter}

\section{A. Soft-Switching Module Conduction Loss Measurement Results}

Table 5.1 shows conduction loss of the main device $Q_{1}-M_{1}$ combination at different temperature conditions. Unlike a conventional IGBT device, which has a fixed voltage drop even at the current near zero, the hybrid switch voltage drop at low currents is proportional to current and at high currents is dominated by the IGBT and increases as the current increases. The rate of increase, however, is much lower than a single IGBT only. It should also be noticed that when the temperature is above $75^{\circ} \mathrm{C}$, the voltage drop at high currents tends to be lower. This is because the selected light-punch-through IGBT has a negative temperature coefficient. The current at which the IGBT dominates the conduction voltage drop is at $50 \mathrm{~A}$, where the conduction voltage drop decreases as the temperature increases from 25 to $125{ }^{\circ} \mathrm{C}$. At currents higher than $300 \mathrm{~A}$, the resistive element of IGBT starts showing effect, and the negative temperature coefficient is no longer monotonic.

Table 5.1. Conduction loss measurement of $Q_{1}-M_{1}$ at different temperature conditions

\begin{tabular}{|c|c|c|c|c|}
\hline Temperature $\left({ }^{\circ} \mathrm{C}\right)$ & 25 & 75 & 100 & 125 \\
\hline Current $(\mathrm{A})$ & $V_{\text {cesat }}(\mathrm{V})$ & $V_{\text {cesat }}(\mathrm{V})$ & $V_{\text {cesat }}(\mathrm{V})$ & $V_{\text {cesat }}(\mathrm{V})$ \\
\hline 10 & 0.186 & 0.282 & 0.330 & 0.375 \\
\hline 50 & 0.798 & 0.775 & 0.735 & 0.688 \\
\hline 100 & 0.992 & 0.933 & 0.893 & 0.844 \\
\hline 150 & 1.088 & 1.050 & 1.013 & 0.967 \\
\hline 200 & 1.168 & 1.151 & 1.118 & 1.077 \\
\hline 250 & 1.240 & 1.240 & 1.218 & 1.177 \\
\hline 300 & 1.312 & 1.331 & 1.311 & 1.277 \\
\hline 350 & 1.384 & 1.416 & 1.403 & 1.371 \\
\hline 400 & 1.455 & 1.503 & 1.494 & 1.467 \\
\hline
\end{tabular}

Figure 5.1 compares the conduction voltage drop between the novel hybrid module and a commercial one. As can be seen, at high temperature $125^{\circ} \mathrm{C}$ and high current $400 \mathrm{~A}$, the voltage drop of the hybrid module is $1.46 \mathrm{~V}$ compared to $1.67 \mathrm{~V}$ of the commercial one, which indicates a loss reduction of $14 \%$.

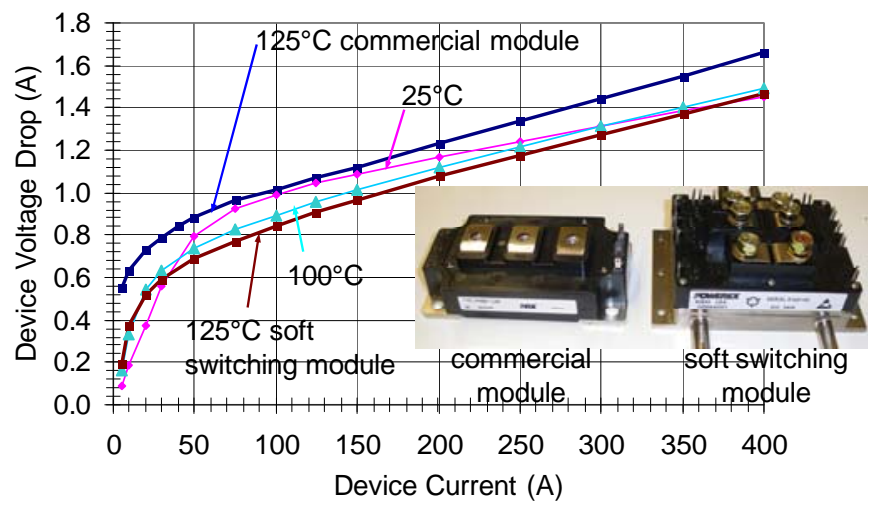

Figure 5.1. Conduction I-V curve comparison between designed module and commercial module. 


\section{B. Soft-Switching Module Switching Loss Measurement Results}

In order to compare switching losses as a function of temperature, we performed tests at several different coolant temperatures. In each temperature condition, the switching loss was analyzed at the following current conditions: 50 A, 100 A, 150 A, 200 A, 250 A and 280 A. Figure 5.2 shows the switching-on waveforms with $0.1-\mu \mathrm{F}$ resonant capacitor at 200-A load current under $25^{\circ} \mathrm{C}$ and $90^{\circ} \mathrm{C}$ conditions. For both temperatures, the bus voltage drops to zero first, and then the current rises up. There is no overlap between voltage and current for all load current and temperature cases. In addition, the bus voltage never swings back after reaching zero. So the switching-on energy is essentially zero for all test conditions.

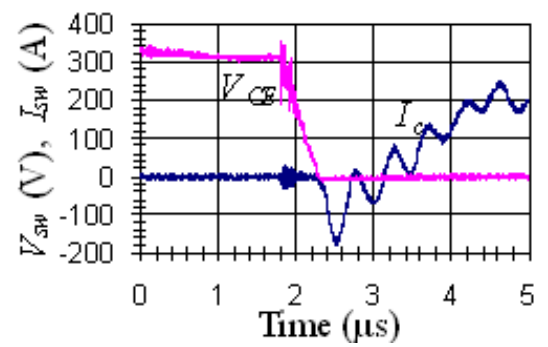

(a)

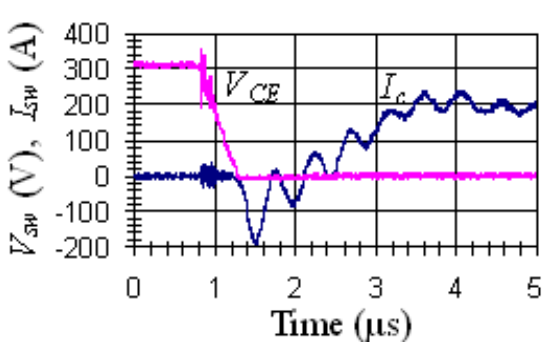

(b)

Figure 5.2. Switching-on waveforms with $0.1-\mu \mathrm{F}$ resonant capacitance at: (a) $25^{\circ} \mathrm{C}$ and (b) $90^{\circ} \mathrm{C}$.

Note that there is a significant ringing at the beginning of the falling edge of the device voltage. This is because the parasitic inductance inside the module rings with the resonant capacitors when the opposite side diode current is cut off and the diode goes through the reverse recovery process. The snappiness of the CoolMOS body diode worsens the parasitic ringing dramatically. This ringing did not occur in the scaled-down version because a larger resonant inductance was used and the slope of the reverse recovery was not as steep. The solutions to alleviating this parasitic ringing are: (1) further increase resonant inductance, (2) reduce the parasitic inductance in the module to nearly zero, and (3) use a lower voltage drop, but softer recovery diode that would prevent the CoolMOS body diode from conducting. The first method of increasing the resonant inductance has a limit because it will increase the resonant period and thus lengthen the short-pulse elimination period. The second method requires a new module layout that allows the resonant capacitor to sit directly over the chip, reducing the parasitic inductance. It has certain degree of difficulty, but is possible to improve the situation. The third method is ultimately the best solution because it will also allow the main device freewheeling current to go through a diode with a larger die size to ensure proper cooling.

Figure 5.3 shows the detailed switching-off waveforms and energy with $0.1-\mu \mathrm{F}$ resonant capacitor at 200-A load current under different temperatures. The switching-off energy increases as the temperature increases. At $25^{\circ} \mathrm{C}$, the switching-off energy, $E_{\text {off }}$ is $1.6 \mathrm{~mJ}$, and it increases to $3.6 \mathrm{~mJ}$ at $90^{\circ} \mathrm{C}$. The voltage and current waveforms look similar under the two temperature conditions. The turn-off voltage slew rate $(\mathrm{d} v / \mathrm{d} t)$ is a function of the resonant capacitance. In this specific case, with $0.1-\mu \mathrm{F}$ resonant capacitor, the measured $\mathrm{d} v / \mathrm{d} t$ at $200 \mathrm{~A}$ current is about 1000 $\mathrm{V} / \mu \mathrm{s}$ and is consistent with the theoretical derivation, which can be simply obtained from $I /\left(2 C_{r}\right)$. A larger capacitor will further reduce $\mathrm{d} v / \mathrm{d} t$ and switching-off energy, and vice versa. The change 
of temperature, however, will not affect $\mathrm{d} v / \mathrm{d} t$, but will impact the switching energy, as will be explained in the following discussions.

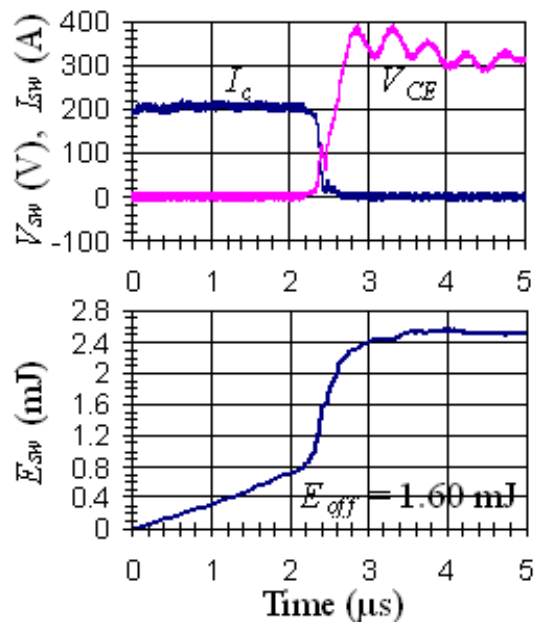

(a)

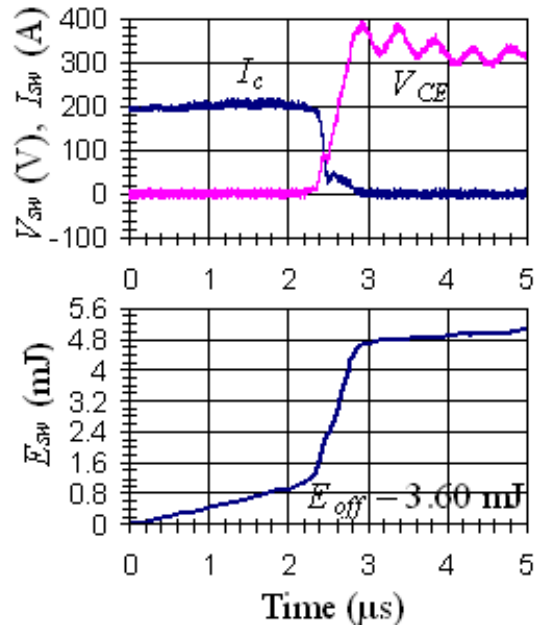

(b)

Figure 5.3. Switching-off waveforms with $0.1-\mu \mathrm{F}$ resonant capacitance at different temperature conditions: (a) $25^{\circ} \mathrm{C}$ and (b) $90^{\circ} \mathrm{C}$.

Figure 5.4 plots the switching energy as a function of device current and compares the results at $25^{\circ} \mathrm{C}, 50^{\circ} \mathrm{C}$, and $90^{\circ} \mathrm{C}$ temperature conditions with $0.1-\mu \mathrm{F}$ resonant capacitance. All the dots were directly from the measurement. The smooth curves were curve-fitted to the following format.

$$
\begin{aligned}
& E_{o n}=h I^{k} \\
& E_{o f f}=m I^{k}
\end{aligned}
$$

Since switching-on energy is zero for all temperature cases, $h$ and $k$ are all zero here. Switchingoff energy increases with temperature rise. The $\mathrm{m}$ and $\mathrm{k}$ parameters are found as follows.

$$
\text { At } 25^{\circ} \mathrm{C}, h=0.000061, k=1.9522
$$

At $50^{\circ} \mathrm{C}, h=0.000204, k=1.777$

At $90^{\circ} \mathrm{C}, h=0.000777, k=1.60$

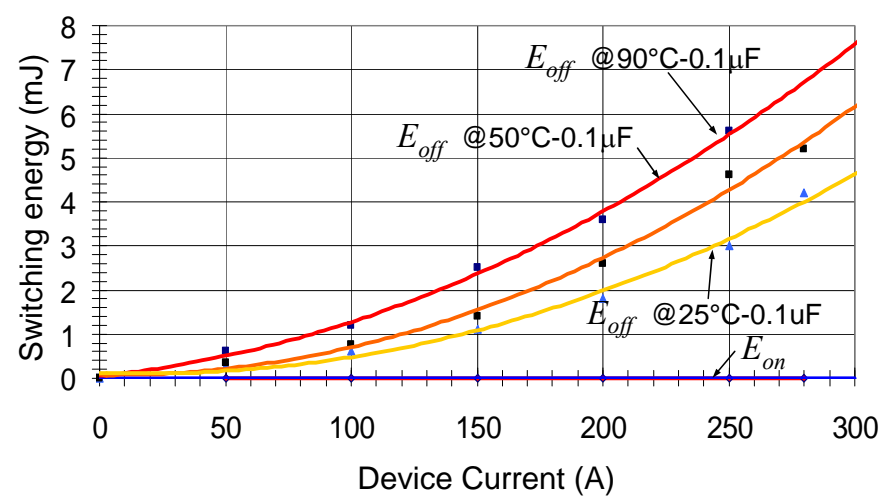

Figure 5.4. Switching energy with $0.1 \mu \mathrm{F}$ resonant capacitance at different temperatures. 


\section{Inverter Power Loss Measurement and Efficiency Prediction Results}

Figure 5.5 shows the power loss as a function of the output kVA under different line frequencies and different temperatures: (a) $25^{\circ} \mathrm{C}$ and (b) $90^{\circ} \mathrm{C}$. The figures clearly indicate that the higher line frequency, which represents higher motor speed, the lower power loss. The reason is the voltage level, and thus the power factor, is higher at a higher line frequency. To achieve the same $\mathrm{kVA}$, the case with higher frequency requires less current or produces less power loss.

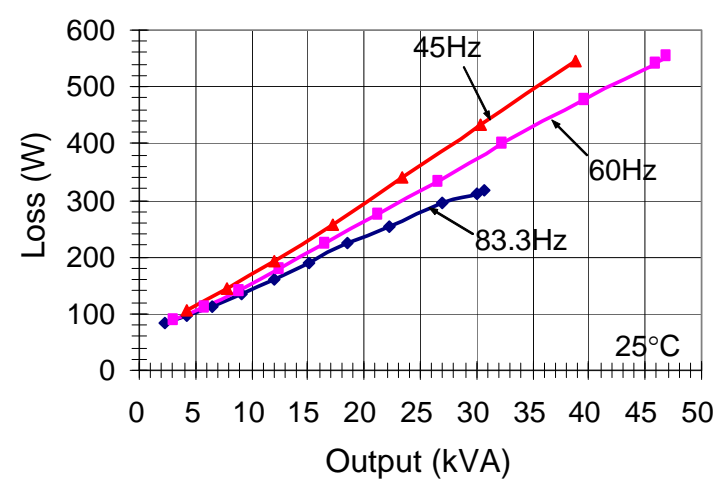

(a)

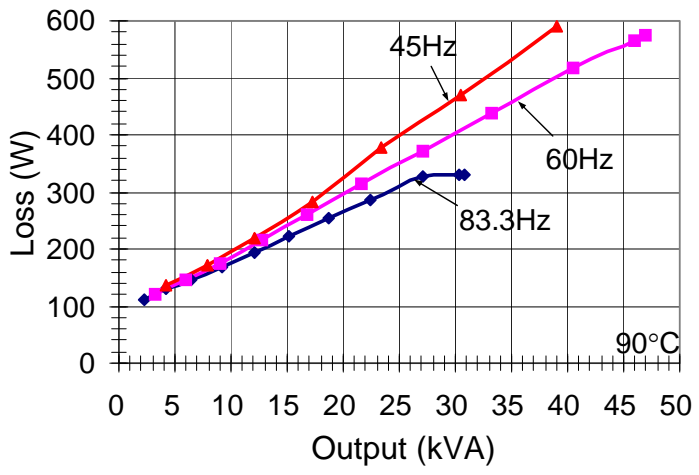

(b)

Figure 5.5. Power loss as a function of the output $\mathrm{kVA}$ under different line frequencies and different temperatures: (a) $25^{\circ} \mathrm{C}$ and (b) $90^{\circ} \mathrm{C}$.

Figure 5.6 shows the power loss as a function of the output kVA under different temperatures and different line frequencies: (a) $45 \mathrm{~Hz}$ and (b) $83.3 \mathrm{~Hz}$. The general trend is the higher temperature, the higher power loss. This indicates that the turn-off loss increases more than the conduction loss decreases. At higher frequency cases, when the modulation index saturates, the loss tends to flatten out, especially at high temperatures, and the loss is less impacted by the temperature. This is because the switching loss is no longer dominating.

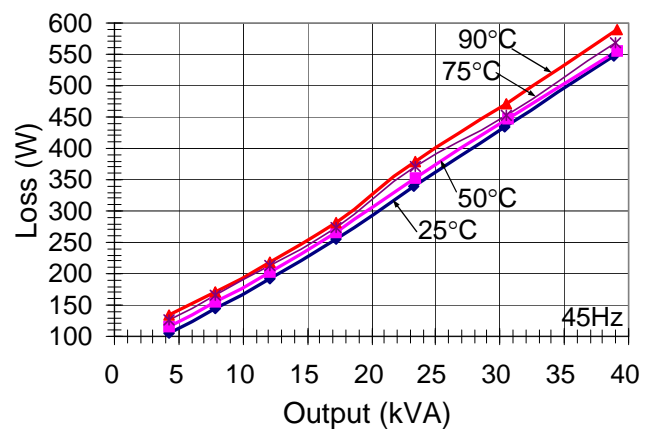

(a)

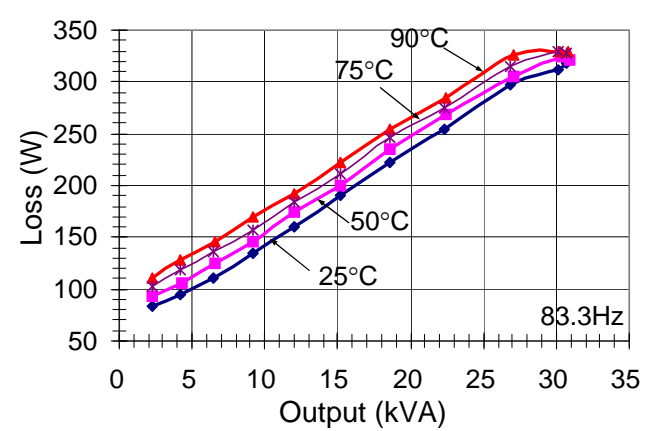

(b)

Figure 5.6. shows the power loss as a function of the output kVA under different temperatures and different line frequencies: (a) $45 \mathrm{~Hz}$ and (c) $83.3 \mathrm{~Hz}$.

Figure 5.7 shows the projected efficiency based on the inductive load measured loss results at 83.3-Hz output line frequency at different temperatures. The power factor is assumed to be unity in this case. It is noted that at the light load condition, the efficiency decrease with increasing temperature is more obvious than that at the heavy load condition. The reason is that at light loads, the MOSFET shares more current, and with a positive temperature coefficient of the $R_{d s-o n}$, the efficiency suffers. However, at heavy loads, the LPT IGBT shares more current, and with the 
negative temperature coefficient, the decrease in efficiency with temperature is not as severe. The peak efficiency approaches $99 \%$.

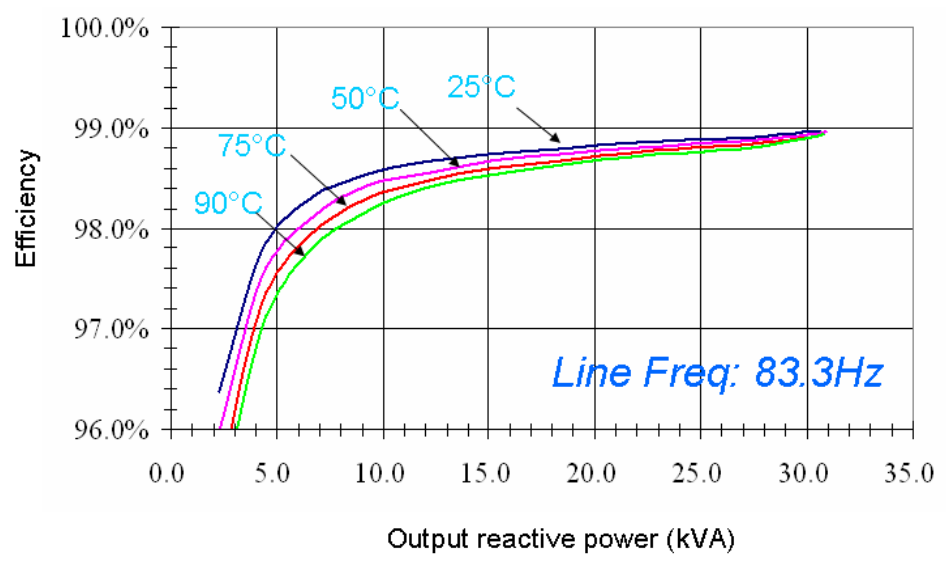

Figure 5.7. Efficiency measurement at $83.3-\mathrm{Hz}$ line frequency and different temperatures.

To compare the efficiency as a function of frequency, the above results are rearranged to compare the projected efficiency at different frequencies under the same temperature condition. Figure 5.8 shows the projected efficiencies for different output line frequencies at $90^{\circ} \mathrm{C}$. The power factor in this case is assumed to be 0.83 , which is the same as what has been tested for the motor drive cases. As can be seen, at the same output power point, the efficiency is higher at a higher output line frequency. That can be translated into higher speed with higher efficiency, which was proven by later motor tests.

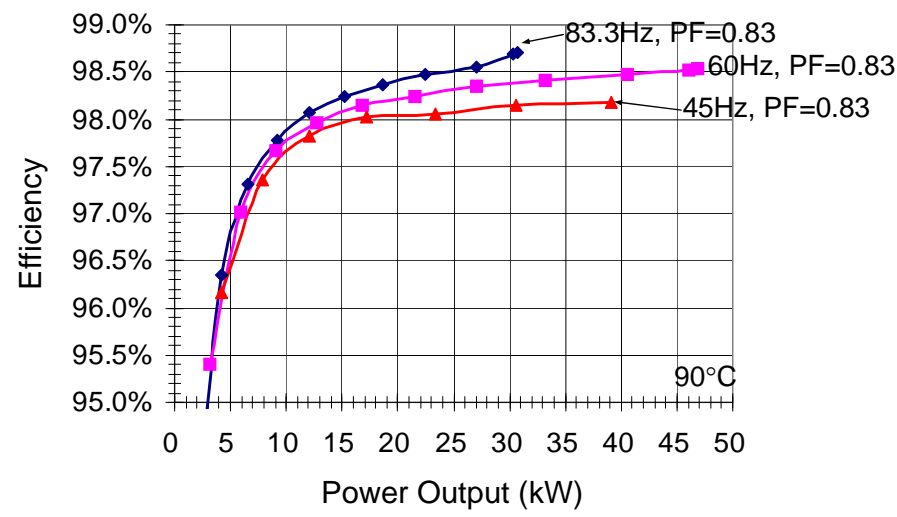

Figure 5.8. Efficiency comparison at $90^{\circ} \mathrm{C}$ and different line frequency conditions.

\section{Inverter Efficiency Test under Motor Load Condition}

The motor test setup is the same as that of inductive load except that the load is a motordynamometer. We tested the motor at different speed conditions, 1000rpm, 1500rpm and $2000 \mathrm{rpm}$ with different output current values, 30A, 40A and 50A at different temperatures, $25^{\circ} \mathrm{C}, 50^{\circ} \mathrm{C}$ and $75^{\circ} \mathrm{C}$. The dynamometer was adjusted to provide the load torque according to motor output current and speed conditions. 
Table 5.2 shows the tested inverter efficiency at different speeds and different output currents at different temperatures reflected to power factor 0.83 . Due to the limited power supply capacity in the lab, we can only test lower power regions. The high power test will be conducted in the next performance period at Azure Dynamics. As can be seen from Table 5.2, at lower output power, the low-temperature efficiency is slightly higher than the high-temperature one. At higher output power, the high-temperature efficiency catches up and may surpass low temperature one. At higher motor speed and thus higher output frequency, the inverter efficiency is higher than lower speed conditions.

Table 5.2. Efficiency measurement with motor test at different temperatures.

\begin{tabular}{|l|r|l|r|l|l|l|}
\hline 1000rpm $(33.3 \mathrm{~Hz})$ & \multicolumn{2}{|c|}{$75^{\circ} \mathrm{C}$} & \multicolumn{2}{c|}{$50^{\circ} \mathrm{C}$} & \multicolumn{2}{c|}{$25^{\circ} \mathrm{C}$} \\
\hline $30 \mathrm{~A}$ & $98.1 \%$ & $9.8 \mathrm{kVA}$ & $98.2 \%$ & $9.8 \mathrm{kVA}$ & $98.3 \%$ & $9.7 \mathrm{kVA}$ \\
\hline $40 \mathrm{~A}$ & $98.2 \%$ & $14.0 \mathrm{kVA}$ & $98.3 \%$ & $14.0 \mathrm{kVA}$ & $98.4 \%$ & $14.0 \mathrm{kVA}$ \\
\hline $50 \mathrm{~A}$ & $98.3 \%$ & $18.3 \mathrm{kVA}$ & $98.3 \%$ & $18.3 \mathrm{kVA}$ & $98.4 \%$ & $18.3 \mathrm{kVA}$ \\
\hline
\end{tabular}

\begin{tabular}{|l|r|l|r|l|l|l|}
\hline $1500 \mathrm{rpm}(50 \mathrm{~Hz})$ & \multicolumn{2}{|c|}{$75^{\circ} \mathrm{C}$} & \multicolumn{2}{c|}{$50^{\circ} \mathrm{C}$} & \multicolumn{2}{c|}{$25^{\circ} \mathrm{C}$} \\
\hline $30 \mathrm{~A}$ & $98.3 \%$ & $12.1 \mathrm{kVA}$ & $98.5 \%$ & $12.1 \mathrm{kVA}$ & $98.6 \%$ & $12.2 \mathrm{kVA}$ \\
\hline $40 \mathrm{~A}$ & $98.6 \%$ & $17.4 \mathrm{kVA}$ & $98.6 \%$ & $17.4 \mathrm{kVA}$ & $98.7 \%$ & $17.4 \mathrm{kVA}$ \\
\hline
\end{tabular}

\begin{tabular}{|l|c|l|c|l|l|l|}
\hline $2000 \mathrm{rpm}(66.6 \mathrm{~Hz})$ & \multicolumn{2}{|c|}{$75^{\circ} \mathrm{C}$} & \multicolumn{2}{|c|}{$50^{\circ} \mathrm{C}$} & \multicolumn{2}{c|}{$25^{\circ} \mathrm{C}$} \\
\hline $30 \mathrm{~A}$ & $98.8 \%$ & $13.7 \mathrm{kVA}$ & $98.9 \%$ & $13.7 \mathrm{kVA}$ & $98.9 \%$ & $13.7 \mathrm{kVA}$ \\
\hline
\end{tabular}

Figure 5.9 shows the efficiency profile of the soft-switching inverter under motor-dynamometer test at $25^{\circ} \mathrm{C}$ coolant condition. The motor was tested with different modulation indexes until the power supply reached its limit. For this plot, the measurements at 0.4 power factor were used to project the efficiency at 0.83 power factor. The measurement results show a consistent trend that the higher power factor, the higher efficiency and the higher speed, the higher efficiency. At higher speeds, the motor terminal voltage is also higher, and for the same current, the loss is less. The efficiency profile shows the inverter efficiency is close to $99 \%$ even when the speed is still below its nominal $2500 \mathrm{rpm}$. This projected result is consistent with what has been tested using the calorimeter at $2800 \mathrm{rpm}$, at which the efficiency is $99.1 \%$.

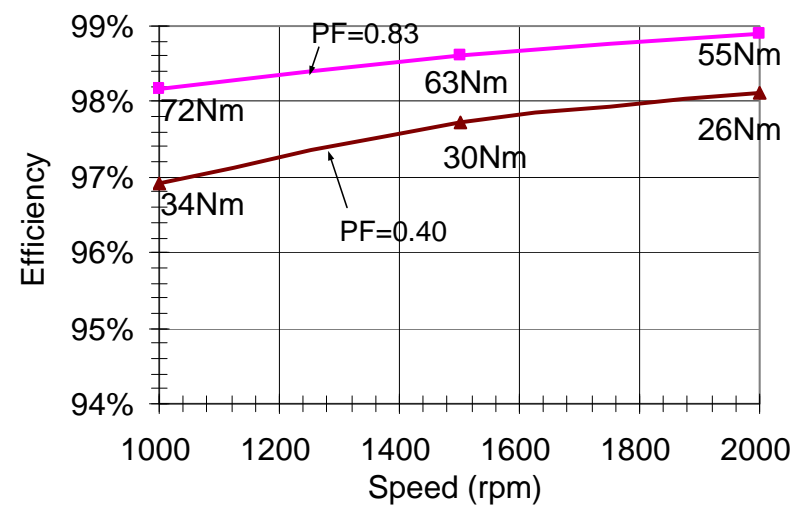

Figure 5.9. Efficiency profile of the soft-switching inverter under motor-dynamometer test. 
Table 5.3 shows the efficiency comparison between inductive load test and motor test. The efficiency with inductive load is projected from a power factor of 0.83 . At the same output power, the motor test efficiency is higher than the pure inductive load test efficiency. The reason is during motor-dynamometer test, the current is mainly conducting through MOSFET and IGBT channels, while in inductive load test, the duty cycle of the anti-parallel diodes increases, and the efficiency suffers slightly. Previous inductive load tests show that at $83.3 \mathrm{~Hz}(30.6 \mathrm{kVA})$, the efficiency is $98.8 \%$; and at $60 \mathrm{~Hz}(46.8 \mathrm{kVA})$, the efficiency is $98.6 \%$. Therefore, the peak efficiency at higher motor load can be expected to exceed $99 \%$.

The above measurement using our power meter becomes inaccurate when the power is further increased because the instrumentation is not well calibrated at these higher power levels. Table 5.4 lists the power meter readings at 30 -minute intervals for the $27-\mathrm{kW}, 1600$-rpm machine output condition. Such a low-speed machine tends to draw larger current than the same power level case with a high-speed machine. In Table 4, the inverter efficiency reading at 4:00pm was exceeding $100 \%$. This clearly indicates that power meter reading is inaccurate and should not be used for the efficiency index. Its voltage and current readings, however, can be used as the reference for the power level.

Table 5.3. Efficiency comparison between inductive load and motor test at different temperatures.

\begin{tabular}{|l|c|l|r|r|r|r|}
\hline & \multicolumn{2}{|c|}{$75^{\circ} \mathrm{C}$} & \multicolumn{2}{c|}{$50^{\circ} \mathrm{C}$} & \multicolumn{2}{c|}{$25^{\circ} \mathrm{C}$} \\
\hline $50 \mathrm{~Hz}$ /motor & $98.3 \%$ & $12.1 \mathrm{kVA}$ & $98.5 \%$ & $12.1 \mathrm{kVA}$ & $98.6 \%$ & $12.2 \mathrm{kVA}$ \\
\hline 45Hz/inductor & $97.9 \%$ & $12.1 \mathrm{kVA}$ & $98.0 \%$ & $12.1 \mathrm{kVA}$ & $98.1 \%$ & $12.1 \mathrm{kVA}$ \\
\hline
\end{tabular}

\begin{tabular}{|l|r|l|r|r|r|r|}
\hline & \multicolumn{2}{|c|}{$75^{\circ} \mathrm{C}$} & \multicolumn{2}{c|}{$50^{\circ} \mathrm{C}$} & \multicolumn{2}{c|}{$25^{\circ} \mathrm{C}$} \\
\hline $66.6 \mathrm{~Hz}$ /motor & $98.8 \%$ & $13.7 \mathrm{kVA}$ & $98.9 \%$ & $13.7 \mathrm{kVA}$ & $98.9 \%$ & $13.7 \mathrm{kVA}$ \\
\hline $60 \mathrm{~Hz}$ /inductor & $98.1 \%$ & $13.7 \mathrm{kVA}$ & $98.2 \%$ & $13.7 \mathrm{kVA}$ & $98.3 \%$ & $13.7 \mathrm{kVA}$ \\
\hline
\end{tabular}

Table 5.4. Readings from power meter at $1600 \mathrm{rpm}, 27 \mathrm{~kW}$ condition

\begin{tabular}{|c|c|c|c|c|c|c|c|c|}
\hline Time & $V_{d c}(\mathrm{~V})$ & $I_{d c}(\mathrm{~A})$ & $P_{i n v}(\mathrm{~kW})$ & $I_{a}(\mathrm{~A})$ & $I_{b}(\mathrm{~A})$ & $I_{c}(\mathrm{~A})$ & $P_{i n v}(\mathrm{~kW})$ & $\eta_{i n v}$ \\
\hline $3: 00 \mathrm{pm}$ & 324 & 84.92 & 27.54 & 91.00 & 90.80 & 90.50 & 26.85 & $97.5 \%$ \\
\hline $3: 30 \mathrm{pm}$ & 325 & 83.55 & 27.12 & 91.00 & 90.00 & 90.00 & 26.55 & $97.9 \%$ \\
\hline $4: 00 \mathrm{pm}$ & 322 & 82.90 & 26.69 & 89.70 & 89.50 & 89.10 & 26.90 & $100.8 \%$ \\
\hline
\end{tabular}

\section{E. Inverter Efficiency Test with Calibrated Calorimeter}

To more accurately measure efficiency, a differential calorimeter has been constructed and calibrated. Figure 5.10 shows photographs of the differential calorimeter setup. Figure 5.10(a) shows the small reference chamber in foreground and the main chamber partially open in the back. Figure 5.10(b) shows the main chamber with the cover removed to see the coolant inlet and outlet. The DC bus and AC output cables passing through the chamber wall can also be seen. A stirring fan, seen at the top of the picture, is to ensure uniform temperature distribution inside the chamber. 


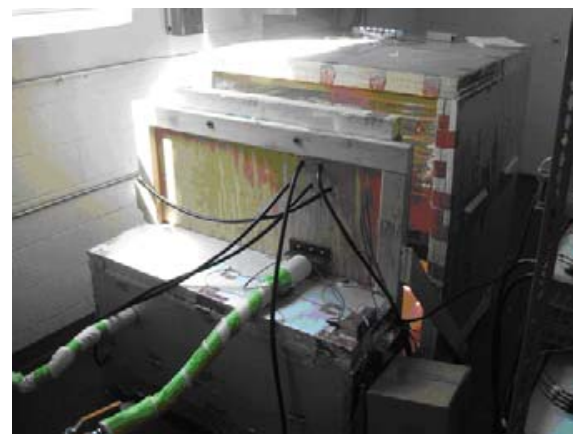

(a)

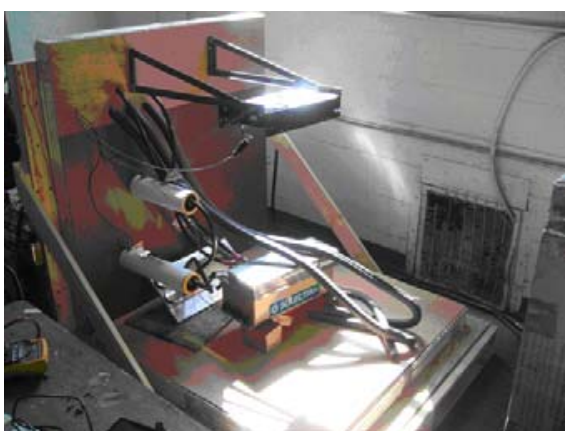

(b)

Figure 5.10. Photographs showing (a) differential-chamber based calorimeter with flow meter box in foreground and inverter chamber partially open in back; (b) main chamber cover removed for the view of coolant inlet and outlet.

The calorimeter test was performed for more than five hours to ensure that the thermal condition reached its steady state for each test point. Figure 5.11 shows the coolant temperatures and the measured inverter efficiency at $27 \mathrm{~kW}$. Different speeds tend to have different power factor were tested. The test was conducted with an MG set with machine rated $90 \mathrm{~kW}$ and $1600 \mathrm{rpm}$. The test was conducted at a higher power output, $27 \mathrm{~kW}$, which is about $50 \%$ of the peak power. The power factor is 0.78 , and the steady-state efficiency is $98.8 \%$.

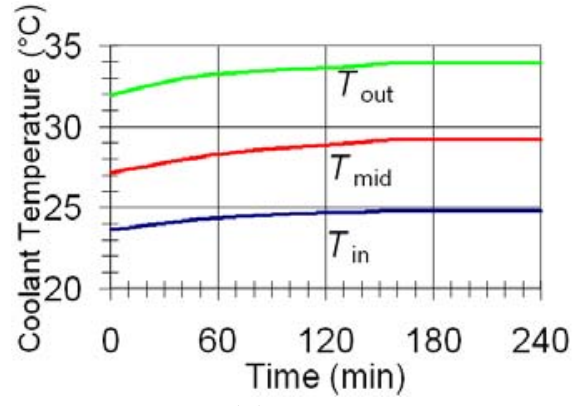

(a)

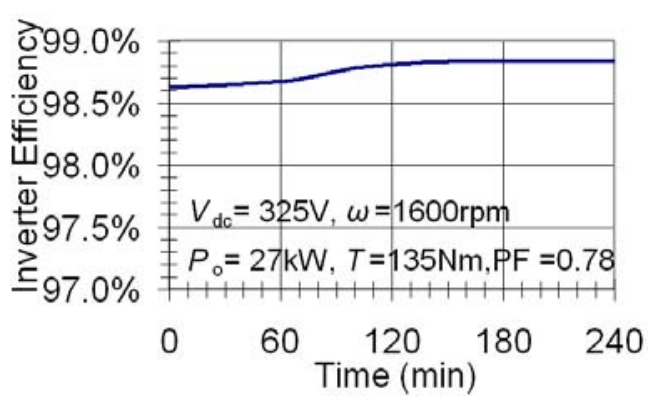

(b)

Figure 5.11. Calorimeter measurement at 27kW: (a) coolant temperatures, (b) inverter efficiency.

\section{F. Improve Design with Failure Mode Effect Analysis}

The Failure Mode Effects Analysis (FMEA) is a tool commonly used by the automotive industry but was developed from techniques started in the high reliability aerospace area. Its purpose is to identify potential problems and to insure that adequate consideration has been given to each. The possible consequences of a failure are identified and severity rankings are given to each issue. Our goal was to complete a quick FMEA on the power stage alone. A production design would have each piece of the overall system analyzed in detail, but in the interest of getting useful feedback while still in the design phase only the aspects of the inverter that would not be present in a conventional six-switch setup were analyzed. The following analysis shows the currents and voltages for a successful and two failed commutations. The failed commutations can be categorized in to two cases.

1. $Q_{x 1}$ opening after $D_{2}$ stops conduction, when the resonant current has reached its peak.

2. $Q_{x 1}$ opening before $D_{2}$ stops conduction, i.e. during the linear phase of the resonant current ramp-up. 
Case 1 results in the worst-case peak current for $D_{x 5}$, however the current decays quickly. Case 2 is different. The worst-case diode current is not as high as for case 1, however, the current decays very slowly (as the voltage across the coupled inductor is zero). This suggests that $D_{x 5}$ and $D_{x 6}$ cannot be 5-A diodes and possibly not even 50-A. Figure 5.12 shows the simulation diagram using MicroCap Ver. 9.

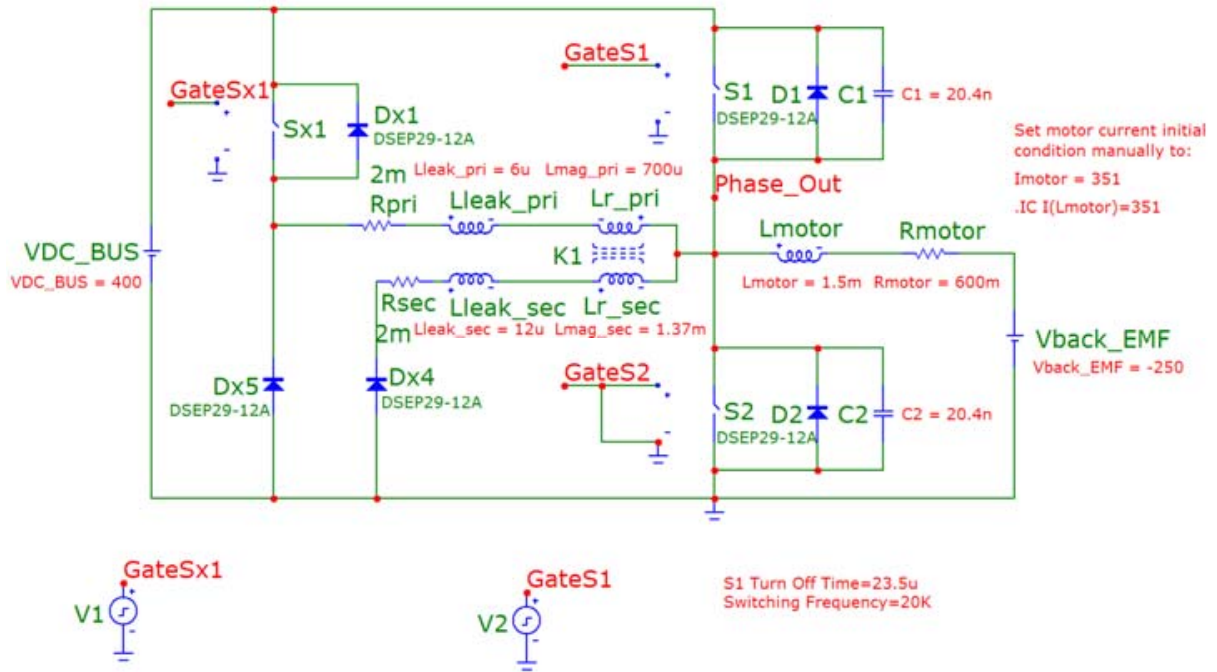

Figure 5.12. Simulation diagram using MicroCap.

Figure 5.13 shows the simulated resonant inductor voltage and current waveforms under normal operation. The top two traces are the gate signals for main $\left(V_{\text {GATESI }}\right)$ and auxiliary $\left(V_{\text {GATESXI }}\right)$ switches. The middle five traces are the motor line current $\left(I_{L M O T O R}\right)$, the primary side resonant inductor current $\left(I_{L E A K_{-} P R I}\right)$, the secondary side resonant inductor current $\left(I_{L L E A K_{-} S E C}\right)$, the clamping diode current $\left(I_{D x 5}\right)$, and the total resonant current $\left(I_{L E A K_{-} P R I}+I_{L L E A K_{-} S E C}\right)$. The bottom two traces are output phase voltage ( $\left.V_{P H A S E} O U T\right)$ and the voltage across the secondary side of the resonant inductor $\left(V_{\text {LLEAK_sec }}+V_{L L E A K_{-} s e c}\right)$. Notice that the clamping diode current $I_{D x 5}$ in the middle graph sees very little current during the normal commutation condition. 


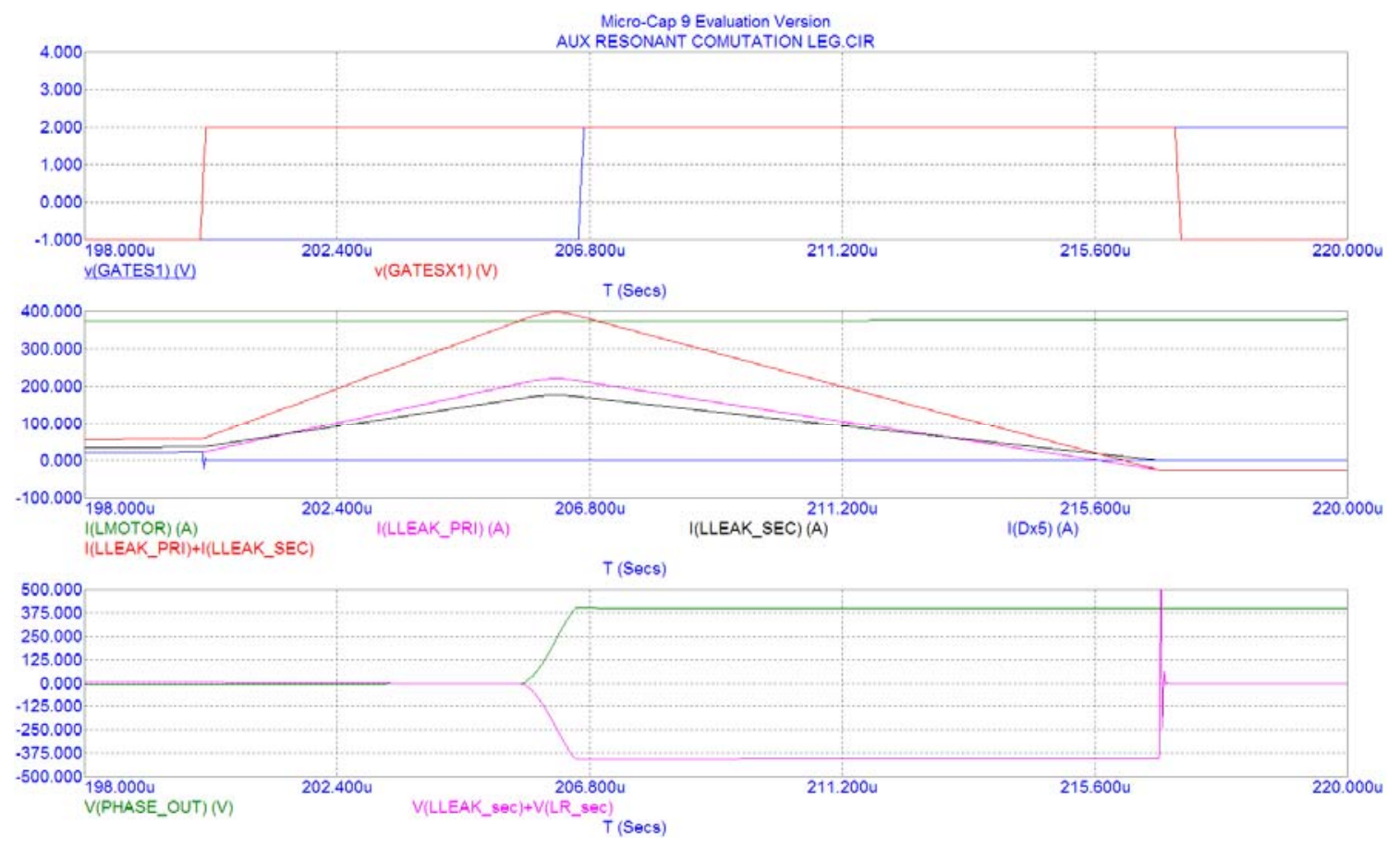

Figure 5.13. Resonant inductor voltage and current under normal operation.

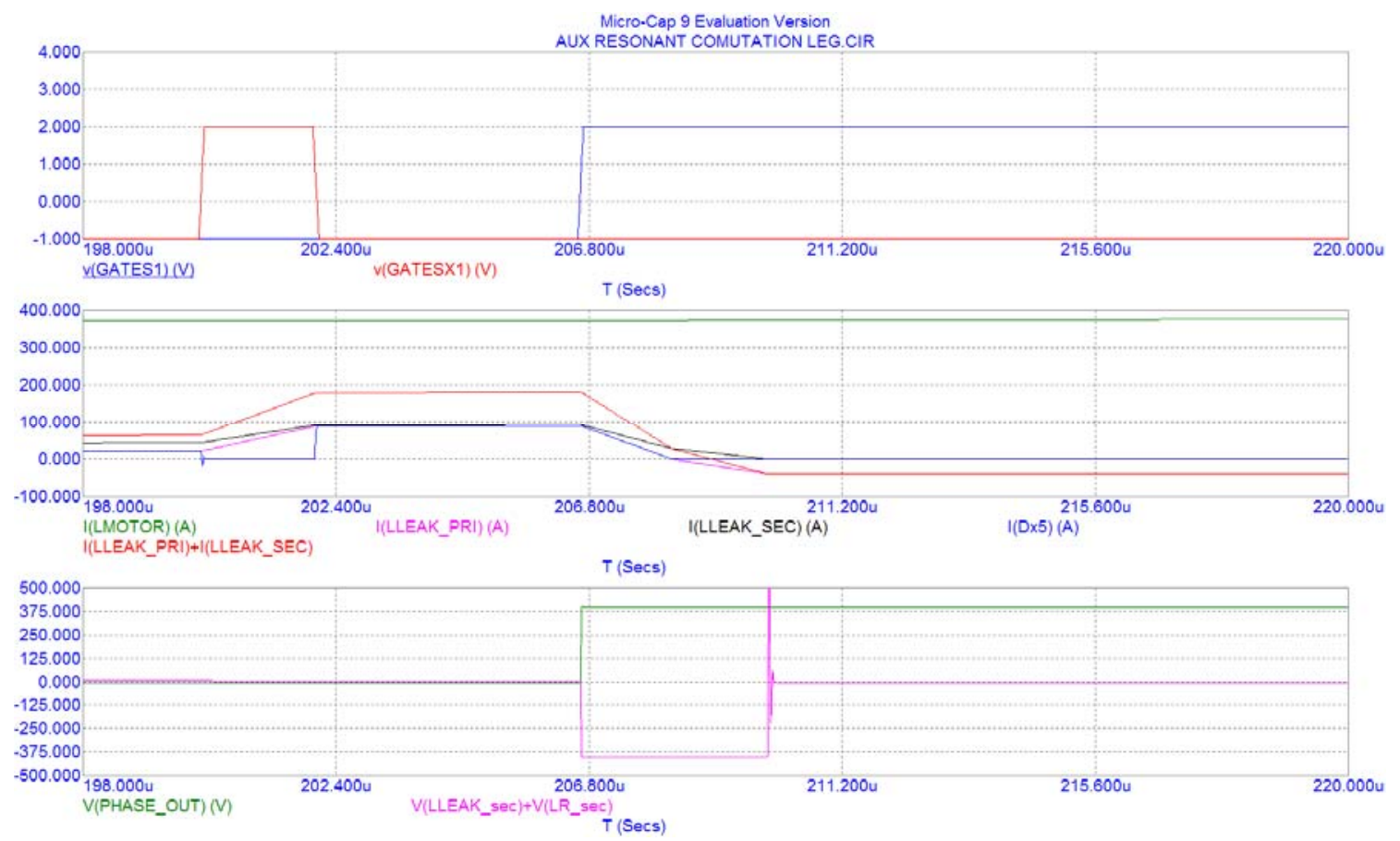

Figure 5.14. Simulated resonant inductor voltages and currents under communication failure.

Figure 5.14 shows the simulated results under the failure of communication between the inverter interface and DSP controller (Case 2 above). At time $202 \mu \mathrm{s}$, the auxiliary switch gate signal is interrupted due to loss of communication. In this case, the resonant current is interrupted, and the clamping diode current $I_{D x 5}$ is equal to the primary resonant current until the main switch gate 
is turned on. A peak current of 90 A flows through the clamping diode for about $3 \mu$ s. This suggests that a 5-A rated diode is inadequate to handle such a failure mode condition.

A communication failure can also cause the interruption of the main gate signal. Figure 5.15 shows the simulation result with loss of communication that interrupts the auxiliary and main gate signals. In this case, the clamping diode will conduct a high current for a long period, which is clearly exceeding its 5-A capability. Therefore, this FMEA study suggests that a much higher rated diode is required for the clamping diode.

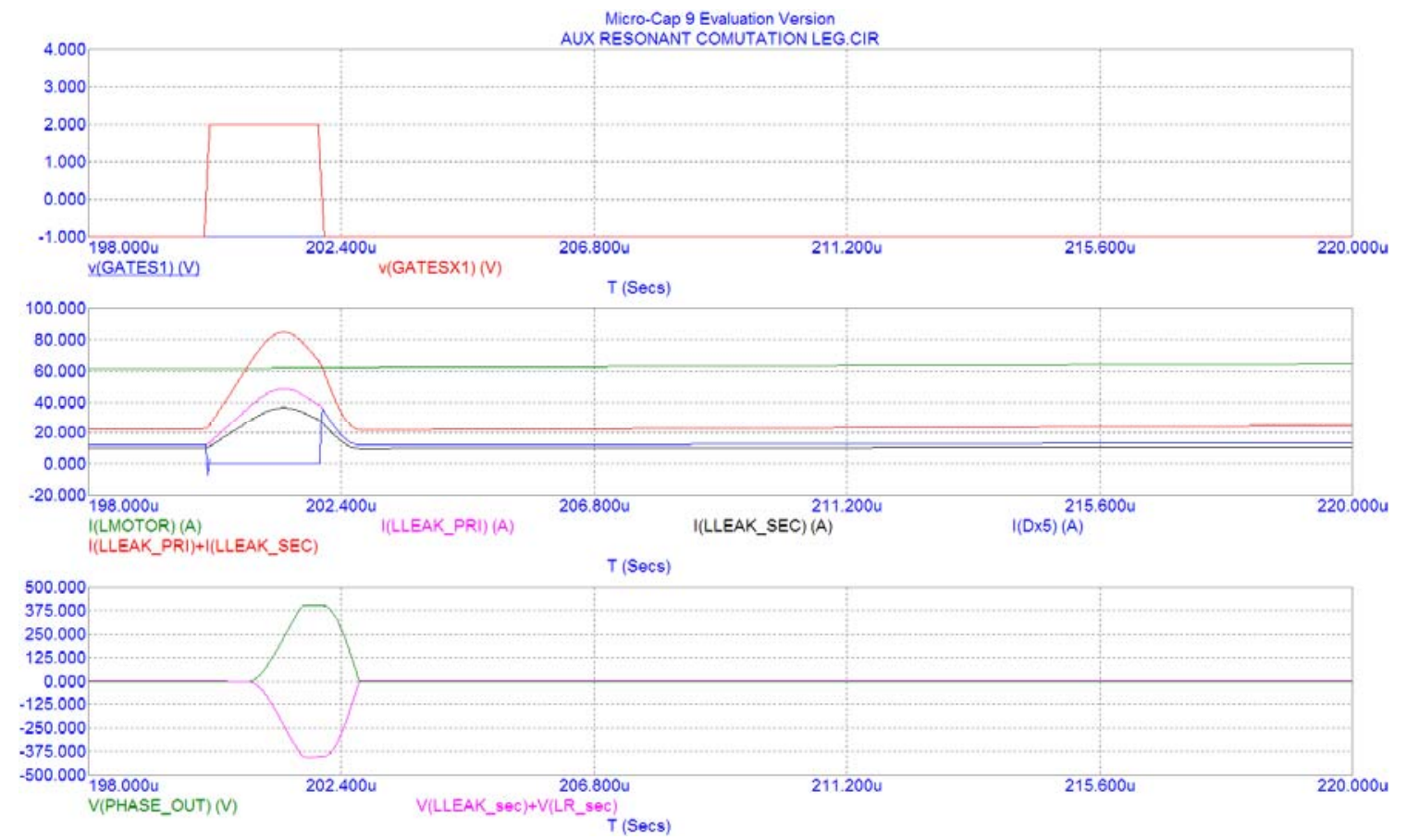

Figure 5.15. Simulation result with loss of communication that interrupts the auxiliary and main gate signals.

\section{G. Test EMI Performance}

Figure 5.16 shows the schematic diagram of EMI measurement setup that includes a set of line impedance separation networks (LISN), the inverter under test, and the load. The measurement instrument needs to have frequency-domain analysis capability. Both dc source side and ac load side EMI and differential-mode (DM) and common mode (CM) performances are measured to see the difference of EMI performance between hard-and soft-switching inverters. The source side current sensing comes from two LISN outputs, and the load side current sensing comes from a Rogowski probe that encloses all three cables that go into the load. The DM output EMI is not measured because it is the inherent load current that should not be different between hard- and soft-switching inverter.

Figure 5.17 compares DM noise at dc source side in the high-frequency region, from 0 to 50 MHz. The bottom traces of hard-switching and soft-switching results represent the measured EMI on the two differential lines, or $I_{d c^{+}}$and $I_{\mathrm{dc}-\cdot}$. By subtracting these two lines from each other, the total noise is the DM noise, which is shown in the top trace. Since the scale is much above 
the base switching frequency of $10 \mathrm{kHz}$, the soft-switching inverter is shown to be more effective at diode reverse recovery and parasitic related EMI noise reduction. By looking at the top traces of hard- and soft-switching inverter noises, the soft-switching inverter apparently lowers the EMI noise by 10 to $20 \mathrm{~dB}$ across the entire frequency range. The main noise reduction regions are in between 2 and $8 \mathrm{MHz}$ and between 18 and $27 \mathrm{MHz}$, where 20-dB reduction by soft switching is clearly identifiable. There are two possible noises that tend to be pronounced in the hardswitching inverter: (1) diode reverse recovery related EMI noise and (2) layout and parasitic component related EMI noises. The dc link capacitor needs to have very low equivalent series resistance (ESR) and equivalent series inductance (ESL) to effectively suppress these high frequency noises. In terms of which noise source is located in which region is still unknown, but the soft switching has demonstrated a significant EMI reduction advantage on the dc source side.

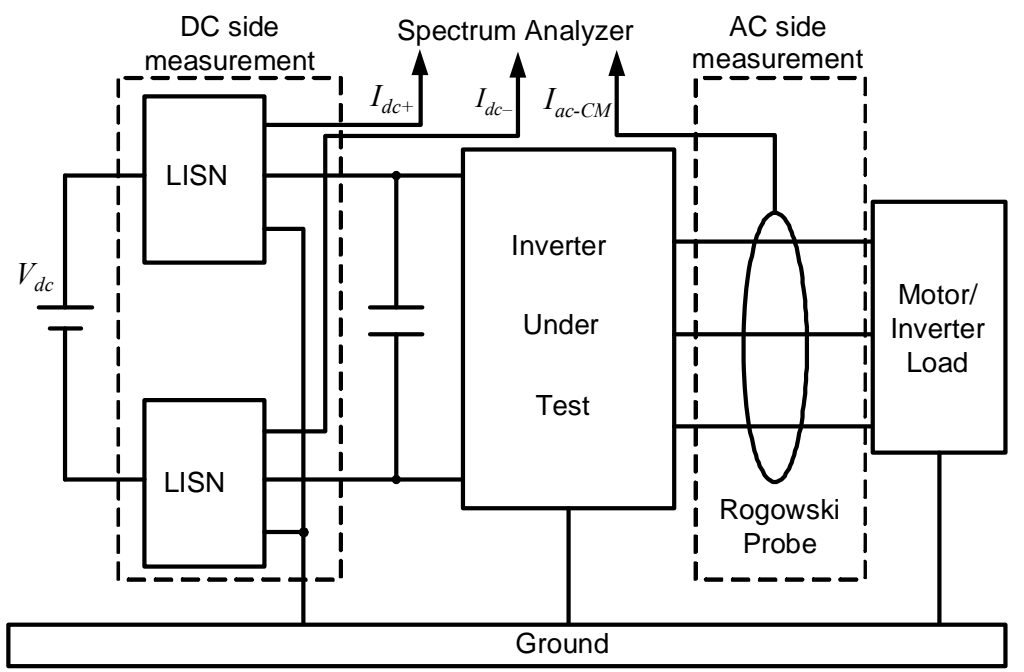

Figure 5.16. Schematic Diagram of EMI Measurement Setup.

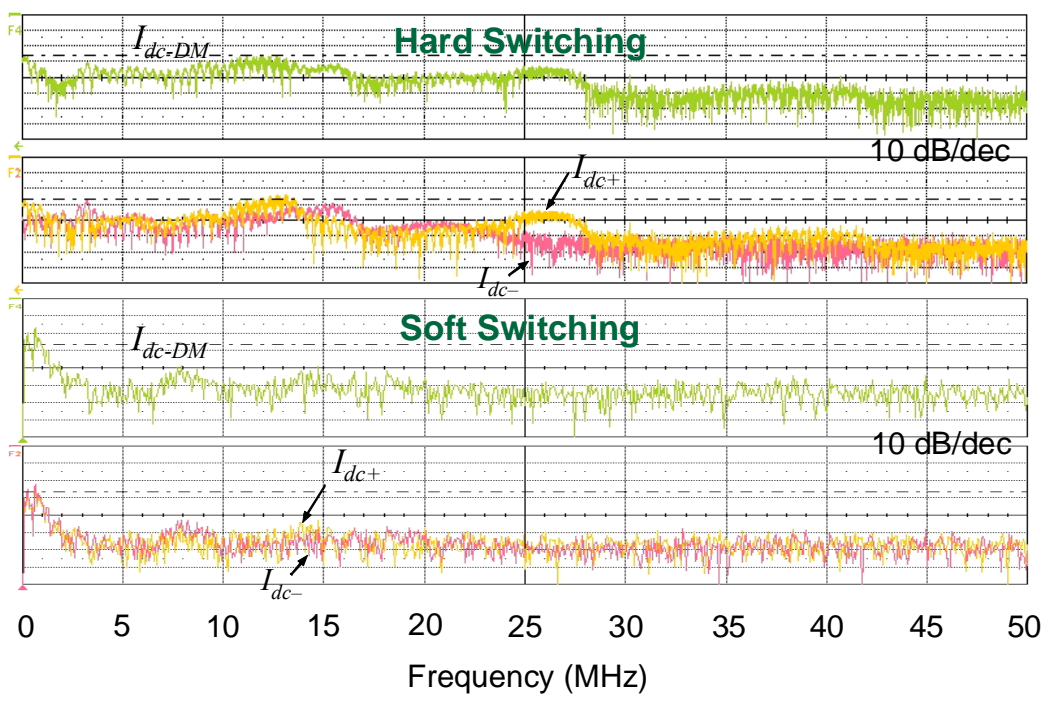

Figure 5.17. Measured High Frequency Range DM Noise at DC Side.

Figure 5.18 compares the CM noise at the dc source side in the high-frequency region. The bottom traces of the hard-switching and soft-switching results represent the measured EMI on 
the two differential lines, or $I_{d c^{+}}$and $I_{\mathrm{dc}-}$. By adding these two lines together, the total noise is the CM noise, which is shown by the top trace. Similar to the DM noise reduction, the main noise reduction regions are spread around certain frequencies. In this case, significant noise reduction is shown between 2 and $7 \mathrm{MHz}$, between 9 and $15 \mathrm{MHz}$, and between 17 and $28 \mathrm{MHz}$ regions, where more than $10-\mathrm{dB}$ reduction by soft switching is clearly identifiable. Again, in terms of which noise source is present in which region is still unknown, but soft switching has demonstrated significant CM EMI reduction advantage on the dc source side.

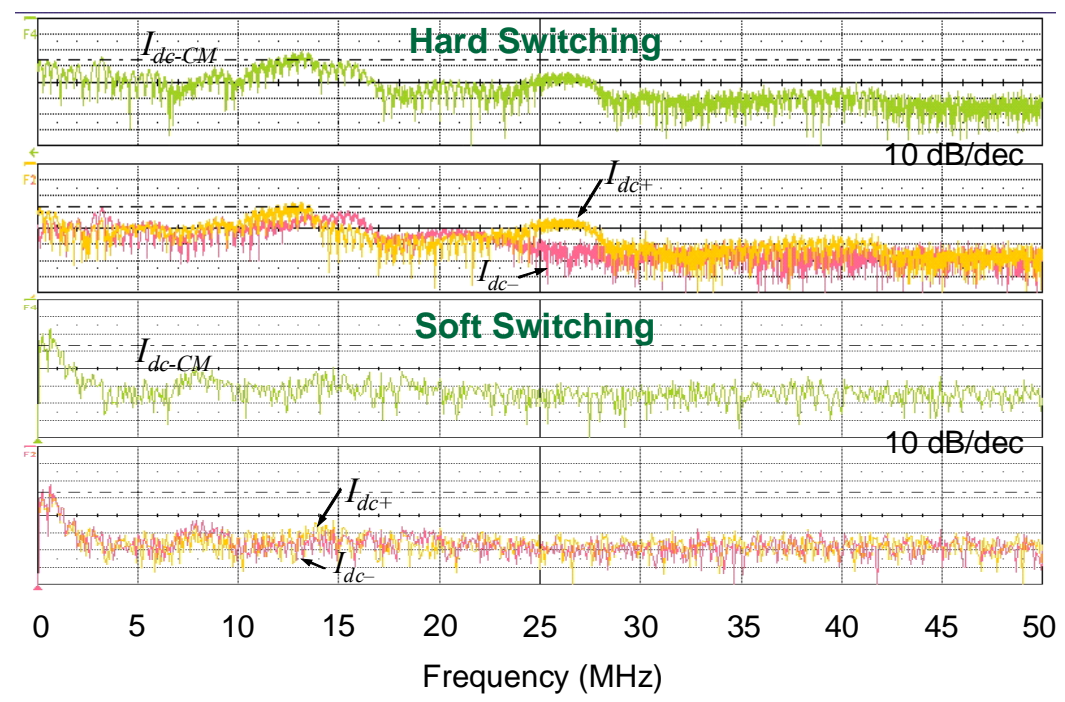

Figure 5.18. Measured High Frequency Range CM Noise at DC Side.

Figure 5.19 compares the ac load-side EMI performance of the hard- and soft-switching inverter in the high-frequency region. Since the low-frequency component is related to the load current, there is not a significant difference between hard and soft switching. At high frequencies, however, the soft-switching inverter demonstrates significant EMI noise reduction. The main noise reduction regions are between 2 and $7 \mathrm{MHz}$ and 13 and $18 \mathrm{MHz}$, in which more than 10$\mathrm{dB}$ reduction is realized.

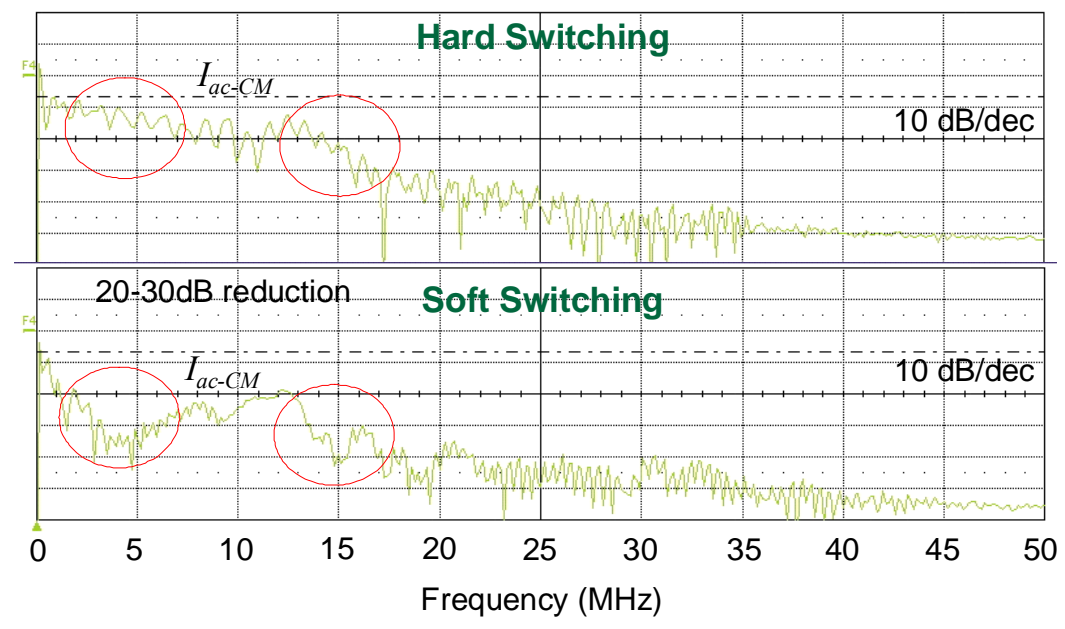

Figure 5.19. Measured High Frequency Range CM Noise at AC Side. 


\subsection{Gen-2 Soft-Switching Inverter}

\section{A. Conduction Loss Measurement Results}

Figure 5.20 compares the voltage drop between Gen-1 and Gen-2 modules. SN102 and SN201 represent the Gen-1 number 2 prototype and Gen-2 number 1 prototype, respectively. Both upper device $\left(Q_{1} / M_{1}\right)$ and lower device $\left(Q_{2} / M_{2}\right)$ clearly show higher voltage drops on the Gen-2 module. For Gen-1, the measurement points are at the power terminals, which are supposed to be far away from the chip. However, the heavy copper bar does not introduce any appreciable voltage drop. For Gen-2, even though the measurement points are near the chip, the voltage drops are high due to the substrate current path resistance. The upper device is worse because its substrate path is narrower. The lower device voltage drop matches that of the Gen-1 module, but its low current region shows a higher voltage drop because the CoolMOS ${ }^{\mathrm{TM}}$ is far away from the measurement point. When measuring from the power terminals, the Gen-2 voltage drop is significantly higher than that of the Gen-1 module. Unlike measuring near the chip, the measurement at the terminal indicates a higher voltage drop on the lower device. This can be explained by looking at the internal layout of the module, where the lower device has an additional length of the substrate.

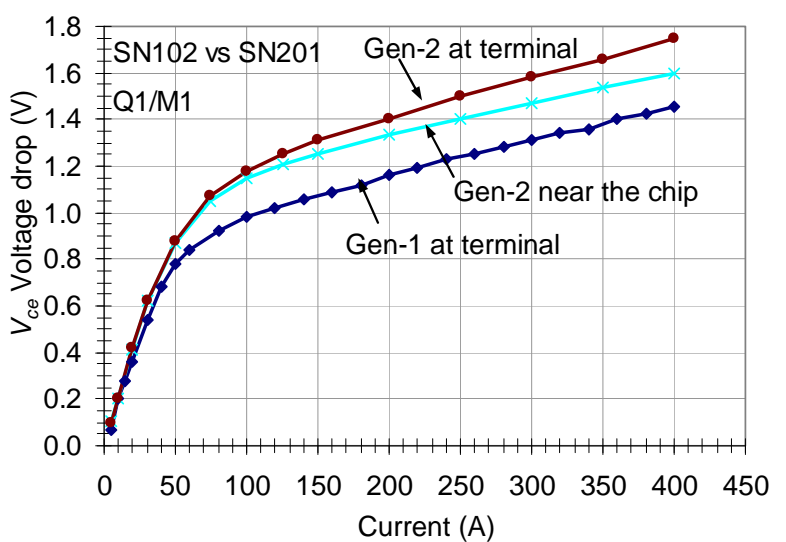

(a)

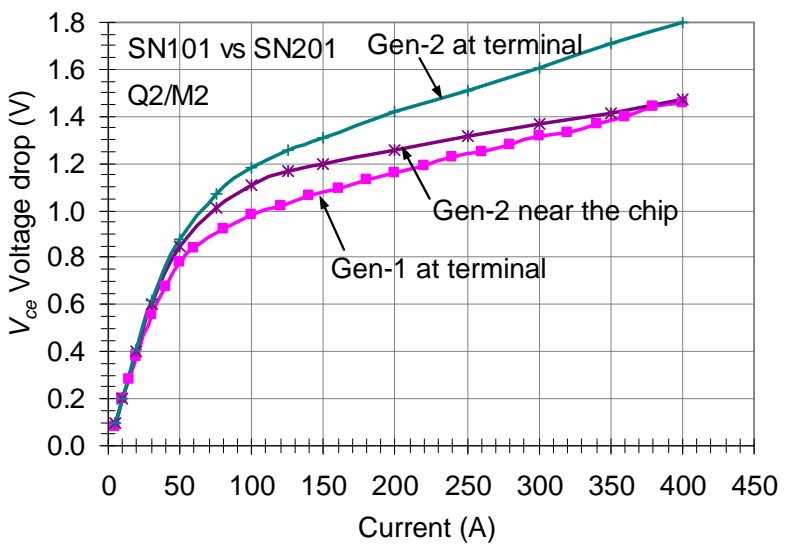

(b)

Figure 5.20. Voltage drop comparison between Gen-1 and Gen-2 modules: (a) upper device and (b) lower device.

In order to ensure that the above voltage drop problem is not caused by measurement error, an additional Gen-2 module prototype, SN210, was measured to compare the results obtained with SN201. Figure 5.21 compares the measured upper device voltage drops near the chip between SN201 and SN210. The difference between these two prototypes is negligible, and the voltage drop of the Gen-2 design is apparently a major issue with inverter efficiency reduction. 


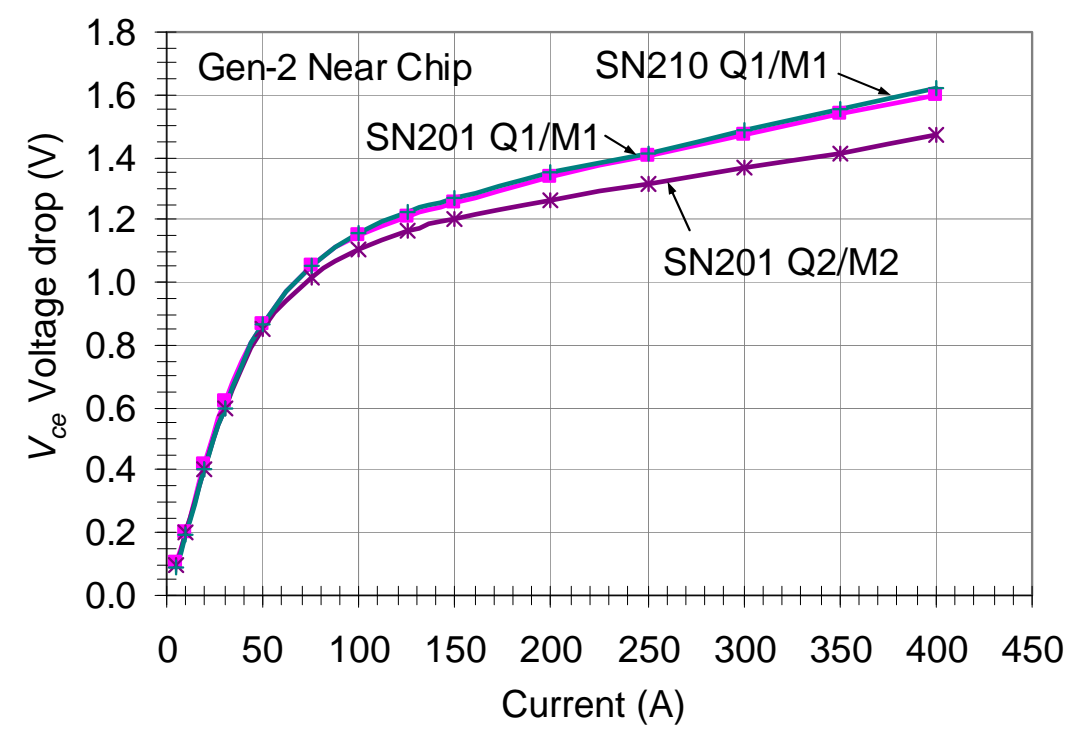

Figure 5.21. Comparison of Gen-2 module prototypes.

To further verify the Gen-2 device voltage drop issue, a production scale Gen-2 module SN211 is compared against the prototype SN201 in Figure 5.22. For comparison purposes, the voltage drops of upper and lower devices of the Gen-1 module are plotted as the base lines. Both lines are overlapped each other, indicating the balance and symmetrical structure of the Gen-1 design. For Gen-2 modules, the voltage drops measured near the chips of SN211 and SN201 are nearly the same and are all significantly higher than the voltage drop measured at the power terminals of the Gen-1 module.

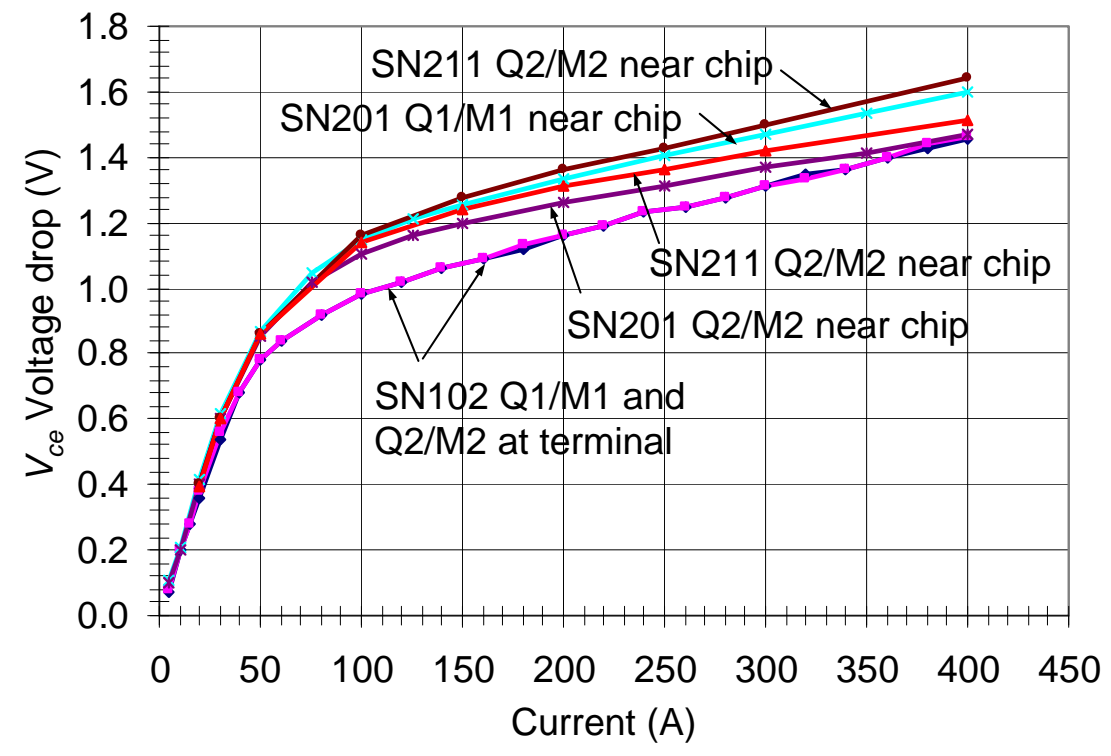

Figure 5.22. Device voltage drop comparison between Gen-1 and Gen-2 modules. 


\section{B. Switching Characterization}

The Gen-2 module showed much clearer voltage and current waveforms during switching transitions. Thanks to the new internal layout, the parasitic inductance of the Gen-2 module has been significantly reduced. The peak switching current has been tested at 400-A, the desired current under full-rated power condition. The comparison between Gen-1 and Gen-2 module performances is shown in this section, including switching characteristics waveforms and calculated parasitic inductance. Figure 5.23 shows the switching test setup. The test parameters are as follows:

- $C_{1}, C_{2}: 0.1 \mu \mathrm{F}, 600 \mathrm{~V} \mathrm{dc} ; C_{3}: 4.7 \mu \mathrm{F} \times 2,630 \mathrm{~V}$ dc $(4.7 \mu \mathrm{F} \times 5$ for $300 \mathrm{~A}$ or more $)$

- $C_{4}: 150 \mu \mathrm{F}, 500 \mathrm{~V} \mathrm{dc} ; C_{5}: 16 \mathrm{mF}, 430 \mathrm{~V} \mathrm{dc}$

- $L: 240 \mu \mathrm{H}, 260 \mathrm{~A} \mathrm{rms}$

- $L_{\text {coupled }}: L_{\mathrm{s}}=540 \mu \mathrm{H}, L_{\mathrm{p}}=293 \mu \mathrm{H}, L_{\mathrm{lkp}}=3.00 \mu \mathrm{H}, N_{\mathrm{s}}=19 \mathrm{~T}, N_{\mathrm{p}}=14 \mathrm{~T}$, ETD $49 \#$

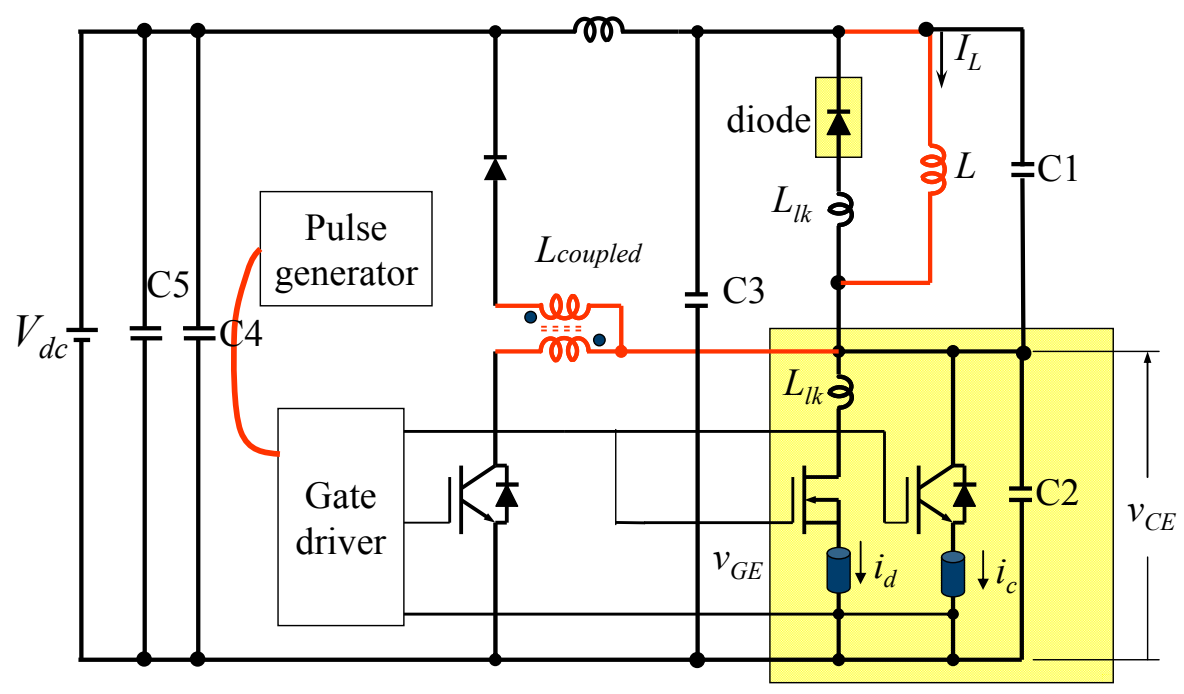

Figure 5.23. Switching characteristic test setup.

Due to the internally-connected power pin $\mathrm{E}_{1} / \mathrm{C}_{2}$ for Gen-2 module, it is not possible to measure device current for one switch and diode current of the opposite switch independently. Therefore, we measured load current $I_{L}$ instead for the switching characterization.

The Gen-1 module was only tested up to 280-A load current due to severe parasitic ringing. For the Gen-2 module, the switching current was quite clean, and thus the 400-A full-rated current was tested successfully. Figures 5.24 to 5.26 compare the switching characteristics between Gen-1 and Gen-2 modules at different load current conditions. The left-side waveforms came from Gen-1 module, while the right-side waveforms were generated from Gen-2 module. 

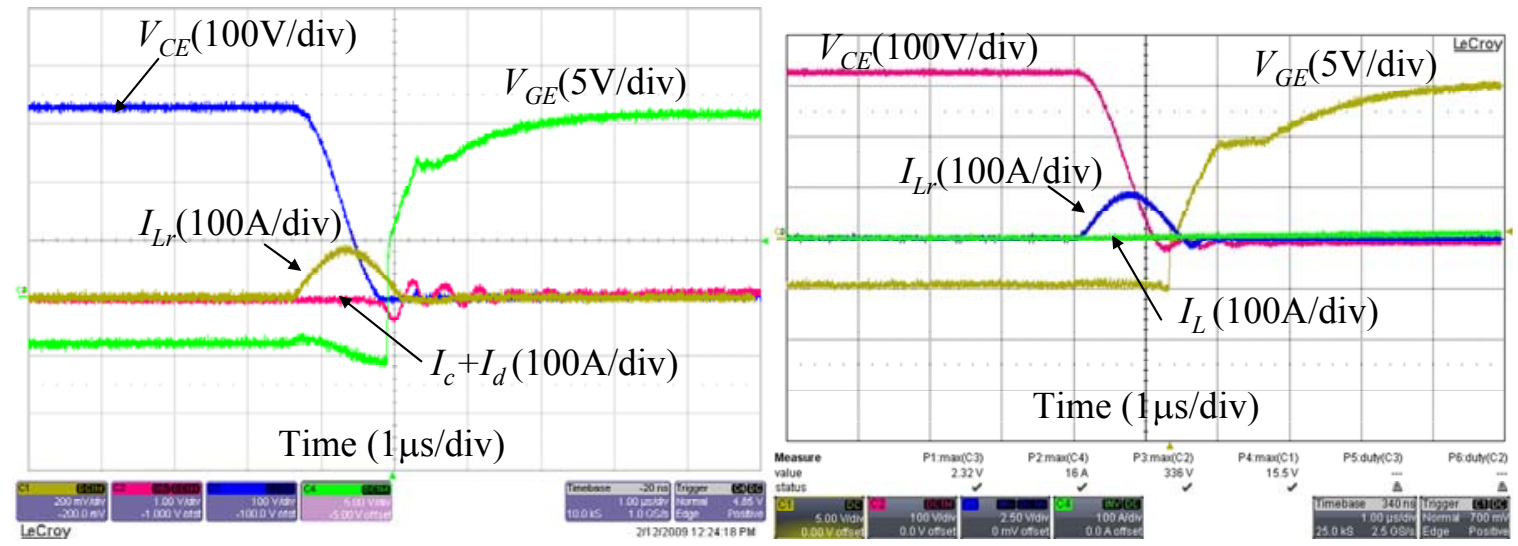

Figure 5.24. Zero load current switching characterization waveforms (left side-Gen 1 module, right side-Gen 2 module).
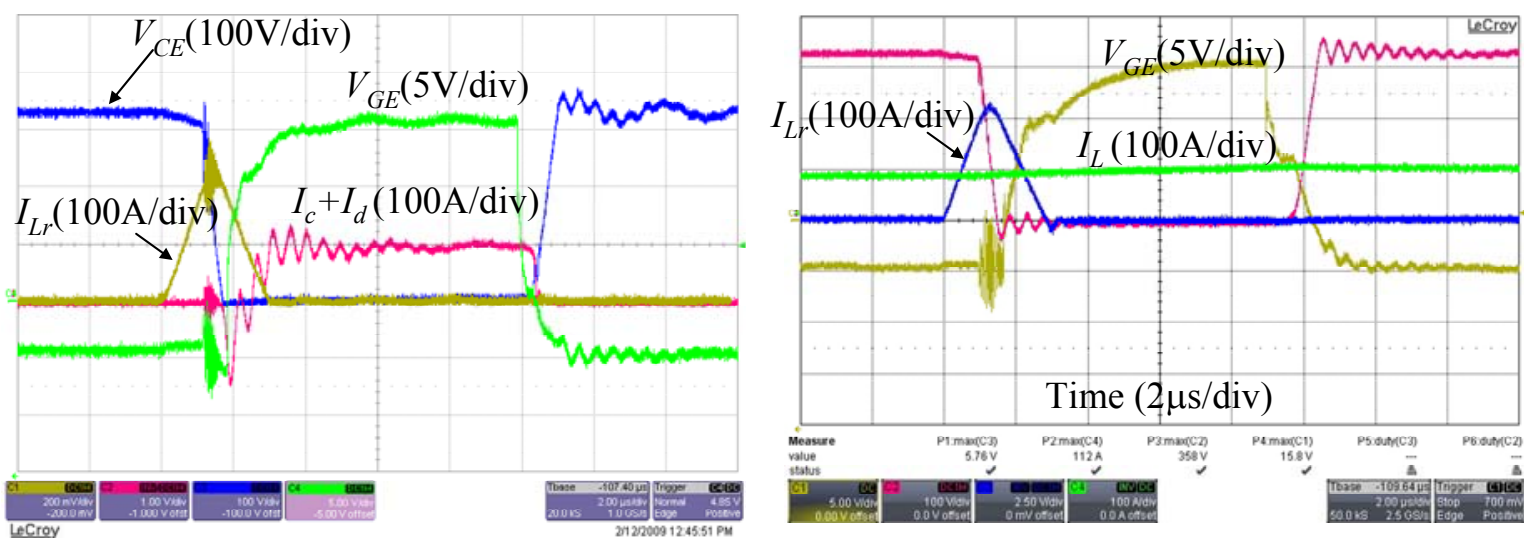

Figure 5.25. 100A load current switching characterization waveforms (left side-Gen 1 module, right side-Gen 2 module).
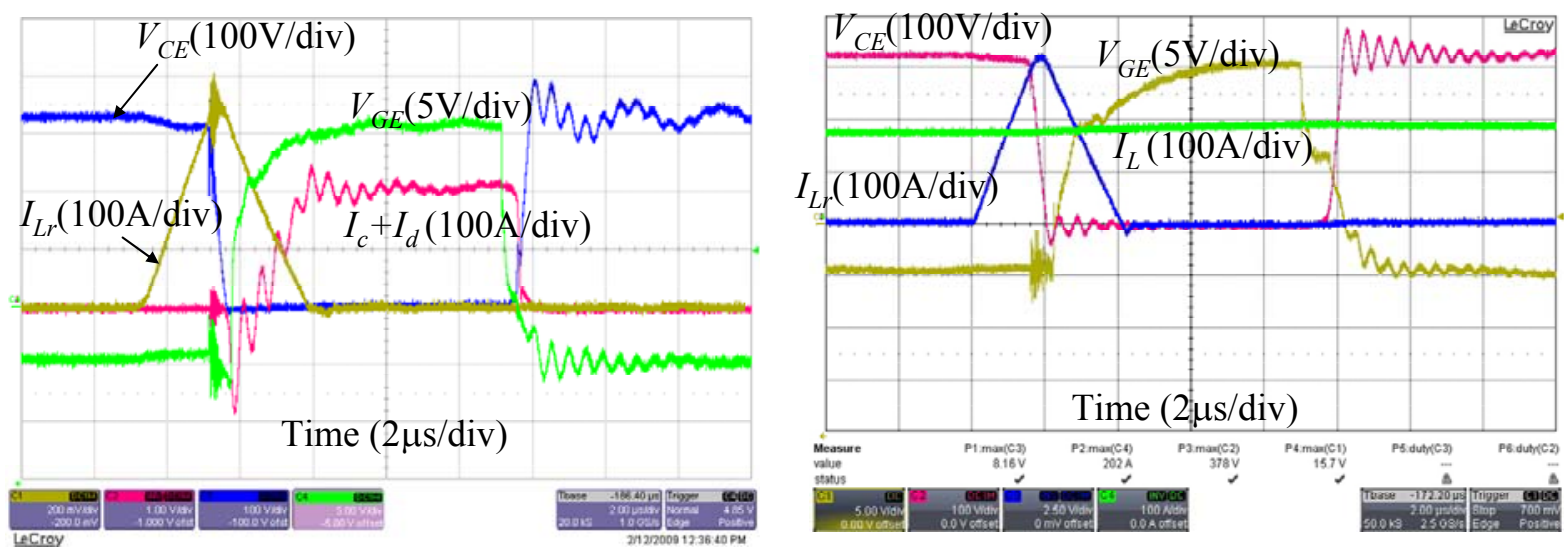

Figure 5.26. 200A load current switching characterization waveforms (left side-Gen 1 module, right side-Gen 2 module). 
Figures 5.27 and 5.28 showed the performance of Gen-2 module at load current 300 and $400 \mathrm{~A}$ conditions. Note that Gen-1 module could not be pushed to these current levels due to severe parasitic ringing.

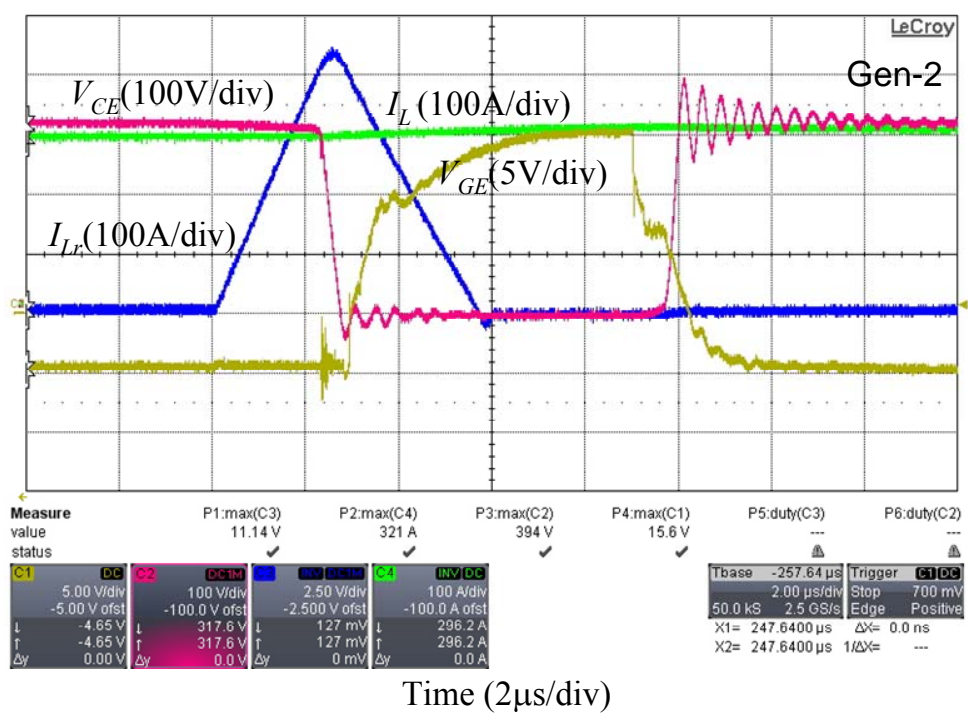

Figure 5.27. 300A load current switching characterization waveforms (Gen 2 module).

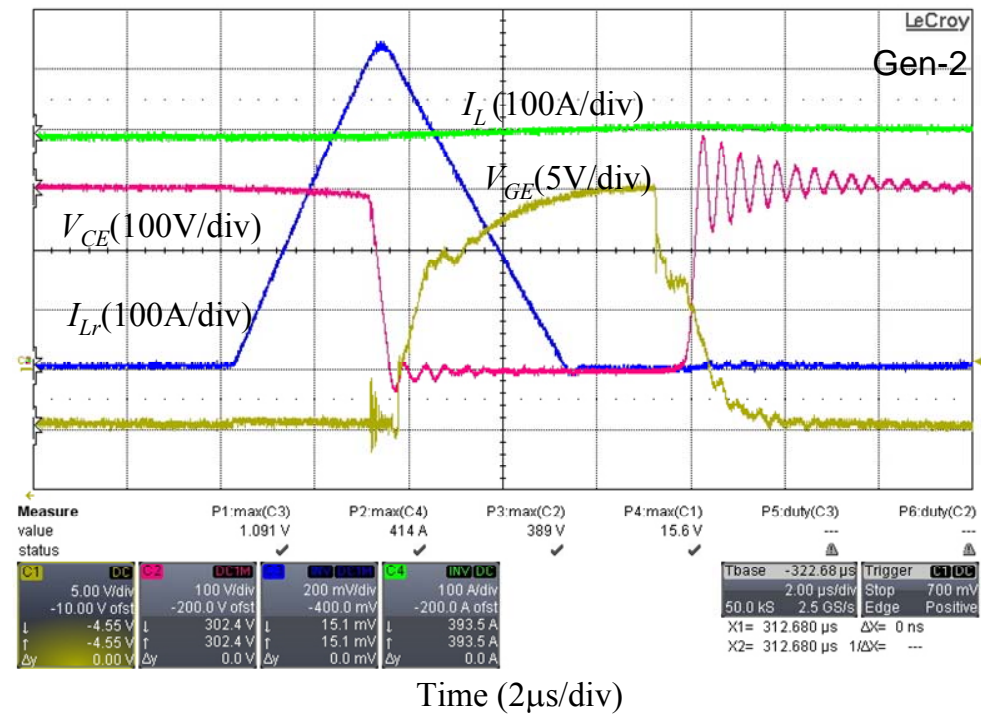

Figure 5.28. 400A load current switching characterization waveforms (Gen 2 module).

From the comparison, we can clearly see that switching transition of Gen-2 module is much improved compared to Gen-1 module. The ringing of voltage and current is greatly reduced. In order to quantify the parasitic improvement, we estimated the parasitic inductance for Gen-2 module by measuring the voltage drop during current rise stage. Figure 5.29 shows the measurement point at 300-A case. 


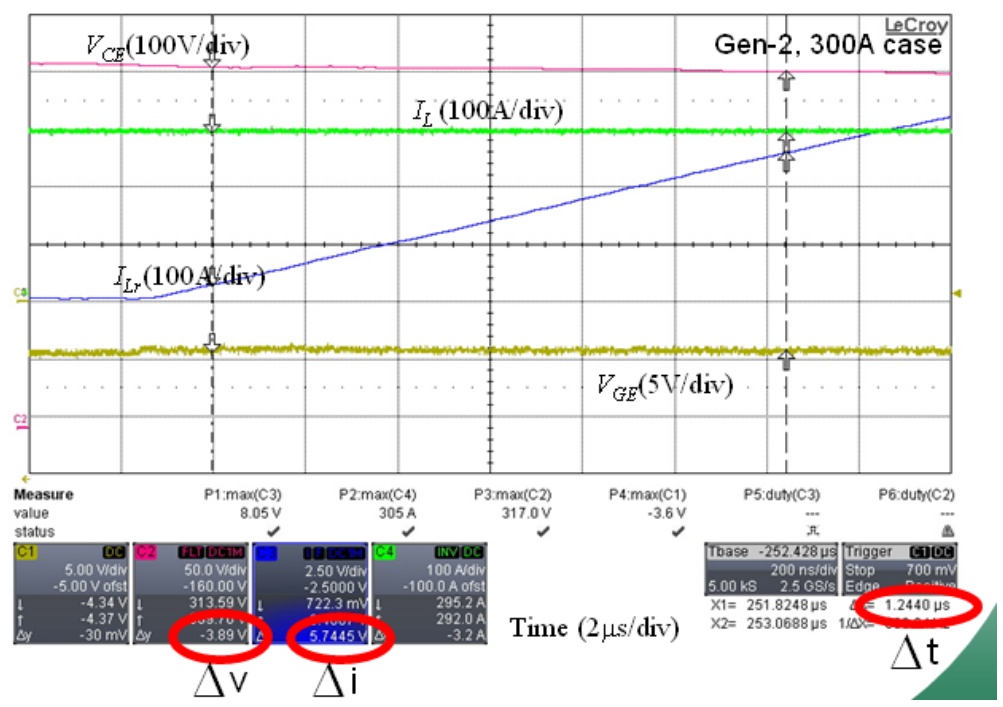

Figure 5.29. Parasitic inductance measurement at 300-A load current case.

The parasitic inductance can be calculated by the equation below:

$$
L_{\text {para }}=\frac{\Delta v \cdot \Delta t}{\Delta i}
$$

Through the repetitive measurements at conditions under 250 and $300-\mathrm{A}$, the parasitic inductance were estimated and shown in Table 5.5. The results indicate that the measurement results are quite consistent under the same current condition. By taking the average over all six measurement results, the parasitic inductance of Gen-2 module is estimated at $19.4 \mathrm{nH}$. With the same measurement and estimation method, the parasitic inductance of Gen-1 module was estimated at $90.5 \mathrm{nH}$. This represents an impressive parasitic reduction, or $78.5 \%$ reduction. Note that the current was measured with a Rogowski coil, which has a reading of $40 \mathrm{~A} / \mathrm{V}$. Its initial reading is in voltage, which needs to be converted to a current value.

Table 5.5. Gen-2 module parasitic inductance measurement.

\begin{tabular}{|c|c|c|c|c|c|}
\hline$\Delta t(\mu \mathrm{s})$ & $\Delta i(\mathrm{~V})$ & $\Delta i(\mathrm{~A})$ & $\Delta v(\mathrm{~V})$ & $L_{\text {para }}(\mathrm{nH})$ & Load current \\
\hline 1.1052 & 5.1629 & 206.516 & 3.33 & 17.8209 & $250 \mathrm{~A}$ \\
\hline 1.1052 & 5.1582 & 206.328 & 3.39 & 18.1586 & $250 \mathrm{~A}$ \\
\hline 1.1052 & 5.1351 & 205.404 & 3.42 & 18.4017 & $250 \mathrm{~A}$ \\
\hline 1.2440 & 5.7445 & 229.780 & 3.89 & 21.0599 & $300 \mathrm{~A}$ \\
\hline 1.2440 & 5.7429 & 229.716 & 3.66 & 19.8203 & $300 \mathrm{~A}$ \\
\hline 1.2440 & 5.7113 & 228.452 & 3.94 & 21.4546 & $300 \mathrm{~A}$ \\
\hline
\end{tabular}

\section{Power Loss Measurement Results}

Due to limited active power supply capability in the lab, the Virginia Tech only performed the inductive load test in order to push to higher output voltage and current conditions. The reactive 
power kVA and the line frequency represent the output power and speed of the motor load, and their losses are in the similar scale. Therefore, it is reasonable to project the efficiency with a reactive power test. The load is a $\Delta$-connected three-phase inductor. Equivalent inductance is about $4.5 \mathrm{mH}$ per phase. By controlling the modulation index, the output voltage, and thus the output reactive power can be controlled. The dc bus voltage was fixed at $325 \mathrm{~V}$, and the output line frequencies varied at $45 \mathrm{~Hz}, 60 \mathrm{~Hz}$ and $83.3 \mathrm{~Hz}$. Temperature was regulated at four different conditions: $25^{\circ} \mathrm{C}, 50^{\circ} \mathrm{C}, 75^{\circ} \mathrm{C}$ and $90^{\circ} \mathrm{C}$.

Figure 5.30 shows the power loss as a function of the output $\mathrm{kVA}$ under different line frequencies and different temperatures: (a) $25^{\circ} \mathrm{C}$, (b) $50^{\circ} \mathrm{C}$, (c) $75^{\circ} \mathrm{C}$, and (d) $90^{\circ} \mathrm{C}$. The figures clearly indicate that the higher line frequency, which represents higher motor speed, the lower power loss. The reason is the voltage level, and thus the power factor is higher at a higher line frequency. To achieve the same kVA, the case with higher frequency requires less current or produces less power loss.

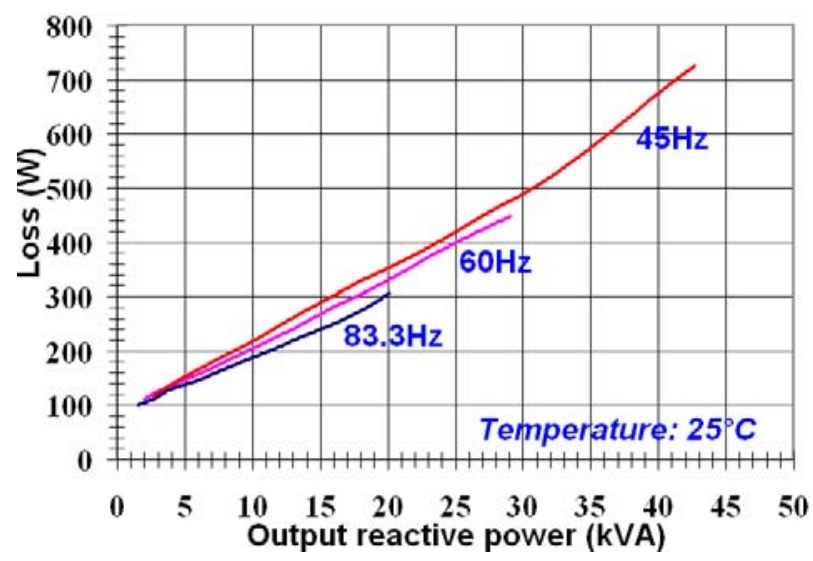

(a)

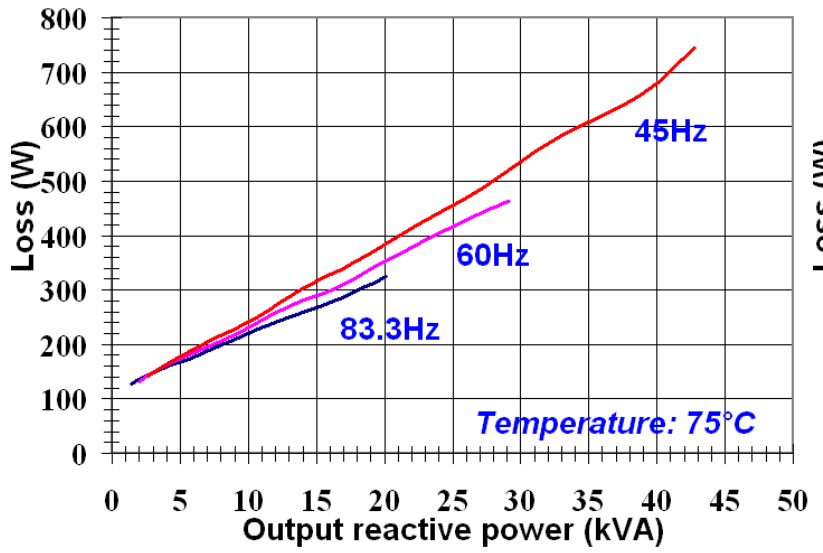

(c)

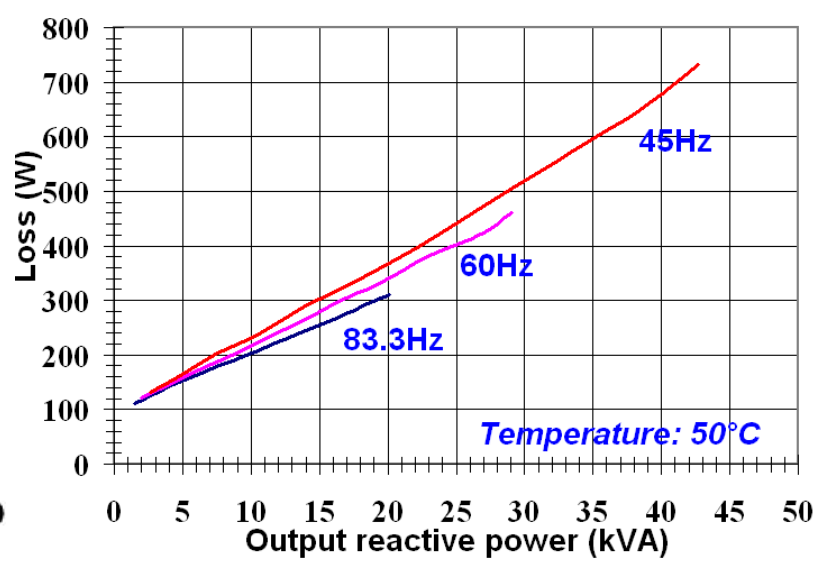

(b)

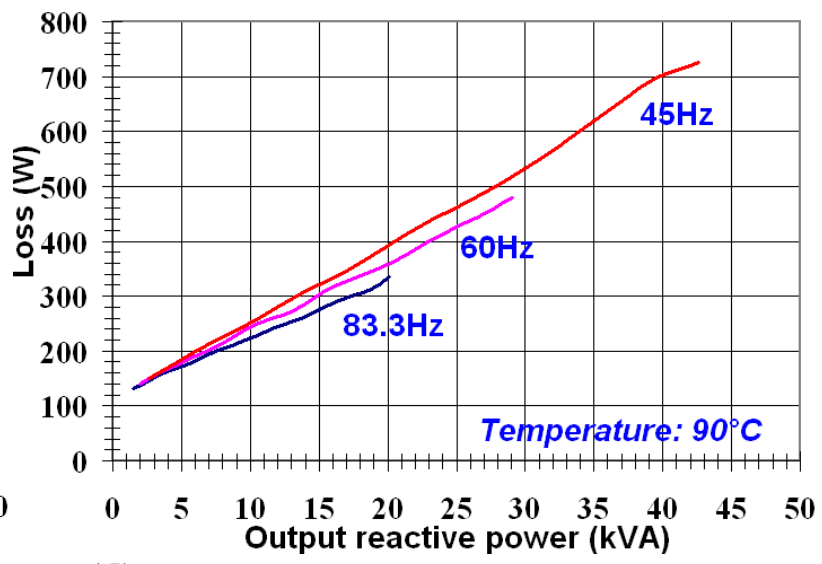

(d)

Figure 5.30. Power loss as a function of the output kVA under different line frequencies and different temperatures: (a) $25^{\circ} \mathrm{C}$, (b) $50^{\circ} \mathrm{C}$, (c) $75^{\circ} \mathrm{C}$, and (d) $90^{\circ} \mathrm{C}$.

Figure 5.31 shows the power loss as a function of the output kVA under different temperatures and different line frequencies: (a) $45 \mathrm{~Hz}$, (b) $60 \mathrm{~Hz}$, and (c) $83.3 \mathrm{~Hz}$. The general trend is the higher temperature, the higher power loss. This indicates that the turn-off loss 
increases more than the conduction loss decreases. At higher frequency cases, when the modulation index saturates, the loss tends to flatten out, especially at high temperatures, and the loss is less impacted by the temperature. This is because the switching loss is no longer dominating.

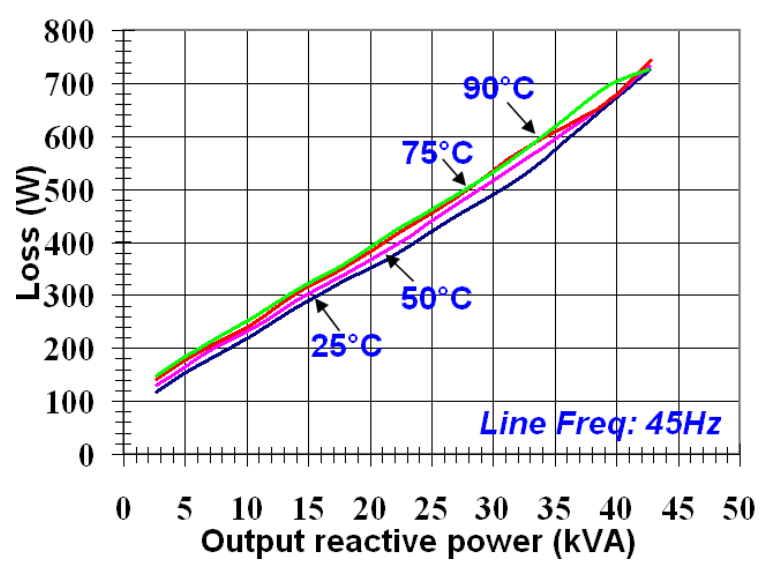

(a)

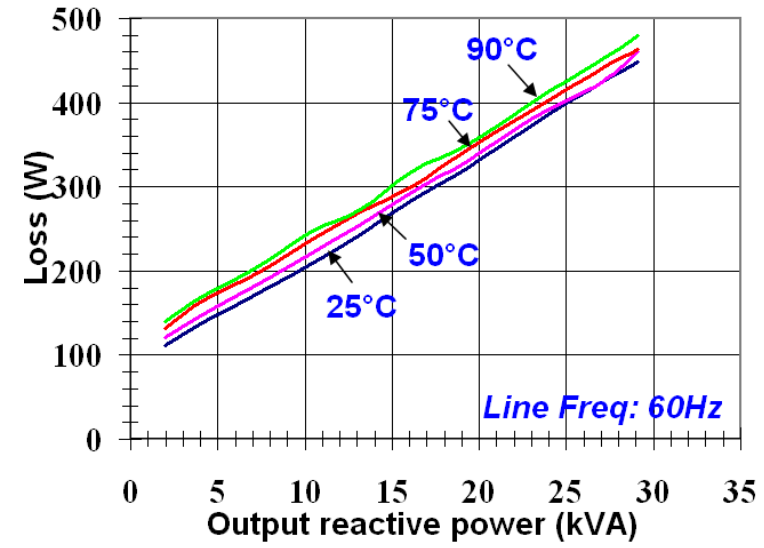

(b)

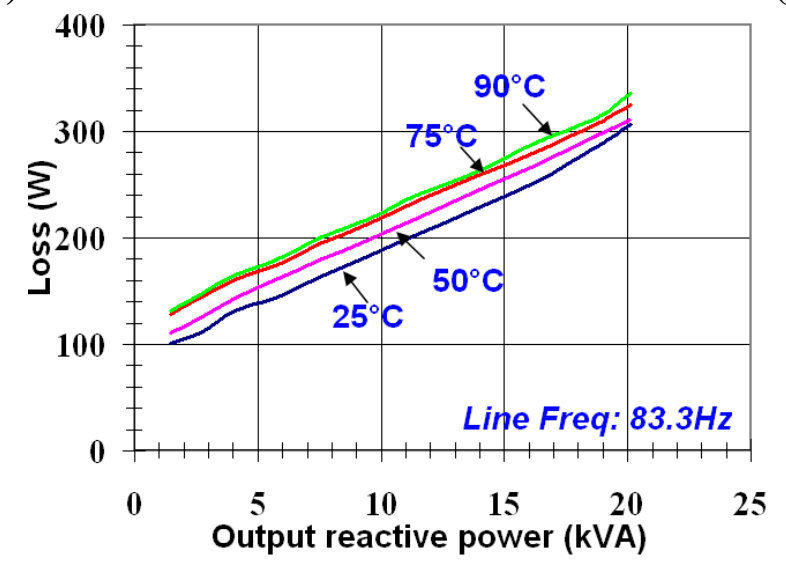

(c)

Figure 5.31. Power loss as a function of the output kVA under different temperatures and different line frequencies: (a) $45 \mathrm{~Hz}$, (b) $60 \mathrm{~Hz}$, and (c) $83.3 \mathrm{~Hz}$.

\section{Projected Efficiency Using the Loss Measurement Results}

Figure 5.32 shows the projected efficiency based on the inductive load measured loss results at 83.3-Hz output line frequency at different temperatures. The power factor is assumed to be unity in this case. It is noted that at the light load condition, the efficiency difference is more obvious than that at the heavy load condition. The reason is that at light loads, the MOSFET shares more current, and with positive temperature coefficient, the efficiency suffers. However, at heavy loads, the LPT IGBT shares more current, and with the negative temperature coefficient, its efficiency impact by temperature is not as severe. The peak efficiency approaches $98.5 \%$.

Figures 5.33 and 5.34 show the projected efficiency based on the inductive load measured loss results at $60-\mathrm{Hz}$ and $45-\mathrm{Hz}$ output line frequencies at different temperatures. The power factor is 
again assumed unity in this case. The efficiency differentials at light and heavy loads show the same trend as those in the $83.3 \mathrm{~Hz}$ case. Overall efficiency reduces as the frequency reduces because of poorer power factor and less modulation index at the same load condition.

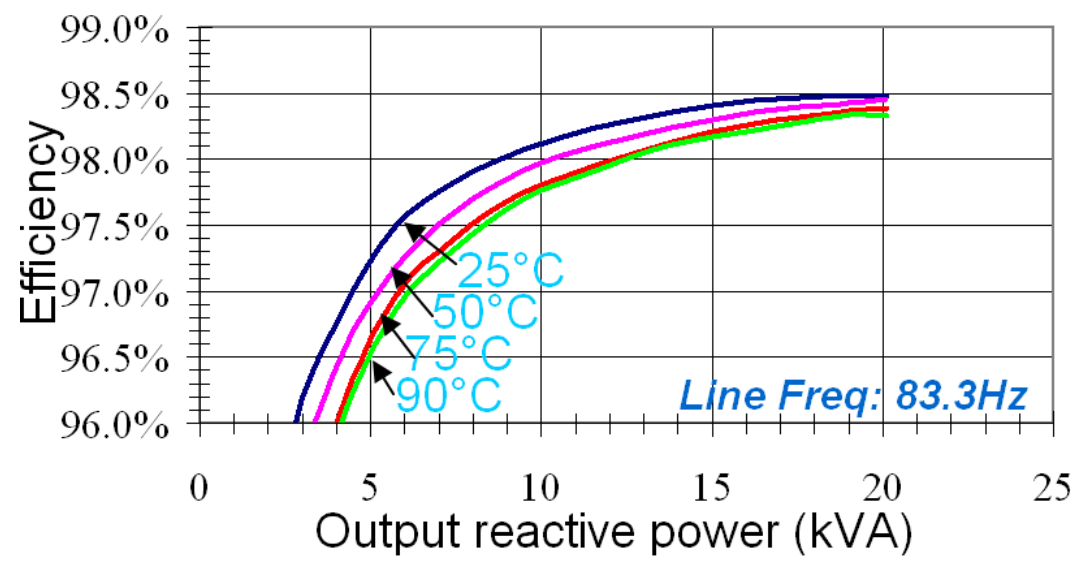

Figure 5.32. Efficiency measurement at $83.3-\mathrm{Hz}$ line frequency and different temperatures.

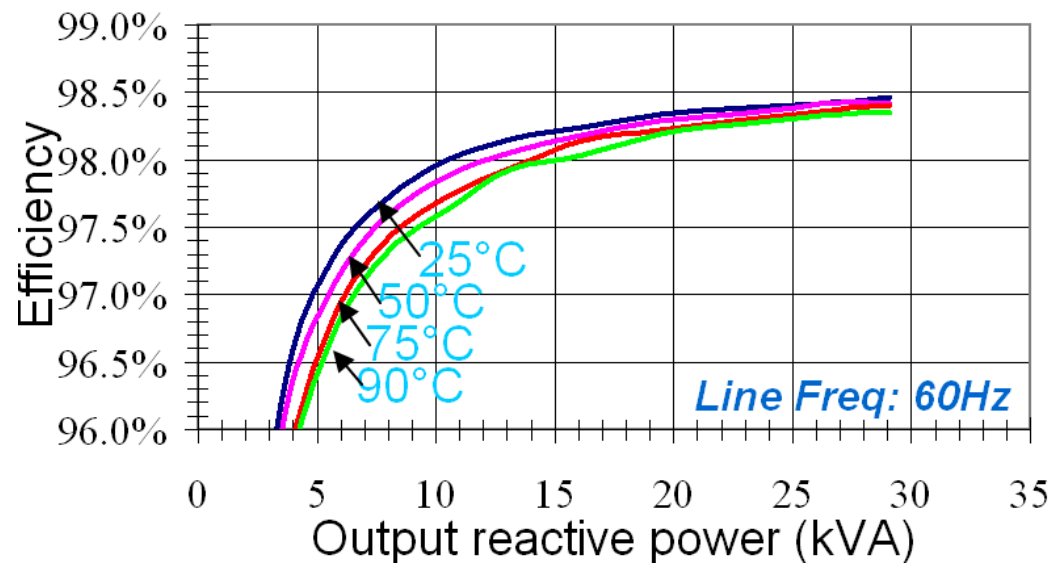

Figure 5.33. Efficiency measurement at $60-\mathrm{Hz}$ line frequency and different temperatures.

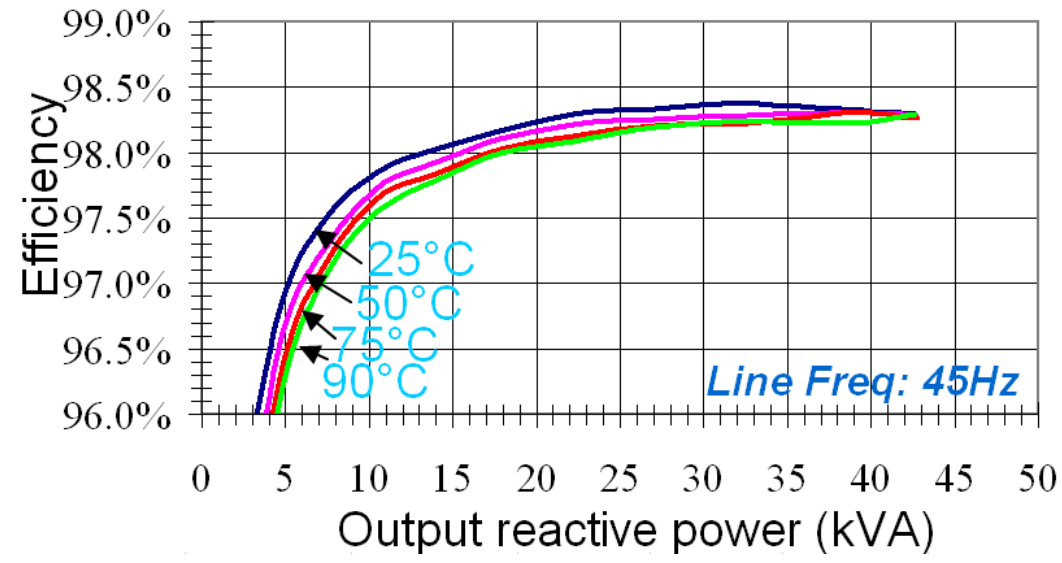

Figure 5.34. Efficiency measurement at $45-\mathrm{Hz}$ line frequency and different temperatures. 
To compare the efficiency under different frequency conditions, the above results are rearranged to compare the projected efficiency at different frequencies under the same temperature condition. Figures 5.35 through 5.38 show the projected efficiencies between different output line frequencies at $25^{\circ} \mathrm{C}, 50^{\circ} \mathrm{C}, 75^{\circ} \mathrm{C}$, and $90^{\circ} \mathrm{C}$, respectively. The power factor in these cases is assumed 0.83 , which is the same as what has been tested on the motor drive cases. As can be seen, at the same output power point, the efficiency is higher at a higher output line frequency. That can be translated into higher speed with higher efficiency, which is proven by later motor tests.

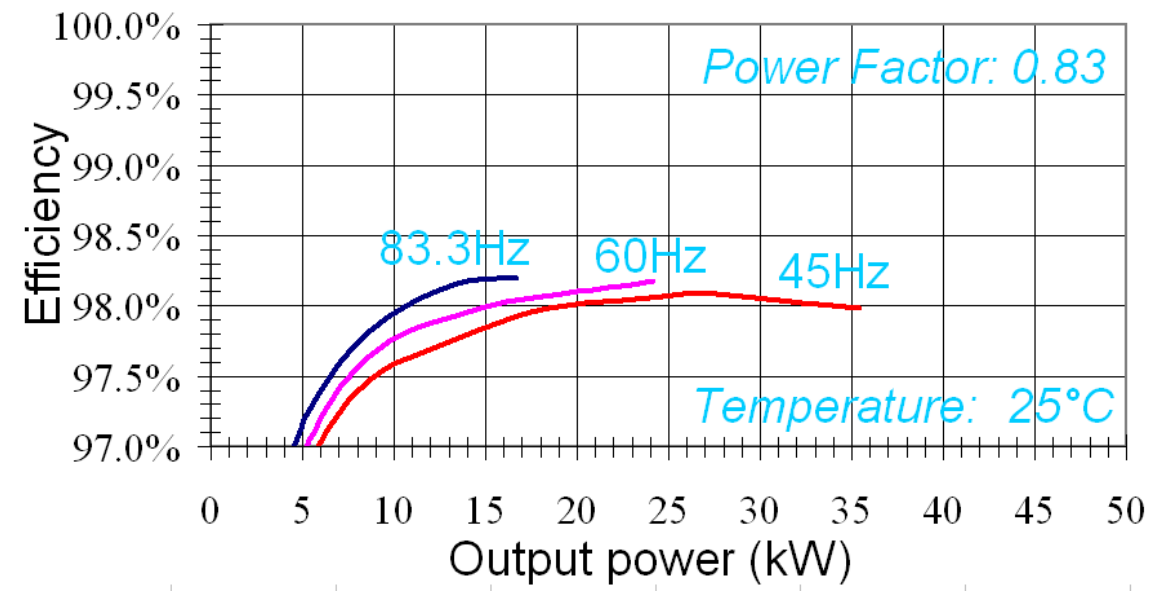

Figure 5.35. Efficiency comparison at $25^{\circ} \mathrm{C}$ and different line frequency conditions.

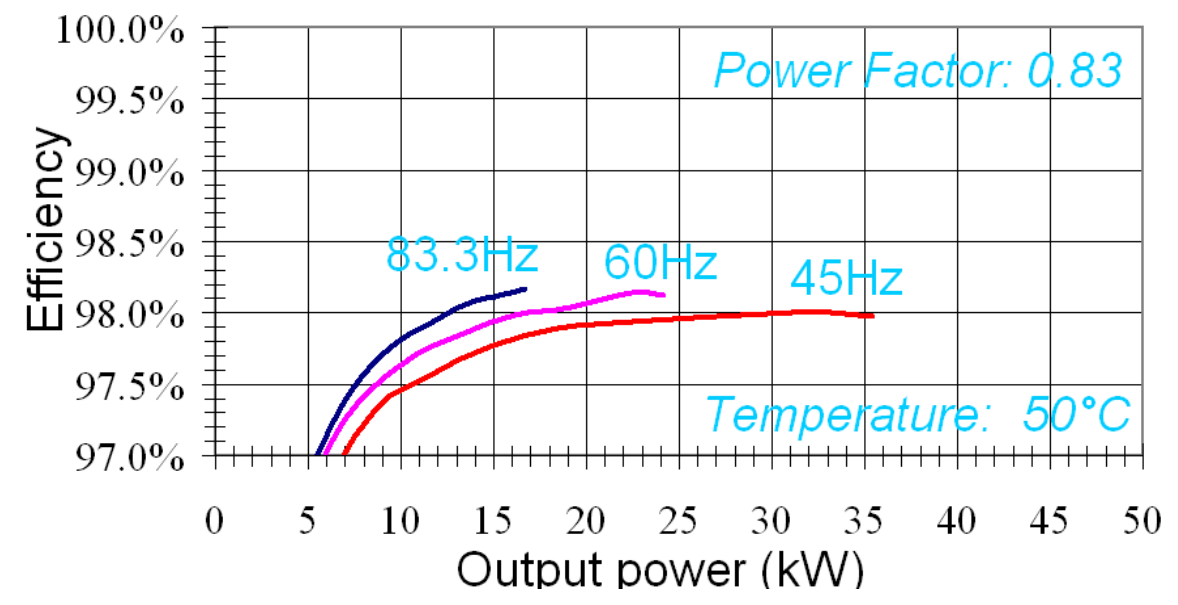

Figure 5.36. Efficiency comparison at $50^{\circ} \mathrm{C}$ and different line frequency conditions. 


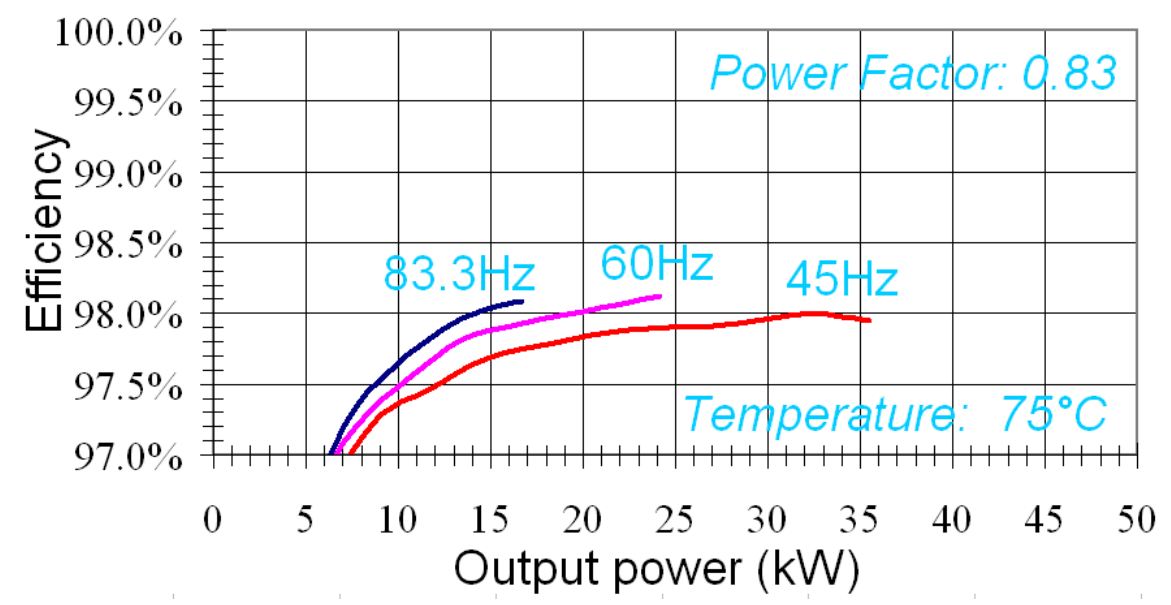

Figure 5.37. Efficiency comparison at $75^{\circ} \mathrm{C}$ and different line frequency conditions.

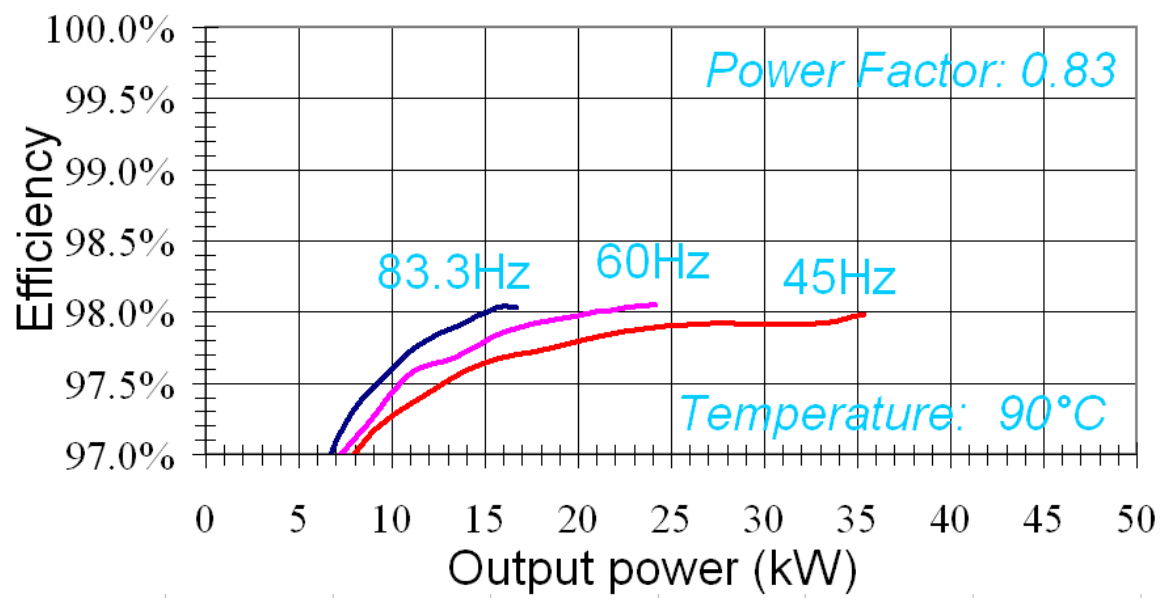

Figure 5.38. Efficiency comparison at $90^{\circ} \mathrm{C}$ and different line frequency conditions.

\subsection{Gen-3 Soft-Switching Inverter}

\section{A. Conduction Loss Measurement Results}

Voltage drops of two Gen-3 modules are listed in this section to show typical device voltage drops and their variations between upper and lower devices and among different modules. Table 5.6 lists measured main power module voltage drop for serial number SN301P at $25^{\circ} \mathrm{C}$ and $125^{\circ} \mathrm{C}$ conditions.

Since each device consists of two 200-A IGBT chips and two MOSFET chips, at low temperature and low current condition, the MOSFET draws more current because it is a resistive device, and its $R_{d s-o n}$ is low at low temperatures. After the current reaches 100A, the IGBT starts conducting more current, and the voltage drop becomes near linear. At high temperatures, the $R_{d s-o n}$ is nearly doubled, and the IGBT starts drawing more current at about 50A, so the voltage drop at low current is higher as compared to the low temperature condition. When the current continues increasing, the IGBT voltage drop is reduced because of its negative temperature 
coefficient characteristic; therefore, the overall voltage drop is nearly the same as at the lowtemperature condition. A similar negative temperature coefficient characteristic is also seen in the body diode voltage drop. This implies the inverter efficiency should stay relatively constant over the entire temperature range.

Table 5.6. Measured main power module voltage drop for SN $301 \mathrm{P}$ at different temperatures

\begin{tabular}{|c|c|c|c|c|}
\hline \multicolumn{5}{|c|}{ Module SN 301P at 25 ${ }^{\circ} \mathbf{C}$} \\
\hline $\begin{array}{c}\text { Current } \\
(\mathbf{A})\end{array}$ & $\begin{array}{c}\mathbf{Q}_{1} / \mathbf{M}_{\mathbf{1}} \\
\boldsymbol{V}_{\text {cesat }} \\
(\mathbf{V})\end{array}$ & $\begin{array}{c}\mathbf{Q}_{2} / \mathbf{M}_{\mathbf{2}} \\
\boldsymbol{V}_{\text {cesat }} \\
(\mathbf{V})\end{array}$ & $\begin{array}{c}\mathbf{M}_{\mathbf{1}} \text { body } \\
\text { diode } \boldsymbol{V}_{\boldsymbol{f}} \\
(\mathbf{V})\end{array}$ & $\begin{array}{c}\mathbf{M}_{\mathbf{2}} \text { body } \\
\text { diode } \boldsymbol{V}_{\boldsymbol{f}} \\
(\mathbf{V})\end{array}$ \\
\hline $\mathbf{1 0}$ & 0.08 & 0.09 & 0.70 & 0.71 \\
\hline $\mathbf{2 5}$ & 0.21 & 0.22 & 0.74 & 0.75 \\
\hline $\mathbf{5 0}$ & 0.39 & 0.42 & 0.78 & 0.81 \\
\hline $\mathbf{7 5}$ & 0.61 & 0.64 & 0.80 & 0.84 \\
\hline $\mathbf{1 0 0}$ & 0.78 & 0.83 & 0.82 & 0.87 \\
\hline $\mathbf{1 2 5}$ & 0.91 & 0.96 & 0.84 & 0.90 \\
\hline $\mathbf{1 5 0}$ & 0.99 & 1.05 & 0.86 & 0.93 \\
\hline $\mathbf{2 0 0}$ & 1.09 & 1.16 & 0.88 & 0.98 \\
\hline $\mathbf{2 5 0}$ & 1.16 & 1.23 & 0.91 & 1.03 \\
\hline $\mathbf{3 0 0}$ & 1.23 & 1.29 & 0.93 & 1.07 \\
\hline $\mathbf{3 5 0}$ & 1.28 & 1.35 & & \\
\hline $\mathbf{4 0 0}$ & 1.34 & 1.40 & & \\
\hline $\mathbf{4 5 0}$ & 1.40 & 1.46 & & \\
\hline
\end{tabular}

\begin{tabular}{|c|c|c|c|c|}
\hline $\begin{array}{c}|c| \\
\text { Module SN 301P at } \mathbf{1 2 5}^{\circ} \mathbf{C} \\
(\mathbf{A})\end{array}$ & $\begin{array}{c}\mathbf{Q}_{1} / \mathbf{M}_{\mathbf{1}} \\
\boldsymbol{V}_{\text {cesat }} \\
(\mathrm{V})\end{array}$ & $\begin{array}{c}\mathbf{Q}_{\mathbf{2}} / \mathrm{M}_{\mathbf{2}} \\
\boldsymbol{V}_{\text {cesat }} \\
(\mathrm{V})\end{array}$ & $\begin{array}{c}\mathbf{M}_{\mathbf{1}} \text { body } \\
\text { diode } \boldsymbol{V}_{\boldsymbol{f}} \\
(\mathrm{V})\end{array}$ & $\begin{array}{c}\mathbf{M}_{\mathbf{2}} \text { body } \\
\text { diode } \boldsymbol{V}_{\boldsymbol{f}} \\
(\mathrm{V})\end{array}$ \\
\hline $\mathbf{1 0}$ & 0.15 & 0.16 & 0.52 & 0.53 \\
\hline $\mathbf{2 5}$ & 0.38 & 0.40 & 0.57 & 0.59 \\
\hline $\mathbf{5 0}$ & 0.59 & 0.62 & 0.62 & 0.66 \\
\hline $\mathbf{7 5}$ & 0.71 & 0.74 & 0.66 & 0.71 \\
\hline $\mathbf{1 0 0}$ & 0.79 & 0.83 & 0.68 & 0.75 \\
\hline $\mathbf{1 2 5}$ & 0.87 & 0.90 & 0.71 & 0.79 \\
\hline $\mathbf{1 5 0}$ & 0.93 & 0.95 & 0.73 & 0.83 \\
\hline $\mathbf{2 0 0}$ & 1.03 & 1.06 & 0.76 & 0.90 \\
\hline $\mathbf{2 5 0}$ & 1.13 & 1.16 & 0.79 & 0.96 \\
\hline $\mathbf{3 0 0}$ & 1.22 & 1.24 & 0.82 & 1.02 \\
\hline $\mathbf{3 5 0}$ & 1.30 & 1.33 & & \\
\hline $\mathbf{4 0 0}$ & 1.38 & 1.41 & & \\
\hline $\mathbf{4 5 0}$ & 1.47 & 1.48 & & \\
\hline
\end{tabular}

Table 5.7 lists results of the same measurement for serial number SN302P main power module. In this module, the upper device $Q_{1} / M_{1}$ has slightly higher voltage drop than that of the lower device $Q_{2} / M_{2}$. This is opposite to the case in SN301P module, and it indicates possible variations among all the production modules. The variation may be caused by the chip itself and the soldering process.

Table 5.7. Measured main power module voltage drop for SN $302 \mathrm{P}$ at different temperatures

\begin{tabular}{|c|c|c|c|c|}
\hline \multicolumn{5}{|c|}{ Module SN 302P at 25 ${ }^{\circ} \mathbf{C}$} \\
\hline $\begin{array}{c}\text { Current } \\
(\mathbf{A})\end{array}$ & $\begin{array}{c}\mathbf{Q}_{\mathbf{1}} / \mathbf{M}_{\mathbf{1}} \\
\mathbf{V}_{\text {cesat }} \\
(\mathbf{V})\end{array}$ & $\begin{array}{c}\mathbf{Q}_{2} / \mathbf{M}_{\mathbf{2}} \\
\mathbf{V}_{\text {cesat }} \\
(\mathbf{V})\end{array}$ & $\begin{array}{c}\mathbf{M}_{\mathbf{1}} \text { body } \\
\text { diode } \boldsymbol{V}_{\boldsymbol{f}} \\
(\mathbf{V})\end{array}$ & $\begin{array}{c}\mathbf{M}_{\mathbf{2}} \text { body } \\
\text { diode } \boldsymbol{V}_{\boldsymbol{f}} \\
(\mathbf{V})\end{array}$ \\
\hline $\mathbf{1 0}$ & 0.09 & 0.09 & 0.70 & 0.70 \\
\hline $\mathbf{2 5}$ & 0.22 & 0.23 & 0.74 & 0.75 \\
\hline $\mathbf{5 0}$ & 0.40 & 0.42 & 0.78 & 0.80 \\
\hline $\mathbf{7 5}$ & 0.62 & 0.65 & 0.80 & 0.84 \\
\hline $\mathbf{1 0 0}$ & 0.79 & 0.83 & 0.82 & 0.87 \\
\hline $\mathbf{1 2 5}$ & 0.93 & 0.96 & 0.84 & 0.90 \\
\hline $\mathbf{1 5 0}$ & 1.04 & 1.05 & 0.85 & 0.93 \\
\hline $\mathbf{2 0 0}$ & 1.16 & 1.16 & 0.88 & 0.98 \\
\hline $\mathbf{2 5 0}$ & 1.24 & 1.23 & 0.91 & 1.03 \\
\hline $\mathbf{3 0 0}$ & 1.31 & 1.29 & 0.93 & 1.08 \\
\hline $\mathbf{3 5 0}$ & 1.37 & 1.35 & & \\
\hline $\mathbf{4 0 0}$ & 1.43 & 1.40 & & \\
\hline $\mathbf{4 5 0}$ & 1.49 & 1.46 & & \\
\hline
\end{tabular}

\begin{tabular}{|c|c|c|c|c|}
\hline \multicolumn{5}{|c|}{ Module SN 302P at $\mathbf{1 2 5}^{\circ} \mathbf{C}$} \\
\hline $\begin{array}{c}\text { Current } \\
(\mathbf{A})\end{array}$ & $\begin{array}{c}\mathbf{Q}_{1} / \mathbf{M}_{\mathbf{1}} \\
\boldsymbol{V}_{\text {cesat }} \\
(\mathrm{V})\end{array}$ & $\begin{array}{c}\mathbf{Q}_{2} / \mathbf{M}_{\mathbf{2}} \\
\boldsymbol{V}_{\text {cesat }} \\
(\mathrm{V})\end{array}$ & $\begin{array}{c}\mathbf{M}_{\mathbf{1}} \text { body } \\
\text { diode } \boldsymbol{V}_{\boldsymbol{f}} \\
(\mathrm{V})\end{array}$ & $\begin{array}{c}\mathbf{M}_{\mathbf{2}} \text { body } \\
\text { diode } \boldsymbol{V}_{\boldsymbol{f}} \\
(\mathrm{V})\end{array}$ \\
\hline $\mathbf{1 0}$ & 0.16 & 0.16 & 0.52 & 0.53 \\
\hline $\mathbf{2 5}$ & 0.38 & 0.40 & 0.57 & 0.59 \\
\hline $\mathbf{5 0}$ & 0.60 & 0.62 & 0.63 & 0.66 \\
\hline $\mathbf{7 5}$ & 0.73 & 0.74 & 0.66 & 0.71 \\
\hline $\mathbf{1 0 0}$ & 0.82 & 0.83 & 0.68 & 0.75 \\
\hline $\mathbf{1 2 5}$ & 0.89 & 0.89 & 0.71 & 0.79 \\
\hline $\mathbf{1 5 0}$ & 0.96 & 0.95 & 0.72 & 0.83 \\
\hline $\mathbf{2 0 0}$ & 1.07 & 1.06 & 0.76 & 0.90 \\
\hline $\mathbf{2 5 0}$ & 1.17 & 1.15 & 0.79 & 0.96 \\
\hline $\mathbf{3 0 0}$ & 1.27 & 1.24 & 0.82 & 1.03 \\
\hline $\mathbf{3 5 0}$ & 1.36 & 1.32 & & \\
\hline $\mathbf{4 0 0}$ & 1.44 & 1.40 & & \\
\hline $\mathbf{4 5 0}$ & 1.52 & 1.48 & & \\
\hline
\end{tabular}


For the individual devices in the main power module, the MOSFET dominates the conduction voltage drop when the current is below 100A. Figure 5.39(a) shows the voltage drop of individual IGBT and MOSFET and their combination. Both upper and lower devices exhibit similar characteristics. Since the MOSFET also conducts in the negative current direction, or synchronous rectification mode, the actual diode voltage drop should be the combination of $M_{1} / D_{1}$ or $M_{2} / D_{2}$.
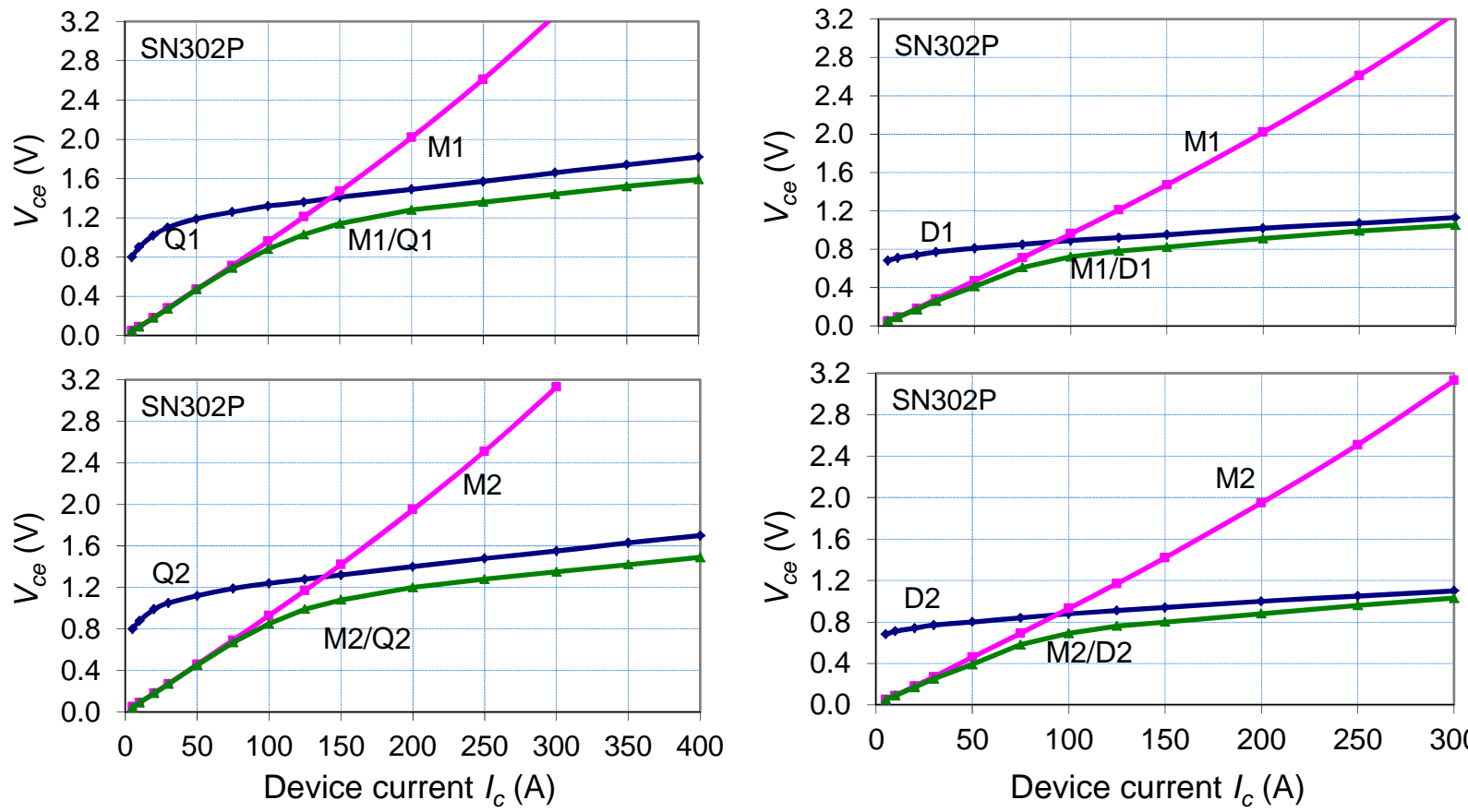

(a)

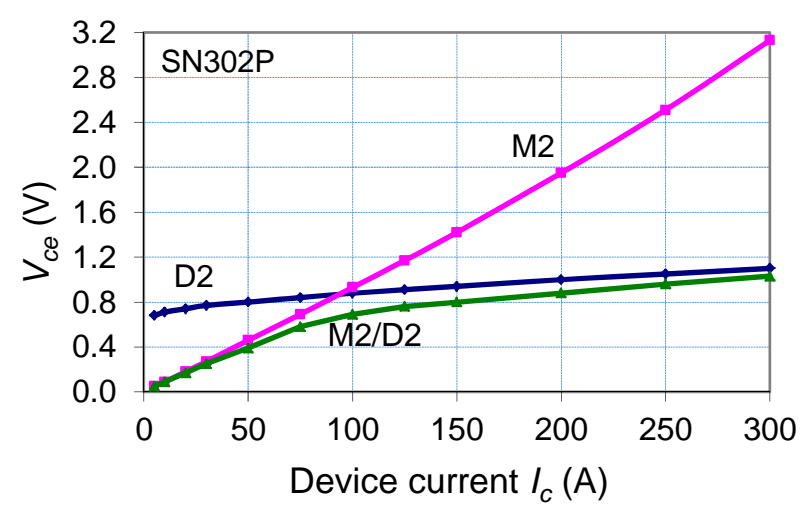

(b)

Figure 5.39. (a) voltage drop $V_{c e}$ of individual devices and their combination of Gen-3 module including upper device $\left(Q_{1} / M_{1}\right)$ and lower device $\left(Q_{2} / M_{2}\right)$; (b) $V_{c e}$ of individual diode and MOSFET and their combination of Gen-3 module including upper device $\left(D_{1} / M_{1}\right)$ and lower device $\left(D_{2} / M_{2}\right)$.

Figure 5.39(b) shows the voltage drop in the freewheeling condition, which is much lower than that in the positive current condition. This also implies that soft-switching inverter using hybrid switches has the best chance to achieve $99 \%$ efficiency or higher because it avoids the fixed voltage drop portion in both positive current and freewheeling paths. In both Figures 5.39(a) and 5.39 (b), this voltage drop is about $0.8 \mathrm{~V}$. It represents $80 \%$ of conduction loss at $100 \mathrm{~A}$ or $50 \%$ of conduction loss at the rated $400 \mathrm{~A}$ condition.

Table 5.8 through Table 5.11 list measured voltage drops for the auxiliary modules SN301A and SN302A at different temperatures. The auxiliary IGBT is rated at 150A. Therefore its negative temperature characteristic is only valid below 150A. Above that, the resistive element picks up and the voltage drop tends to be higher at higher temperatures. All the auxiliary diodes are rated $75 \mathrm{~A}$, their voltage drop is high as compared to the main diodes because they are ultrafast reverse recovery diodes that tend to have high conduction voltage drop. 
Table 5.8. Measured auxiliary module voltage drop for SN $301 \mathrm{~A}$ at $25^{\circ} \mathrm{C}$

\begin{tabular}{|c|c|c|c|c|c|c|c|c|}
\hline $\begin{array}{c}\text { Current } \\
(\mathbf{A})\end{array}$ & $\begin{array}{c}\mathbf{Q}_{\mathbf{x} \mathbf{1}} \\
\boldsymbol{V}_{\text {cesat }}(\mathbf{V})\end{array}$ & $\begin{array}{c}\mathbf{Q}_{\mathbf{x} 2} \\
\boldsymbol{V}_{\text {cesat }}(\mathbf{V})\end{array}$ & $\begin{array}{c}\mathbf{D}_{\mathbf{x} 1} \\
\boldsymbol{V}_{\boldsymbol{f}}(\mathbf{V})\end{array}$ & $\begin{array}{c}\mathbf{D}_{\mathbf{x} 2} \\
\boldsymbol{V}_{\boldsymbol{f}}(\mathbf{V})\end{array}$ & $\begin{array}{c}\mathbf{D}_{\mathbf{x} 3} \\
\boldsymbol{V}_{\boldsymbol{f}}(\mathbf{V})\end{array}$ & $\begin{array}{c}\mathbf{D}_{\mathbf{x} 4} \\
\boldsymbol{V}_{\boldsymbol{f}}(\mathbf{V})\end{array}$ & $\begin{array}{c}\mathbf{D}_{\mathbf{x} 5} \\
\boldsymbol{V}_{\boldsymbol{f}}(\mathbf{V})\end{array}$ & $\begin{array}{c}\mathbf{D}_{\mathbf{x} 6} \\
\boldsymbol{V}_{\boldsymbol{f}}(\mathbf{V})\end{array}$ \\
\hline $\mathbf{1 0}$ & 1.02 & 0.95 & 1.14 & 1.14 & 1.46 & 1.42 & 1.42 & 1.43 \\
\hline $\mathbf{2 5}$ & 1.17 & 1.06 & 1.46 & 1.47 & 1.88 & 1.82 & 1.83 & 1.83 \\
\hline $\mathbf{5 0}$ & 1.27 & 1.16 & 1.87 & 1.88 & 2.29 & 2.21 & 2.22 & 2.21 \\
\hline $\mathbf{7 5}$ & 1.39 & 1.27 & 2.15 & 2.16 & 2.67 & 2.57 & 2.59 & 2.57 \\
\hline $\mathbf{1 0 0}$ & 1.50 & 1.37 & 1.40 & 2.42 & 3.00 & 2.88 & 2.89 & 2.87 \\
\hline $\mathbf{1 5 0}$ & 1.70 & 1.56 & 2.85 & 2.87 & 3.57 & 3.43 & 3.45 & 3.42 \\
\hline $\mathbf{2 0 0}$ & 1.91 & 1.75 & 3.26 & 3.29 & 3.83 & 3.68 & 3.71 & 3.67 \\
\hline $\mathbf{2 5 0}$ & 2.14 & 1.95 & 3.65 & 3.68 & 4.08 & 3.93 & 3.96 & 3.91 \\
\hline
\end{tabular}

Table 5.9. Measured auxiliary module voltage drop for $\mathrm{SN} 301 \mathrm{~A}$ at $125^{\circ} \mathrm{C}$

\begin{tabular}{|c|c|c|c|c|c|c|c|c|}
\hline $\begin{array}{c}\text { Current } \\
(\mathbf{A})\end{array}$ & $\begin{array}{c}\mathbf{Q}_{\times 1} \\
\boldsymbol{V}_{\text {cesat }}(\mathbf{V})\end{array}$ & $\begin{array}{c}\mathbf{Q}_{\mathbf{x} 2} \\
\boldsymbol{V}_{\text {cesat }}(\mathbf{V})\end{array}$ & $\begin{array}{c}\mathbf{D}_{\mathbf{x} 1} \\
\boldsymbol{V}_{\boldsymbol{f}}(\mathbf{V})\end{array}$ & $\begin{array}{c}\mathbf{D}_{\mathbf{x} 2} \\
\boldsymbol{V}_{\boldsymbol{f}}(\mathbf{V})\end{array}$ & $\begin{array}{c}\mathbf{D}_{\mathbf{x} 3} \\
\boldsymbol{V}_{\boldsymbol{f}}(\mathbf{V})\end{array}$ & $\begin{array}{c}\mathbf{D}_{\mathbf{x} 4} \\
\boldsymbol{V}_{\boldsymbol{f}}(\mathbf{V})\end{array}$ & $\begin{array}{c}\mathbf{D}_{\mathbf{x} 5} \\
\boldsymbol{V}_{\boldsymbol{f}}(\mathbf{V})\end{array}$ & $\begin{array}{c}\mathbf{D}_{\mathbf{x} 6} \\
\boldsymbol{V}_{\boldsymbol{f}}(\mathbf{V})\end{array}$ \\
\hline $\mathbf{1 0}$ & 0.75 & 0.70 & 0.91 & 0.91 & 1.10 & 1.08 & 1.08 & 1.08 \\
\hline $\mathbf{2 5}$ & 0.92 & 0.85 & 1.24 & 1.24 & 1.51 & 1.48 & 1.49 & 1.48 \\
\hline $\mathbf{5 0}$ & 1.10 & 1.00 & 1.70 & 1.69 & 1.93 & 1.88 & 1.89 & 1.87 \\
\hline $\mathbf{7 5}$ & 1.27 & 1.15 & 1.99 & 3.00 & 2.31 & 2.25 & 2.27 & 2.25 \\
\hline $\mathbf{1 0 0}$ & 1.43 & 1.28 & 2.26 & 2.28 & 2.64 & 2.57 & 2.59 & 2.56 \\
\hline $\mathbf{1 5 0}$ & 1.73 & 1.53 & 2.74 & 2.77 & 3.22 & 3.13 & 3.16 & 3.11 \\
\hline $\mathbf{2 0 0}$ & 2.02 & 1.77 & 3.17 & 3.20 & 3.47 & 3.38 & 3.42 & 3.36 \\
\hline $\mathbf{2 5 0}$ & 2.32 & 2.01 & 3.55 & 3.60 & 3.72 & 3.63 & 3.67 & 3.60 \\
\hline
\end{tabular}

Table 5.10. Measured auxiliary module voltage drop for SN $302 \mathrm{~A}$ at $25^{\circ} \mathrm{C}$

\begin{tabular}{|c|c|c|c|c|c|c|c|c|}
\hline $\begin{array}{c}\text { Current } \\
(\mathbf{A})\end{array}$ & $\begin{array}{c}\mathbf{Q}_{\mathbf{x} \mathbf{1}} \\
\boldsymbol{V}_{\text {cesat }}(\mathbf{V})\end{array}$ & $\begin{array}{c}\mathbf{Q}_{\mathbf{x} 2} \\
\boldsymbol{V}_{\text {cesat }}(\mathbf{V})\end{array}$ & $\begin{array}{c}\mathbf{D}_{\mathbf{x} 1} \\
\boldsymbol{V}_{\boldsymbol{f}}(\mathbf{V})\end{array}$ & $\begin{array}{c}\mathbf{D}_{\mathbf{x} 2} \\
\boldsymbol{V}_{\boldsymbol{f}}(\mathbf{V})\end{array}$ & $\begin{array}{c}\mathbf{D}_{\mathbf{x} 3} \\
\boldsymbol{V}_{\boldsymbol{f}}(\mathbf{V})\end{array}$ & $\begin{array}{c}\mathbf{D}_{\mathbf{x} 4} \\
\boldsymbol{V}_{\boldsymbol{f}}(\mathbf{V})\end{array}$ & $\begin{array}{c}\mathbf{D}_{\mathbf{x} 5} \\
\boldsymbol{V}_{\boldsymbol{f}}(\mathbf{V})\end{array}$ & $\begin{array}{c}\mathbf{D}_{\mathbf{x} 6} \\
\boldsymbol{V}_{\boldsymbol{f}}(\mathbf{V})\end{array}$ \\
\hline $\mathbf{1 0}$ & 0.95 & 0.95 & 1.10 & 1.12 & 1.40 & 1.46 & 1.42 & 1.54 \\
\hline $\mathbf{2 5}$ & 1.07 & 1.06 & 1.38 & 1.43 & 1.80 & 1.90 & 1.83 & 2.02 \\
\hline $\mathbf{5 0}$ & 1.18 & 1.17 & 1.75 & 1.84 & 2.18 & 2.31 & 2.22 & 2.49 \\
\hline $\mathbf{7 5}$ & 1.29 & 1.27 & 2.00 & 2.10 & 2.53 & 2.69 & 2.58 & 2.92 \\
\hline $\mathbf{1 0 0}$ & 1.40 & 1.36 & 2.22 & 2.35 & 2.83 & 3.02 & 2.89 & 3.28 \\
\hline $\mathbf{1 5 0}$ & 1.60 & 1.56 & 2.61 & 2.78 & 3.36 & 3.61 & 3.45 & 3.94 \\
\hline $\mathbf{2 0 0}$ & 1.80 & 1.75 & 2.96 & 3.18 & 3.60 & 3.89 & 3.70 & 4.23 \\
\hline $\mathbf{2 5 0}$ & 2.02 & 1.95 & 3.31 & 3.56 & 3.84 & 4.14 & 3.95 & 4.51 \\
\hline
\end{tabular}

Table 5.11. Measured auxiliary module voltage drop for SN $302 \mathrm{~A}$ at $125^{\circ} \mathrm{C}$

\begin{tabular}{|c|c|c|c|c|c|c|c|c|}
\hline $\begin{array}{c}\text { Current } \\
(\mathbf{A})\end{array}$ & $\begin{array}{c}\mathbf{Q}_{\mathbf{x} 1} \\
\boldsymbol{V}_{\text {cesat }}(\mathbf{V})\end{array}$ & $\begin{array}{c}\mathbf{Q}_{\mathbf{x} 2} \\
\boldsymbol{V}_{\text {cesat }}(\mathbf{V})\end{array}$ & $\begin{array}{c}\mathbf{D}_{\mathbf{x} 1} \\
\boldsymbol{V}_{\boldsymbol{f}}(\mathbf{V})\end{array}$ & $\begin{array}{c}\mathbf{D}_{\mathbf{x} 2} \\
\boldsymbol{V}_{\boldsymbol{f}}(\mathbf{V})\end{array}$ & $\begin{array}{c}\mathbf{D}_{\mathbf{x} 3} \\
\boldsymbol{V}_{\boldsymbol{f}}(\mathbf{V})\end{array}$ & $\begin{array}{c}\mathbf{D}_{\mathbf{x} 4} \\
\boldsymbol{V}_{\boldsymbol{f}}(\mathbf{V})\end{array}$ & $\begin{array}{c}\mathbf{D}_{\mathbf{x} 5} \\
\boldsymbol{V}_{\boldsymbol{f}}(\mathbf{V})\end{array}$ & $\begin{array}{c}\mathbf{D}_{\mathbf{x} 6} \\
\boldsymbol{V}_{\boldsymbol{f}}(\mathbf{V})\end{array}$ \\
\hline $\mathbf{1 0}$ & 0.71 & 0.70 & 0.88 & 0.90 & 1.07 & 1.10 & 1.09 & 1.13 \\
\hline $\mathbf{2 5}$ & 0.86 & 0.85 & 1.18 & 1.22 & 1.47 & 1.52 & 1.49 & 1.58 \\
\hline $\mathbf{5 0}$ & 1.02 & 1.00 & 1.58 & 1.66 & 1.86 & 1.94 & 1.90 & 2.04 \\
\hline $\mathbf{7 5}$ & 1.18 & 1.15 & 1.86 & 1.96 & 2.22 & 2.33 & 2.27 & 2.46 \\
\hline $\mathbf{1 0 0}$ & 1.32 & 1.28 & 2.10 & 1.22 & 2.53 & 2.67 & 2.60 & 2.82 \\
\hline $\mathbf{1 5 0}$ & 1.58 & 1.53 & 2.53 & 2.70 & 3.08 & 3.27 & 3.17 & 3.46 \\
\hline $\mathbf{2 0 0}$ & 1.84 & 1.76 & 2.91 & 3.12 & 3.33 & 3.53 & 3.43 & 3.73 \\
\hline $\mathbf{2 5 0}$ & 2.10 & 2.00 & 3.26 & 3.50 & 3.56 & 3.78 & 3.68 & 3.95 \\
\hline
\end{tabular}

In resonant circuit operation, all the auxiliary switches and diodes only conduct partial resonant current; therefore they do not need to be fully rated. Depending on the turns ratio, typical current 
distribution at 400 A peak current condition is $250 \mathrm{~A}$ flowing in auxiliary switches and $150 \mathrm{~A}$ flowing in auxiliary diodes. Furthermore, the auxiliary switches and diodes only conduct in a very short period, typically $3 \%$ of main switch conduction period; therefore their conduction loss is negligible.

\section{B. Comparison of Voltage Drop Between Gen-1, Gen-2, and Gen-3 Modules}

Figure 5.40 repeats the PSPICE simulation results of the Gen-3 module design reported in the last year's quarterly report. The measured voltage drops of Gen-1 module, CM400DY-12NF, and CM300DY-12NF are also compared in the graph. At the design stage, two possible configurations were considered for Gen-3 module design. The final selection was to use CM400DY-12NF IGBTs in parallel with two STY11265M5 MOSFETs.

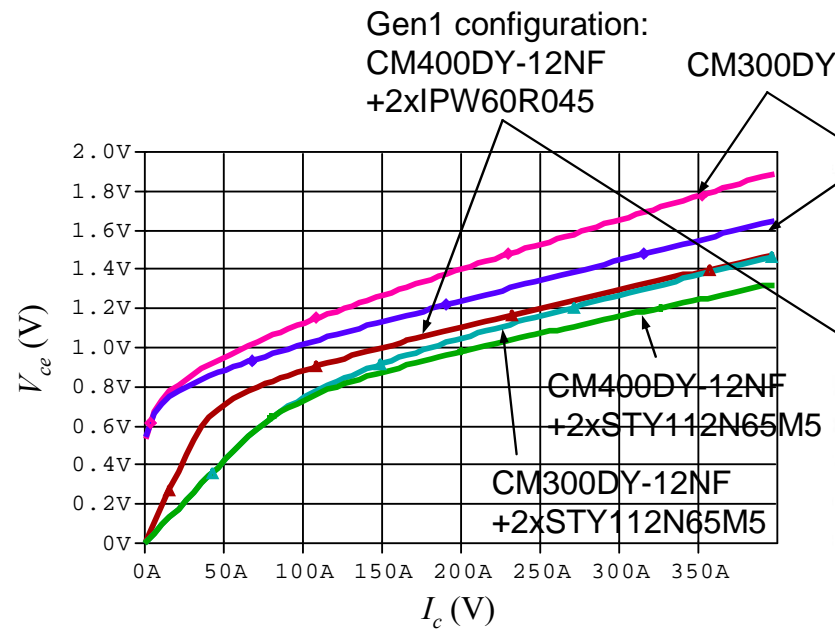

(a)

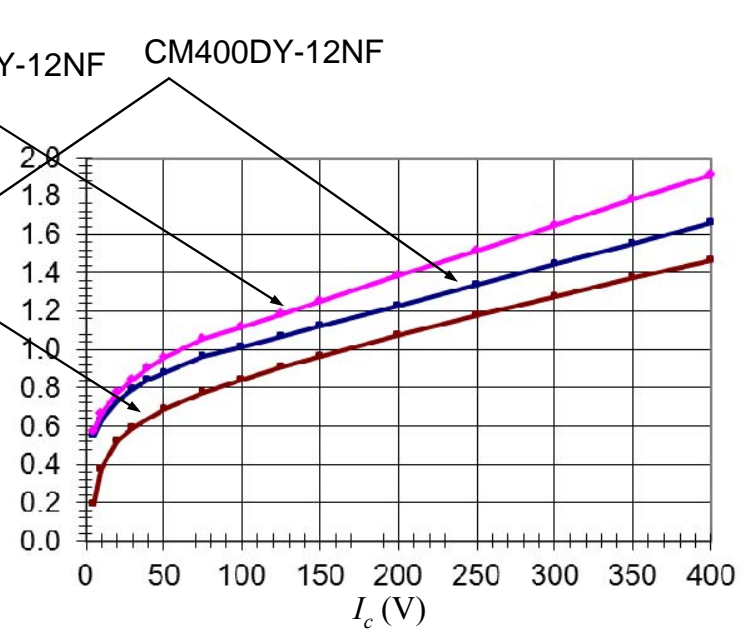

(b)

Figure 5.40. Model verification using Gen-1 module to predict performance of possible Gen-3 module designs.

Figure 5.41 shows the comparison of the measured voltage drop between Gen-1 module SN102, Gen-2 module SN201, and Gen-3 module SN302P. As shown in Figure 5.41(a), the upper device $\left(Q_{1} / M_{1}\right)$ conduction characteristic of SN302P matches the simulated model in Figure 5.40 (a) very well, but the lower device $\left(Q_{2} / M_{2}\right)$ appears to have higher voltage drop at higher current region. The reason of mismatch is most likely caused by the IGBT chip. Some of Gen-3 IGBT chips seemed to have higher voltage drop than that of the Gen-1 IGBT. However, the overall design matches the originally simulated model very well, especially at the lower current region. 


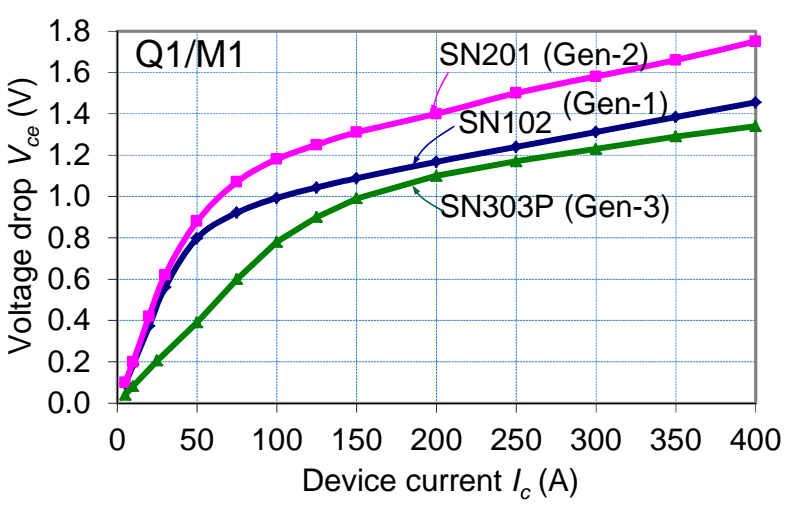

(a)

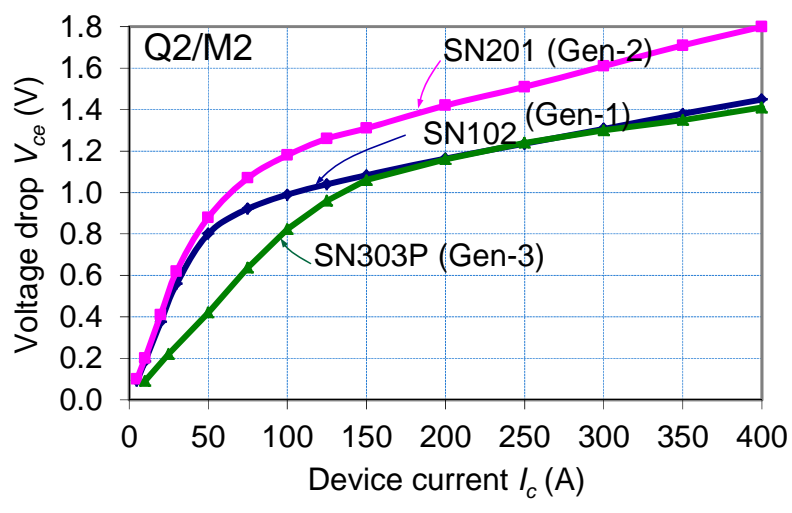

(b)

Figure 5.41. Voltage drop comparison between Gen-1, Gen-2, and Gen-3 modules: (a) upper device and (b) lower device.

\section{Switching Characteristic Measurement Results}

To avoid wiring induced inductance, a multilayer power board is designed to accommodate laminated bus bar and DC bus bypass capacitors. The power board contains 10 copper layers to ensure current carrying capability. Figure 5.42(a) shows the test setup with power board sitting on the main power module and auxiliary module. Figure 5.42(b) shows the complete setup for switching characteristic evaluation. The Gen-3 gate drive board sits on top of the power board with ribbon cables connecting the driving signals from the control board. Low-inductance capacitors are used as the resonant capacitors, which are directly screwed on the right-hand side of the power board. The left-hand side of the power board is for resonant inductor connection.

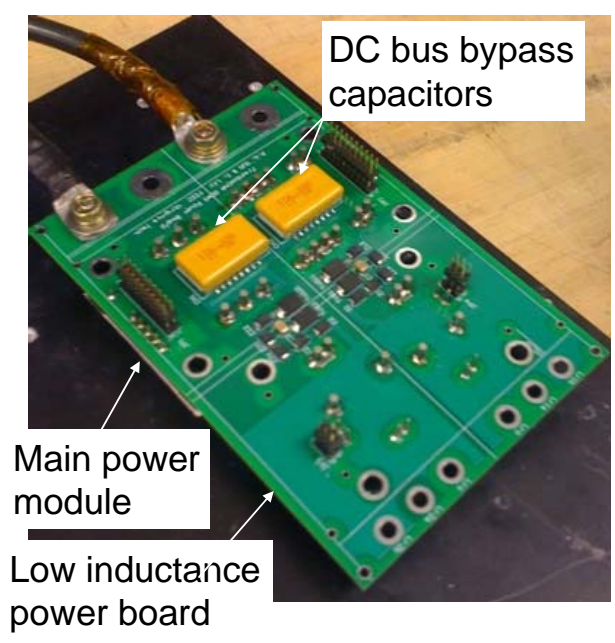

(a)

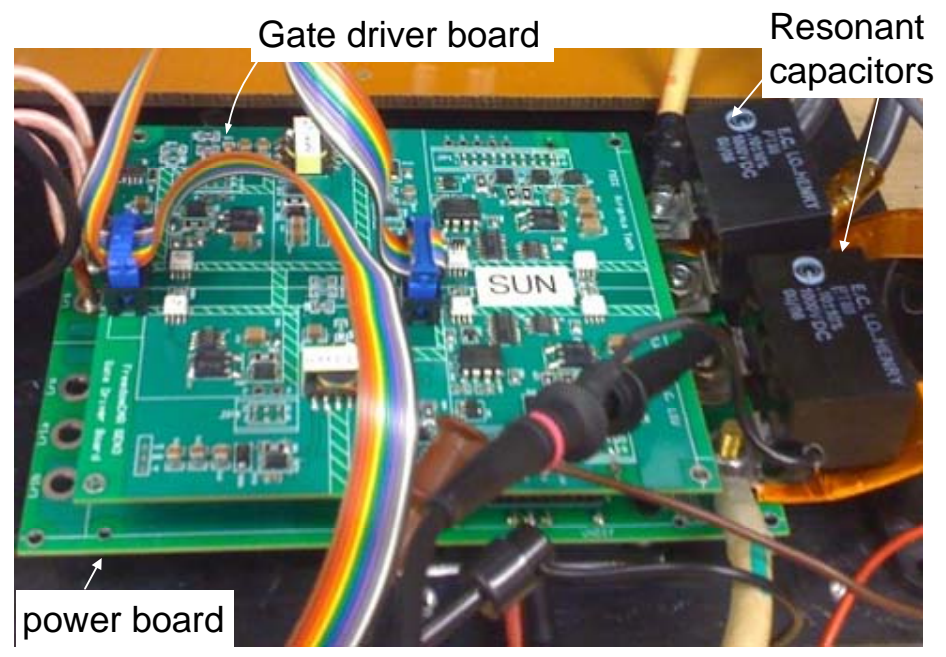

(b)

Figure 5.42. Switching characteristics measurement setup: (a) Gen-3 module power board assembly and (b) complete setup with gate driver board and resonant circuit connection.

In order to show how the Gen-3 module design is superior to both Gen-1 and Gen-2 modules, we first compare Gen-1 and Gen-2 switching characteristics, as shown in Figure 5.43. Although 
both modules can achieve zero-voltage switching, Gen-1 module has a noticeable ringing on resonant current $I_{L r}$ and gate voltage $V_{G E}$. The ringing of $I_{L r}$ waveform is caused by the parasitic inductances of the module internal structure, while the ringing of the $V_{G E}$ waveform is caused by the gate drive circuit and power bus layout.

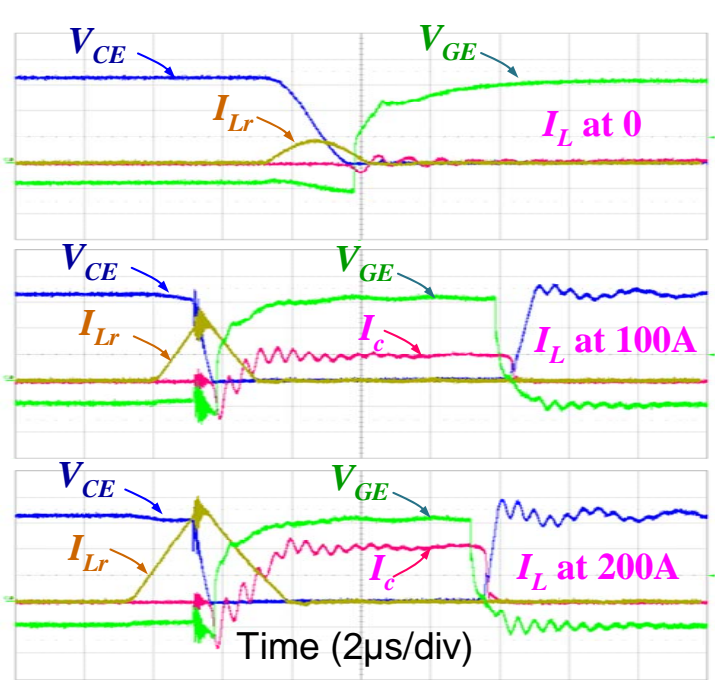

(a)

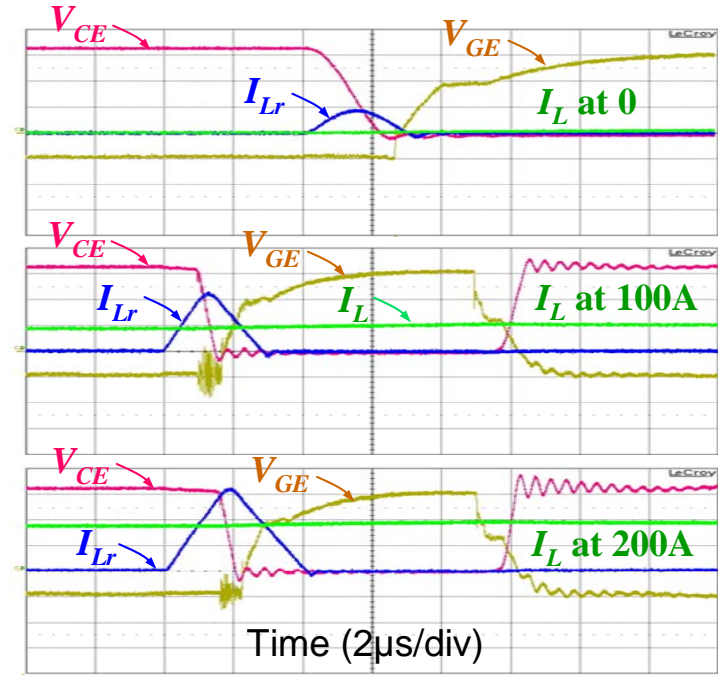

(b)

Figure 5.43. Switching characteristic comparison between Gen-1 and Gen-2 modules: (a) Gen-1 module and (b) Gen-2 module.

Figure 5.44 compares switching waveforms between Gen-2 and Gen-3 modules. The Gen-2 low-profile module was able to eliminate the majority of the module internal inductance. However, its gate drive circuit and associated power board still contains significant parasitic inductance. Thus its $V_{G E}$ waveform contains significant ringing at 100-A and 200-A test conditions. In the Gen-3 design, the gate drive and power boards shorten the gate drive signal length and thus reduce associated parasitic inductance; therefore, the $V_{G E}$ waveform shown in Figure 5.44(b) clearly avoids the parasitic ringing. Zero-voltage switching is clearly seen in all Gen-1, Gen-2 and Gen-3 modules and in all current conditions by noticing that the device voltage $V_{C E}$ drops to zero before gate drive $V_{G E}$ is turned on. Measurement results clearly indicate that Gen-3 module is nearly perfect with not only significant conduction loss reduction, but also switching noise elimination. All waveforms are clean, and zero-voltage switching can be achieved at different current levels. 


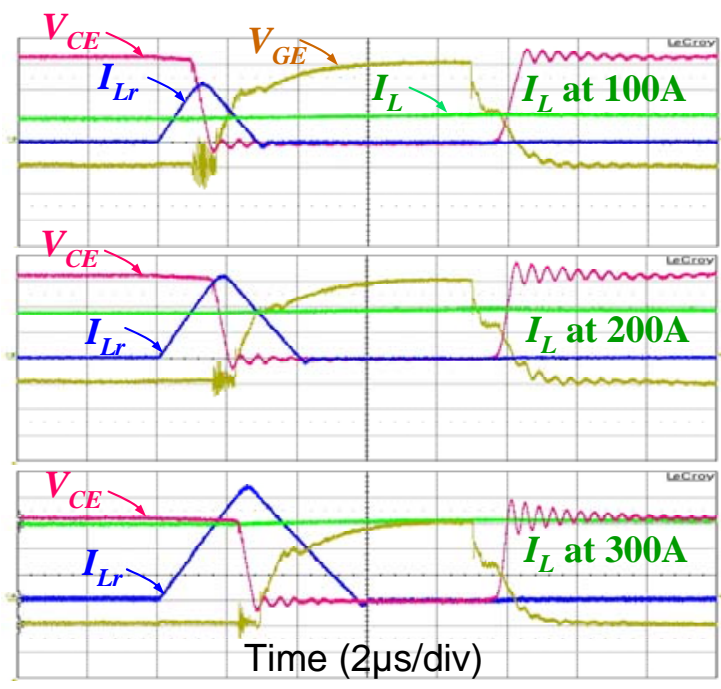

(a)

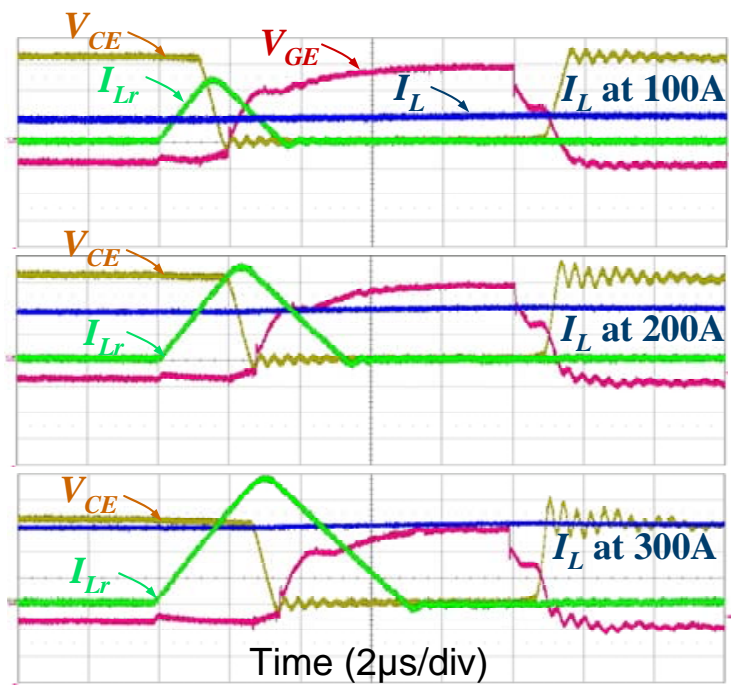

(b)

Figure 5.44. Switching characteristic comparison between Gen-2 and Gen-3 modules: (a) Gen-2 module and (b) Gen-3 module.

Using the measured conduction and switching characteristics, the inverter efficiency can be calculated with the loss separation method. Figure 5.45 shows the projected inverter efficiency for inverters using Gen-1, Gen-2, and Gen-3 modules under 10-kHz switching frequency. Gen-2 is least efficient because its substrate conduction paths introduce substantial voltage drop and associated loss. Gen-3 improves light-load efficiency by about $0.4 \%$ until about $30 \mathrm{~kW}$ and about $0.2 \%$ at full load as compared to Gen-1 because of better MOSFETs and freewheeling path voltage drop reduction.

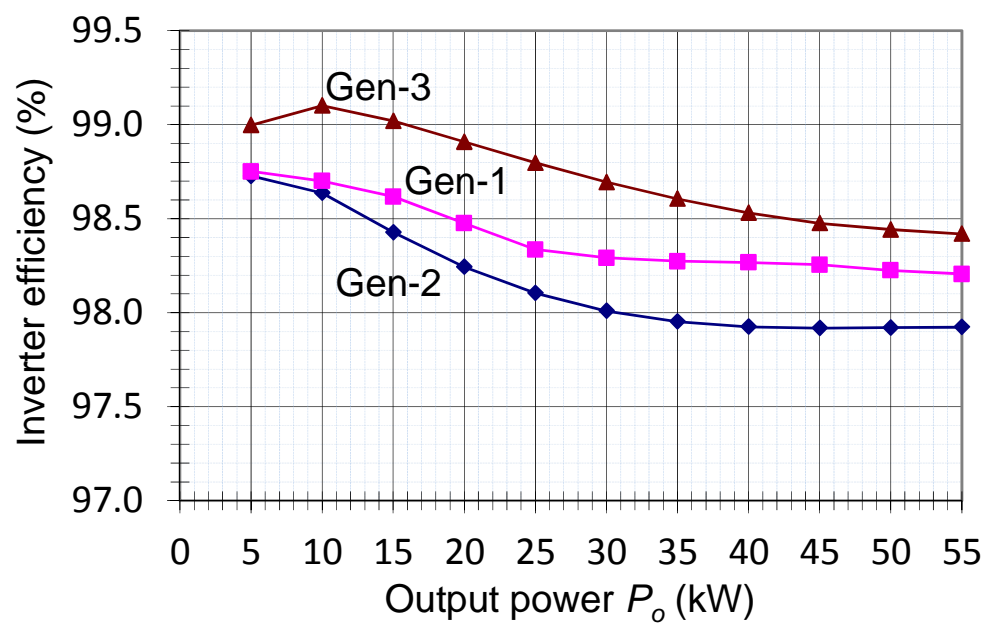

Figure 5.45. Comparison of projected efficiency between Gen-1, Gen-2, and Gen-3 inverters.

As compared to Gen-1, Gen-3 improves efficiency significantly over the entire load range. In average, it shows $0.5 \%$ efficiency improvement because of the conduction loss reduction in both positive current and freewheeling current directions. Further experimental verification is needed to verify the projected efficiency profile. 


\section{Gen-3 Assembly and Preliminary Efficiency Measurement Results}

Figure 5.46 shows photographs of the Gen-3 inverter assembly. The heat sink is air-cooled, and the case has screw holes to allow mounting on the chassis of the Azure Dynamics vehicle. In Figure 5.46(a), the front view shows copper bars for input DC and output AC connections. Two high-frequency capacitors are located on each end. The DSP board is mounted on the top case; its signals are connected to the interface board through a ribbon cable.

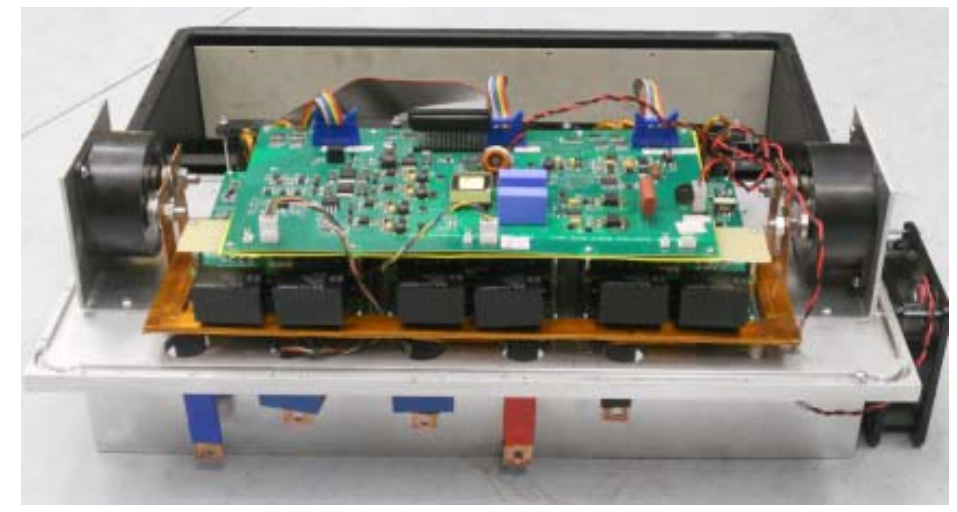

(a)

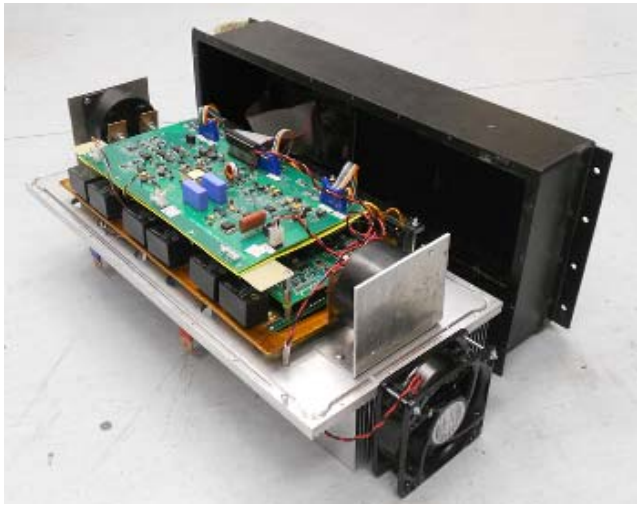

(b)

Figure 5.46. Gen-3 soft-switching inverter assembly: (a) front view and (b) side view.

Figures 5.47, 5.48, and 5.49 show all three generations of the soft-switching inverter. Gen-1 inverter has integrated cooling for the modules, and thus the cooling system requires only one external manifold to distribute the coolant. Gen-2 inverter adopts the low-profile modules that allow both liquid- and air-cooled. In this design, a homemade heat sink was designed to fit the module mounting. The size of coupled magnetics was also reduced. Gen-3 inverter is the only air-cooled design. The size of its coupled magnetics is the same as that in Gen-2 inverter, and the overall size can fit the existing chassis quite comfortably.

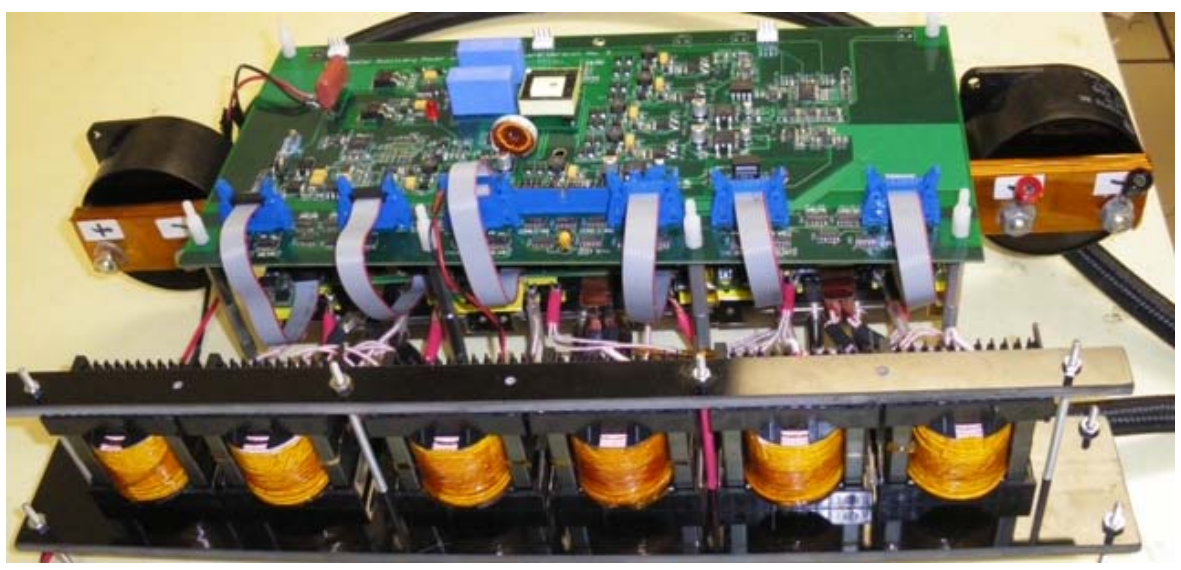

Figure 5.47. Photograph of Gen-1 inverter assembly. 


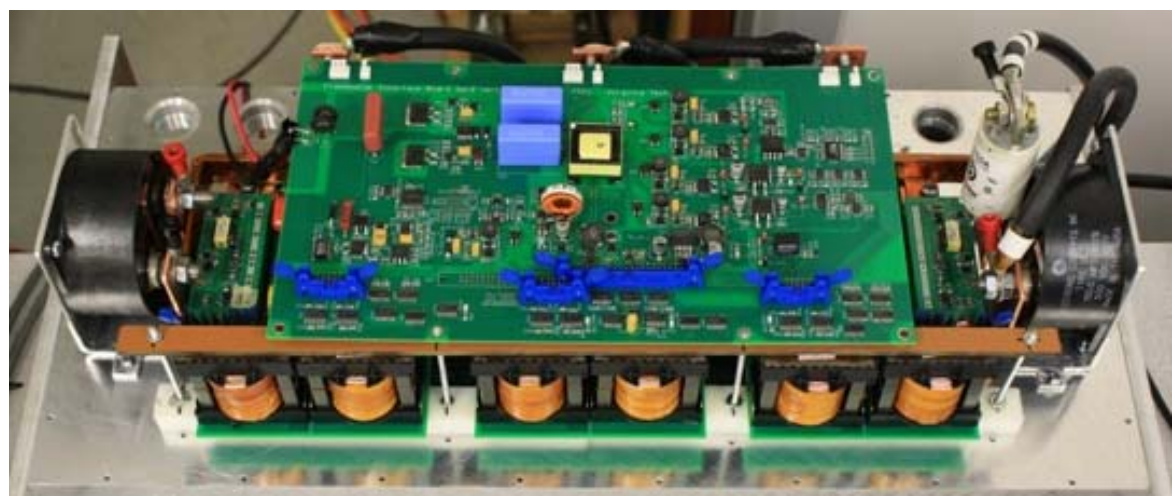

Figure 5.48. Photograph of Gen-2 inverter assembly.

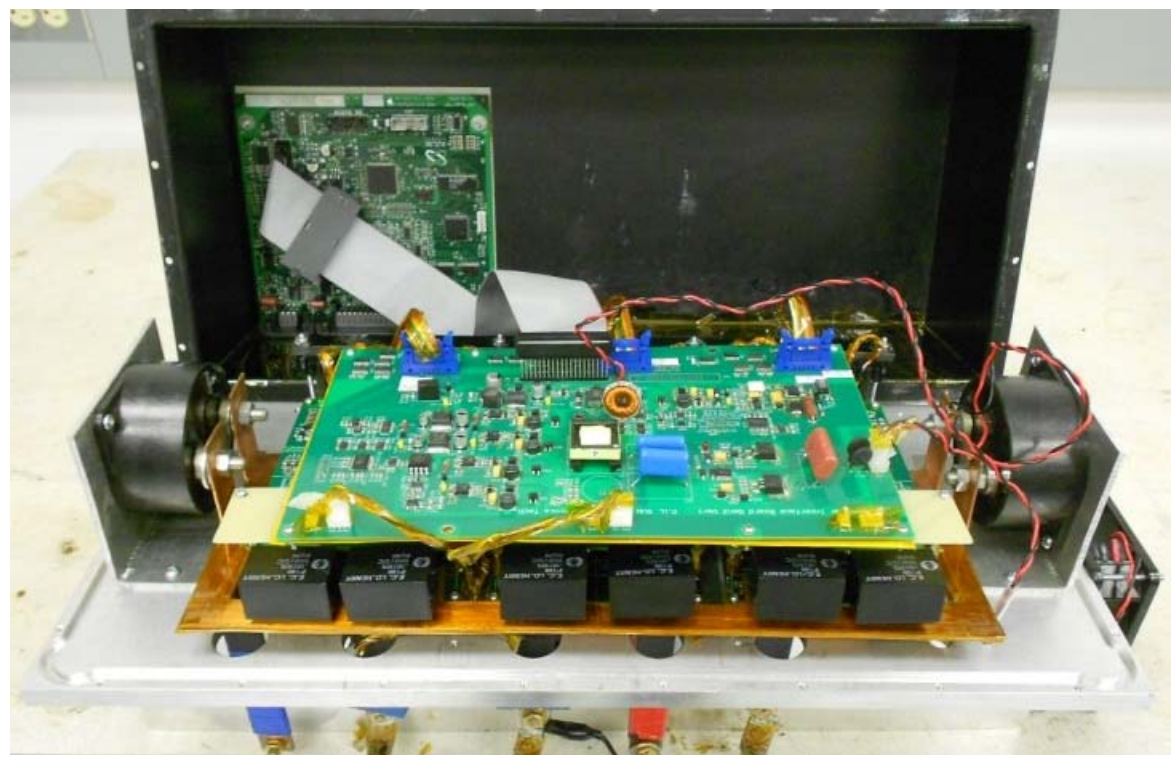

Figure 5.49. Photograph of Gen-3 inverter assembly.

For the efficiency measurement, it is difficult to measure $1 \%$ loss because the input and output results are so close that any instrumentation or recording error can cause significant error in efficiency. Therefore, we used the inductor as the load and measured the loss of the inverter under pure inductor load condition. Since the inductor load only circulates the energy through diode freewheeling, the measured loss under certain $\mathrm{kVA}$ condition should be about the same as that under the same $\mathrm{kW}$ condition. With the synchronous rectification, the reverse conduction loss is comparable to the forward conduction loss, so the inverter efficiency can be calculated using the loss measured with the inductive load. Figure 5.50 compares the inverter efficiency for inverters using Gen-1, Gen-2, and Gen-3 modules under 10-kHz switching frequency at $45-\mathrm{Hz}$ fundamental frequency or 2700-rpm condition. Each of the three generation inverters was tested under the same inductive load conditions. Gen-2 is least efficient because its substrate conduction paths introduce substantial voltage drop and associated losses. Gen-1 has a different modulation method, so its light load efficiency seems to be the same or potentially higher than that of Gen-3, but overall Gen-3 inverter improves the efficiency over Gen- 1 by about $0.4 \%$ and about $0.7 \%$ over Gen-2. 


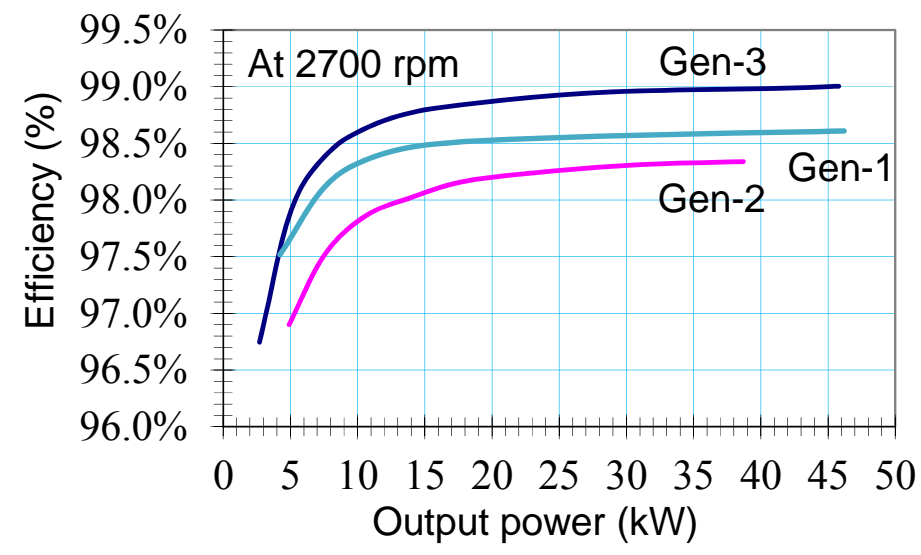

Figure 5.50. Comparison of measured efficiency between Gen-1, Gen-2, and Gen-3 inverters at 2700-rpm condition.

Figures 5.51 and 5.52 compare the inverter efficiency for inverters using Gen-1, Gen-2, and Gen3 modules under $10-\mathrm{kHz}$ switching frequency at $60-$ and $83.3-\mathrm{Hz}$ fundamental frequencies or 3600- and 5000-rpm conditions. All three-generation inverters were tested under the same inductive load conditions. Gen-2 is again the least efficient. Gen-1 has tends to have a higher light-load due to a different modulation scheme, but Gen-3 still show the best efficiency overall with the improvement over Gen-1 by about $0.3 \%$ and about $0.6 \%$ over Gen- 2 in most operating range. The results agree with the loss calculation based on conduction and switching loss separation method that were reported in the last quarterly report quite well in 10 to $30 \mathrm{~kW}$ range.

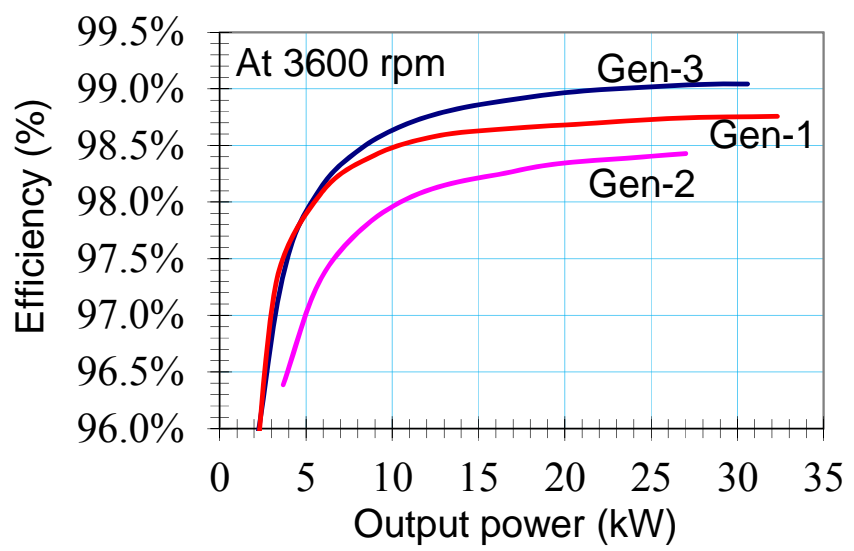

Figure 5.51. Comparison of measured efficiency between Gen-1, Gen-2, and Gen-3 inverters at 3600-rpm condition. 


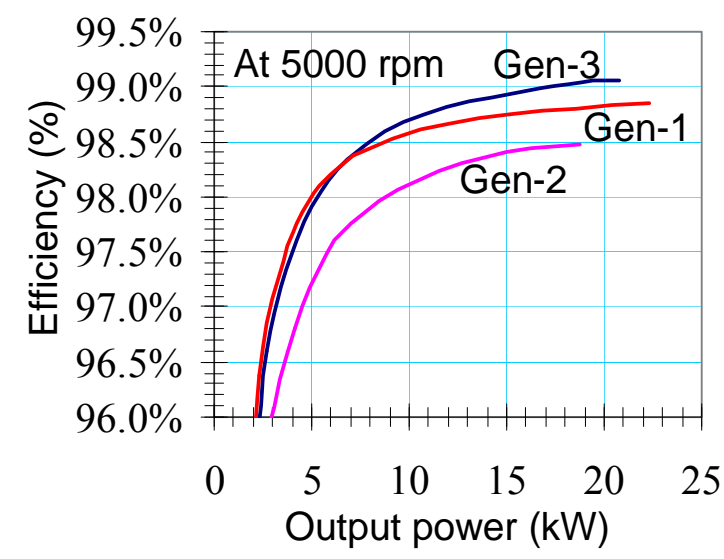

Figure 5.52. Comparison of measured efficiency between Gen-1, Gen-2, and Gen-3 inverters at 5000-rpm condition. 


\section{IN-VEHICLE TEST}

\subsection{Dynamometer Testing}

Figure 6.1 shows the complete circuit diagram of the three-phase soft-switching inverter prototypes showing the key components of the power circuit including the soft-switching modules, resonant capacitors, and coupled magnetics.

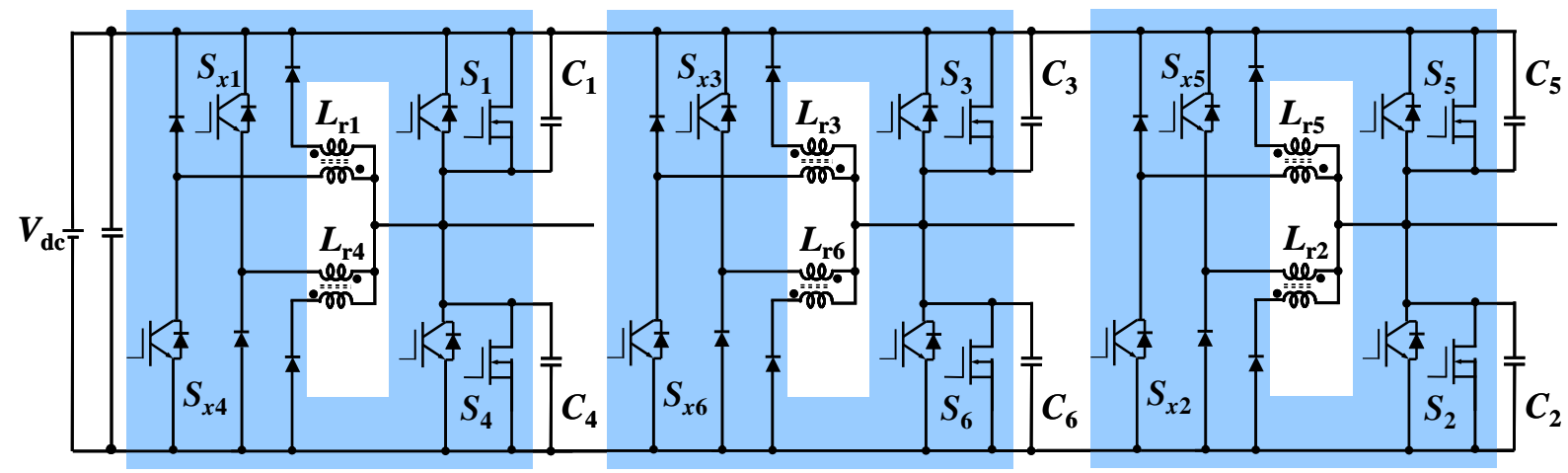

Figure 6.1. Three-phase soft-switching inverter using hybrid switches, and (b) Photograph of a 325V, 30-kW prototype.

Figure 6.2 shows the photograph of the Gen-3 inverter prototype. It can be seen that the unit fits inside the existing case provided by Azure Dynamics. Figure 6.2(a) shows the front view of the inverter with the key components marked on the figure. Figure 6.2(b) shows the back view of the inverter. The resonant inductors are integrated as a part of the complete assembly. The markings also indicate the temperature monitoring points during the dyno testing.

The entire inverter has only one 3-W cooling fan to serve for air circulation. There are eight thermal couples installed at different locations: module case, DC bus capacitor, three heat sink points, two resonant inductor points, and ambient. The measured module case point is the farthest point away from the fan and is the worst case among all the modules. One of the measured resonant inductor point is also farthest point are from the fan and is the worst case among all the inductors.

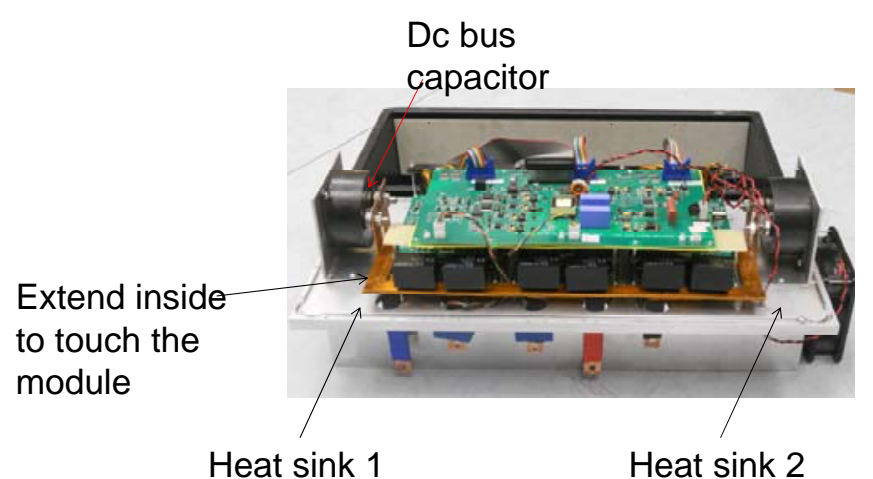

(a)

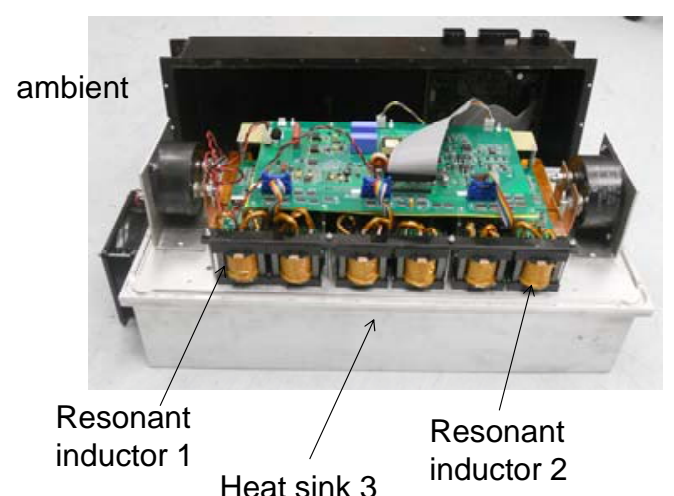

(b)

Figure 6.2. Photograph of the Gen-3 soft-switching inverter prototype: (a) front view and (b) back view. 
Figure 6.3 shows the photograph of the Gen-3 inverter mounted on the test rack for the dynamometer testing. The control board is attached to the top case. The DC input lines are directly connected to the DC bus capacitor, and the AC output lines are connected through cables to the measurement box and then to the motor under test. Two of the three output cables have current sensors attached to them. The measurement box has voltage and current calibrated to provide signals to a Yogokawa power meter - WT1600. All thermal couples are also connected to a data acquisition system that can record the temperature information for a long period. In this setup, the data were recorded in 1-s interval.

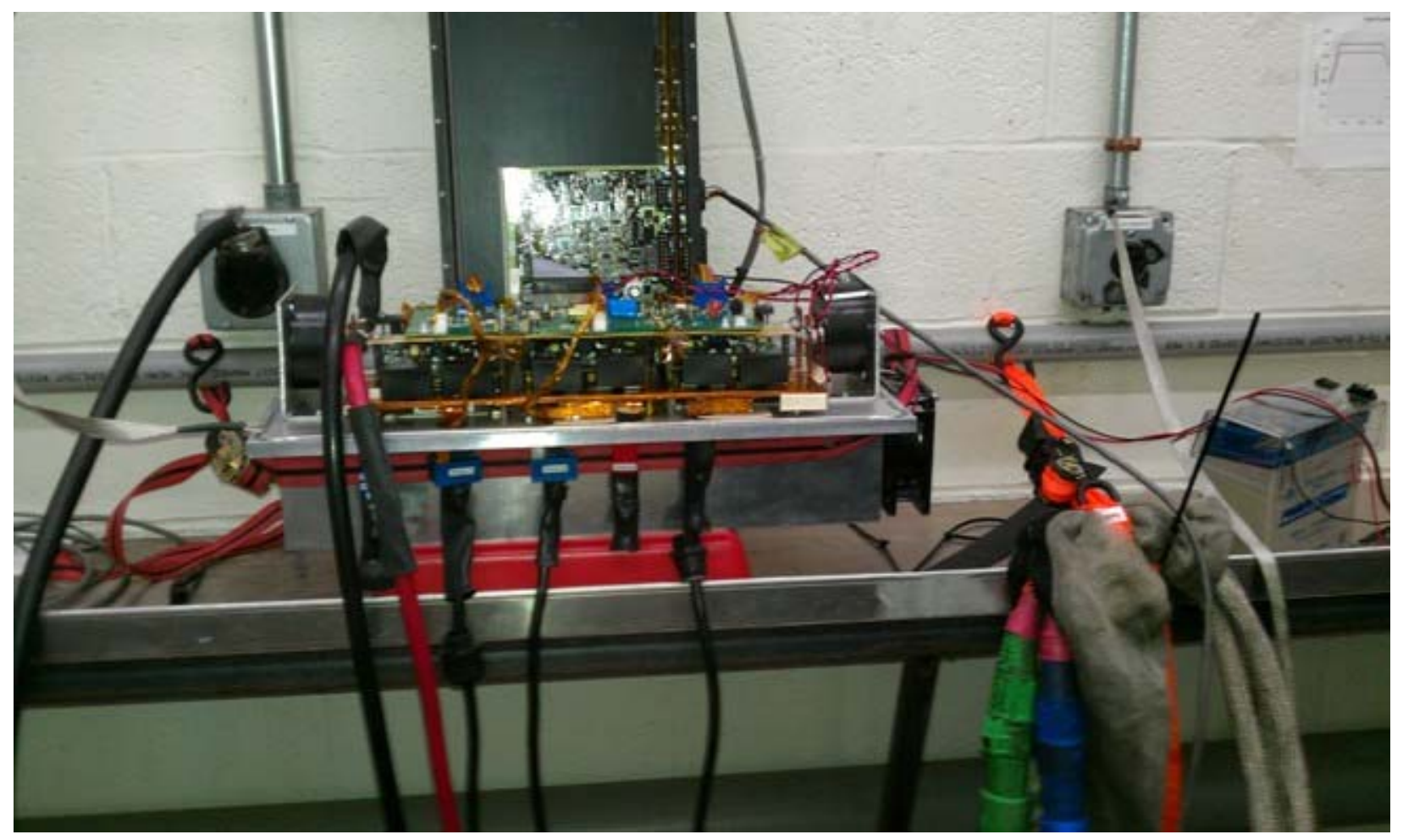

Figure 6.3. Photograph showing the Gen-3 inverter mounted on the test rack for the dyno testing.

The inverter operates under discontinuous PWM mode with $10-\mathrm{kHz}$ switching frequency. It was tested with three voltage levels: 275,325 , and $375 \mathrm{~V}$ for a 4-pole, $90-\mathrm{kW}$ induction motor for electric vehicle traction drives. Table 6.1 lists the three different speed and torque test conditions in which the efficiency and other performance such as the output current waveforms were monitored. With a 4-pole machine, the setting at $3000 \mathrm{rpm}$ means a fundamental frequency of $100 \mathrm{~Hz}$, and the setting at $1000 \mathrm{rpm}$ means a fundamental frequency of $33.3 \mathrm{~Hz}$.

The dynamometer is a re-generation type that allows the speed to be set constant while the motor under test can adjust torque from positive to negative. Therefore, we not only tested the motoring mode with positive torque, but also tested one re-gen condition at $1000 \mathrm{rpm},-100 \mathrm{Nm}$ for each voltage setting. 
Table 6.1. Test conditions that are run more than 10 minutes for each data set

\begin{tabular}{llll}
$\begin{array}{l}\text { Op. } \\
\text { Point }\end{array}$ & $\begin{array}{l}\text { DC bus } \\
\text { supply(V) }\end{array}$ & $\begin{array}{c}\text { Dyno } \\
(\mathrm{rpm})\end{array}$ & $\begin{array}{c}\text { Torque } \\
(\mathrm{Nm})\end{array}$ \\
\hline & & & \\
1 & 325 & 3000 & 100 \\
2 & 325 & 1000 & 200 \\
3 & 325 & 1000 & -100 \\
& & & \\
4 & 275 & 3000 & 100 \\
5 & 275 & 1000 & 200 \\
6 & 275 & 1000 & -100 \\
7 & 375 & 3000 & 100 \\
8 & 375 & 1000 & 200 \\
9 & 375 & 1000 & -100 \\
\hline
\end{tabular}

Figures 6.4(a) and 6.4(b) show the output phase current waveforms at $3029 \mathrm{rpm}, 115 \mathrm{Nm}$ and $1030 \mathrm{rpm}, 225 \mathrm{Nm}$ load conditions. Both conditions were tested with 325-V DC bus. The highspeed operation tends to have waveform distortion due to insufficient voltage. However, in this case, it was due to the control loop parameter mismatch. The program assumed a 55-kW machine, but the motor under test was a $90-\mathrm{kW}$ machine. Therefore, by accident, the inverter was tested at a power level much higher than the initial setting. The inverter output in Figure 6.4(a) condition reaches $40 \mathrm{~kW}$, which is highest power that the Gen-3 inverter has ever been tested. The Azure Dynamics team fixed the control parameters this test, and the waveforms were all clean sinusoidal since then. Figure 6.4(b) represents highest phase current condition. Even though the output power is only $27 \mathrm{~kW}$, the inverter output current rms is $146 \mathrm{~A}$, much higher than the $40-\mathrm{kW}$ output at $3000 \mathrm{rpm}$ condition.

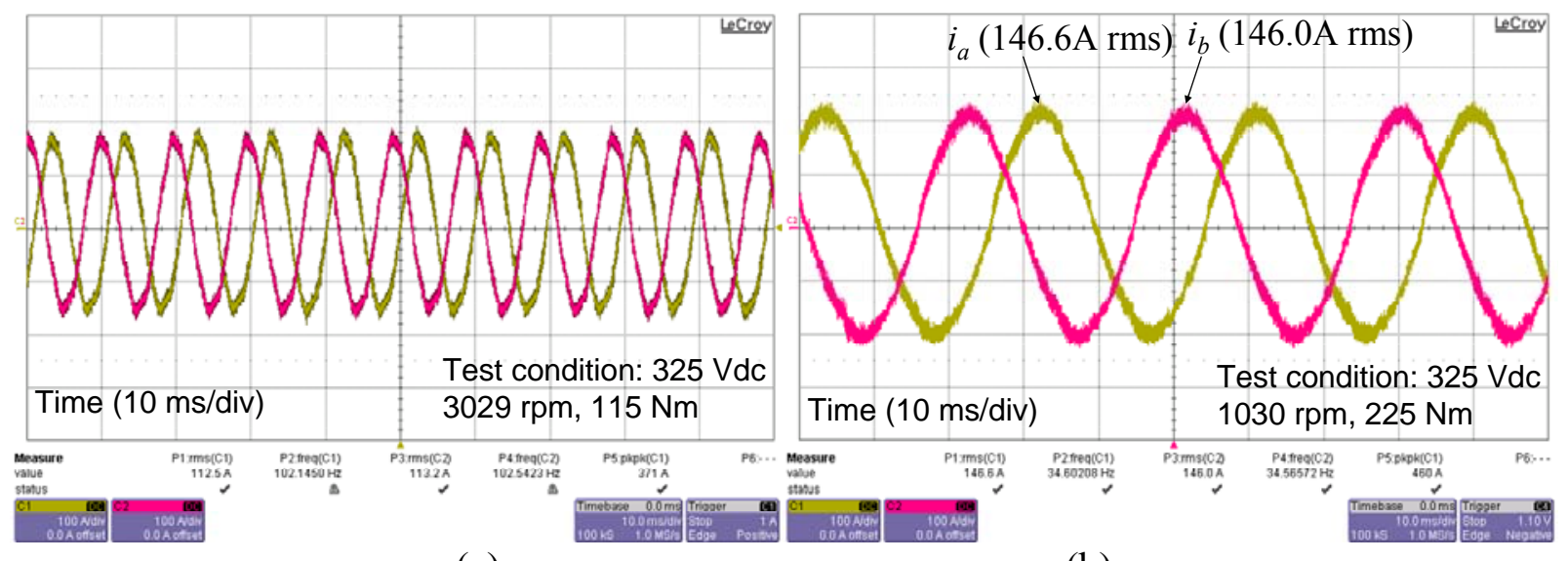

(a)

(b)

Figure 6.4. Experimental inverter output current waveforms at (a) 40-kW, 3029rpm, $115 \mathrm{Nm}$, and (b) 27-kW, 1030 rpm, $225 \mathrm{Nm}$.

Figure 6.5(a) shows the inverter output current waveforms at 3030-rpm, 110-Nm load condition at $275-\mathrm{V}$ input. In this case, the inverter output current is $150 \mathrm{~A} \mathrm{rms}$, and the output power is 39 $\mathrm{kW}$. Notice that the waveform quality is much better than that shown in Figure 6.4(a) even with a lower input voltage because the control parameter has been fully tuned for the $90-\mathrm{kW}$ machine. 
Figure 6.5(b) shows the inverter output current waveforms at $2980 \mathrm{rpm}, 110 \mathrm{Nm}$ motor load at $375-\mathrm{V}$ dc input voltage condition. In this case, the inverter output current is about $101 \mathrm{~A} \mathrm{rms,}$ and the output power is $38 \mathrm{~kW}$. Higher input voltage tends to have lower output current at the high speed region because the control loop adapts the maximum torque per ampere (MTPA) control to minimize the motor current with the available input voltage. Note that the tested power level far exceeds the continuous rated power, which is essential because of the need of high currents during startup and short-term acceleration.

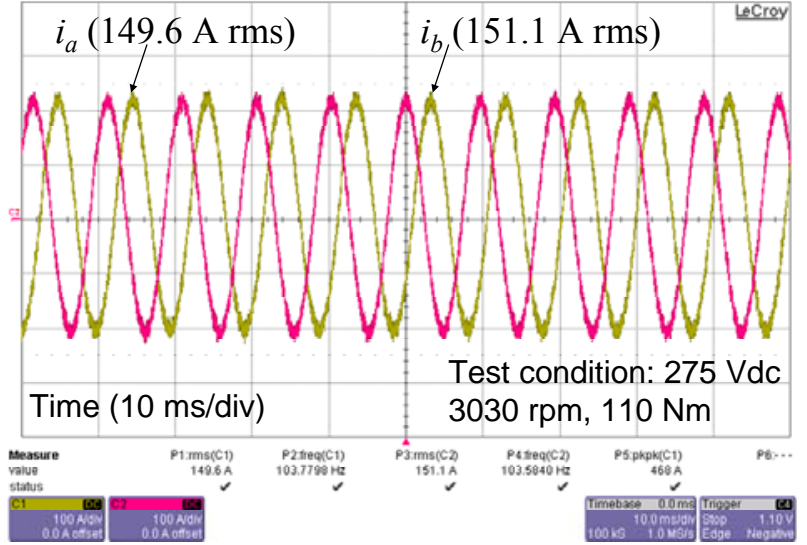

(a)

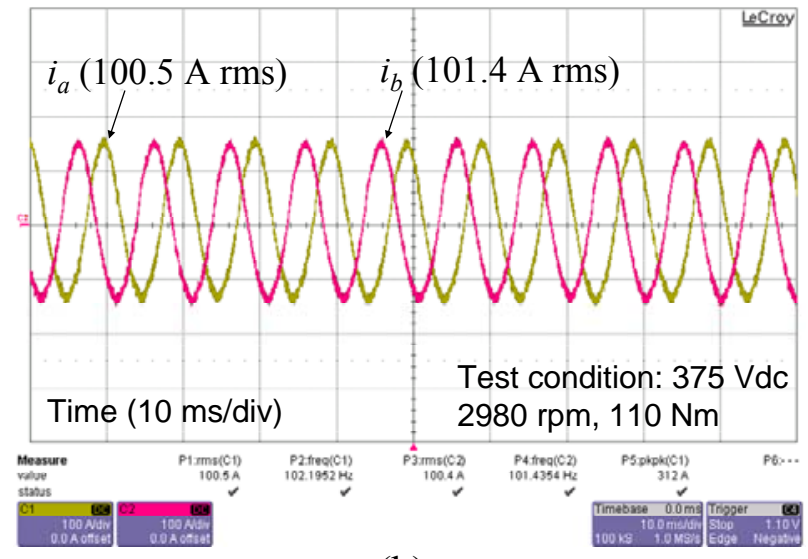

(b)

Figure 6.5. Experimental inverter output current waveforms at (a) $275 \mathrm{~V}, 39 \mathrm{~kW}$ and (b) $375 \mathrm{~V}, 38$ kW conditions.

Figure 6.6(a) shows the efficiency as a function of the output power at 3000-rpm condition. In this measurement, the auxiliary power and fan losses are all included as a part of total losses. With hybrid switch and adaptive timing soft-switching operation, the efficiency at 325-V input exceeds $99 \%$ at $30-\mathrm{kW}$ nominal load condition. At $375-\mathrm{V}$ input, $38-\mathrm{kW}$ output, the efficiency reaches $99.3 \%$. Such efficiencies are not possible to measure with any power meter that measures the dc input and PWM ac output. In order to verify the efficiency numbers, our approach is to measure the module case temperature over a long period and use it as the loss to project the efficiency. Figure 6.6(b) shows the measured power module case temperature over a 12-minute interval. The $325-\mathrm{V}$ condition was started at a temperature that is considered steady state, so over the 12-minute interval there was not any appreciable temperature rise. At the $20^{\circ} \mathrm{C}$ room temperature test condition, the entire inverter was only cooled by a $3-\mathrm{W}$ fan, and the monitored module which is far away from the fan has a case temperature of $47^{\circ} \mathrm{C}$ under steadystate $325-\mathrm{V}$ input, $38-\mathrm{kW}$ output condition.

With soft switching, the achieved ultrahigh efficiency is mainly attributed to the conduction voltage drop reduction by the hybrid switch. Take $375-\mathrm{V}$ case as the example, the conduction voltage drop is less than $2 \times 0.8 \mathrm{~V}$ at 100 -A condition, or $0.43 \%$ of the total loss. With near zero switching loss in both main and auxiliary switches, the remaining major loss component is the resonant circuit conduction, which is estimated to be around $0.1 \%$. The total losses from gate drives, controller, conditioning circuit, fan, and auxiliary power supplies were measured at $19 \mathrm{~W}$, or $0.05 \%$. The dc bus capacitors, power bus, and other parasitic losses attribute another $0.05 \%$. Therefore, $99.3 \%$ efficiency at $375-\mathrm{V}$ input, $100-\mathrm{A}$ output current and $38-\mathrm{kW}$ output power is a conservative projection from the temperature measurement. 


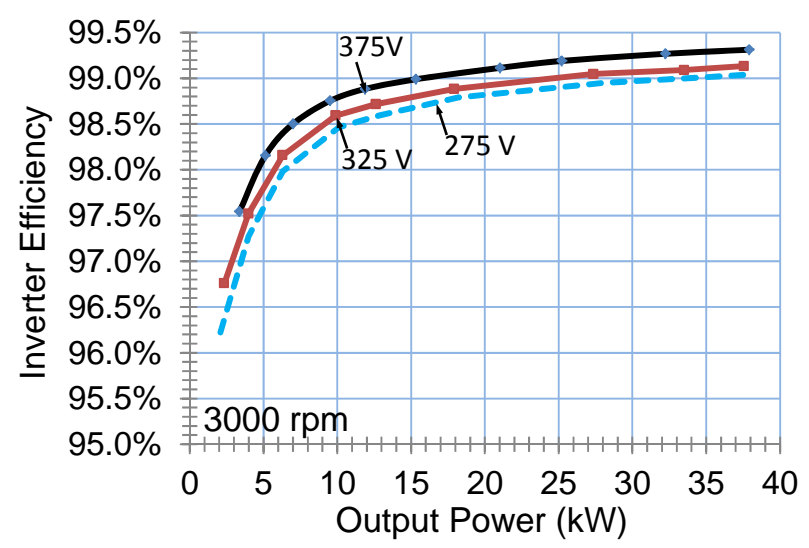

(a)

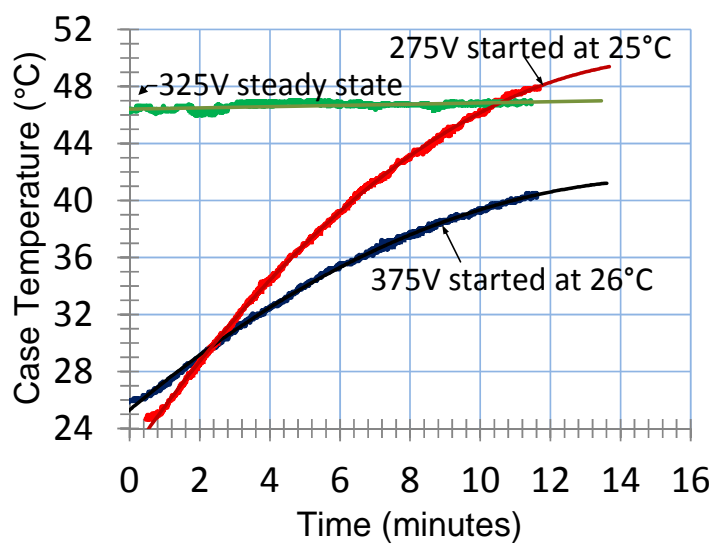

(b)

Figure 6.6. (a) Measured efficiency as a function of output power at 3000-rpm operation, and (b) Measured module case temperature over a 12-minute interval at 38-kW output condition.

Table 6.2 lists detailed loss components under three input voltage and two motor load conditions. The first nominal load is $3000 \mathrm{rpm}, 100 \mathrm{Nm}$, and the second nominal load is $1000 \mathrm{rpm}, 200 \mathrm{Nm}$. Actual speed and torque vary during the test because of the error of the control loop tracking.

Table 6.2. Loss separation under three input voltage and two load conditions

\begin{tabular}{|l|c|c|c|c|c|c|}
\hline Nominal Testing Condition & \multicolumn{3}{|c|}{$3000 \mathrm{rpm}, 100 \mathrm{Nm}$} & \multicolumn{3}{c|}{$1000 \mathrm{rpm}, 200 \mathrm{Nm}$} \\
\hline DC bus voltage, $\mathrm{V}$ & 275 & 325 & 375 & 275 & 325 & 375 \\
\hline Motor speed, rpm & 3011.1 & 3006.4 & 3007.9 & 1028.4 & 1015.6 & 1020 \\
\hline Motor torque, Nm & 107.1 & 107.4 & 109.2 & 230.4 & 220 & 227 \\
\hline Line-line voltage, Vrms & 172.2 & 213.8 & 247.6 & 134.2 & 124.7 & 130.1 \\
\hline Phase current, Irms & 150.6 & 114.7 & 101.8 & 148.62 & 147.1 & 147.2 \\
\hline Frequency, Hz & 103.26 & 101.83 & 101.41 & 35.4 & 35.5 & 34.7 \\
\hline Inductor temperature at 12 minute, ${ }^{\circ} \mathrm{C}$ & 56 & 70.1 & 51 & 65.9 & 62.4 & 76.7 \\
\hline Module case temperature at 12 minute, ${ }^{\circ} \mathrm{C}$ & 48 & 47.1 & 42 & 51.9 & 45.4 & 53.9 \\
\hline Main IGBTs, $Q_{1}-Q_{6}$, losses $(\mathrm{W})$ & 70.8 & 28.2 & 18.3 & 67.2 & 66 & 64.8 \\
\hline MOSFETs, $M_{1}-M_{6}$, losses $(\mathrm{W})$ & 240 & 216 & 180 & 247.2 & 246 & 243 \\
\hline Auxiliary IGBTs, $Q_{x 1}-Q_{x 6}$, losses $(\mathrm{W})$ & 16.5 & 12 & 11.7 & 16.8 & 16.8 & 16.8 \\
\hline Auxiliary Diodes, $D_{x 1},-D_{x 6}$, losses $(\mathrm{W})$ & 6.3 & 4.8 & 4.3 & 6.0 & 5.8 & 6.2 \\
\hline Resonant inductor, $L_{r}$, loss $(\mathrm{W})$ & 36 & 31 & 30 & 37 & 40 & 42 \\
\hline Auxiliary power, gate, sensor, IC ckts, $(\mathrm{W})$ & 19 & 19 & 19 & 19 & 19 & 19 \\
\hline Parasitic bus bar, capacitor, connection $(\mathrm{W})$ & 7 & 6 & 5 & 7 & 7 & 7 \\
\hline Total losses $(\mathrm{W})$ & 395.6 & 317.0 & 268.3 & 400.2 & 400.62 & 398.84 \\
\hline Output power, $P_{o}(\mathrm{~W})$ & 38244 & 37213 & 37591 & 28036 & 26846 & 27201 \\
\hline Input power, $P_{i n}(\mathrm{~W})$ & 38640 & 37530 & 37859 & 28436 & 27247 & 27600 \\
\hline Inverter efficiency & $98.98 \%$ & $99.16 \%$ & $99.29 \%$ & $98.59 \%$ & $98.53 \%$ & $98.55 \%$ \\
\hline
\end{tabular}

With motor current less than 150 Arms for all test conditions, the majority of current conducts through MOSFET. Thus the MOSFET loss is dominant in all cases. The parasitic loss is a lump number that is projected from the load current magnitude. All other losses can be found either by temperature projection or by the switch conduction and switching characteristics. All switch and inductor rms currents can also be obtained from circuit simulation to ensure their accuracy. The 
combined loss of the auxiliary power supply, gate drive, and controller board losses was obtained from no-load test.

\subsection{In-Vehicle Test}

The purpose of in-vehicle test is to verify that the inverter package is secured, and the operating range is wide enough to adapt to different acceleration and deceleration conditions. The test can also verify if the inverter is susceptible to noise or not. Azure Dynamics has an all-electric Citivan that allows the inverter prototype to be placed on a test stand inside the vehicle with all the wiring already hooked up for vehicle driving test. Figure 6.7 shows the photograph of the vehicle under test.

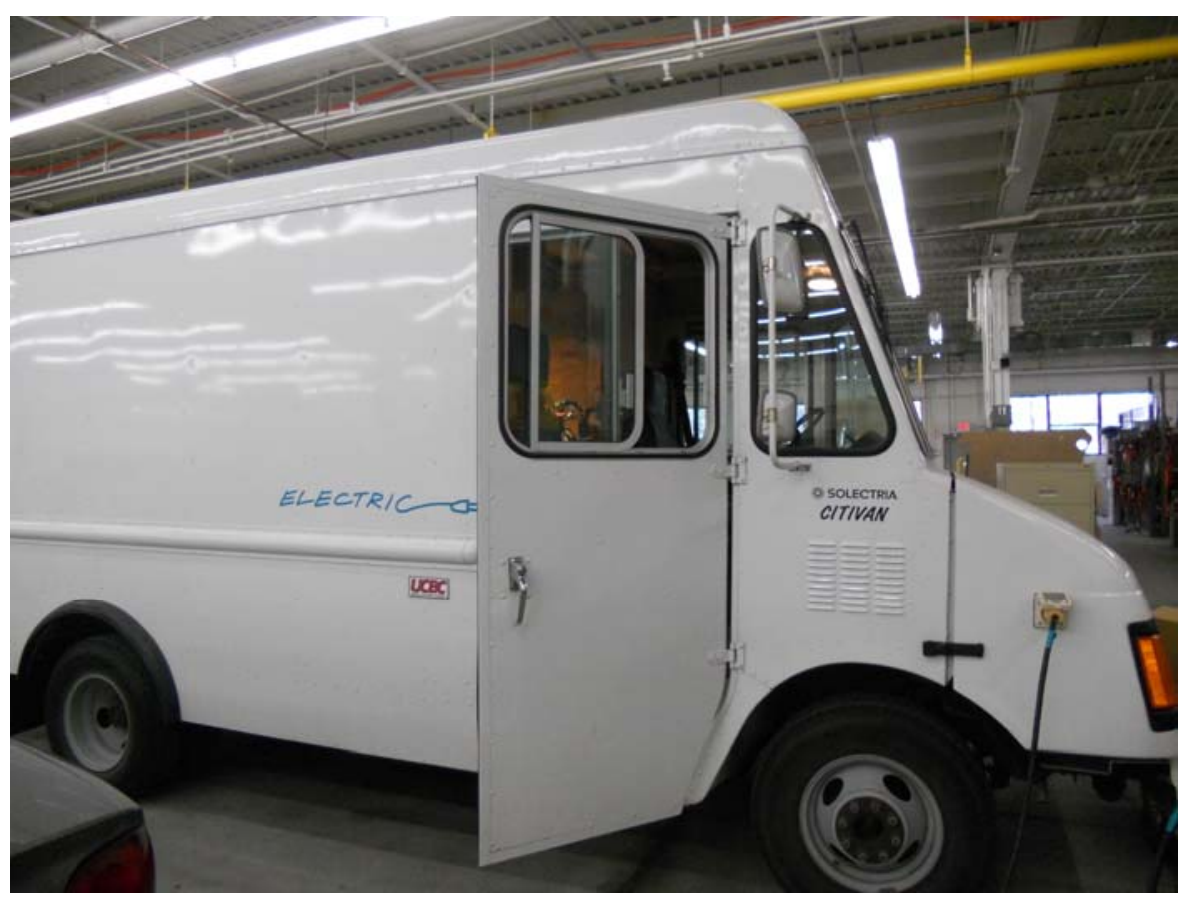

Figure 6.7. Photograph of all-electric Citivan for in-vehicle testing.

Figure 6.8 shows the photograph of in-vehicle test setup. A spare inverter is sitting underneath the test stand. In case the inverter-under-test fails on the road, a simple rewiring would allow the vehicle to operate again. 


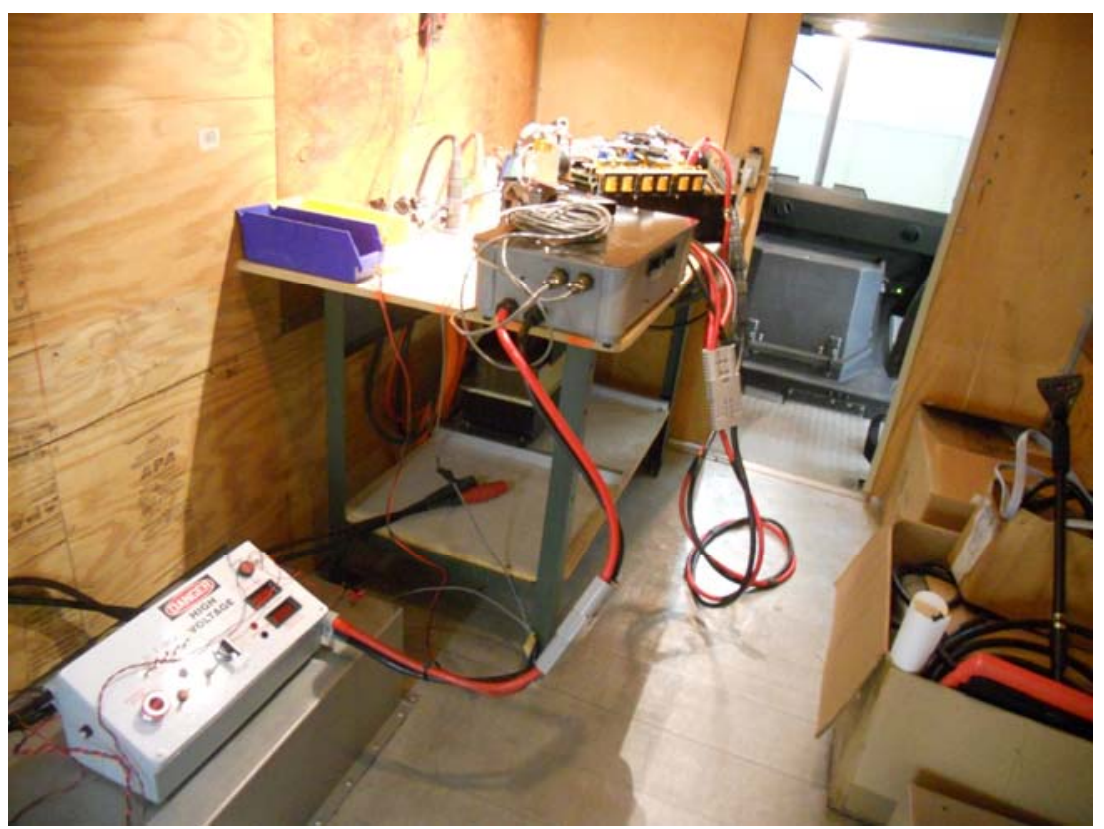

Figure 6.8. In-vehicle test setup.

During the vehicle test drive, the operating conditions of the inverter and motor were all recorded. Figure 6.9 shows the motor speed and current during a 4-minute driving cycle. The red line is the motor speed and is fluctuating from -200 to $1000 \mathrm{rpm}$. The blue line is the peak phase current. Maximum recorded peak phase current during hill climbing was $380 \mathrm{~A}$, or $268 \mathrm{~A}$. This current is much higher than the maximum current under dyno test condition, or $150 \mathrm{~A}$. However, its corresponding speed and thus the power level was low at such a high-current condition.

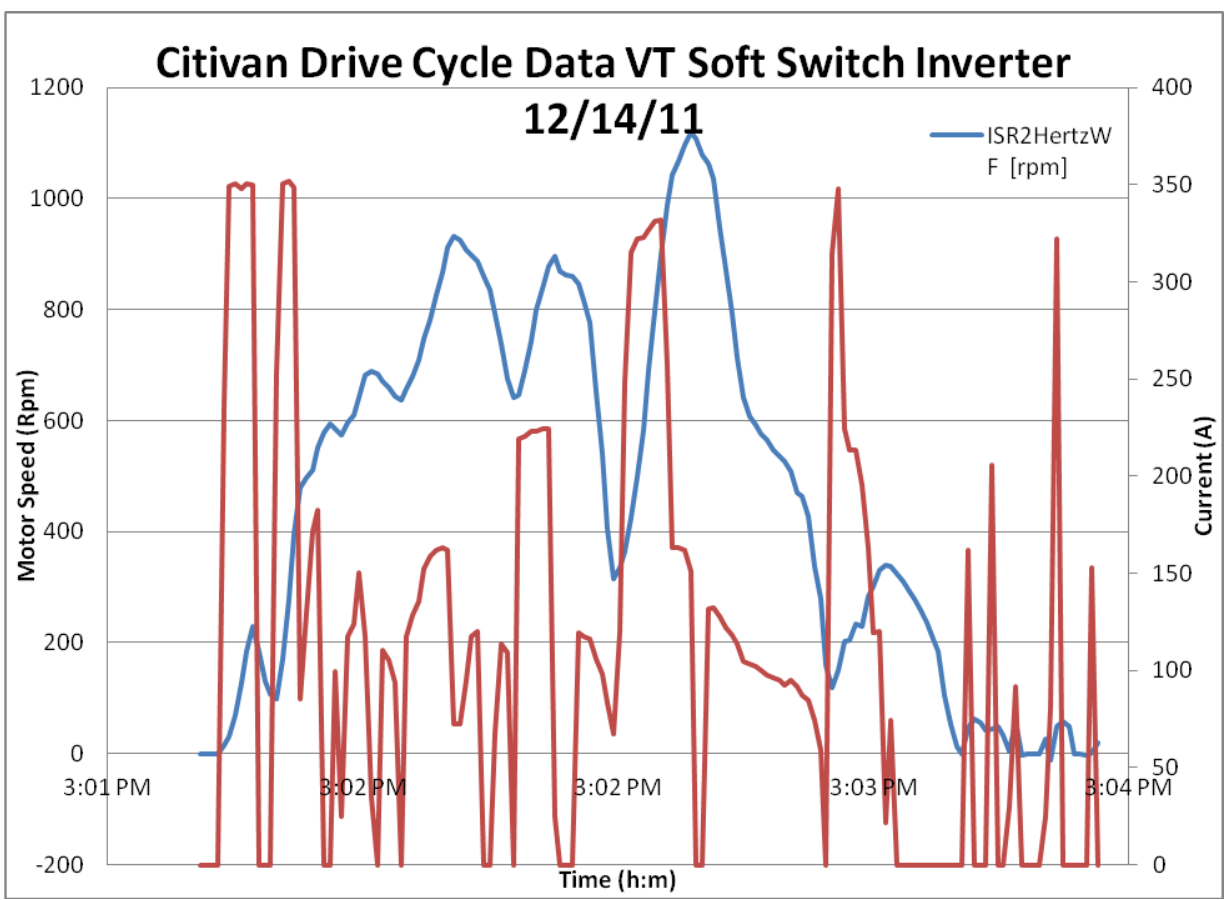


Figure 6.9. Recorded in-vehicle tested motor speed and phase current during a 4-minute city driving cycle.

The complete drive cycle of a city block lasted about 15 minutes. After the van returned, the heat sink did not show an appreciable temperature rise. It was the same as the outdoor temperature. The superiority of ultrahigh efficiency inverter operation was fully proven. At the time stamp between $3.02 \mathrm{pm}$ and 3:03pm, the motor current reached the peak current, and the maximum power occurred at $950 \mathrm{rpm}, 380 \mathrm{~A}$. This current corresponds to about $400 \mathrm{Nm}$ torque, and the power level is about $40 \mathrm{~kW}$. 


\section{INVERTER COST ESTIMATE}

\subsection{Soft-Switching Module Cost Estimate}

As compared to the Gen-2 module, the Gen-1 module has lower conduction voltage drop and lower thermal impedance through direct liquid cooling. The measured inverter efficiency reflects the advantage of the low conduction voltage drop. However, the Gen-2 module significantly reduced the height and parasitic loop inductance. The layout has minimum path for terminal connection, especially the connection between resonant capacitor and the chip. A separate power terminal is brought out directly from the substrate for resonant capacitor connection. The substrate and housing package adopts a low profile, industry standard Powerex "NX-M" series package family, which has the same height, but will be slightly longer and wider than the standard NX package. As a result, the standard high volume parts such as terminals, plastics and baseplates will minimize the module cost. The low height profile will reduce size, weight, parasitic inductance, and filling materials. The ease of assembly also contributes to the labor cost reduction. This package is designed to be compatible with either liquid or air cooling. Table 1 shows the cost comparison between Gen-1 and Gen-2 modules.

Table 7.1. Cost comparison between Gen-1 and Gen-2 modules.

\begin{tabular}{|c|c|c|c|c|}
\hline \multirow{3}{*}{ 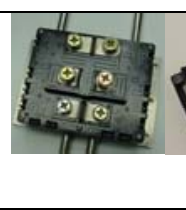 } & \multirow{3}{*}{$\begin{array}{c}\text { Gen 1 } \\
\begin{array}{c}\text { Direct Liquid } \\
\text { Cooled }\end{array} \\
\text { Low Volume }\end{array}$} & \multicolumn{2}{|c|}{ Gen 2} & \multirow{2}{*}{$\begin{array}{c}\text { Gen } 3 \\
\text { Standard } \\
\text { Package } \\
\end{array}$} \\
\hline & & $\begin{array}{l}\text { Standard } \\
\text { Package }\end{array}$ & $\begin{array}{l}\text { Direct Liquid } \\
\text { Cooled }\end{array}$ & \\
\hline & & High Volume & High Volume & High Volume \\
\hline Materials & $\$ 545.87$ & $\$ 98.25$ & $\$ 114.25$ & $\$ 110.95$ \\
\hline Labor & $\$ 360.00$ & $\$ 35.00$ & $\$ 35.00$ & $\$ 35.00$ \\
\hline Total & $\$ 1,222.92$ & $\$ 179.89$ & $\$ 201.89$ & $\$ 197.03$ \\
\hline
\end{tabular}

For the Gen-3 module, further cost reduction is achieved by eliminating two diodes per switch, as shown in Figure 4.28. However, splitting the module into a separate Auxiliary and Power module does result in some duplication of parts such as the plastic case and lid, ceramic substrates and baseplates, thus increasing the overall materials costs slightly over those of Gen 2 . The complete phase leg module cost is estimated at $\$ 197.03$ when produced in 100,000 quantities. Further module cost reduction is possible when the power semiconductor wafer size is increased from current 8 " to 12 " diameter. This wafer size reduction has been confirmed by super-junction MOSFET manufacturers. However, the following inverter cost estimate will continue use the 8 " wafer as the basis.

\subsection{Soft-Switching Inverter Cost Estimate}

Table 7.2 lists major circuit components and their price for the Gen-3 inverter cost estimate. The proposed package differs from conventional inverter mainly on the use of coupled magnetics for soft switching and the power circuit board to serve as the bus bar. The rest components should be common and similar to the conventional hard-switching inverter. The overall cost is about $\$ 938$ for the $60-\mathrm{kW}$ inverter. There is room for cost reduction. For example, the integration of power and gate drive boards and the integration of interface and DSP boards altogether should 
reduce the total cost by at least $10 \%$. If the large wafer power semiconductors are available, the soft-switch module may allow another $10 \%$ total cost reduction. Overall we can expect the cost around $\$ 800$. Notice that the design allows total elimination of forced-air or liquid cooling system. Overall this is a durable design option for the next generation EV traction motor drive inverter.

Table 7.2. Cost estimate for the soft-switching inverter at 100,000 quantity production

\begin{tabular}{|l|c|r|r|}
\hline Major components & Quantity & Unit price & \multicolumn{1}{|c|}{ Ext. price } \\
\hline Coupled magnetics & 6 & $\$ 8.40$ & $\$ 50.40$ \\
\hline Power board/bus bar & 1 & $\$ 43.02$ & $\$ 43.02$ \\
\hline Bus capacitors & 2 & $\$ 42.00$ & $\$ 84.00$ \\
\hline Soft-switch modules & 3 & $\$ 197.03$ & $\$ 591.09$ \\
\hline Gate drive boards & 3 & $\$ 13.49$ & $\$ 40.47$ \\
\hline Interface/sensor board & 1 & $\$ 37.54$ & $\$ 37.54$ \\
\hline DSP board & 1 & $\$ 12.44$ & $\$ 12.44$ \\
\hline Heat sink/Case & 1 & $\$ 43.37$ & $\$ 43.37$ \\
\hline Total Material & & & $\$ 902.33$ \\
\hline Labor/Testing & & & $\$ 36.20$ \\
\hline Total & \multicolumn{3}{|l}{} \\
\hline
\end{tabular}

\subsection{Volume and Weight}

The inverter was designed to fit into the existing chassis built by Azure Dynamics and can be directly used for in-vehicle testing. Therefore, the design was not to optimize the volume and weight but to focus on the efficiency and reliable operation. For example, the measured weight is $15 \mathrm{~kg}, 3$ times the DOE weight target, which assumes liquid cooled system. If our heat sink is removed, the overall weight is less than $5 \mathrm{~kg}$, which is not far from DOE target. For the volume, the case of Azure Dynamics chassis is 12.5 liter, which is almost 3 times the DOE target but not by design.

Table 7.3 compares the specification of the VT soft-switching inverter and DOE inverter target. The VT design satisfies electrical performance and efficiency targets, but not size and weight. Some conditions were not tested due to the limitation of the electric motor and the control loop stability. For example, the electric machine in the final test is a $90-\mathrm{kW}$ induction machine, which has much higher torque but relatively lower speed. The maximum frequency was not tested at $1000 \mathrm{~Hz}$ due to the complicated dynamometer setup. The designed operating range was from 250 to $450 \mathrm{~V}$ but only tested from 275 to $375 \mathrm{~V}$ in steady state due to battery bank voltage range. Since our ultimate goal was to test the inverter to operate with the actual vehicle, some variations on the specification were unavoidable. Our successful in-vehicle test should justify such design variations. 
Table 7.3. Comparison of the VT prototype and DOE target

\begin{tabular}{|c|c|c|}
\hline Requirement & DOE Target & VT Results \\
\hline Continuous power output & $30 \mathrm{~kW}$ & $40 \mathrm{~kW}$ (tested) \\
\hline Peak power output for 18 seconds & $55 \mathrm{~kW}$ & $60 \mathrm{~kW}$ (tested at startup) \\
\hline Weight & $\leq 4.6 \mathrm{~kg}$ & $\begin{array}{l}5 \mathrm{~kg} \text { electronics, } 10 \mathrm{~kg} \\
\text { heat sink }\end{array}$ \\
\hline Volume & $\leq 4.6$ liter & $\begin{array}{l}\text { 12.5liter; } \\
(25 \mathrm{~cm} \times 50 \mathrm{~cm} \times 10 \mathrm{~cm})\end{array}$ \\
\hline Unit Cost for quantities of 100,000 & $\leq \$ 275$ & $\$ 938$ \\
\hline Operating voltage & $\begin{array}{l}200 \text { to } 450 \mathrm{~V} \\
\text { nominal: } 325 \mathrm{~V}\end{array}$ & $\begin{array}{l}275 \text { to } 375 \mathrm{~V} \text { tested; } \\
\text { nominal: } 325 \mathrm{~V}\end{array}$ \\
\hline Power factor of load & $>0.8$ & 0.87 typical \\
\hline Maximum current per phase & $400 \mathrm{~A}$ & $400 \mathrm{~A}$ \\
\hline Precharge time-- 0 to $200 \mathrm{Vdc}$ & $2 \mathrm{~s}$ & $<1 \mathrm{~s}$ \\
\hline $\begin{array}{l}\text { Efficiency at } 10 \text { to } 100 \% \text { of maximum speed for } 20 \% \text { of } \\
\text { rated torque }\end{array}$ & $>97 \%$ & $>99 \%$ \\
\hline $\begin{array}{l}\text { Output current ripple - peak to peak ( } \% \text { of fundamental } \\
\text { peak) }\end{array}$ & $\leq 3$ & $<3 \%$ \\
\hline Maximum switching frequency & $20 \mathrm{kHz}$ & $10 \mathrm{kHz}$ \\
\hline Current loop bandwidth & $2 \mathrm{kHz}$ & $\begin{array}{l}\text { Trade secret of Azure } \\
\text { Dynamics }\end{array}$ \\
\hline Maximum fundamental electrical frequency & $1000 \mathrm{~Hz}$ & Tested at $150 \mathrm{~Hz}$ \\
\hline $\begin{array}{l}\text { Minimum isolation impedance-input and phase terminals } \\
\text { to ground }\end{array}$ & 1Mohm & $>1 \mathrm{Mohm}$ \\
\hline Minimum motor input inductance & $0.5 \mathrm{mH}$ & $0.14 \mathrm{mH}$ \\
\hline Ambient operating temperature & -40 to $+140^{\circ} \mathrm{C}$ & Not tested \\
\hline
\end{tabular}




\section{CONCLUSION}

Three generations of the advanced soft-switching inverter were progressively developed to achieve ultrahigh efficiency while avoiding excessive cost penalty. The first-generation variable timing, soft-switching inverter was based on a newly developed integrated liquid-cooled softswitching module. The module characteristics of conduction, switching, and thermal resistance were measured to predict efficiency and junction temperatures first. The efficiency of the threephase soft-switching inverter was then measured with an inductive load and motordynamometer. A peak efficiency higher than $99 \%$ was found with power meter measurement, but the accuracy of the power meter became doubtful at higher power outputs. Therefore, the inverter was then tested with a calibrated differential calorimeter for long-time ( 8 hours) operation. The calorimeter inlet and outlet temperature increases were then used to find the inverter loss for efficiency calculation. The results of calorimeter tests show efficiencies between $98.5 \%$ and $99 \%$ for loads between $12 \mathrm{~kW}$ and $27 \mathrm{~kW}$. As compared to the DOE target of $97 \%$ efficiency, the proposed soft-switching already exceeded the goal in the first phase effort.

In addition to efficiency measurements, we also performed extensive FMEA analyses and measured EMI for CISPR-25 compliance. The FMEA results suggest that the auxiliary diodes that are not carrying steady-state current need to be sized large enough to avoid catastrophic device failure during controller malfunction or loss of communication between the DSP controller and the power circuit board. The EMI measurement results show significant high frequency EMI reduction with the soft-switching inverter. Overall, the first-generation softswitching inverter was successfully developed to demonstrate superior performance in efficiency and EMI.

The effort in the development of the second generation soft-switching inverter was to reduce both cost and volume. The cost reduction was achieved by using more standard low-profile module package. The volume reduction was achieved by using smaller magnetic cores. However, the low-profile module had higher internal parasitic resistances due to chip layout and resulted in additional conduction losses. Nevertheless, the parasitic inductance reduction was noticeable, and the switching noise was significantly reduced.

For the third generation inverter, two soft-switching inverters were constructed and fully tested to higher than the full power range. With the nominal $325-\mathrm{V}, 30-\mathrm{kW}$ continuous rating, the actual tests were conducted at three different voltage ratings: 275,325 , and $375 \mathrm{~V}$ and three different speed and torque ranges: $3000 \mathrm{rpm} / 100 \mathrm{Nm}$ motoring, $1000 \mathrm{rpm} / 200 \mathrm{Nm}$ motoring, and $1000 \mathrm{rpm} / 100 \mathrm{Nm}$ regenerating. The highest power tested was $39-\mathrm{kW}$ continuous, $30 \%$ higher than the specification. The peak power is rated at $55-\mathrm{kW}$, but it is under transient condition, making the waveforms difficult to capture, and thus the $55 \mathrm{~kW}$ results are not reported.

The major discrepancies between the test conditions and the specifications of the original Request for Proposals (RFP) are:

1. Voltage levels: the RFP voltage range is between 200 and $450 \mathrm{~V}$. Our test range is between 275 and $375 \mathrm{~V}$. There are two main reasons. The first reason is due to our auxiliary power supply operating range. In order to have a standalone unit, the power 
supply is designed have the DC bus as the input and is not good for very wide input voltage range for a high efficiency design. The second reason is the motor control loop stability. The control loop is not suitable to operate at every point under different voltages. At low voltages, it cannot operate in high speed because the supply voltage is lower than the equivalent back electromagnetic force (EMF). At high voltages, the control loop gain increases, and the stability margin is reduced. Through initial tests, we decided to stay within 275 and $375 \mathrm{~V}$ range, which works quite well even in real life operation.

2. Temperature operating range: The RFP requires the inverter to operate at $105^{\circ} \mathrm{C}$ temperature condition. Through our Gen-1 inverter test, we found the main issue of high-temperature operation was the DC bus capacitor and other circuit components such as opto-couplers and current sensors. The power module temperature rise was never a problem with our high-efficiency design. Therefore, we only developed a forced-air cooled package for the Gen-2 inverter and natural convention cooling for Gen-3 inverter, and the actual test temperature was under room temperature condition.

Experimental results of Gen-3 inverter with the total loss projected by the temperature rise indicated that at the nominal $325-\mathrm{V}$ input, $30-\mathrm{kW}$ output, the efficiency was $99 \%$, and at $375-\mathrm{V}$ input, $38-\mathrm{kW}$ output, the efficiency exceeded $99.3 \%$. The inverter also succeeded in-vehicle testing. With a 15-minute city block driving cycle, the heat sink stayed as cold as the outdoor temperature. The maximum current and power recorded during the in-vehicle test were $380 \mathrm{~A}$ and $40 \mathrm{~kW}$, respectively.

Key accomplishments include:

1. Completed vehicle level simulation to verify the inverter voltage and current levels at different speed and torque conditions. According to the simulation, semiconductor devices were selected and characterized power for hard- and soft-switching and room temperature and $105^{\circ} \mathrm{C}$ conditions.

2. Developed a scaled soft-switching inverter with variable timing control showing measured efficiency above $98.5 \%$ in a wide load range. Two scaled version variable timing controlled soft-switching inverters.

3. Designed and laid out three generations of soft-switching modules and associated gate drive circuits. Three generations of soft-switching inverters and the DSP interface were designed and built accordingly. The Gen-1 soft-switch module was integrated with chilled plate. Tested a scaled version soft-switching inverter with both RL and motor loads.

4. Tested the scaled inverter with dynamometer under speed reversal conditions.

5. Developed the ratio-metric calorimetric loss measurement method.

6. Failure mode effects analysis for a robust inverter design consideration.

7. Projected junction and inside chassis temperatures using finite element analysis

8. Number of circuit board reductions: Gen-2 module requires two gate drive boards, one power bus board, and associated connectors and mounting bracket. Gen-3 module requires only one gate drive board and one power board. Both boards can be stacked on each other, thus avoiding the external connector and mounting bracket. 
9. Thick copper laminated power circuit board: Gen-2 module requires an external power bus bar to conduct the main current. Gen-3 module has a heavy-copper based printed circuit board serving as the current carrying path while reducing inductance significantly.

10. Three-phase board integration: The printed circuit board can be easily integrated in a three-phase configuration to eliminate the external power bus bar to further reduce the cost.

11. Elimination of power screw terminals: Gen-3 module eliminates all the power screw terminals and brings power terminals directly out of the chip to allow significant parasitic inductance reduction. The parasitic inductance reduction of the resonant circuit loop was demonstrated in the Gen-2 module. However, the conducting path from MOSFET to the main screw terminal was too far, resulting in a significant increase in the conduction loss. In Gen-3 module, the loop inductance reduction also allows significant reduction in the conduction path of the MOSFET.

12. Elimination of main diode: The MOSFET used in Gen-3 module has a body diode that has a large enough chip area to conduct the freewheeling current, thus the main diode used in Gen-1 and Gen-2 module can be completely eliminated. This should clearly reduce the cost of the final product.

13. Achieved ultrahigh efficiency operation with the Gen-3 module. A set of dynamometer testing was performed to verify the operation under high speed, high torque, and regeneration operation. Peak efficiency was found at $99.3 \%$ under $3000-\mathrm{rpm}, 100-\mathrm{Nm}$ test condition.

14. Completed in-vehicle testing with the Gen-3 inverter. The inverter was retrofitted into the Citivan all-electric test vehicle for the road test. A 15-minute drive cycle was recorded. With only one $3-\mathrm{W}$ fan cooling, at the end of the drive cycle, the heat sink temperature rise was less than $5^{\circ} \mathrm{C}$.

Overall, the soft-switching design achieved major performance improvements in conduction loss and parasitic inductance reduction, and cost reduction through elimination of circuit boards, connectors, and main diodes. Ultrahigh efficiency operation allows complete elimination of the cooling system.

Although not all the DOE design targets were met, this project has demonstrated some breakthrough designs that should change the conventional wisdom on what a traction motor drive inverter should be. The efficiency of the newly developed soft-switching inverter suggested that natural convection cooling is possible with the soft-switching design. In fact, the soft-switching idea in conventional wisdom was to eliminate the switching loss, but an additional new concept should be the reduction of conduction losses by using resistive-drop devices such as super-junction MOSFETs in parallel with IGBTs. With significant progress on super-junction semiconductor devices in the last decade, it is possible for the soft-switching inverter to reach 99.5\% peak efficiency within another year or two if the development path continues. In this case, it is unnecessary to have any external cooling system, and the cost saving on the cooling system should allow room for inverter cost margin. The clean input current with soft-switching along with the elimination of the high temperature cooling loop should also allow the use of conventional capacitors and avoid any expensive high temperature capacitors. 
We suggest future work should continue on power module package cost reduction and inverter circuit integration. Our projected entire inverter cost is about three times the DOE target, and the major cost item is the soft-switch module. With significant progress on super junction power MOSFET development in recent years, it is possible to reduce the chip count and the material cost, but the packaging technology needs further improved to cut down the soft-switching module cost. Integrating the main and auxiliary modules into one module for each phase leg or integrating all three phase main and auxiliary modules into one module should also help reduce the packaging cost. Similar integration can also be applied to the rest of the inverter circuitry to reduce the number of circuit boards and interconnections. More circuit integration can not only reduce the cost, but also improve the reliability. 


\section{GLOSSARY}

\begin{tabular}{|c|c|}
\hline A & - Ampere, a current unit \\
\hline $\mathrm{AC}$ & - Alternate current \\
\hline AlN & - Aluminum nitride \\
\hline APEC & - Applied Power Electronics Conference and Exposition \\
\hline CISPR & - Comité International Spécial des Perturbations Radioélectriques \\
\hline $\mathrm{CM}$ & - Common mode \\
\hline CoolMOS & - A commercial MOSFET trademarked by Infineon \\
\hline DBC & - Direct bond copper \\
\hline $\mathrm{DC}$ & - Direct current \\
\hline $\mathrm{DM}$ & - Differential mode \\
\hline DQ & - direct-quadrant axes \\
\hline DOE & - Department of Energy \\
\hline DSP & - Digital Signal Processor \\
\hline Dyno & - Dynamometer \\
\hline EGC & - Ethylene-glycol \\
\hline EMF & - Electromagnetic force \\
\hline EMI & - Electromagnetic interference \\
\hline ESL & - Equivalent series inductance \\
\hline ESR & - Equivalent series resistance \\
\hline FEA & - Finite element analysis \\
\hline FMEA & - Failure Mode Effect Analysis \\
\hline GPM & - Gallon per minute \\
\hline $\mathrm{H}$ & - Henry, an inductance unit \\
\hline $\mathrm{Hz}$ & - Hertz, a frequency unit \\
\hline IEEE & - Institute of Electrical and Electronics Engineering \\
\hline IGBT & - Insulated Gate Bipolar Transistor \\
\hline $\mathrm{J}$ & - Joule, an energy unit \\
\hline $\mathrm{kHz}$ & - Kilo Hertz, a frequency unit \\
\hline $\mathrm{kVA}$ & - kilo volt-ampere, a power unit \\
\hline $\mathrm{kW}$ & - kilo watts, a power unit \\
\hline LISN & - Line impedance separation network \\
\hline LPT & - Light punch through \\
\hline MDMesh & - A commercial MOSFET trademarked by ST Microelectronics \\
\hline MG & - Motor-generator set \\
\hline $\mathrm{mJ}$ & - milli Joule, an energy uint \\
\hline $\mathrm{mH}$ & - milli Henry, an inductance unit \\
\hline $\mathrm{MHz}$ & - Mega Hertz, a frequency unit \\
\hline MOSFET & - Metal Oxide Semiconductor Field Effect Transistor \\
\hline $\mathrm{MPH}$ & - Miles per hour \\
\hline $\mathrm{Nm}$ & - Newton Meter, a torque unit \\
\hline NPT & - Non-punch through \\
\hline PCB & - Printed circuit board \\
\hline PI & - Proportional-Integral \\
\hline PT & - Punch through \\
\hline
\end{tabular}




$\begin{array}{ll}\text { PWM } & - \text { Pulse Width Modulation } \\ \text { RPM } & - \text { revolution per minute, a unit for rotational speed } \\ \text { RMS } & \text { - Root means square } \\ \text { RTD } & \text { - Resistive temperature detector } \\ \text { SiC } & \text { - silicon carbide } \\ \text { SVM } & \text { - space vector modulation } \\ \text { V } & \text { - Volt, a voltage unit } \\ \text { Virginia Tech } & \text { - Virginia Polytechnic Institute and State University } \\ \text { W } & \text { - Watt, a power unit } \\ \text { ZVS } & - \text { Zero voltage switching }\end{array}$




\section{Publications and Patents}

\section{A. Journals}

1. P. Sun, J.-S. Lai, C. Liu, W. Yu, "A 55kW Three-Phase Inverter Based on Hybrid-Switch Soft-Switching Modules for High Temperature Hybrid Electric Vehicle Drives Application," IEEE Trans. on Industry Applications, June 2012.

2. W. Yu, J.-S. Lai, and S.-Y. Park, "An Improved Zero-Voltage-Switching Inverter Using Two Coupled Magnetics in One Resonant Pole," IEEE Trans. on Power Electronics, April 2010, pp. 952-961.

\section{B. Conference Proceedings}

1. J.-S. Lai, "Hybrid Switch Based Soft-Switching Inverter for Ultrahigh Efficiency Traction Motor Drives," to appear in Proc. of IEEE Energy Conversion Congress and Exposition, Sep. 2012, Raleigh, NC.

2. P. Sun, J.-S. Lai, H. Qian, W. Yu, C. Smith, J. Bates, and B. Arnet, A. Litvinov, and S. Leslie, "Efficiency Evaluation of A 55kW Soft-Switching Module Based Inverter for High Temperature Hybrid Electric Vehicle Drives Application," in Proc. of IEEE Applied Power Electronics Conference and Exposition, Palm Springs, CA. Feb. 2010, pp. 474-479.

3. P. Sun, J.-S. Lai, H. Qian, W. Yu, C. Smith, and J. Bates, "High Efficiency Three-Phase Soft-Switching Inverter for Electric Vehicle Drives," in Proc. of IEEE Vehicle Power and Propulsion Conference, Dearborn MI, Sep. 2009, pp. 761-766.

4. J.-S. Lai, W. Yu, S.-Y. Park, "Variable Timing Control for Wide Current Range ZeroVoltage Soft-Switching Inverters," in Proc. of IEEE Applied Power Electronics Conference and Exposition, Washington, DC. Feb. 2009, pp. 407-412.

5. W. Yu, J.-S. Lai, S.-Y. Park, "An Improved Zero-Voltage-Switching Inverter Using Two Coupled Magnetics In One Resonant Pole, in Proc. of IEEE Applied Power Electronics Conference and Exposition, Washington, DC. Feb. 2009, pp. 401-406.

6. J.-S. Lai, W. Yu, H. Qian, P. Sun, P. Ralston, K. A. Meehan, "High Temperature Device Characterization for Hybrid Electric Vehicle Traction Inverters, in Proc. of IEEE Applied Power Electronics Conference and Exposition, Washington, DC. Feb. 2009, pp. 665-670.

\section{Patent Disclosures}

1. J.-S. Lai, Wensong Yu, and Huijie Yu, "Soft-Switching Inverter Module," VTIP 08-075 Invention Disclosure, Provisional Application on July 22, 2008.

2. J.-S. Lai and Wensong Yu, "Soft-Switching with Variable Timing," VTIP 09-009 Invention Disclosure, Provisional Application on July 22, 2008.

3. J.-S. Lai and Wensong Yu, "A Hybrid Switch for Soft-Switching Inverter Efficiency Improvement," VTIP 08-080 Invention Disclosure, US Patent filed on August 10, 2010. 


\section{REFERENCES}

[1] Oak Ridge National Laboratory, "Evaluation of the 2007 Toyota Camry Hybrid Synergy Drive System," ORNL report, ORNL/TM-2007/190.

[2] M. Ishiko, T. Kondo, M. Usui, and H. Tadano, "A Compact Calculation Methos for Dynamic Electro-Thermal Behavior of IGBTs in PWM Inverters," Proc. of Power Conversion Conf., PCCNagoya, April 2007, Nagoya, Japan, pp. 1043-1048.

[3] T. Kojima, Y. Yamada, Y. Nishibe, and K. Torii, "Novel RC Compact Thermal Model of HV Inverter Module for Electro-Thermal Coupling Simulation," Proc. of Power Conversion Conf., PCC-Nagoya, April 2007, Nagoya, Japan, pp. 1025-1029.

[4] Z. J. Shen and I. Omura, “ Power Semiconductor Devices for Hybrid, Electric, and Fuel Cell Vehicles," IEEE Proceedings, Vol 95, No. 4, pp. 778-789, Apr. 2007.

[5] J.-S. Lai, "Resonant Snubber-Based Soft-Switching Inverters for Electric Propulsion Drives," IEEE Trans. on Industrial Electronics, pp. 71-80, Feb. 1997.

[6] J.-S. Lai, J. Zhang, H. Yu, and H. Kouns, "Source and Load Adaptive Design for a High-Power Soft-Switching Inverter," IEEE Trans. Power Electronics, pp. 1667-1675, Nov. 2006.

[7] J.-S. Lai, et al., "A Delta Configured Auxiliary Resonant Snubber Inverter," IEEE Trans. Industry Appl., pp. 518-524, May/June 1996.

[8] W. Dong, J-Y. Choi, Y. Li, D. Boroyevich, F. C. Lee, Jih-Sheng Lai, "Comparative Experimental Evaluation of Soft-Switching Inverter Techniques for Electric Vehicle Drive Applications," Conf. Rec. of IEEE IAS Annual Mtg, Chicago, IL, Sep. 2001, pp. 1469-1476.

[9] W. Dong, J, Choi, H. Yu, F. Lee, D. Boroyevich and J. Lai, "Comprehensive Evaluation of Auxiliary Resonant Commutated Pole Inverter for Electric Vehicle Applications," Proc. of IEEE Power Electronics Specialists Conf., Vancouver, Canada, June 2001, pp. 625-630.

[10] X. Kang, L. Lu, X. Wang, E. Santi, J.L. Hudgins, P.R. Palmer, J.F. Donlon, "Characterization and Modeling of the LPT CSTBT - the 5th Generation IGBT," Conf. Rec. of IEEE Industry Appl., Salt Lake City, UT, Oct. 2003, pp. 82-87.

[11] H. Iwamoto, H. Haruguchi, Y. Tomomatsu, J. F. Donlon, E. R. Motto, "A New Punch-Through IGBT Having a New n-Buffer Layer," IEEE Trans. on Industry Appl., vol. 38, pp. 168-174, Jan./Feb. 2002.

[12] E. R. Motto and J. F. Donlon, "The Latest Advanced in Industrial IGBT Module Technology," in Proc. of IEEE APEC, Anaheim, CA, Feb. 2004, pp. 235-240.

[13] A.R. Hefner, "Analytical modeling of device-circuit interactions for the power insulated gate bipolar transistor (IGBT)," IEEE Trans. on Industry Appl., vol. 26, pp. 995 - 1005, Nov./Dec. 1990.

[14] A.R. Hefner, "Modeling Buffer Layer IGBT's for Circuit Simulation", Proc. of Power Electronics Specialists Conf., pp. 60-69, 1993.

[15] J.-S. Lai, R.W. Young, and J. McKeever, "Efficiency Consideration for Soft Switching Inverters in Motor Drive Applications," Proc. of IEEE Power Electronics Specialists Conf., Taipei, Taiwan, June 1994, pp. 1003-1010.

[16] L. M. Tolbert, B. Ozpineci, M. Chinthavali, S. K. Islam, and F. Z. Peng, "Impact of SiC Power Electronic Devices for Hybrid Electric Vehicles," SAE J. Passenger Cares - Electronic Electrical Systems, pp. 771-765, 2003.

[17] B. Ozpineci, M. Chintavali, and L. M. Tolbert, "A $55 \mathrm{~kW}$ Three-Phase Automotive Traction Inverter with SiC Schottky Diodes," Proc. of IEEE Vehicle Propulsion and Power Conf., Chicago, IL, Sep. 2005, pp. 541-546.

[18] T.W. Ching, "Soft-Switching Converters for Electric Vehicle Propulsion," Journal of Asian Electric Vehicles, Dec. 2007, pp. 1019-1026. 
[19] V. K. Khanna, IGBT Theory and Design, John Wiley \& Sons, 2003.

[20] S. Clemente and B. Pelly, "An Algorithm for the Selection of the Optimum Power Device for the Electric Vehicle Propulsion," in Proc. of IEEE Workshop on Power Electronics in Transportation, Oct. 1992, pp.129-136.

[21] Mitsubishi CM400DY-12NF IGBT Module Datasheet, July 2004, Mitsubishi Electric.

[22] W. McMurray, "Resonant Snubbers With Auxiliary Switches," in Proc. IEEE Ind. Appl. Soc., San Diego, CA, Oct. 1989, pp. 829-834.

[23] R. W. DeDoncker and J. P. Lyons "The auxiliary resonant commutated power converters," in Proc. IEEE Ind. Appl. Soc., Oct. 1990, pp. 1228-1235.

[24] D. M. Divan, G. Venkataramanan, R. W. DeDoncker, "Design Methodologies for Soft Switched Inverters," IEEE Trans. Ind. Appl., Vol. 29, no. 3, Jan./Feb. 1993, pp. 126-135.

[25] I. Barbi and D. C. Martins, "A true PWM zero-voltage switching pole with very low additional RMS current stress," in Proc. IEEE Power Electron. Spec. Conf., 1991, pp. 261-267.

[26] X. Yuan and I. Barbi, "Analysis, designing, and experimentation of a transformer-assisted PWM zero-voltage switching pole inverter," IEEE Trans. Power Electron., vol. 15, no. 1, Jan. 2000, pp. $72-82$.

[27] J. P. Gegner and C. Q. Lee "Zero-voltage-transition converters using inductor feedback techniques," in Proc. IEEE Appl. Power Electron. Conf., 1994, pp. 862-868.

[28] S. Frame, D. Katsis , D. H. Lee, D. Borojevic and F. C. Lee "A three-phase zero-voltage-transition inverter with inductor feedback," in Proc. VPEC Sem. Blacksburg, VA, 1996, pp. 189-194.

[29] J. S. Lai, "Practical design methodology of auxiliary resonant snubber inverter," in Proc. IEEE Power Electron. Spec. Conf., Baveno, Italy, Jun. 1996, pp. 432-437.

[30] H. Yu, X. Huang and J.-S. Lai, "A novel load adaptive zero voltage switching utilizing diode reverse recovery current for soft-switching choppers and inverters," in Proc. IEEE Power Electron. Spec. Conf., Vancouver, BC, Jun. 2001, pp. 146-151.

[31] W. Dong, D. Peng, H. Yu, F. C. Lee, and J.-S. Lai, "A simplified control scheme for zero voltage transition (ZVT) inverter using coupled inductors," in Proc. Power Electron. Spec. Conf., Galway, Ireland, vol. 3, Jun. 2000, pp. 1221-1226.

[32] F. R. Salberta, J. S. Mayer, and R. T. Cooley, "An improved control strategy for a 50-kHz auxiliary resonant commutated pole converter," in Proc. Power Electron. Spec. Conf., 1997, pp. 1246-1252.

[33] A. Toba, T. Shimizu, G. Kimura, M. Shioya, and S. Sano, "Auxiliary resonant commutated pole inverter using two internal voltage-points of DC source," in IEEE Trans. Ind. Eletron., vol. 45, Apr. 1998, pp. 200-206. 